\title{
TRATAMENTO DE ESGOTO SANITÁRIO EM UM REATOR DE LEITO EXPANDIDO EM ESCALA PLENA, OPERADO COM REGIÕES ANAERÓBIA E AERÓBIA SOBREPOSTAS
}

Dissertação apresentada ao Programa de PósGraduação em Engenharia Hidráulica e Saneamento da Escola de Engenharia de São Carlos da Universidade de São Paulo para obtenção do título de Mestre em Engenharia.

Área de Concentração: Hidráulica e Saneamento Orientador: Prof. Tit. José Roberto Campos. 
AUTORIZO A REPRODUÇÃO E DIVULGAÇÃO TOTAL OU PARCIAL DESTE TRABALHO, POR QUALQUER MEIO CONVENCIONAL OU ELETRÔNICO, PARA FINS DE ESTUDO E PESQUISA, DESDE QUE CITADA A FONTE.

Ficha catal ográfica preparada pela Seção de Tratamento

da Informação do Serviço de Biblioteca - EESC/USP

S586t Silva, Rafael Ceribelli da
Tratamento de esgoto sanitário em um reator de leito expandido em escala plena, operado com regiões anaeróbia e aeróbia sobrepostas / Rafael Ceribelli da Silva ; orientador José Roberto campos. -- São Carlos, 2009.

Dissertação (Mestrado-Programa de Pós-Graduação e Área de Concentração em Hidráulica e Saneamento) -- Escola de Engenharia de São Carlos da Universidade de São Paulo, 2009 .

1. Reator de leito expandido. 2. Nitrificação. 3. Material suporte. 4. Areia. 5. Tratamento anaeróbio e aeróbio. 6. Flotação. I. Título. 
FOLHA DE JULGAMENTO

Candidato: Engenhciro RAFAEL CERIBELLI DA SILVA

Dissertaçāo defendida e julgada em 26/06/2009 perante a Comissāo Julgadora:

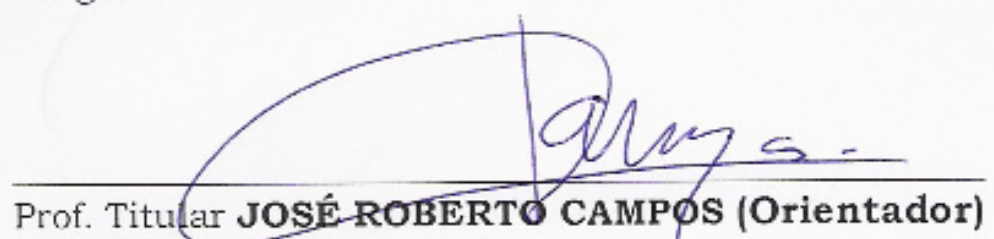

Aprovado (Escola de Engenharia de São Cartos/USP)

Godson / Silva

Prof. Dr. EDSON LUIZ SILVA

(Universidade Federal de São Carlos/UFSCar)
Aprovado

APROV420

Prof. Titular PEDRO ALÉM SOBRINHO (Escola Politécnica/U\$P)

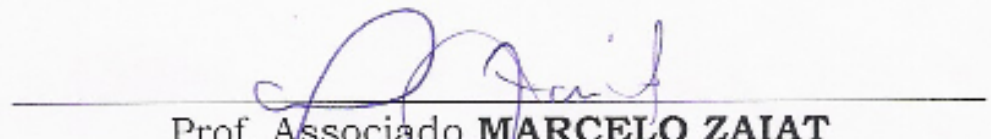

Prof. Associado MARCELo ZAIAT

Coordenador/do Prograna de Pós-Graduação cm Engenlyaria (Hidraulica e Saneamento)

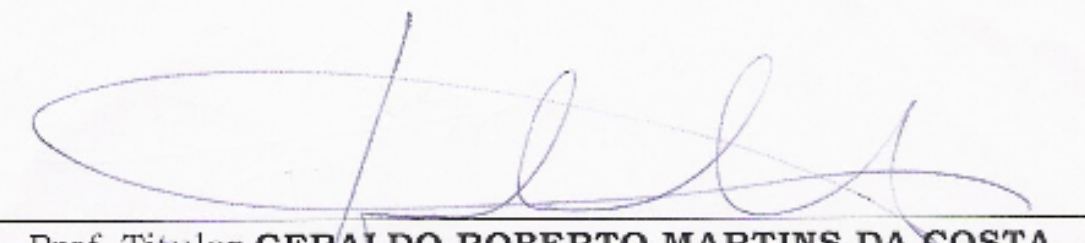

Prof. Titular GERALDO ROBERTO MARTINS DA COSTA Presidente da Comissão da Pós-Graduaçāo da EESC 
Página intencionalmente deixada em branco. 
Dedico este trabalho àqueles que deram a sua vida pela minha formação, sempre me apoiando e ajudando a construir os meus sonhos... 
Página intencionalmente deixada em branco. 


\section{AGRADECIMENTOS}

A Deus, pela saúde e perseverança na realização deste trabalho, e a Nossa Senhora pelas inúmeras vezes que fui auxiliado, junto a sua intercessão.

Aos meus pais, e a minha irmã, pela compreensão e apoio que me incentivaram a persistir no desenvolvimento deste trabalho.

Ao Prof. Dr. José Roberto Campos pela confiança depositada em mim para o desenvolvimento deste trabalho.

A Profa ${ }^{D^{a}}$ Deize Dias Lopes por todo o ensinamento e sugestões no desenvolvimento deste trabalho.

A Profa ${ }^{\mathrm{D}}{ }^{\mathrm{a}}$ Sandra Márcia Cesário Pereira da Silva por todo o incentivo e sugestões dadas ao longo deste trabalho.

A Dra Márcia Helena Rissato Zamariolli Damianovic pela dedicação, disposição e colaboração no desenvolvimento desta dissertação.

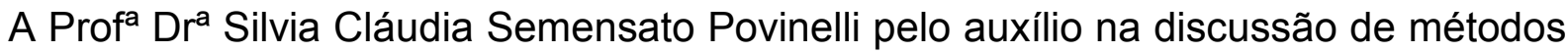
utilizados neste trabalho.

Ao Prof. Dr. Marco Antônio Penalva Reali pelas sugestões dadas para o desenvolvimento do ensaio de flotação.

Ao Sr. Alcino de Paula por toda a dedicação e ajuda prestada no desenvolvimento da parte experimental deste trabalho.

Aos Srs. Edson Aguirre e Maurílio Rosa por todos os serviços realizados no sistema experimental. 
Ao José Luciano Marques e a Aurélia Almeida por todo o auxílio dado na operação do sistema experimental.

Ao Departamento de Geotecnia da Escola de Engenharia de São Carlos, USP, pela autorização na realização dos ensaios de granulometria.

Ao Laboratório de Geotecnia da Universidade Estadual de Londrina, em especial ao Sr. Pedro Cândido de Souza pela realização de ensaios com o material suporte.

Aos técnicos do Laboratório de Saneamento, do Departamento de Hidráulica e Saneamento (SHS): Júlio, Paulo, Cidinha, Juliana e Natália, pela colaboração prestada na realização das análises químicas.

Aos funcionários do Departamento de Hidráulica e Saneamento (SHS): Sá, Pavi, Valderez, Cecília, Márcia, Fernanda, Flávia, André, Valdecir, em especial a Rose e a Jacquelyne, por toda a atenção e colaboração.

Ao Conselho Nacional de Pesquisa (CNPq) pela concessão da bolsa de estudos durante o mestrado (Processo CNPq 135448/2007-7).

À Fundação de Amparo à Pesquisa de São Paulo (FAPESP), pelo auxílio financeiro do projeto de pesquisa (Processo FAPESP 2008/50020-0).

Aos meus amigos em São Carlos, Daniele Vich, Gabriel Souto, Francisco Gláucio, Aline Tavares, André Pioltine, Ricardo Oliveira, Theo Souza, Ana Flávia Pontes, Juliana Lourenção, Bruna Moraes, Renata Barreira, por todas as lições e momentos de descontração.

Aos meus amigos de Londrina pela amizade que sempre me dedicaram.

Aos meus familiares por me incentivarem durante todo o desenvolvimento deste trabalho. 
$\mathcal{E}$ agora, eis o que diz o Senhor, aquele que te criou, Jacó, e te formou, Israel: nada temas, pois eu te resgato, eu te chamo pelo nome, és meu.

Se tiveres de atravessar a água, estarei contigo. $\mathcal{E}$ os ríos não te submergirão; se caminhares pelo fogo, não te queimarás, e a chama não te consumirá.

Poís eu sou o Senhor, teu Deus, o Santo de Israel, teu salvador. 
Página intencionalmente deixada em branco. 


\section{RESUMO}

SILVA, R.C. (2009). Tratamento de esgoto sanitário em um reator de leito expandido em escala plena, operado com regiões anaeróbia e aeróbia sobrepostas. 192 p. Dissertação (Mestrado) - Escola de Engenharia de São Carlos, Universidade de São Paulo, São Carlos.

A presente pesquisa teve como objetivo principal a avaliação do desempenho de um reator de leito expandido $\left(159,0 \mathrm{~m}^{3}\right)$, em escala plena, operado sob condições anaeróbia e anaeróbia-aeróbia sobrepostas, tratando esgoto sanitário. Como objetivos específicos, foi avaliado o uso de areias comerciais para complementação do leito de partículas, bem como a distribuição do material suporte ao longo da altura do reator. Além disso, houve a simulação da flotação do efluente do sistema a fim de otimizar a eficiência na remoção de sólidos, visto pela ineficiência do sistema na separação dos sólidos biológicos. Dentre os materiais selecionados para compor o leito de partículas, foi escolhida a areia com tamanho médio dos grãos igual a $0,69 \mathrm{~mm}$ e massa específica de $2690 \mathrm{~kg} \cdot \mathrm{m}^{-3}$. Esta pesquisa foi dividida em duas etapas experimentais, sendo que a primeira o sistema foi operado somente sob a condição anaeróbia, enquanto na segunda, o sistema foi submetido à condição anaeróbia e aeróbia sobrepostas. Para a primeira etapa, o sistema obteve maior eficiência na remoção de matéria orgânica, com TDH de 14 horas, quando foi removido 0,84 $\mathrm{kgDQ} \mathrm{b}_{\text {bruta }} \cdot \mathrm{m}^{-3} \cdot \mathrm{dia}^{-1}$, sendo que foi aplicado 1,26 $\mathrm{kgDQO}_{\text {bruta. }} \mathrm{m}^{-3} \cdot \mathrm{dia}^{-1}$. As eficiências médias de remoção de $\mathrm{DQO}_{\text {bruta, }} \mathrm{DQO}_{\text {filt }}, \mathrm{DBO}_{\text {bruta, }}, \mathrm{DBO}_{\text {filt }}, \mathrm{SST}$ e SSV foram de 65\%; 64\%; 80\%; 70\%; 58\% e 69\%. O efluente apresentou, em média, $245 \mathrm{mgDQO}_{\text {bruta. }} \cdot \mathrm{L}^{-1}, 117 \mathrm{mgDQO}_{\text {filt }} \mathrm{L}^{-1}, 104 \mathrm{mgDBO}_{\text {bruta }} \cdot \mathrm{L}^{-1}, 76 \mathrm{mgDBO}_{\text {filt }} \cdot \mathrm{L}^{-1}$; $88 \mathrm{mgSST} . \mathrm{L}^{-1}$ e $69 \mathrm{mgSSV} . \mathrm{L}^{-1}$. O grau de amonificação obtido foi de $90 \%$, evidenciando a potenciabilidade do sistema na conversão de matéria nitrogenado orgânico em amoniacal. Para a segunda etapa, a maior eficiência na remoção de matéria orgânica foi obtida com TDH de 16 horas, quando foi removido 0,29 $\mathrm{kgDQO}$ bruta $\cdot \mathrm{m}^{-3} \cdot \mathrm{dia}^{-1}$, sendo que foi aplicado $0,84 \mathrm{kgDQO}$ bruta. $\mathrm{m}^{-3} \cdot \mathrm{dia}^{-1}$. As eficiências médias de remoção de $\mathrm{DQO}_{\text {filt }}$ e $\mathrm{DBO}_{\text {filtr }}$ foram de $80 \%$ e $95 \%$, respectivamente. O efluente apresentou, em média, $72 \mathrm{mgDQO}_{\text {filtr. }} \mathrm{L}^{-1}$, e $13 \mathrm{mgDBO}_{\text {filtr. }} \mathrm{L}^{-1}$. O grau de amonificação obtido foi de $85 \%$, no entanto houve baixa eficiência na oxidação do $\mathrm{N}$-amoniacal, no máximo $25 \%$, sendo que as concentrações máximas no efluente foram de $4 \mathrm{mgN}-\mathrm{NO}_{2}{ }^{-} \cdot \mathrm{L}^{-1}$ e $2 \mathrm{mgNO}_{3}{ }^{-} \cdot \mathrm{L}^{-1}$, respectivamente. Em relação à distribuição do material suporte, foi verificada que a proporção de carvão ativado granular e carvão antracitoso foi superior em relação à areia, nos diferentes pontos de coleta, sendo que essa proporção tendeu a se reduzir ao longo das amostragens, além disso, foram verificadas que as características do fluxo não estão adequadas para proporcionar a fluidificação/expansão do leito de partículas. Os melhores resultados obtidos na simulação da flotação do efluente, quando foi aplicada recirculação com concentração de ar de $17,5 \mathrm{mg}_{\mathrm{ar}} \mathrm{L}_{\mathrm{am}}{ }^{-1}$, e velocidade ascensional de $10 \mathrm{~cm} \cdot \mathrm{min}^{-1}$. As eficiências de remoção de SST; SSF; SSV; DQO, cor e turbidez obtidas foram de 64; $82 ; 62 ; 62 ; 53$ e $73 \%$, respectivamente. O efluente flotado apresentou 63 mgSST.L ${ }^{-1}$; 5 mgSSF.L ${ }^{-1} ; 59$ mgSSV.L ${ }^{-1} ; 127$ mgDQO bruta. $^{-1}, 431$ uC e 29 uT.

Palavras-chave: Reator de leito expandido; Nitrificação; Material suporte; Areia; Tratamento anaeróbio e aeróbio; Flotação. 


\section{ABSTRACT}

SILVA, R.C. (2009). Treatment of sanitary wastewater in a full scale expanded bed reactor, operated with overlap anaerobic and aerobic regions. $192 \mathrm{p}$. Dissertation (Master) - Escola de Engenharia de São Carlos, Universidade de São Paulo, São Carlos.

This present research had as main objective the evaluation of the performance of a full scale expanded bed reactor $\left(159.0 \mathrm{~m}^{3}\right)$, operated under anaerobic and overlapping anaerobic-aerobic, treating sanitary wastewater. As specific objectives, it was evaluated using commercial sand to complement the bed of particles and distribution of material support along the height of reactor. Besides, it was simulated the flotation of the effluent system in order to optimize the efficient removal of solids, due to inefficiency of the system in the separation of biological solids. Among the materials selected to compose the bed of particles was chosen with the average size of sand grains equal to $0.69 \mathrm{~mm}$ and density of $2690 \mathrm{~kg} \cdot \mathrm{m}^{-3}$. This research was divided into two experimental stages, the first being that the system was operated only under the anaerobic condition, while the second, the system was submited to anaerobic and aerobic conditions overlaped. For the first step, the system achieved greater efficiency in removing organic matter, with hydraulic detention time of 14 hours, when it was removed from $0.84 \mathrm{kgCOD}$ raw $\mathrm{m}^{-3} \cdot \mathrm{day}^{-1}$, which was applied $1.26 \mathrm{kgCOD} \cdot \mathrm{m}^{-3} \cdot \mathrm{day}^{-1}$. The mean removal efficiencies of $\mathrm{DQO}_{\text {raw }}, \mathrm{DQO}_{\text {filtered, }}, \mathrm{BOD}_{\text {raw, }}$, $\mathrm{BOD}_{\text {filtered }}$, TSS and VSS were $65 \% ; 64 \% ; 80 \% ; 70 \% ; 58 \%$ and $69 \%$. The effluent had an average of $245 \mathrm{mgCODraw} . \mathrm{L}^{-1} ; 117 \mathrm{mgCOD}$ filtered. $\mathrm{L}^{-1} ; 104 \mathrm{mgBOD}_{\text {raw. }} \mathrm{L}^{-1}$; $76 \mathrm{mgBOD}_{\text {filtered }} \mathrm{L}^{-1} ; 88 \mathrm{mgTSS} . \mathrm{L}^{-1}$ and $69 \mathrm{mgVSS} . \mathrm{L}^{-1}$. The ammonification obtained was $90 \%$, demonstrating the potencial of the system in the conversion of organic matter into ammonia nitrogen. For the second stage, the most efficient in the removal of organic matter was obtained with hydraulic detention time of 16 hours when it was removed from $0.29 \mathrm{kgCOD}$ raw $\cdot \mathrm{m}^{-3}$. day ${ }^{-1}$, which was applied $0.84 \mathrm{kgCOD}$ raw. $\mathrm{m}^{-3} \cdot \mathrm{day}^{-1}$. The mean removal efficiencies of $\mathrm{COD}_{\text {filtered }}$ and $\mathrm{BOD}_{\text {filtered }}$ were $80 \%$ and $95 \%$, respectively. The effluent had an average of $72 \mathrm{mgCOD}_{\text {filtere. }} \mathrm{L}^{-1}$, and $13 \mathrm{mgBOD}_{\text {filtered }} \mathrm{L}^{-1}$. The ammonification obtained was $85 \%$, however there was low efficiency in oxidation of ammonia- $\mathrm{N}$, at most $25 \%$, and the maximum concentrations in the effluent were $4 \mathrm{mgN}-\mathrm{NO}_{2}{ }^{-} \cdot \mathrm{L}^{-1}$ and $2 \mathrm{mgN}-\mathrm{NO}_{3}{ }^{-} \cdot \mathrm{L}^{-1}$, respectively. Regarding the distribution of material support, it was found that the proportion of activated granular carbon and anthracite carbon was higher on sand, in different points of collection, whereas this proportion tended to drop over the sample, moreover, was found that the characteristics of the flow are not adequate to provide fluidization/expansion of the bed of particles. The best results obtained in the simulation of the flotation of the effluent when it was applied with recirculation of air concentration of $17.5 \mathrm{mg}_{\text {air }} \mathrm{L}_{\text {sample }}{ }^{-1}$, and ascension velocity of $10 \mathrm{~cm} \cdot \mathrm{min}^{-1}$. Removal efficiencies of TSS; FSS; VSS; COD, color and turbidity were obtained from 64; 82; 62; 62; 53 and $73 \%$, respectively. The effluent had $63 \mathrm{mgTSS}^{-1} ; 5 \mathrm{mgFSS} . \mathrm{L}^{-1} ; 59 \mathrm{mgVSS}^{-1}$; $127 \mathrm{mgCOD}_{\text {raw }} \mathrm{L}^{-1} ; 431 \mathrm{uC}$ and 29 UT.

Keywords: Expanded bed reactor; Nitrification; Support material; Sand; Anaerobic and aerobic treatment; Flotation. 


\section{LISTA DE FIGURAS}

Figura 3.1 Esquema do reator de leito expandido

Figura 3.2 Esquema de duas situações do leito suporte em reator de leito expandido/fluidificado

Figura 3.3 Processos envolvidos na formação e crescimento de biofilmes

Figura 4.1 Esquema simplificado do reator de leito expandido

Figura 4.2 Estação de tratamento de esgoto da EESC-USP - Área 1: vista parcial.

Figura 4.3 Areia disposta nos big bags

Figura 4.4 Transporte da areia nos big bags até a parte superior do reator de leito expandido

Figura 4.5 Compressor de parafuso, modelo PS20D

Figura 4.6 Disposição das fibras de carbono na superfície do reator de expandido

Figura 4.7 Micro peneira utilizada para remoção de sólidos grosseiros

Figura 4.8 Relação ente a vazão e a rotação do motor das bombas de recirculação anaeróbia (B2) e aeróbia (B1)

Figura 4.9 Interface do software SCADAT\&S

Figura 4.10 Diagrama de blocos da automação da estação elevatória de esgoto bruto, tanque pulmão e do reator de leito expandido

Figura 4.11 Localização dos pontos de coleta ao longo da altura do reator

Figura 4.12 Equipamento de floculação/flotação em escala de laboratório (flotateste)

Figura 5.1 Curva granulométrica da areia II

Figura 5.2 Resultados de $\mathrm{pH}$ do afluente e do efluente do reator anaeróbio de leito expandido, para as Fases 1 e 2 da Etapa I

Figura 5.3 Resultados de AT (alcalinidade total), AP (alcalinidade parcial) e AI (alcalinidade intermediária) do afluente e do efluente do reator anaeróbio de leito expandido, para as Fases 1 e 2 da Etapa I

Figura 5.4 Resultados de AGV (ácidos graxos voláteis) do afluente e do efluente do reator anaeróbio de leito expandido, para as Fases 1 e 2 da Etapa I 
Figura 5.5 Relações Al/AP (alcalinidade intermediária/alcalinidade parcial) e AGVIAT (ácidos graxos voláteis/alcalinidade total) do efluente do reator anaeróbio de leito expandido, para as Fases 1 e 2 da Etapa I

Figura 5.6 Resultados de DQO bruta e filtrada do afluente e do efluente do reator anaeróbio de leito expandido, para as Fases 1 e 2 da Etapa I

Figura 5.7 Resultados da eficiência de remoção de DQO bruta e filtrada, do reator anaeróbio de leito expandido, durante as Fases 1 e 2 da Etapa I

Figura 5.8 Resultados de DBO bruta e filtrada do afluente e do efluente do reator anaeróbio de leito expandido, para as Fases 1 e 2 da Etapa I

Figura 5.9 Resultados da eficiência de remoção de DBO bruta e filtrada do reator anaeróbio de leito expandido, durante as Fases 1 e 2 da Etapa I

Figura 5.10 Resultados de ST (sólidos totais), STF (sólidos totais fixos) e STV (sólidos totais voláteis) do afluente e do efluente do reator anaeróbio de leito expandido, para as Fases 1 e 2 da Etapa I

Figura 5.11 Resultados de SST (sólidos em suspensão totais), SSF (sólidos em suspensão fixos) e SSV (sólidos em suspensão voláteis) do afluente e do efluente do reator anaeróbio de leito expandido, para as Fases 1 e 2 da Etapa I

Figura 5.12 Relação SSV/SST (sólidos em suspensão voláteis/sólidos em suspensão totais) do afluente e do efluente do reator anaeróbio de leito expandido, para as Fases 1 e 2 da Etapa I

Figura 5.13 Resultados de NKT (nitrogênio Kjeldahl total), N-amon (nitrogênio amoniacal) e N-org (nitrogênio orgânico) do afluente e do efluente do reator anaeróbio de leito expandido, para as Fases 1 e 2 da Etapa I

Figura 5.14 Relação N-amon/NKT (nitrogênio amoniacal/nitrogênio Kjeldahl total) do afluente e do efluente do reator anaeróbio de leito expandido, para as Fases 1 e 2 da Etapa I

Figura 5.15 Resultados de $\mathrm{P}$ (fósforo) do afluente e do efluente do reator anaeróbio de leito expandido, para as Fases 1 e 2 da Etapa I

Figura 5.16 Resultados de $\mathrm{pH}$ do afluente e do efluente do reator anaeróbioaeróbio de leito expandido, para as Fases 1; 2; 3 e 4 da Etapa II 
Figura 5.17 Resultados de AT (alcalinidade total), AP (alcalinidade parcial) e AI (alcalinidade intermediária) do afluente e do efluente do reator anaeróbio-aeróbio de leito expandido, para as Fases 1; 2; 3 e 4 da Etapa II

Figura 5.18 Resultados de AGV (ácidos graxos voláteis) do afluente e do efluente do reator anaeróbio-aeróbio de leito expandido, para as Fases 1; 2; 3 e 4 da Etapa II

Figura 5.19 Resultados de DQO bruta e filtrada do afluente e do efluente do reator anaeróbio-aeróbio de leito expandido, para as Fases 1; 2; 3 e 4 da Etapa II

Figura 5.20 Resultados da eficiência de remoção de DQO bruta e filtrada, do reator anaeróbio-aeróbio de leito expandido, durante as Fases 1; 2; 3 e 4 da Etapa II

Figura 5.21 Relação $\mathrm{DQO}_{\mathrm{f}} / \mathrm{DQO}_{\mathrm{b}}$ afluente e do efluente do reator anaeróbioaeróbio de leito expandido, para as Fases 1; 2; 3 e 4 da Etapa II

Figura 5.22 Resultados de DBO bruta e filtrada do afluente e do efluente do reator anaeróbio-aeróbio de leito expandido, para as Fases $1 ; 2 ; 3$ e 4 da Etapa II

Figura 5.23 Resultados da eficiência de remoção de DBO total e filtrada do reator anaeróbio-aeróbio de leito expandido, durante as Fases 1; 2; 3 e 4 da Etapa II

Figura 5.24 Resultados de ST (sólidos totais), STF (sólidos totais fixos) e STV (sólidos totais voláteis) do afluente e do efluente do reator anaeróbio-aeróbio de leito expandido, para as Fases 1; 2; 3 e 4 da Etapa II

Figura 5.25 Resultados de SST (sólidos em suspensão totais), SSF (sólidos em suspensão fixos) e SSV (sólidos em suspensão voláteis) do afluente e do efluente do reator anaeróbio-aeróbio de leito expandido, para as Fases 1; 2; 3 e 4 da Etapa II

Figura 5.26 Relação SSVISST (sólidos em suspensão voláteis/sólidos em suspensão totais) do afluente e do efluente do reator anaeróbioaeróbio de leito expandido, para as Fases 1; 2; 3 e 4 da Etapa II

Figura 5.27 Resultados de NKT (nitrogênio Kjeldahl total), N-amon (nitrogênio amoniacal) e $\mathrm{N}$-org (nitrogênio orgânico) do afluente e do efluente do reator anaeróbio-aeróbio de leito expandido, para as Fases 1; 2; 3 e 4 da Etapa II

Figura 5.28 Relação N-amon/NKT (nitrogênio amoniacal/nitrogênio Kjeldahl total) do afluente e do efluente bruto e filtrado do reator anaeróbioaeróbio de leito expandido, para as fases 1; 2; 3 e 4 da etapa II 
Figura 5.29 Resultados de $\mathrm{P}$ (fósforo) do afluente e do efluente do reator anaeróbio-aeróbio de leito expandido, para as Fases 1; 2; 3 e 4 da Etapa II

Figura 5.30 Resultados de pH do perfil 1; 2 e 3

Figura 5.31 Resultados de alcalinidade total (a), alcalinidade parcial (b) e alcalinidade intermediária (c) do perfil $1 ; 2$ e 3

Figura 5.32 Resultados de AGV (ácidos graxos voláteis) do perfil 1; 2 e $3 \quad 128$

Figura 5.33 Resultados de $\mathrm{DQO}_{\text {filtrada }}$ (a) e $\mathrm{DBO}_{\text {filtrada }}$ do perfil 1; 2 e 3

Figura 5.34 Resultados de nitrogênio Kjeldahl total (a), nitrogênio amoniacal (b) e nitrogênio orgânico (c) do perfil 1; 2 e 3

Figura 5.35 Resultados de $\mathrm{P}$ (fósforo) do perfil 1; 2 e 3

Figura 5.36 Eficiência na remoção de SST (sólidos em suspensão totais) em função das concentrações de ar fornecidas durante o ensaio de flotação

Figura 5.37 Eficiência na remoção de SSF (sólidos em suspensão fixos) em função das concentrações de ar fornecidas durante o ensaio de flotação

Figura 5.38 Eficiência na remoção de SSV (sólidos em suspensão voláteis) em função das concentrações de ar fornecidas durante o ensaio de flotação

Figura 5.39 Eficiência na remoção de DQO (demanda química de oxigênio) em função das concentrações de ar fornecidas durante o ensaio de flotação

Figura 5.40 Eficiência na remoção de cor em função das concentrações de ar fornecidas durante o ensaio de flotação

Figura 5.41 Eficiência na remoção de turbidez em função das concentrações de ar fornecidas durante o ensaio de flotação

Figura 5.42 Eficiência na remoção de $\mathrm{P}$ (fósforo) em função das concentrações de ar fornecidas durante o ensaio de flotação 


\section{LISTA DE TABELAS}

Tabela 3.1 Trabalhos realizados com Reatores de Leito Expandido

Tabela 4.1 Areias comerciais estudadas

Tabela 4.2 Informações técnicas do compressor

Tabela 4.3 Variáveis de operação do reator de leito expandido: valores médios

Tabela 4.4 Variáveis analisadas e métodos de análise

Tabela 4.5 Variáveis analisadas e métodos de análise realizados no ensaio de flotação

Tabela 5.1 Porcentagem, em massa, de grãos de areia na faixa de 0,2 e 0,5 $\mathrm{mm}$

Tabela 5.2 Variáveis de operação do reator de leito expandido: Etapa I

Tabela 5.3 Valores médios, desvios padrões, valores mínimos e máximos e números de dados analisados de $\mathrm{pH}$, AT (alcalinidade total), AP (alcalinidade parcial), AI (alcalinidade intermediária) e AGV (ácidos graxos voláteis) das Fases 1 e 2, da Etapa I

Tabela 5.4 Valores médios, desvios padrões, valores mínimos e máximos e números de dados analisados de DQO das Fases 1 e 2, da Etapa I

Tabela 5.5 Valores médios, desvios padrões, valores mínimos e máximos e números de dados analisados de DBO das Fases 1 e 2, da Etapa I

Tabela 5.6 Valores médios, desvios padrões, valores mínimos e máximos e números de dados analisados de sólidos totais e sólidos em suspensão das Fases 1 e 2, da Etapa I

Tabela 5.7 Valores médios, desvios padrões, valores mínimos e máximos e números de dados analisados de nitrogênio e fósforo das Fases 1 e 2, da Etapa I

Tabela 5.8 Variáveis de operação do reator de leito expandido: Etapa II

Tabela 5.9 Valores médios, desvios padrões, valores mínimos e máximos e números de dados analisados de $\mathrm{pH}$, AT (alcalinidade total), AP (alcalinidade parcial), AI (alcalinidade intermediária) e AGV (ácidos graxos voláteis) das Fases 1; 2; 3 e 4, da Etapa II 
Tabela 5.10 Valores médios, desvios padrões, valores mínimos e máximos e números de dados analisados de DQO das Fases 1; 2; 3 e 4, da Etapa II

Tabela 5.11 Valores médios, desvios padrões, valores mínimos e máximos e números de dados analisados de DBO das Fases 1; 2; 3 e 4, da Etapa II

Tabela 5.12 Valores médios, desvios padrões, valores mínimos e máximos e números de dados analisados de sólidos totais e sólidos em suspensão das Fases 1; 2; 3 e 4, da Etapa II

Tabela 5.13 Valores médios, desvios padrões, valores mínimos e máximos e números de dados analisados de nitrogênio e fósforo das Fases 1; 2; 3 e 4, da Etapa II

Tabela 5.14 Proporção em relação ao volume de carvão ativado granular (CAG), carvão antracitoso (CA) e areia ao longo da altura do reator 


\section{LISTA DE ABREVIATURAS E SIGLAS}

\begin{tabular}{|c|c|}
\hline ABNT & Associação Brasileira de Normas Técnicas \\
\hline AGV & Ácidos graxos voláteis $\left[\mathrm{mgHac} . \mathrm{L}^{-1}\right]$ \\
\hline Al & Alcalinidade intermediária $\left[\mathrm{mgCaCO}_{3} \cdot \mathrm{L}^{-1}\right]$ \\
\hline ANAMMOX & Anaerobic Ammonium Oxidation \\
\hline $\mathrm{AP}$ & Alcalinidade parcial $\left[\mathrm{mgCaCO}_{3} \cdot \mathrm{L}^{-1}\right]$ \\
\hline AT & Alcalinidade total $\left[\mathrm{mgCaCO}_{3} \cdot \mathrm{L}^{-1}\right]$ \\
\hline B1 & Bomba de alimentação \\
\hline B2 & Bomba de recirculação anaeróbia \\
\hline B3 & Bomba de recirculação aeróbia \\
\hline BPIT & Banda de rodagem de pneus inservíveis triturada \\
\hline CNPq & Conselho Nacional de Desenvolvimento Científico e Tecnológico \\
\hline $\mathrm{CA}$ & Carvão antracitoso \\
\hline CAG & Carvão ativado granular \\
\hline CPFL & Companhia Paulista de Força e Luz \\
\hline CONAMA & Conselho Nacional do Meio Ambiente \\
\hline cov & Carga orgânica volumétrica $\left[\mathrm{kg} \cdot \mathrm{m}^{-3} \cdot \mathrm{dia}^{-1}\right]$ \\
\hline CNV & Carga de nitrogênio volumétrica $\left[\mathrm{kg} \cdot \mathrm{m}^{-3} \cdot \mathrm{dia}^{-1}\right]$ \\
\hline DBO & Demanda bioquímica de oxigênio $\left[\mathrm{mg}^{\left.-\mathrm{L}^{-1}\right]}\right.$ \\
\hline $\mathrm{DBO}_{\mathrm{b}}$ & DBO de amostras brutas $\left[\mathrm{mg} \cdot \mathrm{L}^{-1}\right]$ \\
\hline $\mathrm{DBO}_{\mathrm{f}}$ & DBO de amostras filtradas $\left[\mathrm{mg} \cdot \mathrm{L}^{-1}\right]$ \\
\hline DQO & Demanda química de oxigênio $\left[\mathrm{mg} \cdot \mathrm{L}^{-1}\right]$ \\
\hline $\mathrm{DQO}_{\mathrm{b}}$ & DQO de amostras brutas $\left[\mathrm{mg} \cdot \mathrm{L}^{-1}\right]$ \\
\hline $\mathrm{DQO}_{\mathrm{f}}$ & $\mathrm{DQO}$ de amostras filtradas $\left[\mathrm{mg} \cdot \mathrm{L}^{-1}\right]$ \\
\hline EESC & Escola de Engenharia de São Carlos \\
\hline
\end{tabular}




\begin{tabular}{|c|c|}
\hline EPS & Substância polimérica extracelular (extracellular polymeric substances) \\
\hline ETE & Estação de tratamento de esgoto \\
\hline FAD & Flotação por ar dissolvido \\
\hline LPS & Lipopolissácarídeos \\
\hline N-Amon & Nitrogênio amoniacal $\left[\mathrm{mg} \cdot \mathrm{L}^{-1}\right]$ \\
\hline $\mathrm{N}-\mathrm{NH}_{3}$ & Nitrogênio na forma de amônia livre, não ionizada $\left[\mathrm{mg} \cdot \mathrm{L}^{-1}\right]$ \\
\hline $\mathrm{N}-\mathrm{NH}_{4}^{+}$ & Nitrogênio na forma de íon amônio $\left[\mathrm{mg} \cdot \mathrm{L}^{-1}\right]$ \\
\hline $\mathrm{N}-\mathrm{NO}_{2}^{-}$ & Nitrogênio na forma de nitrito $\left[\mathrm{mg} \cdot \mathrm{L}^{-1}\right]$ \\
\hline $\mathrm{N}-\mathrm{NO}_{3}^{-}$ & Nitrogênio na forma de nitrato $\left[\mathrm{mg} \cdot \mathrm{L}^{-1}\right]$ \\
\hline $\mathrm{N}$-org & Nitrogênio orgânico $\left[\mathrm{mg}^{\left.-\mathrm{L}^{-1}\right]}\right.$ \\
\hline NKT & Nitrogênio Kjeldahl total $\left[\mathrm{mg} \cdot \mathrm{L}^{-1}\right]$ \\
\hline OD & Oxigênio dissolvido $\left[\mathrm{mg}^{-\mathrm{L}^{-1}}\right]$ \\
\hline $\mathrm{pH}$ & Potencial hidrogeniônico \\
\hline PAC & Policloreto de Alumínio \\
\hline PAM & Poli-acrilamida \\
\hline PVC & Policloreto de vinila \\
\hline RALE $_{X}$ & Reator anaeróbio de leito expandido \\
\hline RAALE $_{X}$ & Reator anaeróbio-aeróbio de leito expandido \\
\hline SHARON & Single reactor high activity ammonia removal over nitrite \\
\hline SHS & Departamento de Hidráulica e Saneamento \\
\hline SSF & Sólidos em suspensão fixos $\left[\mathrm{mg} \cdot \mathrm{L}^{-1}\right]$ \\
\hline SST & Sólidos em suspensão totais $\left[\mathrm{mg} \cdot \mathrm{L}^{-1}\right]$ \\
\hline SSV & Sólidos em suspensão voláteis [mg. $\left.\mathrm{L}^{-1}\right]$ \\
\hline ST & Sólidos totais $\left[\mathrm{mg} \cdot \mathrm{L}^{-1}\right]$ \\
\hline STF & Sólidos totais fixos $\left[\mathrm{mg}^{-\mathrm{L}^{-1}}\right]$ \\
\hline
\end{tabular}


STV Sólidos totais voláteis $\left[\mathrm{mg} \cdot \mathrm{L}^{-1}\right]$

TDH Tempo de detenção hidráulica [h]

TRC Tempo de retenção celular [dia]

UASB Reator anaeróbio de manta de lodo (upflow anaerobic sludge blanket)

USP Universidade de São Paulo

YSI $\quad$ Yellow Spring Incorporated 


\section{LISTA DE SÍMBOLOS}

$\begin{array}{ll}\theta h & \text { Tempo de detenção hidráulica [h] } \\ \theta \mathrm{c} & \text { Tempo de retenção celular [dia] } \\ \mathrm{L}_{0} & \text { altura inicial }[\mathrm{m}] \\ \mathrm{L}_{1} & \text { altura }[\mathrm{m}] \\ \mathrm{Q} & \text { Vazão }\left[\mathrm{m}^{3} \cdot \mathrm{dia}^{-1}\right] \text { ou }\left[\mathrm{m}^{3} \cdot \mathrm{h}^{-1}\right] \\ \mathrm{Q}_{\mathrm{ar}} & \text { Vazão de } \operatorname{ar}\left[\mathrm{m}^{3} \cdot \mathrm{dia}^{-1}\right] \\ \mathrm{Q}_{\mathrm{r}} & \text { Vazão de recirculação }\left[\mathrm{m}^{3} \cdot \mathrm{h}^{-1}\right] \\ \mathrm{T} & \text { Temperatura }\left[{ }^{\circ} \mathrm{C}\right] \\ \mathrm{t} & \text { Tempo }[\mathrm{min}] \\ \mathrm{V} & \text { Volume }\left[\mathrm{m}^{3}\right] \\ \mathrm{V}_{\mathrm{asc}} & \text { Velocidade ascensional }\left[\mathrm{m} \cdot \mathrm{h}^{-1}\right]\end{array}$




\section{SUMÁRIO}

1 INTRODUÇÃO 25

2 OBJETIVOS $\quad 29$

3 LEVANTAMENTO BIBLIOGRÁFICO 31

3.1 Considerações Iniciais 31

3.2 Reatores Biológicos de Leito Expandido/fluidificado 31

3.2.1 Configuração de Reatores de Leito Expandido/Fluidificado 31

3.2.2 Expansão e Fluidificação do Leito 33

3.2.3 Remoção de Matéria Orgânica e de Nitrogênio em Reatores de Leito Expandido/Fluidificado

3.2.4 Alguns Trabalhos Desenvolvidos na EESC/USP sobre Reatores de Leito Expandido/fluidificado

3.3 Biofilme

3.3.1 Características do Biofilme $\quad 45$

3.3.2 Formação do Biofilme $\quad 46$

3.3.3 Remoção do Biofilme $\quad 48$

3.3.4 Biofilme em Reatores de Leito Expandido/Fluidificado 49

3.4 Nitrogênio em Sistemas Biológicos $\quad 51$

3.4.1 Nitrogênio no Meio Ambiente $\quad 51$

3.4.2 Formas do Nitrogênio $\quad 52$

3.4.3 Remoção Biológica de Nitrogênio 53

3.4.3.1 Considerações Gerais $\quad 53$

3.4.3.2 Nitrificação: Aspectos Físico-químicos e Microbiológicos 54

3.4.3.3 Desnitrificação: Aspectos Físico-químicos e Microbiológicos 58

3.4.4 Novos Processos Biológicos para Remoção de Nitrogênio 59

\section{MATERIAL E MÉTODOS 61}

4.1 Descrição do Reator de Leito Expandido e Sistema de Tratamento de Esgoto da EESC/USP - Área $1 \quad 61$

4.2 Material Suporte 65

4.2.1 Seleção do Material Suporte Adequado para Complementar o Leito do Reator

4.2.2 Caracterização da Areia utilizada como Material Suporte 66

$\begin{array}{ll}\text { 4.2.3 Material Suporte Escolhido } & 67\end{array}$

4.3 Sistema de Aeração 68

4.4 Reformas Realizadas Durante o Trabalho Experimental $\quad 70$

4.4.1 Generalidades $\quad 70$

4.4.2 Correção dos Vazamentos no Reator de Leito Expandido 70

4.4.3 Mudança no Sistema de Tratamento Preliminar $\quad 71$

4.5 Controle Operacional do Sistema $\quad 72$

4.6 Etapas Experimentais $\quad 75$

4.7 Procedimento Experimental $\quad 76$

4.8 Distribuição do Material Suporte ao Longo da Altura do Reator $\quad 79$

4.9 Ensaio de Flotação $\quad 81$ 
5.1 Considerações Iniciais 83

5.2 Areia Utilizada para Complementar o Material Suporte 84

5.3 Avaliação do Desempenho do Reator de Leito Expandido 85

5.3.1 Etapa I $\quad 86$

5.3.1.1 Condições Operacionais - Etapa I 86

5.3.1.2 Resultados de Desempenho do Reator Anaeróbio de Leito Expandido

5.3.1.3 Análise Global dos Resultados Obtidos durante a Etapa I

$\begin{array}{ll}\text { 5.3.2.1 Condições Operacionais - Etapa II } & 105\end{array}$

5.3.2.2 Resultados de Desempenho do Reator Anaeróbio-Aeróbio de Leito Expandido

$\begin{array}{ll}\text { 5.3.2.3 Análise Global dos Resultados Obtidos durante a Etapa II } & 124 \\ \text { 5.3.2.4 Comparação dos Resultados da Etapa I e II } & 125\end{array}$

5.3.3 Perfis de Amostras ao Longo da Altura do Reator 126

5.3.4 Distribuição do Material Suporte 131

5.3.5 Resultados do Ensaio de Flotação 133

6 CONCLUSÕES 141

REFERÊNCIAS $\quad 145$

ANEXO A - ENSAIOS GRANULOMÉTRICOS REALIZADOS COM AREIAS PARA ESCOLHA DE MATERIAL SUPORTE

ANEXO B - RESULTADOS DE ANÁLISES E DETERMINAÇÕES: ETAPA I

ANEXO C - RESULTADOS DE ANÁLISES E DETERMINAÇÕES: ETAPA II

ANEXO D - RESULTADOS DE ANÁLISES E DETERMINAÇÕES: PERFIS $1,2 \mathrm{E} 3$

ANEXO E - RESULTADOS DE ANÁLISES E DETERMINAÇÕES: ENSAIO DE FLOTAÇÃO 


\section{INTRODUÇÃO}

As crescentes exigências dos órgãos ambientais tem provocado modificações na concepção de novos sistemas de tratamento de água residuárias, de tal modo, que nesses projetos devem ser considerados aspectos social, econômico, técnico e ambiental.

Dentre as alternativas para o tratamento de águas residuárias, os processos biológicos constituem a forma mais usual e econômica quando comparados a outros processos, como por exemplo, processos físico-químicos.

Entre as configurações de sistemas empregadas para o tratamento de esgoto sanitário, o reator de leito expandido, classificado como sendo de filme fixo e leito móvel, está entre alternativas que vem sendo aprimorada nos últimos anos.

Estão sendo desenvolvidas pesquisas sobre a remoção conjunta de matéria orgânica, nitrogênio e fósforo (PATEL; ZHU; NAKHLA, 2006), em reatores de filmes biológicos fixos em leitos fluidizados/expandidos, como descrito por Ha e Ong (2007) e outros. Porém, a maior parte dessas pesquisas baseia-se em reatores em escala de bancada ou piloto.

O estudo de reator em escala plena, que é o presente caso, permite a observação do comportamento de um sistema tal qual aplicado em cenário real, além de tratar das questões de engenharia de concepção e ações operacionais, necessárias à eventual aplicação futura dessa tecnologia como alternativa de 
tratamento de efluentes industriais e de esgoto de sanitário, ou seja, enfocar a engenharia de execução e aprimoramento do reator.

A Escola de Engenharia de São Carlos, através do Departamento de Hidráulica e Saneamento, vem estudando desde a década de 80, a aplicação de reatores biológicos (anaeróbio e/ou aeróbio) de leito de partículas expandido para o tratamento de esgoto sanitário. Durante esse período, foi estudada, em escala de bancada e piloto, a utilização desse sistema sob condições anaeróbias e aeróbias, conforme pode ser verificado nos trabalhos de Akutsu (1984), Araújo (1995), Barros (1989), Campos (1989), Costa (1994), Cuba Terán (1990, 1995), Hamada (1992), Maragno (1988), Mendonça (1998, 2004), Niciura (2005), Pereira (2000), Santos (2001), Silva (1995), Siman (2007), Therezo (1993) e Vieira (1989).

Contudo, a partir do trabalho pioneiro de Fdz-Polanco, Real e Garcia (1994) foi sugerida a potencialidade da configuração desse tipo de reator no tratamento de esgoto sanitário. Nesse trabalho, os autores utilizaram, em escala piloto, um reator cilíndrico de leito fluidificado, com regiões anaeróbia e aeróbia sobrepostas.

A partir disso, Mendonça (2004) trabalhou na concepção, construção e operação de reator anaeróbio-aeróbio de leito expandido em escala plena (159,0 m³) para o tratamento de esgoto sanitário. O autor concluiu que, dentre os materiais estudados para compor o leito do reator, o carvão ativado foi o que apresentou as características mais adequadas, pois demonstrou bom potencial para a nitrificação, além de permitir a boa aderência de microrganismos e formação do biofilme. 0 fornecimento de oxigênio para o sistema aeróbio foi realizado por meio de tanque criogênico, ou seja, fornecia-se oxigênio puro ao sistema. Isso gerou elevados custos por metro cúbico de esgoto tratado, mostrando que a alternativa, de aeração com oxigênio puro, pode ser questionável economicamente. 
Visando a redução de custos, utilizar-se-á, nesta pesquisa, um sistema de aeração, através de insuflação de ar, por meio de compressor, em substituição ao oxigênio puro, em reator de leito expandido com região anaeróbia e aeróbia sobrepostas no tratamento de esgoto sanitário. 
Página intencionalmente deixada em branco. 


\section{OBJETIVOS}

A presente pesquisa teve como objetivo principal a avaliação do desempenho de um de reator leito expandido $\left(159,0 \mathrm{~m}^{3}\right)$, em escala plena, operado sob condições anaeróbia e anaeróbia e aeróbia sobrepostas, tratando esgoto sanitário.

Como objetivos específicos, destacam-se:

- Avaliação de areias comerciais quanto à granulometria para complementação do leito de partículas;

- Avaliação da distribuição do material suporte ao longo da altura do reator;

- Simulação da flotação do efluente do sistema, a fim de otimizar a eficiência na remoção de sólidos. 
Página intencionalmente deixada em branco. 


\section{LEVANTAMENTO BIBLIOGRÁFICO}

\subsection{Considerações Iniciais}

Neste capítulo são abordados aspectos sobre reatores biológicos de leito expandido/fluidificado, biofilme e conversão de nitrogênio em reatores biológicos.

No item sobre reatores biológicos de leito expandido/fluidificado serão descritas as configurações e características destes reatores, bem como a diferenciação entre expansão e fluidificação.

No item seguinte, são mostradas as características, formação e remoção de biofilme, bem como o emprego de biofilme em reatores de leito expandido/fluidificado.

Sobre a conversão de nitrogênio em reatores biológicos, são descritos de forma expedita, os fundamentos da remoção biológica de nitrogênio, bem como os processos não-convencionais da conversão do material nitrogenado.

\subsection{Reatores Biológicos de Leito Expandido/fluidificado}

\subsubsection{Configuração de Reatores de Leito Expandido/Fluidificado}

Os reatores biológicos de leito expandido ou fluidificado são classificados como reatores de leito móvel e filme fixo. Nesses reatores apresentam-se três fases distintas: sólida, líquida e gasosa. 
A fase sólida é formada por biopartículas (material suporte e biofilme) que tem a função de reter a biomassa no reator, a fase líquida, é constituída, basicamente pela água residuária, já a fase gasosa, é constituída do biogás Ge

rado pelo processo anaeróbio ou pela inserção de oxigênio, quando o reator é aerado.

Nesse tipo de reator, o leito é formado por material granular (areia; carvão antracitoso; ativado granular; materiais poliméricos; etc.), o qual tem suas partículas envolvidas por microrganismos, formando biopartículas, que ficam em suspensão, devido ao movimento vertical ascendente ou descendente da massa líquida.

Esses reatores possuem, geralmente, separador de fases e sistema de recirculação, destinados, respectivamente, à coleta de gases e ao controle da velocidade ascensional empregada na região de reação. Na Figura 3.1 é mostrado um esquema típico de reatores de leito expandido.

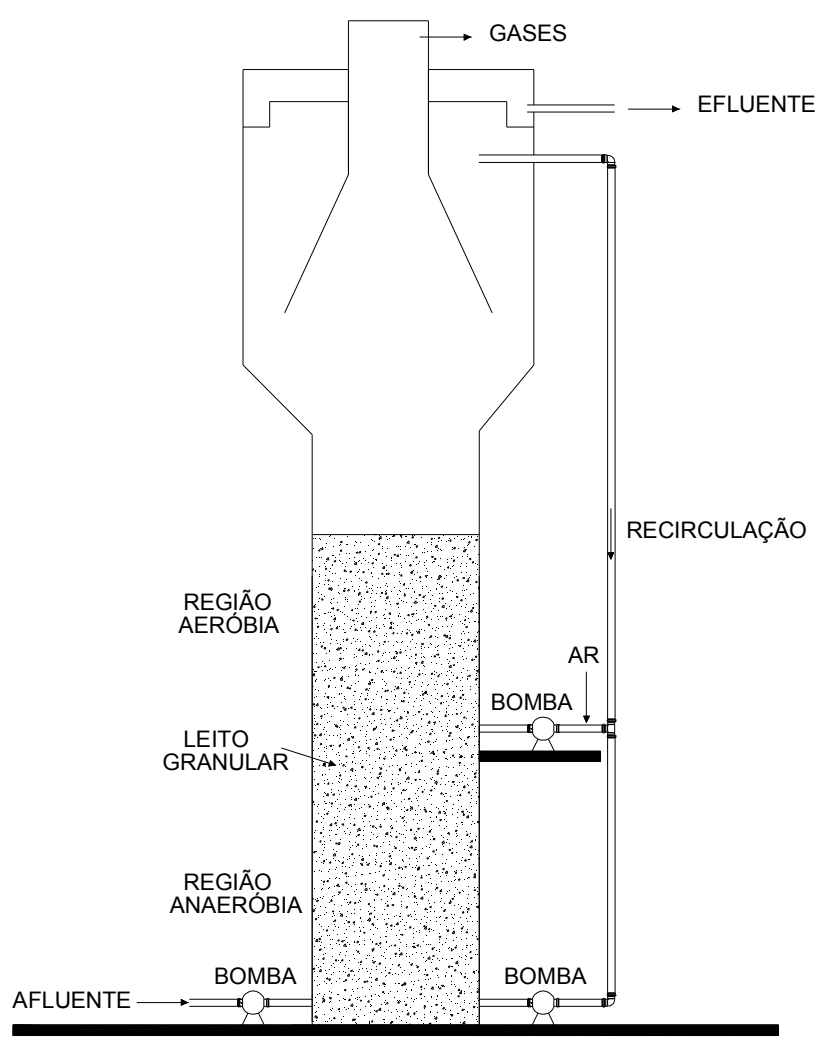

Figura 3.1 Esquema do reator de leito expandido

Fonte: Adaptado de Siman (2007) 


\subsubsection{Expansão e Fluidificação do Leito}

A eficiência do reator de leito expandido/fluidificado, bem como o controle operacional e a formação dos consórcios de microrganismos dependem da movimentação das partículas aderidas ao suporte, às quais se desenvolve o biofilme. A velocidade ascensional empregada deve ser tal que promova a expansão ou a fluidificação das biopartículas contidas na zona de reação e não provoque a desagregação do biofilme.

Na Figura 3.2 são mostradas de forma esquemática as modificações na região ocupada pelo leito (zona de reação) que podem ocorrer durante a operação do reator com partículas em suspensão.

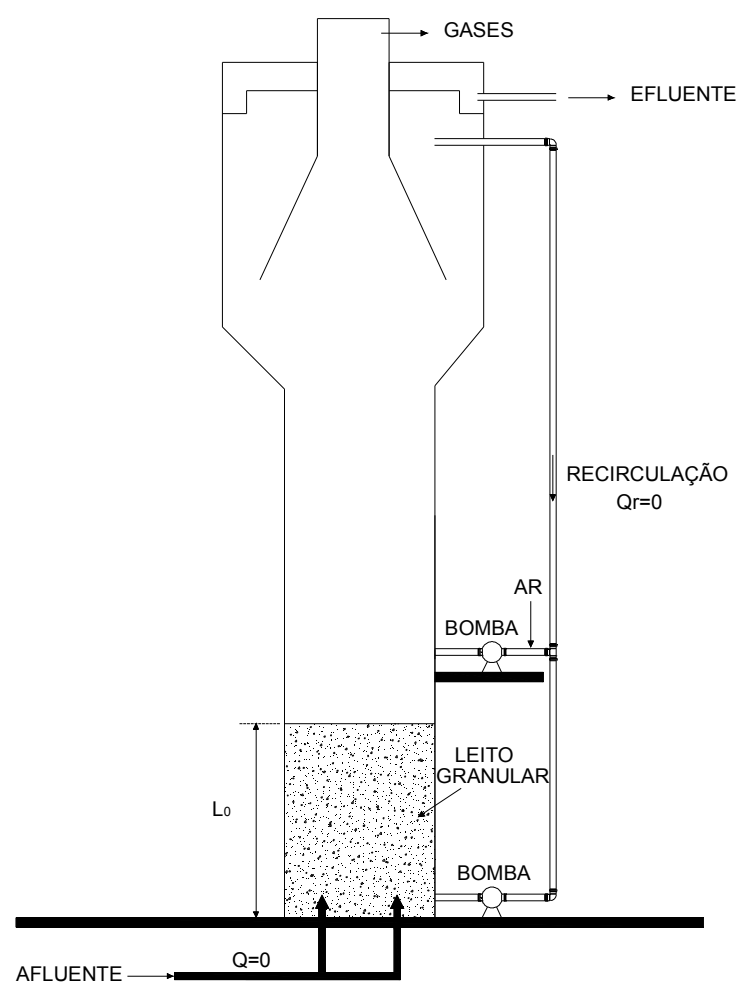

(a)

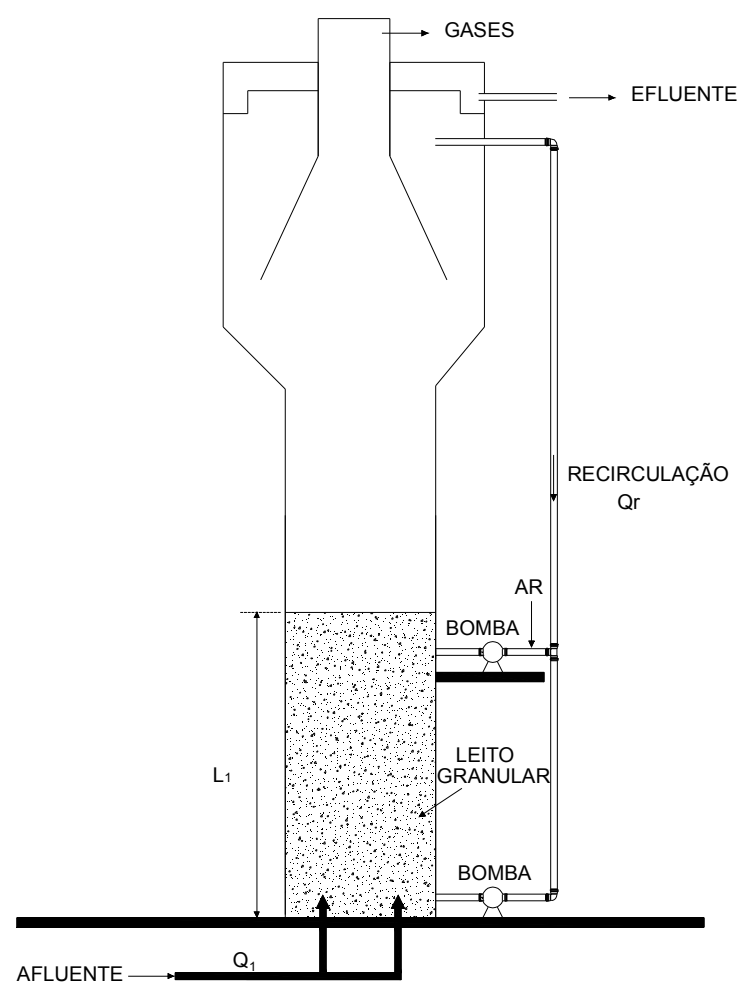

(b)

Figura 3.2 Esquema de duas situações do leito suporte em reator de leito expandido/fluidificado Fonte: Adaptado de Campos e Pereira (1999) 
Quando o reator não está em operação, o leito encontra-se estático (velocidade ascensional nula), tendo altura inicial igual a $L_{0}$ (Figura 3.2a).

Ao se iniciar a alimentação, com vazão baixa, ocorre pequena movimentação do leito e acomodação das partículas. O aumento da vazão de alimentação $\left(Q_{1}\right)$ provoca o aumento da velocidade ascensional e, portanto, a elevação na superfície do leito para altura $L_{1}$ (Figura 3.2b).

O aumento gradativo da velocidade ascensional proporciona a suspensão do leito, até que se alcance a condição em que as forças de arraste e o empuxo se igualem ao peso da partícula. Esse fenômeno é conhecido como fluidificação.

Kunii e Levenspiel (1969) consideram que o leito está fluidificado quando o gradiente de pressão, observado ao longo do leito de partículas, não depende da velocidade ascensional, ou seja, as forças de atrito entre as fases líquida e sólida superam o peso da partícula. Enquanto, reatores expandidos são aqueles que são operados com velocidades ascensionais inferiores a velocidade mínima de fluidificação.

Por outro lado, Jewell et al. (1981) consideram que um reator é de leito expandido quando ocorre expansão da ordem de 10 a $20 \%$ do leito estático inicial. Quando a expansão é superior a $100 \%$ o reator é considerado de leito fluidificado.

\subsubsection{Remoção de Matéria Orgânica e de Nitrogênio em Reatores de Leito Expandido/Fluidificado}

A utilização de reatores de leito expandido/fluidificado é considerada uma das inovações tecnológicas no tratamento de águas residuárias, visto que apresentam grande eficiência de conversão de substratos orgânicos biodegradáveis, devido à 
alta concentração de biomassa ativa que fica aderida ao material suporte e da pequena espessura do biofilme, que facilita a difusão do substrato.

Há quase duas décadas, vem sendo estudados, na linha de pesquisa empregando reatores de leito expandido/fluidificado, vários aspectos que influenciam a concepção, o controle e o monitoramento desses reatores. A seguir são apresentados resultados de alguns desses trabalhos.

Em trabalho pioneiro de Fdz-Polanco, Real e Garcia (1994) foi sugerida a potencialidade da configuração desse tipo de reator. Esses pesquisadores avaliaram em escala piloto, o desempenho de um reator cilíndrico de leito fluidificado, com 6,8 $\mathrm{m}$ de altura e 1,1 $\mathrm{m}$ de diâmetro interno (volume útil de 5,3 $\mathrm{m}^{3}$ ), aplicado ao tratamento de esgoto sanitário. Foi utilizada pedra-pome pulverizada como material suporte. Observa-se naquele trabalho, que os autores obtiveram eficiências de remoção superiores a 80\%; 90\%; 95\% e 80\% para $\mathrm{DQO}_{\text {solúvel, }} \mathrm{DBO}_{\text {solúvel, }} \mathrm{N}$-amon e NKT, respectivamente. A taxa de carregamento orgânico aplicado foi de $1,2 \mathrm{~kg} \cdot \mathrm{m}^{-3} \cdot \mathrm{dia}^{-1}$ e de nitrogênio de $0,2 \mathrm{~kg} \cdot \mathrm{m}^{-3} \cdot \mathrm{dia}^{-1}$ e TDH de 24 horas. Porém, foi verificado o arraste de sólidos junto ao efluente.

Patel, Zhu e Nakhla (2006) avaliaram o desempenho de um reator de leito fluidificado, composto por zona aeróbia $(3,31 \mathrm{~L})$, seguida por zona anóxica $(0,8 \mathrm{~L})$, com recheio de partículas de rocha vulcânica, aplicados à remoção de matéria orgânica, nitrogênio e fósforo de esgoto sanitário municipal. O sistema foi operado primeiramente sem recirculação de biopartículas do reator aeróbio para o anóxico (260 dias), e depois com a recirculação das partículas (110 dias). Durante o período em que as biopartículas não foram recirculadas, o sistema, operado com TDH de $2 \mathrm{~h}$ (1,65 h no reator aeróbio e 0,385 h no reator anóxico), alcançou eficiências de remoção de carbono, nitrogênio e fósforo de $94 \%$; $80 \%$ e $65 \%$, respectivamente, 
gerou-se efluente com concentrações médias de 18 mgDQO.L ${ }^{-1}$ 0,35 mgN-amon. $\mathrm{L}^{-1}$ e $1,7 \mathrm{mgP} \cdot \mathrm{L}^{-1}$. No período em que as biopartículas foram recirculadas (100\%) o sistema alcançou eficiência de $91 \%$; $78 \%$ e $85 \%$ na remoção de carbono, nitrogênio e fósforo, respectivamente, gerando-se um efluente com concentrações de $26 \mathrm{mgDQO} \cdot \mathrm{L}^{-1}, 0,67 \mathrm{mgN}$-amon. $\mathrm{L}^{-1}$ e $0,76 \mathrm{mgP} \cdot \mathrm{L}^{-1}$. O reator foi operado com tempo de retenção celular de 45 a 50 dias atingindo uma produção de lodo de 0,12 a 0,135 gSSV.gDQO ${ }^{-1}$.

Lassman et al. (2006) estudaram a remoção simultânea de carbono e de nitrogênio em reator anaeróbio de leito fluidificado e fluxo descendente com altura de 1,37 m e diâmetro interno de 4,48 cm (volume útil de 1,9 L), alimentado com esgoto sintético. O material suporte foi composto por esferas de sílica, com diâmetro médio de $169 \mu \mathrm{m}$ e densidade de $0,70 \mathrm{~g} \cdot \mathrm{cm}^{-3}$. O reator foi operado com taxa de carregamento orgânico (TCO) de 15 gDQO.L $\mathrm{L}^{-1} \cdot$ dia-1 e submetido a duas concentrações de nitrogênio de 100 e $250 \mathrm{mgN}^{-N^{-}}{ }_{3}^{-} \cdot \mathrm{L}^{-1}$, que corresponde a um TCN (taxa de carregamento de nitrogênio) de 0,67 e 1,67 mgN-NO${ }_{3}^{-} \cdot \mathrm{L}^{-1} \cdot \mathrm{dia}^{-1}$, respectivamente. A remoção de nitrogênio nos dois casos foi maior que $90 \%$, enquanto a remoção média de carbono foi de $65 \%$ para a alimentação de $100 \mathrm{mgN}-\mathrm{NO}_{3}{ }^{-} \cdot \mathrm{L}^{-1}$ e $70 \%$ para a alimentação de $250 \mathrm{mgN}-\mathrm{NO}_{3}^{-} \cdot \mathrm{L}^{-1}$. Além disso, foi verificado que para altos valores da relação de $\mathrm{DQO} / \mathrm{N}$, a redução dissimilativa do nitrato é favorecida, já para baixos valores a desnitrificação e a digestão anaeróbia ocorre simultaneamente.

Dempsey et al. (2006) estudaram em escala piloto um biofiltro aeróbio de leito expandido, construído em PVC, com altura de 3,0 m e diâmetro de 0,5 m (volume útil de $0,5 \mathrm{~m}^{3}$ ), alimentado com esgoto sanitário. Foi utilizado coque vítreo como 
material suporte (DEMPSEY, $2003^{1}$ apud DEMPSEY et al., 2006). O reator foi operado com taxa de carregamento hidráulica média de $25 \mathrm{~m}^{3} \cdot \mathrm{m}^{-3} \cdot \mathrm{dia}^{-1}$, obtendo eficiências médias de $98 \%, 62 \%$ e $56 \%$ para $\mathrm{N}$-amon, SS e DBO, respectivamente, gerando-se um efluente com concentrações médias de $0,4 \mathrm{mgN}$-amon. $\mathrm{L}^{-1}$, $5,4 \mathrm{mgSS} . \mathrm{L}^{-1}, 9,0 \mathrm{mgDBO} \cdot \mathrm{L}^{-1}$.

Wang et al. (2007) operaram em escala piloto um reator aeróbio de leito fluidificado com altura de $160 \mathrm{~cm}$, alimentado com esgoto sanitário. Os autores empregaram a coagulação química em conjunto com a degradação biológica. Para isso, aplicaram no esgoto sanitário bruto, policloreto de alumínio - PAC (45 mg. $\left.\mathrm{L}^{-1}\right)$ seguido de poli-acrilamida - PAM (peso molecular $5 \times 10^{6} \mathrm{~g} \cdot \mathrm{mol}^{-1}$ ). A função do PAC foi de desestabilizar as partículas, enquanto o PAM foi de fortificar a agregação entre as partículas. $\mathrm{O}$ reator foi operado com TDH de 33 minutos e taxa de recirculação de $50 \%$, obtendo eficiências médias de remoção de $90 \%, 93,6 \%, 95,6 \%, 43,8$ e 34,6 para DQO, DBO, SS, NKT e N-amon, respectivamente. Gerou-se um efluente com 22,6 mgDQO. $\mathrm{L}^{-1}, \quad 7,9 \quad \mathrm{mgDBO} . \mathrm{L}^{-1}, \quad 7,8 \quad \mathrm{mgSS} . \mathrm{L}^{-1}, \quad$ 17,3 $\quad \mathrm{mgNKT}^{-\mathrm{L}^{-1}} \quad$ e $16,8 \mathrm{mgN}$-amon. $\mathrm{L}^{-1}$.

Ha e Ong (2007) avaliaram, em escala piloto, o desempenho de um filtro biológico expandido, alimentado com esgoto sintético, com $0,1 \mathrm{~m}$ de diâmetro e 2,5 m de altura e composto de zonas anaeróbia, anóxica e aeróbia. O reator foi preenchido com areia média, com diâmetro médio de $10 \mathrm{~mm}$ nas zonas anaeróbia/anóxica e 5,0 mm na zona aeróbia. O reator operado com TDH "ótimo" de 3 horas, taxas de recirculação de 200 e $300 \%$. A taxa de carregamento de nitrogênio foi 0,19 kgN-amon $\cdot \mathrm{m}^{-3} \cdot \mathrm{dia}^{-1}$ para a recirculação de $200 \%$ e de $0,21 \mathrm{kgN}-a m o n \cdot \mathrm{m}^{-3} \cdot \mathrm{dia}^{-1}$ para recirculação de $300 \%$. Obtiveram-se eficiências

\footnotetext{
1 DEMPSEY M.J. (2003). Improvements in and relating to fluid bed expansion and fluidization.
} Bioresource technology, v.99, n.16, p.7781-7787. 
médias de remoção de DQO acima de $96 \%$ e de NKT de $75 \%$, para ambos os casos.

Chowdhury, Nakhla e Zhu (2008) operaram um sistema de reatores de leito fluidificado, alimentado com esgoto sintético, composto por duas colunas, uma funcionava como reator anóxico, com diâmetro interno de $2,5 \mathrm{~cm}(0,77 \mathrm{~L})$ e a outra como reator aeróbio, como diâmetro interno de $7,6 \mathrm{~cm}(3,33 \mathrm{~L})$. O material suporte foi composto por partículas de rocha vulcânica, com diâmetro médio de 670 นm (300 a $1000 \mu \mathrm{m}$ ). Aplicaram-se ao sistema quatro tempos de detenção hidráulica (TDH) de 0,$82 ; 0,65 ; 0,55$ e 0,44 h para avaliar a capacidade de remoção de nitrogênio no sistema. Obteve-se um efluente com concentrações de DBO de 8 mg. $\mathrm{L}^{-1}$ e NKT menores que $10 \mathrm{mg} \cdot \mathrm{L}^{-1}$, quando o reator foi operado com TDH de 0,44 h e cargas de carregamento orgânico de 5,3 kgDQO $\cdot \mathrm{m}^{-3} \cdot \mathrm{dia}^{-1}$ e de nitrogênio de 0,54 kN.m $\mathrm{m}^{-3} \cdot \mathrm{dia}^{-1}$. Houve baixa produção de lodo de 0,14 a 0,21 gSSV.gDQO-1.

Sowmeyan e Swaminathan (2008) estudaram o desempenho de um reator anaeróbio de leito fluidificado e fluxo descendente para o tratamento de esgoto com alta concentração de matéria orgânica. Uma coluna formava o reator, com volume total de 5,0 L (0,08 m de diâmetro interno e 1,0 m de altura). Como material suporte foi utilizado perlita, com diâmetro médio de 1,0 mm e área superficial específica de $7,0 \mathrm{~m}^{2} \cdot \mathrm{g}^{-1}$. Obteve-se eficiência de remoção de DQO de $84 \%$, quando o sistema foi operado com taxa de carregamento orgânico de $35 \mathrm{kgDQO} \cdot \mathrm{m}^{-3} \cdot \mathrm{dia}^{-1}$ e tempo de detenção hidráulica de 3,8 h. O material suporte foi muito efetivo para o crescimento da biomassa, alcançando concentrações de $0,66 \mathrm{~g}_{\mathrm{ssv}} \cdot \mathrm{g}_{\mathrm{sólido}}{ }^{-1}$.

Aslan e Dahab (2008) avaliaram a eficiência de reatores de leito fluidificado para o tratamento de esgoto com alta concentração de nitrogênio. O sistema foi composto por dois reatores (76 $\mathrm{mm}$ de diâmetro e 1,5 $\mathrm{m}$ de altura), um usado para a 
nitrificação, seguido de outro para a desnitrificação. Foi utilizado metanol como fonte de carbono para a desnitrificação. Como material suporte foi utilizado areia uniforme com diâmetro médio de $0,83 \mathrm{~mm}$ e área superficial específica de $4200 \mathrm{~m}^{2} \cdot \mathrm{m}^{-3}$. Durante a operação alcançou-se eficiência média de remoção de nitrogênio total de $90 \%$. As concentrações de nitrito e nitrato no efluente foram de 3,0 e $0,9 \mathrm{mg} \cdot \mathrm{L}^{-1}$, com taxa de carregamento igual $0,08 \mathrm{kgNKT} \cdot \mathrm{m}^{-3} \cdot \mathrm{dia}^{-1}$.

Yoochatchaval et al. (2008) estudaram um reator anaeróbio de leito expandido com volume de 2,0 L alimentado com esgoto sintético. O reator foi operado com velocidade ascensional de 5,0 m.h $\mathrm{h}^{-1}$, tempo de detenção hidráulica de $1,0 \mathrm{~h}$ e taxa de carregamento orgânico de 7,2 a 9,6 kgDQO.m ${ }^{-3} \cdot \mathrm{dia}^{-1}$. Entretanto nessa configuração o sistema apresentou baixa eficiência de remoção de DQO (50 a $60 \%$ ), isso ocorreu provavelmente pelo baixo tempo detenção do substrato no sistema. Por essa razão, foi associado ao sistema um UASB (sem recirculação e com velocidade ascensional de $0,7 \mathrm{~m} \cdot \mathrm{h}^{-1}$ ) para aumentar o valor da DQO na manta de lodo do reator de leito expandido. Com isso, obteve-se um excelente desempenho do sistema, obtendo eficiências de remoção médias de DQO de 91\%.

Vale destacar, que a maioria dos trabalhos levantados são baseados em escala de laboratório, sendo alguns em escala piloto, sob condições controladas e parâmetros de análises pré-definidos. Isso proporciona um distanciamento na realidade do sistema desta pesquisa, visto que o aumento na escala tende a gerar divergências operacionais, que podem ser refletidas no desempenho do sistema. Sendo assim, as comparações com o presente trabalho ficam comprometidas, devido às grandes diferenças (instabilidades) atribuídas às condições de operação e manutenção do reator em escala plena. 


\subsubsection{Alguns Trabalhos Desenvolvidos na EESC/USP sobre Reatores de Leito Expandido/fluidificado}

A Escola de Engenharia de São Carlos (EESC/USP) vem desenvolvendo, na linha de pesquisa sobre reatores de leito expandido/fluidificado, estudos enfocando vários aspectos que influenciam a concepção, o controle e o monitoramento desses reatores.

Maragno (1988) operou um reator anaeróbio de leito fluidificado, em escala de laboratório, para tratamento de água residuária sintética, com baixo valor de DQO (100 a $500 \mathrm{mg} / \mathrm{L}^{-1}$ ). O reator com volume de $10,5 \mathrm{~L}$ foi operado durante 305 dias. $\mathrm{O}$ meio suporte foi constituído de areia fina, com diâmetro médio de 0,2 mm. A eficiência média de DQO atingida pelo sistema, operado com TDH igual a 1,5 h, foi de $72 \%$, ou seja, o efluente apresentou um valor médio $68 \mathrm{mgDQO} \cdot \mathrm{L}^{-1}$. A autora comenta que a concentração de sólidos em suspensão sofreu influência da variação da vazão afluente, pois com o seu aumento, houve arraste do meio suporte para fora do reator, representado pelos menores grãos de areia.

Barros (1989) avaliou a eficiência da nitrificação de um reator aeróbio de leito fluidificado, com volume útil de 9,5 L. Foi empregada areia como material suporte para o biofilme, com tamanho médio de 0,5 mm. Obtiveram-se as maiores eficiências médias de $75 \%$ e $80 \%$ na conversão de NKT e na nitrificação, respectivamente, quando operado com $\mathrm{TDH}$ de $1,9 \mathrm{~h}$ e taxa de carregamento de nitrogênio de $0,37 \mathrm{kgNKT} \cdot \mathrm{m}^{-3} \cdot \mathrm{dia}^{-1}$. A autora constatou que, conforme a relação DQO/N-amon aumentou $(1,70$ a 4,9) a produção volumétrica de nitratos decresceu de 0,32 a $0,05 \mathrm{kgN}-\mathrm{NO}_{3}{ }^{-} \cdot \mathrm{m}^{-3} \cdot \mathrm{dia}^{-1}$. 
Vieira (1989) avaliou o desempenho de um reator anaeróbio de leito fluidificado, em escala de laboratório, no tratamento de efluentes líquidos com baixo valor de DQO. O reator possuía volume de 9,5 L e como material suporte foi utilizado areia com diâmetro médio de $0,18 \mathrm{~mm}$. O sistema apresentou eficiência média de remoção de $\mathrm{DQO}$ de $87 \%$, quando o reator foi submetido a uma carga de carregamento orgânico de $3,27 \mathrm{kgDQO} \cdot \mathrm{m}^{-3} \cdot \mathrm{dia}^{-1}$ e TDH de $3,5 \mathrm{~h}$. O efluente apresentou valor médio de $97 \mathrm{mgDQO} \cdot \mathrm{L}^{-1}$.

Campos (1989) operou sistema de três reatores de filme fixo em série, constituído por um reator anaeróbio de leito fluidificado (10,9 L), um reator anóxico de leito fixo $(73,6 \mathrm{~L})$ e um reator aeróbio de leito fluidificado $(9,5 \mathrm{~L})$, alimentado com despejos líquidos sintéticos. $\mathrm{O} T \mathrm{TH}$, em cada reator variou nas seguintes faixas: reator anaeróbio: 1,5 a 5,2 h; reator anóxico: 10,2 a 35 h e reator aeróbio: 1,3 a $4,5 \mathrm{~h}$. a velocidade ascensional, no reator aeróbio, variou entre 5,33 a $8,4 \mathrm{~m} \cdot \mathrm{h}^{-1}$. O sistema obteve remoção média global de $98 \% ; 78,3 \%$ e 88,5\% para DQO, NKT e fósforo, respectivamente. $\mathrm{O}$ autor comenta, que os maiores valores obtidos na remoção de fósforo ocorreram quando o sistema foi submetido a condições mais drásticas de sobrecarga. Além disso, foi estudada a relação DQO/N-amon na carga volumétrica removida, e constatou-se que, conforme o valor dessa relação foi aumentando de 1,8 a 2,8, a carga volumétrica de $\mathrm{N}$-amoniacal removida decresceu de 0,270 a $0,054 \mathrm{kgN}$-amon.m $\mathrm{m}^{-3} \cdot \mathrm{dia}^{-1}$.

Therezo (1993) avaliou o desempenho de um reator anaeróbio de leito expandido operado sob condições instáveis de carregamento orgânico e hidráulico. O reator com volume útil de $10,9 \mathrm{~L}$ foi alimentado continuamente com substrato sintético. O material utilizado como suporte para o crescimento de microrganismo foi constituído por areia com diâmetro médio de 0,177 mm. Foram aplicadas taxas de 
carregamento orgânico que variaram de 5,5 a $40 \mathrm{kgDQO} \cdot \mathrm{m}^{-3} \cdot \mathrm{dia}^{-1}$. O sistema apresentou eficiência média de remoção de $\mathrm{DQO}$ em torno de $74 \%$, para taxa de carregamento orgânico de 12,8 $\mathrm{kgDQO} \cdot \mathrm{m}^{-3} \cdot \mathrm{dia}^{-1}$ e TDH igual a 1,6 h. O autor comenta a necessidade de uma melhor separação de sólidos na zona de decantação do reator, pois a contribuição dos sólidos em suspensão na DQO do efluente representou, em media, $44 \%$ do valor global.

Cuba Terán (1995) estudou o desempenho de um reator anaeróbio de leito fluidificado no tratamento de esgoto sanitário sintético. O reator apresentava volume total de $20 \mathrm{~L}$, a camada suporte do reator foi constituída por areia com diâmetro de aproximadamente $0,2 \mathrm{~mm}$ e massa especifica de $1,35 \mathrm{~g} \cdot \mathrm{cm}^{-3}$. O reator alcançou remoção máxima de DQO de $91,5 \%$ com TDH de 6,5 h e taxa de carregamento orgânico de 2,22 kgDQO.m $\mathrm{m}^{-3} \cdot \mathrm{dia}^{-1}$. O autor comenta que o reator pode ser operado com taxas de carregamento da ordem de $10 \mathrm{kgDQO} \cdot \mathrm{m}^{-3} \cdot \mathrm{dia}^{-1} \mathrm{com}$ remoção média de $\mathrm{DQO}_{\text {total }}$ de $75 \%$.

Araújo (1995) acompanhou a evolução do biofilme no mesmo reator operado por Cuba Terán (1995). A autora observou que o aumento da taxa de carregamento orgânico de $1,0 \mathrm{kgDQO} \cdot \mathrm{m}^{-3} \cdot \mathrm{dia}^{-1}$ a $24,38 \mathrm{kgDQO} \cdot \mathrm{m}^{-3} \cdot \mathrm{dia}^{-1}$ levou a uma produção expressiva de polímeros extracelulares no biofilme, além disso, o crescimento da biomassa foi de $10 \mathrm{~g} . \mathrm{L}^{-1}$ para $50 \mathrm{~g} \cdot \mathrm{L}^{-1}$. Em decorrência do aumento da matriz polimérica e do crescimento da biomassa, a espessura do biofilme passou de cerca de $10 \mu \mathrm{m}$ para cerca de $70 \mu \mathrm{m}$. Ela comenta que houve a formação de "aglomerados", derivados do encapsulamento de várias biopartículas, cujo tamanho variou de 2,0 a $5,0 \mathrm{~mm}$.

A partir das conclusões obtidas nesses trabalhos foi possível realizar o "scale up" desta configuração de reator (PEREIRA, 2000), pois se verificou, em termos 
práticos, que o reator de leito expandido/fluidificado é realmente eficiente no tratamento de águas residuárias e de abastecimento, mesmo quando trabalhando com baixos TDHs comparado a outras configurações.

Pereira (2000) monitorou o tratamento de esgoto sanitário, utilizando reator anaeróbio de leito expandido $\left(31,3 \mathrm{~m}^{3}\right)$, com altura de $14,9 \mathrm{~m}$ e diâmetro de $1,5 \mathrm{~m}$, cujo leito foi composto por carvão ativado granular (CAG). O reator foi operado com velocidade ascensional de $10,5 \mathrm{~m} \cdot \mathrm{h}^{-1}$, taxa de recirculação de 0,85 e tempo de detenção hidráulica médio de 3,1 h, alcançou resultados satisfatórios na remoção de $\mathrm{DQO}_{\text {total }}$ e SST de $79,5 \%$ e $76,3 \%$, respectivamente, produzindo efluente com 235,0 mgDQO.L $\mathrm{L}^{-1}$ e 81,0 mgSST.L $\mathrm{L}^{-1}$, em média, associado a custo relativamente baixo com energia elétrica da ordem de $\mathrm{R} \$ 0,0427 / \mathrm{m}^{3}$ de esgoto tratado (custo da tarifa domiciliar de $\mathrm{R} \$$ 0,144385 por kWh, utilizado pela CPFL em março de 1998).

Mendonça (2004) abordou o projeto, a construção e a operação de um reator anaeróbio-aeróbio de leito expandido $\left(\right.$ RAALE $\left._{\mathrm{x}}\right)$ em escala plena $\left(159,0 \mathrm{~m}^{3}\right)$ para o tratamento de esgoto sanitário. O RAALE foi submetido à condição anaeróbia e anaeróbia-aeróbia de operação em quatro meses. Na condição anaeróbia, após inoculação e operação durante 60 dias, para TDH de 2,69 h e carga orgânica volumétrica de 3,4 kgDQO. $\mathrm{m}^{-3} \cdot \mathrm{dia}^{-1}$, obteve-se eficiência média de remoção de DBO, DQO e SST de $76 \% ; 72 \%$ e $80 \%$, respectivamente, gerando-se efluente com concentrações de $98 \mathrm{mgDBO} . \mathrm{L}^{-1}, 225 \mathrm{mgDQO} . \mathrm{L}^{-1}$ e $35 \mathrm{mgSST} . \mathrm{L}^{-1}$. Nessas condições, para carga nitrogenada volumétrica de $0,27 \mathrm{kgN} \cdot \mathrm{m}^{-3} \cdot \mathrm{dia}^{-1}$ obteve-se efluente com concentrações média de nitrogênio orgânico de $8,0 \mathrm{mg} \cdot \mathrm{L}^{-1}$ e $\mathrm{N}$-amon de $37 \mathrm{mg} \cdot \mathrm{L}^{-1}$, com remoção média de NKT de $4 \%$, contudo demonstrando elevada eficiência no potencial de amonificação (82\%). Para a condição anaeróbia-aeróbia, o 
tempo de operação do RAALE , foi inferior a dois meses, sem alcançar regime de equilíbrio dinâmico.

Siman (2007) operou o mesmo reator que Mendonça (2004), mas com leito de carvão granular (ativado e antracito) expandido e parcialmente aerado (oxigênio puro), para promover remoção de matéria orgânica e nutrientes ( $\mathrm{N}$ e $\mathrm{P}$ ) do esgoto sanitário. No RAALEx, após 451 dias de operação, obtiveram-se remoções médias de $\mathrm{DQO}_{\text {filt }}$, NKT e fosfato total de $78 \% ; 56 \%$ e $42 \%$, respectivamente, quando o reator foi operado com TDH médio de $8,8 \mathrm{~h}$. Para o restante do período, o sistema demonstrou remoções médias de $65 \pm 20 \%$ para $\mathrm{DQO}_{\mathrm{F}}, 25 \pm 21 \%$ para NKT e $48 \pm$ $18 \%$ para o fosfato total.

$\mathrm{Na}$ Tabela 3.1, são enumerados diversos trabalhos que já foram concretizados, na EESC-USP, utilizando essa configuração de reator.

Tabela 3.1 Trabalhos realizados com Reatores de Leito Expandido

\begin{tabular}{|c|c|c|c|c|}
\hline $\begin{array}{c}\text { Volume } \\
\text { Reator (L) }\end{array}$ & Afluente & Leito & $\theta h(h)$ & Referência \\
\hline 35,3 & Ind. Alimentícia & Areia & 6 a $2 h$ & Akutsu (1984) \\
\hline 10,5 & Esgoto Sintético & Areia & 1,0 a 1,5 & Maragno (1988) \\
\hline 9,5 & Esgoto Sintético & Areia & 1,4 a 2,0 & Barros (1989) \\
\hline 9,5 & Esgoto Sintético & Areia & 1,3 a 10,0 & Campos (1989) \\
\hline 9,5 & Esgoto Sintético & Areia & 1,5 a 7,0 & Vieira (1989) \\
\hline 21 & Água de Abastecimento & Areia & 0,3 a 2,0 & Cuba Terán (1990) \\
\hline 21 & Água de Abastecimento & Areia & 1,14 a 13,8 & Hamada (1992) \\
\hline 10,9 & Esgoto Sintético & Areia & 1,4 a 5,2 & Therezo (1993) \\
\hline 3,2 & Fenol & $\mathrm{CAG}^{* 1}$ & 144 a 1,2 & Costa (1994) \\
\hline 3,3 & Fenol & Areia & 0,5 a 7,0 & Silva (1995) \\
\hline 20 & Esgoto Sintético & Areia & 2,4 a 12,0 & Cuba Terán (1995) \\
\hline 20 & Esgoto Sintético & Areia & 12 a 3,2 & Araújo (1995) \\
\hline 32.000 & Esgoto Sanitário & $\mathrm{CAG}^{* 1}$ & 7 a 3,2 & Mendonça (1998) \\
\hline 32.000 & Esgoto Sanitário & $\mathrm{CAG}^{* 1}$ & 3,2 & Pereira (2000) \\
\hline 32.000 & Esgoto Sintético (c/ coagulante) & $\mathrm{CAG}^{* 1}$ & 7 a 3,2 & Santos (2001) \\
\hline 160.000 & Esgoto Sanitário & $\mathrm{CAG}^{* 1}$ & 2,7 & Mendonça (2004) \\
\hline 32.000 & Esgoto Sanitário & BPIT $^{* 2}$ & 3,2 & Niciura (2005) \\
\hline 160.000 & Esgoto Sanitário & $\mathrm{CAG}^{* 1}+\mathrm{CA}^{* 3}$ & 8,8 & Siman (2007) \\
\hline
\end{tabular}

${ }^{{ }^{1}}$ Carvão Ativado Granular

${ }^{* 2}$ Banda de Rodagem de Pneus Inservívies Triturada

${ }^{\star 3}$ Carvão Antracitoso

Fonte: Adaptado de Mendonça (2004) 
Nesses trabalhos, verificou-se a aplicabilidade de reatores de leito expandido no tratamento de águas residuárias e no pré-tratamento de águas de abastecimento para a remoção de DBO, nitrificação e desnitrificação sob condições aeróbias e anaeróbias, respectivamente. Houve enfoque nos aspectos de concepção, operação, bem como a formação do biofilme e caracterização da morfologia microbiana do material aderido ao suporte.

\subsection{Biofilme}

\subsubsection{Características do Biofilme}

Os biofilmes são caracterizados como um consórcio de microrganismos imobilizados junto a uma matriz de substâncias poliméricas de origem microbiana. Segundo Araújo (1995), o biofilme pode formar-se sobre qualquer superfície que apresente atividade microbiana, podendo ser encontrado em sistemas naturais ou de origem antrópica, que forem expostos a um ambiente líquido não estéril.

Essa agregação de microrganismos no biofilme facilita a cooperação entre os organismos, o que reduz a distância para a transferência de metabólitos. Essa associação beneficia a degradação do substrato orgânico como os carboidratos, propionato, butirato, etanol e propanol (SPEECE, 1995).

A estrutura do biofilme é definida pela sua atividade, ou seja, o crescimento de células microbianas, a produção e excreção de $E^{2} S^{2}$, aliada a fatores externos

\footnotetext{
${ }^{2}$ EPS (extracellular polymeric substances), matriz de polímeros extracelulares que mantém o biofilme coeso.
} 
como as forças de atrito, definidas pela hidrodinâmica do reator (STOODLEY et al., 1999).

Segundo Lens et al. (Ed.) (2003), os polímeros extracelulares (EPS), além de serem importantes no processo de aderência do biofilme, também determinam a estrutura do mesmo. Os exopolímeros são produzidos e excretados pelas células microbianas, que incluem polissacarídeos, proteínas, glicoproteínas, lipopolissácarídeos (LPSs), lipídeos, entre outros e fazem parte da matriz polimérica. Além dos exopolímeros, a matriz do biofilme também é constituída por restos celulares e produtos extracelulares de atividades hidrolíticas.

\subsubsection{Formação do Biofilme}

O processo de formação de biofilme aderido à superfície de um meio suporte é iniciado mediante a presença de microrganismos existente no meio, que após se fixarem na superfície, iniciam o processo de crescimento, utilizando-se dos substratos da fase líquida.

A formação do biofilme, bem como a sua estrutura são influenciadas pela taxa de carregamento do substrato na superfície do biofilme, pelas condições hidrodinâmicas do reator e pelo tipo de microrganismo envolvido na degradação da matéria orgânica (VAN LOOSDRECHT et al., 1995³ apud MENDONÇA 1998; VELUCHAMY; BEYENAL; LEWANDOWSKI, 2008).

Segundo Xavier, Picioreanu e Almeida (2005), a formação e o aumento da espessura de biofilmes é resultado de vários processos de natureza física e

\footnotetext{
${ }^{3}$ VAN LOOSDRECHT, M.C.M. et al. (1995). Biofilms structures. Water Science and Technology, v.32, n.8, p.35-43.
} 
biológica. Na Figura 3.3 são representados alguns dos processos envolvidos na formação do biofilme.

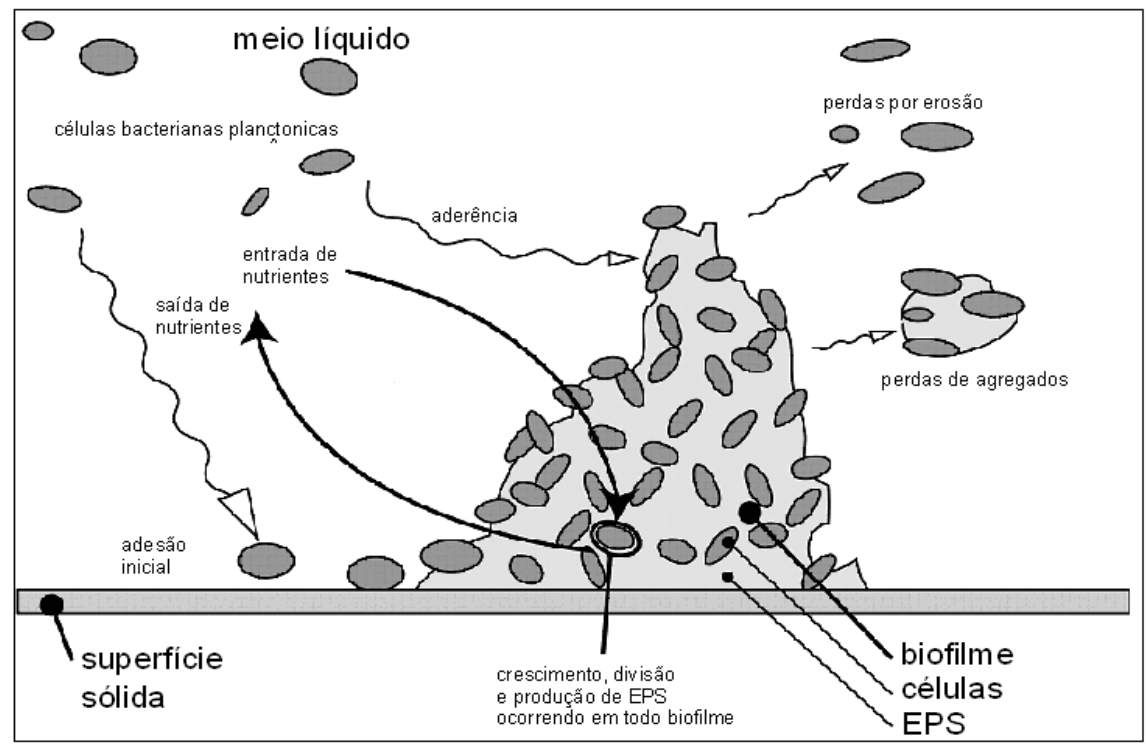

Figura 3.3 Processos envolvidos na formação e crescimento de biofilmes

Fonte: Xavier, Picioreanu e Almeida (2005)

Na Figura 3.3 são mostrados quatro processos envolvidos na formação e crescimento do biofilme:

- Aderência Inicial: neste processo ocorre o transporte e fixação de células livres do meio líquido para uma superfície sólida;

- Crescimento, divisão e produção de EPS: devido à presença de nutrientes no meio líquido, ocorre o crescimento e divisão de células fixadas, além da produção e excreção de EPS;

- Aderência: nesta fase ocorre a fixação de células bacterianas flutuantes, que contribuem para a acumulação do biofilme;

- Perdas: ocorre a liberação de material celular, através da erosão (perda de células individuais ou perda de agregados maiores).

A formação de biofilme e agregados microbiológicos são requisitos necessários para o sucesso nas operações de tratamento biológico de esgotos, bem 
como em sistemas de remoção de nutrientes (FLEMMING, $1993^{4}$ apud LENS et al. (Ed.) ( 2003).

Estudo sobre biofilme tem avançado, fazendo desta área uma das mais ativas na biotecnologia ambiental (GRAY, $1999^{5}$ apud LENS et al. (Ed.), 2003).

\subsubsection{Remoção do Biofilme}

A "remoção" do biofilme é de fundamental importância no desempenho de reatores de tratamento de águas residuárias, pois afeta diretamente as características físicas, químicas e biológicas do biofilme

O processo de remoção do biofilme pode ocorrer pela predação, cisalhamento, abrasão e desprendimento. A predação pode ser ocasionada pela ação de outros microrganismos, como protozoários. O cisalhamento é caracterizado pelas condições hidrodinâmicas do escoamento. A abrasão se dá pela agitação e, conseqüente colisão entre as partículas e o biofilme. Já o desprendimento é um fenômeno atribuído a depleção de oxigênio e de nutrientes nas camadas interiores do biofilme.

Estudos realizados por Nicolella et al. (1997) sobre mecanismos de remoção de biofilme em reatores de leito fluidificado, mostram que o desprendimento do biofilme é causado por processos contínuos e descontínuos; ou seja, a ação das forças cisalhantes exercidas pelo fluxo promove a constante remoção de células individuais ou pequenos grupos de células da superfície do biofilme; desprendimento

\footnotetext{
${ }^{4}$ FLEMMING, H.C. (1993). Biofilms and environmental protection. Water Science Technology, v.27, n.1, p.1-10.

${ }^{5}$ GRAY, N.F. (1999). Water technology: an introduction for environmental scientists and engineers. Londres: Arnold.
} 
relativos de grandes parcelas de biomassa e abrasão, que é resultado das colisões entre as partículas sólidas com o biofilme.

Cheng, Chen e Hwang (1997) estudaram a formação de biofilme num reator trifásico de leito fluidificado em escala de laboratório. O reator possuía altura de 134 $\mathrm{cm}$ e diâmetro interno de $14,3 \mathrm{~cm}$. O material suporte utilizado foi o CAG. Os autores observam que, quando a velocidade ascensional média do líquido foi aumentada de 61,1 a $76,5 \mathrm{~m} \cdot \mathrm{h}^{-1}$, a biomassa aderida no CAG foi reduzida de 30,4 para 15,6 mgSSV.gCAG ${ }^{-1}$. Isso foi causado pelo aumento das forças cisalhantes e pelo atrito entre as superfícies das partículas. Por outro lado, as bactérias nitrificantes foram induzidas a secretar mais exopolímeros para cobrir as colônias de bactérias sobre o CAG, o que favoreceu a adesão de novos microrganismos.

Zhang et al. (2006) estudaram os microrganismos responsáveis pela formação do biofilme e do fenômeno conhecido por desprendimento. Neste estudo, eles observaram que as comunidades microbianas presentes na superfície do meio suporte podem ser muito diferentes das presentes na biomassa em suspensão. Os resultados obtidos durante o trabalho sugerem a investigação minuciosa das células aderidas ao meio suporte, bem como o desenvolvimento de estratégias para o controle do fenômeno conhecido por biofouling, pois isso pode se tornar uma questão crítica, na engenharia ambiental.

\subsubsection{Biofilme em Reatores de Leito Expandido/Fluidificado}

Os sistemas baseados em biofilme utilizados no tratamento de águas residuárias incluem: reator de leito expandido/fluidificado, filtros biológicos percoladores, biodiscos, filtros aerados submersos e filtros anaeróbios. 
Rabah e Dahab (2004) estudaram em escala de laboratório a concentração de biomassa e as características do biofilme em um reator anóxico de leito fluidificado para o tratamento de esgoto sintético com alta concentração de nitrato. 0 reator possuía 2,0 $\mathrm{m}$ de altura e $76 \mathrm{~mm}$ de diâmetro interno. Como material suporte foi utilizada areia uniforme com diâmetro médio de $0,84 \mathrm{~mm}$, densidade específica de $2,65 \mathrm{~g} \cdot \mathrm{cm}^{-3}$ e área específica de $4200 \mathrm{~m}^{2} \cdot \mathrm{m}^{-3}$. Eles observaram que houve diminuição na concentração da biomassa ao se aumentar a velocidade ascensional (45 para $65 \mathrm{~m} \cdot \mathrm{h}^{-1}$ ) e isso ocorreu independentemente das taxas de carregamento de nitrogênio $\left(6 ; 8 ; 12\right.$ e $\left.16 \mathrm{kgN} \cdot \mathrm{m}^{-3} \cdot \mathrm{dia}^{-1}\right)$. Além disso, eles relatam que alta concentração de biomassa foi encontrada aderida ao material suporte, na parte inferior do reator, e que diminuía ao longo da altura do mesmo. A espessura do biofilme aumentava da base para o topo do reator, indicando que houve estratificação do leito.

Cresson et al. (2006) estudaram em escala de laboratório a formação de biofilme em reator anaeróbio trifásico de leito fluidificado com volume de 7,24 L. A areia formava o meio suporte, com diâmetro médio igual a $172 \mu \mathrm{m}$, área especifica de $24,08 \mathrm{~m}^{2} \cdot \mathrm{L}^{-1}$. O reator foi inoculado com lodo anaeróbio proveniente de outro reator semelhante utilizado no tratamento vinhaça. A taxa de carregamento orgânica foi progressivamente aumentada de 0,5 a $20 \mathrm{gDQO} \cdot \mathrm{L}^{-1} \cdot \mathrm{dia}^{-1}$. A formação do biofilme e o desempenho do reator foram monitorados durante 90 dias. Na fase inicial, nos primeiros dez dias (TCO igual a 0,5 gDQO $\cdot \mathrm{L}^{-1} \cdot \mathrm{dia}^{-1}$ ), observou-se eficiência de remoção de DQO de 90\%, acompanhada com o contínuo crescimento do biofilme. Na fase posterior, após o trigésimo oitavo dia, a taxa de carregamento orgânico aumentou para $6 \mathrm{gDQO} \cdot \mathrm{L}^{-1} \cdot \mathrm{dia}^{-1}$, o que fez com que a eficiência do reator caísse rapidamente, havendo acúmulo de ácidos graxos voláteis, bem como queda na 
atividade metanogênica específica. Segundo os autores, esse fenômeno ocorreu devido à limitação de micronutrientes, especialmente o cobalto e o níquel. Após a complementação com solução mineral, a atividade metanogênica e a remoção de DQO foram restauradas. O reator alcançou eficiências de remoção de carbono maiores que $90 \%$ com taxa de carregamento orgânico igual a $20 \mathrm{gDQO} \cdot \mathrm{L}^{-1} \cdot \mathrm{dia}^{-1}$.

Zhou et al. (2008) investigaram o desempenho de reator aeróbio de leito fluidificado com altura de $762 \mathrm{~mm}$ e diâmetro interno de $102 \mathrm{~mm}$, alimentado com esgoto sintético. A aeração foi feita através do borbulhamento de oxigênio puro no sistema. O material suporte foi composto por partículas de carvão ativado com diâmetro médio de 0,6 mm e superfície específica de 1100 a $1300 \mathrm{~m}^{2} \cdot \mathrm{g}^{-1}$. O reator foi inoculado com bactérias cultivadas naturalmente em solução de nutrientes durante quatro dias. Após a inoculação, houve a recirculação do líquido, durante um dia, para que as bactérias aderissem à superfície do carvão ativado. Após duas semanas de operação do sistema, com TDH de 45 min, a taxa de remoção de DQO foi de $82,3 \%$ e a espessura do biofilme de $24 \pm 2 \mu \mathrm{m}$.

\subsection{Nitrogênio em Sistemas Biológicos}

\subsubsection{Nitrogênio no Meio Ambiente}

O nitrogênio, quando presente juntamente com fósforo, no meio aquático, pode estimular o crescimento exagerado de algas e plantas aquáticas, ocorrendo o fenômeno denominado de eutrofização.

O nitrogênio amoniacal (uma das formas do nitrogênio), além de ser tóxico a algumas espécies aquáticas, pode ser oxidado por organismos nitrificantes, que ao 
consumirem o oxigênio disponível no meio, podem tornar a vida aquática aeróbia inviável.

O nitrato, forma oxidada do nitrogênio, oriundo de fertilizantes químicos adicionados aos solos (sais de amônio, amônia anidro e uréia) estão sujeitos a processos de lixiviação, podendo atingir os lençóis freáticos, contaminando, assim, os mananciais de água subterrânea. Além disso, a ocorrência de nitratos em águas de abastecimento pode ser responsável pela incidência da doença infantil denominada metahemoglobinemia.

Em função dos usos da água, o CONAMA criou nove classes em função da qualidade a ser mantida no corpo de água. Essa qualidade é expressa na forma de padrões estabelecidos pela resolução CONAMA 357/2005, que também apresenta padrões para o lançamento de efluentes nos corpos de água, assim como padrões de balneabilidade.

No caso, dos padrões de lançamento para efluentes, a concentração máxima permitida para o lançamento de nitrogênio amoniacal total é de $20,0 \mathrm{mgN} \cdot \mathrm{L}^{-1}$. Essa condição foi revogada pela resolução CONAMA 397/2008, que dispensa, temporariamente, o atendimento deste parâmetro, no caso estrito de estações de tratamento de esgoto sanitário.

\subsubsection{Formas do Nitrogênio}

No esgoto sanitário, em geral, as concentrações dos compostos de nitrogênio são baixas, com predominância de N-orgânico (60\%) e N-amoniacal (40\%), e ocasionalmente (menos de 1\%), o nitrogênio pode ser oxidado a formas de nitrito ou nitrato (SEDLAK (Ed.), 1991). 
O nitrogênio apresenta-se em diversas formas no esgoto sanitário. Na forma orgânica, encontra-se como proteínas, uréia e aminoácidos. Já na forma inorgânica encontra-se na forma de nitrogênio amoniacal, que é oriundo da decomposição de proteínas e da hidrólise da uréia, ou sob formas oxidadas, como nitrito $\left(\mathrm{NO}_{2}^{-}\right)$e nitrato $\left(\mathrm{NO}_{3}{ }^{-}\right)$.

O nitrogênio amoniacal compõe-se de duas formas, no meio líquido pode-se apresentar na forma livre, gás amoníaco $\left(\mathrm{NH}_{3}\right)$, ou ionizada, íon amônio $\left(\mathrm{NH}_{4}{ }^{+}\right)$, sendo que a proporção de cada composto é influenciada pelo $\mathrm{pH}$ e pela temperatura do meio.

\subsubsection{Remoção Biológica de Nitrogênio}

\subsubsection{Considerações Gerais}

No tratamento de águas residuárias, o nitrogênio pode ser removido através de processos físico-químicos e biológicos, sendo que o primeiro processo, geralmente são mais onerosos e exigem manutenção mais intensiva, além de poderem causar impactos ambientais secundários significativos, como a liberação de amônia nos sistemas de stripping. Por isso, os sistemas biológicos têm sido a melhor alternativa para a remoção deste composto, pois envolvem menores custos de operação, produção de menores quantidades de resíduos, além da melhor qualidade do efluente (BRATBY, 2003).

A remoção biológica de nitrogênio pode ser efetuada mediante processos de nitrificação e desnitrificação, sendo que o $\mathrm{N}$-amoniacal (íon amônio + amônia) oxidado a nitrito (nitritação) e, posteriormente, a nitrato (nitratação), sob condições 
aeróbias. Em condições anóxicas, o nitrato é reduzido a nitrito e seqüencialmente a nitrogênio gasoso.

Essas condições podem ser atingidas em sistemas de dois estágios ou sistemas seqüenciais (sistema anaeróbio, aeróbio e anóxico).

\subsubsection{Nitrificação: Aspectos Físico-químicos e Microbiológicos}

A nitrificação predominantemente é um processo autotrófico, isto é, a energia usada para o crescimento bacteriano é derivada da oxidação de compostos de nitrogênio, principalmente o íon amônio $\left(\mathrm{NH}_{4}{ }^{+}\right)$, nitrito $\left(\mathrm{NO}_{2}^{-}\right)$e nitrato $\left(\mathrm{NO}_{3}{ }^{-}\right)$, usando o dióxido de carbono $\left(\mathrm{CO}_{2}\right)$ como fonte para síntese de novas células (WASTEWATER..., 2003).

Wastewater... (2003) apresentam as etapas envolvidas durante o processo de nitrificação (Equações 3.1, 3.2 e 3.3).

$$
\begin{aligned}
& \mathrm{NH}_{4}^{+}+3 / 2 \mathrm{O}_{2} \rightarrow \mathrm{NO}_{2}^{-}+2 \mathrm{H}^{+}+\mathrm{H}_{2} \mathrm{O} \\
& \frac{\mathrm{NO}_{2}^{-}+1 / 2 \mathrm{O}_{2} \rightarrow \mathrm{NO}_{3}^{-}}{\mathrm{NH}_{4}^{+}+2 \mathrm{O}_{2} \rightarrow \mathrm{NO}_{3}^{-}+2 \mathrm{H}^{+}+\mathrm{H}_{2} \mathrm{O}}
\end{aligned}
$$

Nesse processo, Nitrosomonas (principalmente N. europea e N. monocella), Nitrosospira, Nitrosococcus, Nitrosolobus e Nitrosovibrio são as bactérias responsáveis pela oxidação do $\mathrm{N}$-amoniacal a nitrito, etapa essa denominada de nitritação (Equação 3.1).

As bactérias envolvidas na nitratação, conversão do nitrito a nitrato, (Equação 3.2) são Nitrobacter (N. agilis e N. winogradskyi), Nitrospira, Nitrospina e Nitrococcus. 
A nitritação é a etapa limitante no processo de nitrificação, pois sua velocidade de oxidação é relativamente mais lenta do que a velocidade da reação de nitratação.

A equação global de conversão de $\mathrm{N}$-amoniacal a nitrato, na qual a síntese da biomassa é representada pela concentração média dos constituintes da célula $\left(\mathrm{C}_{5} \mathrm{H}_{7} \mathrm{NO}_{2}\right)$, é apresentada na Equação 3.4 (WASTEWATER..., 2003).

$$
22 \mathrm{NH}_{4}^{+}+37 \mathrm{O}_{2}+4 \mathrm{CO}_{2}+\mathrm{HCO}_{3}^{-} \rightarrow \mathrm{C}_{5} \mathrm{H}_{7} \mathrm{NO}_{2}+21 \mathrm{NO}_{3}^{-}+20 \mathrm{H}_{2} \mathrm{O}+42 \mathrm{H}^{+} \text {(Equação 3.4) }
$$

Pela estequiometria da Equação 3.4, para cada grama de $\mathrm{N}$-amoniacal oxidado, são consumidos $4,33 \mathrm{~g}$ de $\mathrm{O}_{2} ; 7,14 \mathrm{~g}$ de alcalinidade e 0,08 $\mathrm{g}$ e carbono inorgânico e são formadas 0,15 g de novas células (SEDLAK (Ed.), 1991).

Segundo Henze et al. (1997), a temperatura, o pH, a concentração de oxigênio dissolvido (OD), relação DBO/NKT, tempo de retenção celular são parâmetros importantes na cinética de nitrificação.

- temperatura

O processo de nitrificação ocorre numa larga faixa de temperatura, de $4^{\circ}$ a $45^{\circ} \mathrm{C}$, sendo a temperatura ótima para a nitritação igual a $35^{\circ} \mathrm{C}$ e para nitratação na faixa de 35 a $42^{\circ} \mathrm{C}$.

A taxa de nitrificação decresce acima da faixa 30 a $35^{\circ} \mathrm{C}$. Esta faixa de temperatura é limitada pelo resultado de dois processos interativos: o aumento da velocidade de reação com a temperatura e a desnaturação de proteínas (HENZE et al., 1997).

Segundo Ford e Churchwell (1980) a faixa ótima de temperatura para a nitrificação está compreendida entre 30 a $36^{\circ} \mathrm{C}$. 
- $\mathrm{pH}$

Segundo Wastewater... (2003), o pH ótimo para a nitrificação está na faixa de 7,2 a 9,0 . O pH influencia o equilíbrio do $\mathrm{N}$-amon, na forma livre ou ionizada, sendo que a amônia na forma livre inibe as bactérias que oxidam o $\mathrm{N}$-amon.

Segundo Surampalli et al. (1997), quando se tem valores de $\mathrm{pH}$ inferiores a 7 ou superiores a 9 , a velocidade de nitrificação é menor que $50 \%$ da ótima.

- CONCENTRAÇÃO DE OXIGÊNIO DISSOLVIDO (OD)

A concentração de OD tem efeito significante nas taxas de crescimento dos organismos nitrificantes. As velocidades máximas de nitrificação ocorrem em concentrações de OD acima de $2,0 \mathrm{mg} \cdot \mathrm{O}_{2} \cdot \mathrm{L}^{-1}$.

- Relação DBO/NKT

Segundo Wastewater... (2003) a presença de bactérias nitrificantes, em reatores aeróbios de crescimento em suspensão, é função da relação DBO/NKT. Para relação DBO/NKT maior que 5 , a presença de bactérias nitrificantes tende a ser menor, por isso o processo é classificado como a combinação da oxidação da matéria carbonácea e do nitrogênio. Quando essa relação for menor que 3, a presença de bactérias nitrificantes tende a ser maior, sendo que o processo é classificado como predominantemente de nitrificação.

Ling e Chen (2005) estudaram o impacto do carbono orgânico na eficiência da nitrificação em reator de leito fluidificado, com volume de 0,29 L. Como material suporte foi utilizada areia com área superficial específica media igual a $6070 \mathrm{~m}^{2} \cdot \mathrm{m}^{-3}$. O reator foi alimentado com solução sintética contendo $10 \mathrm{mgN} \cdot \mathrm{L}^{-1}$, variando-se a relação carbono/nitrogênio ( $\mathrm{C} / \mathrm{N}$ igual a $0 ; 0,5$ e 2,0). O sistema foi operado durante 5 semanas até que se alcançasse equilíbrio dinâmico. Foi observado que houve 
redução, de 60 a $70 \%$, na taxa de nitrificação, quando houve aumento na relação $\mathrm{C} / \mathrm{N}$ de 0,5 para 2,0 .

Michaud et al. (2006) avaliaram o efeito da matéria orgânica nas comunidades de bactérias autotróficas e na eficiência da nitrificação em filtro biológico submerso (altura de $85 \mathrm{~cm}$ e diâmetro de $11 \mathrm{~cm}$ ) operado em escala piloto. $\mathrm{O}$ reator foi alimentado com esgoto sintético, continuamente, durante 4 semanas para permitir a formação do biofilme. Foram aplicadas ao reator relações de $\mathrm{C} / \mathrm{N}$ iguais a $0 ; 0,5 ; 1,0$ e 2,0, sendo que a concentração de nitrogênio, no afluente, foi mantida constante (2 mgN.L ${ }^{-1}$ ). Eles concluíram que a eficiência da nitrificação é fortemente afetada pela presença de matéria orgânica. A taxa de produção de nitrato diminuiu $24 \%$ para $\mathrm{C} / \mathrm{N}=0,5,56 \%$ para $\mathrm{C} / \mathrm{N}=1$ e $73 \%$ para $\mathrm{C} / \mathrm{N}=2$, quando comparadas com a taxa $\mathrm{C} / \mathrm{N}=0$. Isso ocorreu, pois o carbono orgânico biodegradável acelera a atividade dos organismos heterotróficos, resultando na competição com os organismos quimioautotróficos por oxigênio, nutrientes, causando a redução nas taxas de nitrificação. Os autores comentam que esta competição entre os diferentes tipos de organismos afeta a transferência de massa, e conseqüentemente a eficiência da nitrificação e que o aumento na relação $\mathrm{C} / \mathrm{N}$ pode resultar na estratificação do sistema e inibição da nitrificação.

Salvetti et al. (2006) avaliaram o efeito da temperatura na taxa de nitrificação em dois reatores pilotos de leito móvel e filme fixo, alimentado com efluente secundário proveniente de uma estação municipal de tratamento de esgoto. Cada reator possuía um volume de $1 \mathrm{~m}^{3}$ e foi preenchido com material suporte com área superficial específica de $700 \mathrm{~m}^{2} \cdot \mathrm{m}^{-3}$. O primeiro reator (R1) foi operado sob concentrações limites de amônia, enquanto o segundo reator (R2) foi operado sob concentrações limites de oxigênio. Eles observaram que a temperatura não 
influenciou a taxa de nitrificação do R1; já no R2 houve uma grande influencia. Visto isso, eles concluíram que sob concentrações limite de oxigênio, a atividade da biomassa específica (isto é, a relação entre a taxa de nitrificação e a concentração da biomassa) é fortemente influenciada pelo efeito da combinação da penetração do oxigênio dentro do biofilme, na faixa de temperatura de 23 a $28^{\circ} \mathrm{C}$, enquanto que este efeito foi menos acentuado na faixa de 22 a $25^{\circ} \mathrm{C}$.

\subsubsection{Desnitrificação: Aspectos Físico-químicos Microbiológicos} e

A desnitrificação compreende a etapa complementar para a remoção de nitrogênio através de via biológica.

A desnitrificação ocorre em ambiente anóxico, onde as bactérias heterótrofas reduzem nitrito e nitrato a nitrogênio gasoso, além de compostos intermediários como $\mathrm{HNO}_{2}$, $\mathrm{NO}$ e $\mathrm{N}_{2} \mathrm{O}$.

Nesse processo participam as bactérias dos seguintes gêneros, entre outras: Achromobacter, Aerobacter, Alcaligenes, Bacillus, Brevibacterium, Flavobacterium, Lactobacillus, Micrococcus, Proteus, Pseudomonas e Spirillum.

Enquanto, a nitrificação consome alcalinidade, a desnitrificação produz em torno de 3,47 de alcalinidade na forma de carbonato de cálcio para cada grama de $\mathrm{N}-\mathrm{NO}_{3}{ }^{-}$removido do processo.

A água residuária para ter o nitrato removido pela desnitrificação deve conter carbono orgânico em quantidade suficiente para servir de fonte de energia e de carbono e, na ausência de oxigênio, o nitrato será utilizado como aceptor de elétrons, para a conversão do nitrato a nitrogênio gasoso. 
O requerimento de carbono pode ser provido por meio de fonte externa (etanol, acetato, glicose, entre outros) ou interna (material celular ou o carbono da própria água residuária) (WASTEWATER..., 2003).

Segundo Wastewater... (2003), a temperatura, o pH, a concentração de oxigênio dissolvido (OD) podem afetar a velocidade de desnitrificação.

- temperatura

A desnitrificação ocorre em temperaturas na faixa de 10 a $30^{\circ} \mathrm{C}$.

- $\mathrm{pH}$

Segundo Wastewater... (2003), a faixa "ótima" de pH para a desnitrificação está na faixa de 6,5 a 8,0.

Segundo Surampalli et al. (1997), valores de pH inferiores a 6,0 e superiores a 9,0 reduzem a velocidade de desnitrificação, principalmente, devidos ao aumento na produção de óxidos nítricos que inibem o processo.

- CONCENTRAÇÃO DE OXIGÊNIO DISSOLVIDO (OD)

Concentrações de oxigênio dissolvido acima de $1,0 \mathrm{mg} \cdot \mathrm{O}_{2} \cdot \mathrm{L}^{-1}$ inibem o processo de desnitrificação.

\subsubsection{Novos Processos Biológicos para Remoção de Nitrogênio}

A concepção de sistemas para remoção biológica de nitrogênio tem incorporado novos processos microbianos e outras rotas metabólicas: SHARON, ANAMMOX, OLAND, De-amonificação, entre outros.

O processo SHARON (Single Reactor High Activity Ammonia Removal Over Nitrite) baseia-se na oxidação da amônia até a forma de nitrito. Isso é obtido, mediante o uso de reator de mistura completa e aeração intermitente, operado com 
baixo tempo de residência celular e altas temperaturas, que favorece o desenvolvimento predominante das Nitrosomonas, resultando em economia de energia (VERSTRAETE; PHILIPS, 1998).

Esse processo acontece em reator de mistura completa, sem retenção de lodo, e é mais adequado para efluentes contendo concentração de íon amônio maiores que $500 \mathrm{mgN} \cdot \mathrm{L}^{-1}$, portanto não se aplica a esgoto sanitário.

O processo ANAMMOX (Anaerobic Ammonium Oxidation) fundamenta-se na conversão direta do nitrogênio amoniacal a nitrogênio gasoso, utilizando-se o nitrito como receptor de elétrons sob condições anaeróbias.

O processo de De-amonificação é utilizado no tratamento de águas residuárias com altas concentrações de material nitrogenado, consiste na conversão do $\mathrm{N}$-amoniacal a $\mathrm{N}_{2}$, sob controle rígido do oxigênio dissolvido, o qual é mantido a baixa pressão parcial (VERSTRAETE; PHILIPS, 1998).

O processo OLAND se fundamenta, principalmente, na oxidação do íon amônio acoplada à redução de nitrito. Isso gera uma economia de $62,5 \%$ em $\mathrm{O}_{2}$ e $100 \%$ em doadores de elétrons, sendo que a reações são catalisadas por culturas enriquecidas de bactérias nitrificantes autotróficas (VERSTRAETE; PHILIPS, 1998). 


\section{MATERIAL E MÉTODOS}

\subsection{Descrição do Reator de Leito Expandido e Sistema de Tratamento de Esgoto da EESC/USP - Área 1}

O reator de leito expandido, utilizado neste trabalho, faz parte da Estação de Tratamento de Esgoto (ETE) do Campus da USP - Área 1 em São Carlos, SP. Ele foi construído, durante o doutorado de Neyson Martins Mendonça (MENDONÇA, 2004), em concreto armado, com altura total de $18,0 \mathrm{~m}$ e volume de $159,0 \mathrm{~m}^{3}$, projetado para receber vazões na faixa de 5 a $40 \mathrm{~m}^{3} \cdot \mathrm{h}^{-1}$. O reator é caracterizado por apresentar flexibilidade operacional, ou seja, ele pode funcionar sob condições anaeróbias e aeróbias distintas, bem como, combinadas.

O reator é composto por duas câmaras, a de reação $\left(91,9 \mathrm{~m}^{3}\right)$, em formato cilíndrico, com altura de $13,0 \mathrm{~m}$ e diâmetro interno de $3,0 \mathrm{~m}$ e a câmara de sedimentação $\left(67,1 \mathrm{~m}^{3}\right)$, sobreposta à câmara de reação, em formato de cálice, com altura de 5,0 m e diâmetros inferior e superior de 3,0 m e 4,5 m, respectivamente.

O reator dispõe de 3 bombas, sendo uma utilizada para a alimentação do sistema (B1), e as outras duas para a recirculação de parte do efluente tratado para a região anaeróbia (fundo do reator, B2), e para região aeróbia (ponto intermediário do reator, B3), neste ponto o ar é injetado ao sistema, formando, assim a região aerada. 
$\mathrm{Na}$ Figura 4.1 observa-se um esquema simplificado do reator de leito expandido, bem como os sistemas de alimentação e recirculação.

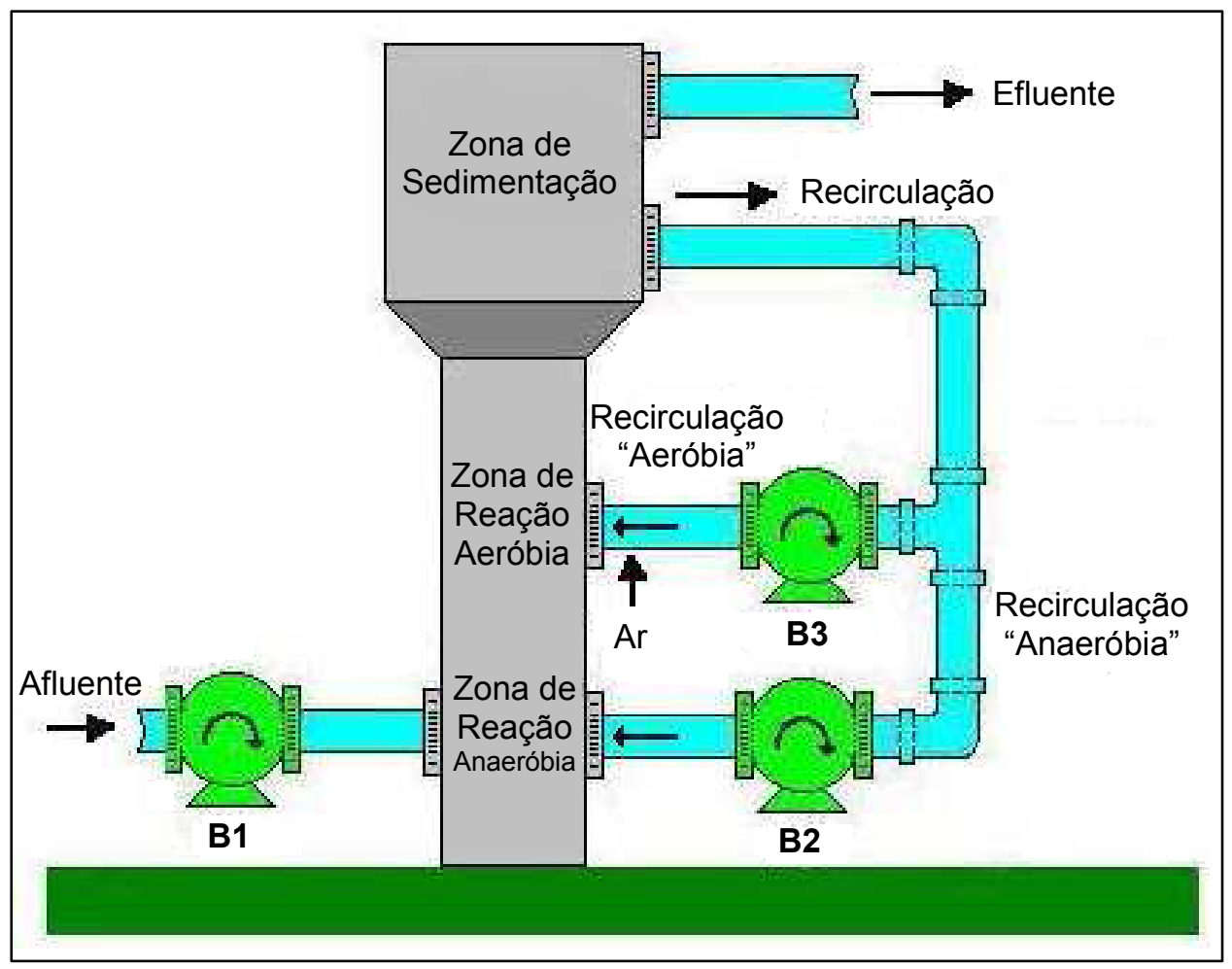

Figura 4.1 Esquema simplificado do reator de leito expandido

Fonte: Siman (2007)

O sistema dispõe de um tanque pulmão $\left(11,64 \mathrm{~m}^{3}\right)$ para a regularização da vazão de esgoto, de estação elevatória de esgoto bruto, além de sistema preliminar, composto de peneira e caixa de areia.

Na foto da Figura 4.2 são apresentadas parte das unidades que compõem o sistema de tratamento de esgoto da EESC-USP - Área 1.

O esgoto sanitário para alimentação do reator foi proveniente do Campus da EESC-USP, São Carlos-SP, acrescentado de parcela oriunda de bairros próximos ao Campus. 


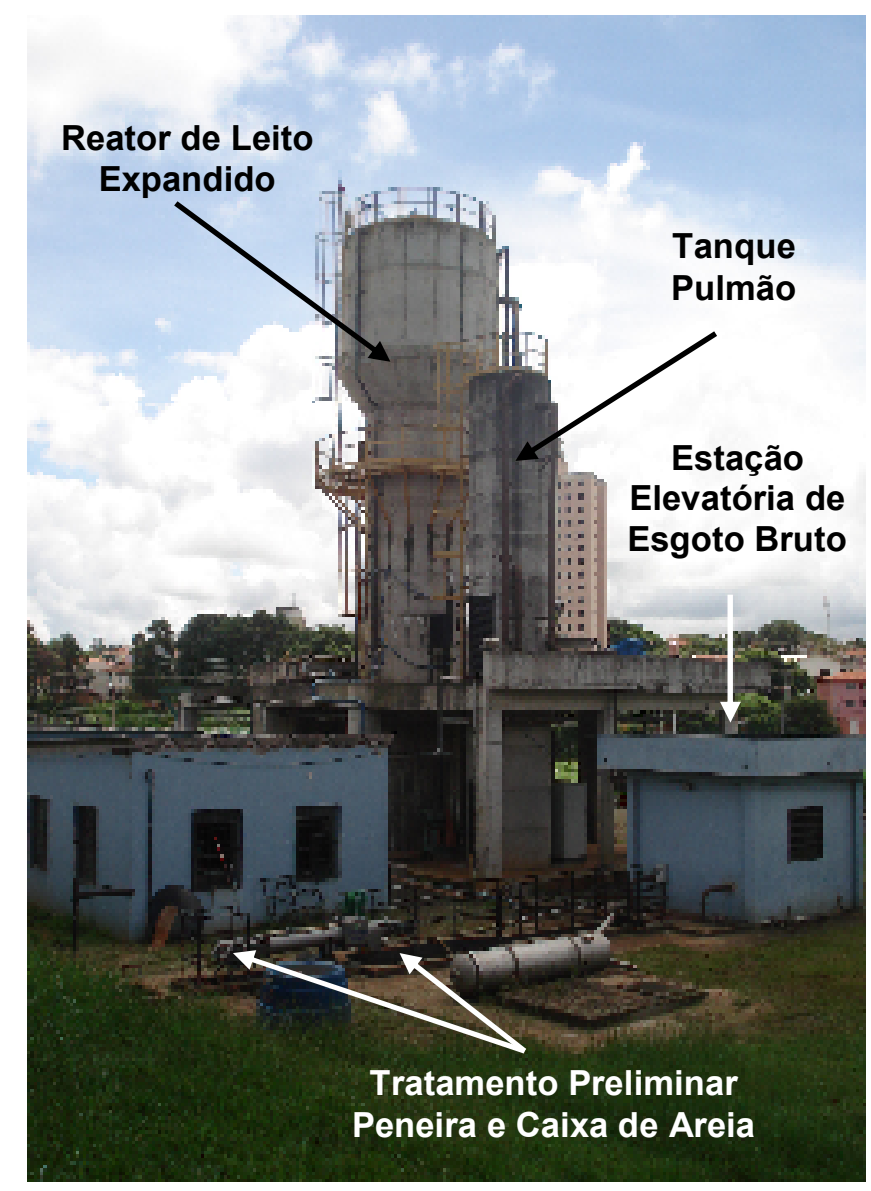

Figura 4.2 Estação de tratamento de esgoto da EESC-USP - Área 1: vista parcial.

O reator de leito expandido, bem como as unidades que compõem a estação de tratamento de esgoto dispõe dos seguintes equipamentos e assessórios principais:

- Dois conjuntos moto-bombas para recalque do esgoto, após o tratamento preliminar, da elevatória para o tanque pulmão (Bomba IMBIL-E3, Potência de 10HP, altura manométrica de $18 \mathrm{mca}$ e vazão de até $\left.60 \mathrm{~m}^{3} \cdot \mathrm{h}^{-1}\right)$

- Um conversor de freqüência (SIEMENS) para variação da vazão do conjunto moto-bomba da elevatória;

- Um conjunto moto-bomba helicoidal (B1) para bombeamento do esgoto afluente para $\mathrm{o}$ reator de leito expandido (Bomba NEMO- 
NM076SY01L04J, Potência de 11HP, altura manométrica de 40 mca e vazão de 12 a $\left.50 \mathrm{~m}^{3} \cdot \mathrm{h}^{-1}\right)$;

- Um conjunto moto-bomba helicoidal (B2) para recirculação do efluente para a zona anaeróbia, base do reator (Bomba NEMO-NM090SY01L04J, Potência de $20 \mathrm{HP}$, altura manométrica de 30 mca e vazão de 22 a 80 $\left.\mathrm{m}^{3} \cdot \mathrm{h}^{-1}\right)$;

- Um conjunto moto-bomba helicoidal (B3) para recirculação do efluente para o início da zona aeróbia, ponto intermediário do reator (Bomba NEMO-NM063SY01L04J, Potência de 7HP, altura manométrica de $30 \mathrm{mca}$ e vazão de 10 a $\left.40 \mathrm{~m}^{3} \cdot \mathrm{h}^{-1}\right)$;

- Três conversores de freqüência (DANFOSS VLT-5011; DANFOSS VLT5016 e DANFOSS VLT-5032) para controle da vazão dos conjuntos motobombas helicoidais;

- Um medidor de vazão eletromagnético (CONAUT IFS 4000/67 $60 \mathrm{~m}^{3} \cdot \mathrm{h}^{-1}$ ) para controle da vazão do efluente;

- Válvulas automáticas micro-processadas (T\&S MOT-600) tipo wafer para tubulações PVC FoFo de $\Phi=100$ mm (2 unidades) e $\Phi=150 \mathrm{~mm}$ (1 unidade);

- Um controlador lógico programável (CLP ATOS MCP4004);

- Um microcomputador (Processador Pentium III-128RAM);

- Um sistema de monitoramento de $\mathrm{pH}$, condutividade, POR, temperatura e OD (YSI-6500);

- Dois coletores automáticos de amostra (ISCO-6700);

- Um medidor ultra-sônico (NIVOCAL PQS-220) para controle de nível no tanque pulmão. 


\subsection{Material Suporte}

\subsubsection{Seleção do Material Suporte Adequado para Complementar o Leito do Reator}

Inicialmente, durante o período de construção desse reator (MENDONÇA, 2004), foram alocadas, em duas etapas, aproximadamente 45 toneladas de carvão mineral dentro do reator para o desenvolvimento do biofilme. Na primeira etapa, foram colocadas 22 toneladas de carvão ativado granular (CAG), e na segunda, mais 23 toneladas de carvão antracitoso.

Posteriormente, Siman (2007) observou a necessidade de preenchimento do leito do reator com mais material suporte. Em perfis executados ao longo da altura, nos anos de 2005 e 2006 foi identificada perda significativa no material suporte. Amostras coletadas a $8,9 \mathrm{~m}$ de altura, já não apresentavam qualquer indício de material suporte. Isso correspondia a aproximadamente $30 \%$ da câmara de reação.

Para a seleção do material adequado para utilização como meio suporte do reator foram considerados os seguintes fatores: i) imobilização da biomassa, pois se devem utilizar suportes resistentes à degradação biológica e as forças mecânicas; ii) custo do material.

A partir desses fatores, em meados de junho de 2007, o aluno de iniciação científica, José Luciano Verçosa Marques efetuou o levantamento de diferentes tipos de material suporte para complementar o leito do reator. Dentre os materiais levantados, considerou-se o carvão ativado granular (CAG), já utilizado no reator. Contudo, devido aos altos custos desse material, quando de qualidade para esse fim (cerca de $\mathrm{R} \$ 3.000,00 / \mathrm{t}$ ), ficou inviabilizado o uso do mesmo. 
Também se estudou a possibilidade em se utilizar o antracito, visto que o mesmo já fazia parte do material suporte do reator, porém este material também apresentou custos elevados, além da baixa resistência à abrasão.

Considerou-se, também a utilização de bandas de rodagem trituradas (NICIURA, 2005). Contudo, o uso desse material ainda exige estudos sobre as velocidades ascensionais aplicadas para fluidificação do meio.

Por fim, o aluno de iniciação científica e o autor deste trabalho optaram pelo uso de areia. Inicialmente, foi questionada a viabilidade do uso de areia comercial de construção civil frente à utilização de areia classificada. Porém, foi constatado, por levantamento de preço, que a areia comercial apresentava custo de cerca de dez vezes menor que o da classificada, e, além disso, as condições para seu uso como material suporte não são tão restritivas quanto para o uso como meio filtrante.

\subsubsection{Caracterização da Areia utilizada como Material Suporte}

Conforme verificado por Campos (1989), com base em pesquisas anteriores e bibliografia sobre o tema, uso de areia para esse fim reside em granulometria entre $0,2 \mathrm{~mm}$ e $0,5 \mathrm{~mm}$, preponderantemente.

A partir disso, foi realizado levantamento de doze tipos de areias comerciais, de minerações da região de São Carlos-SP, conforme mostrado na Tabela 4.1. 
Tabela 4.1 Areias comerciais estudadas

\begin{tabular}{cc}
\hline \hline Areia & Denominação de mercado \\
\hline I & Grossa \\
\hline$I I$ & Média \\
\hline III & Grossa \\
\hline$I V$ & Grossa "mais ou menos" \\
\hline $\mathrm{V}$ & Fina "áspera" \\
\hline $\mathrm{VI}$ & Fina \\
\hline $\mathrm{VII}$ & Grossa \\
\hline $\mathrm{VIII}$ & Fina \\
\hline $\mathrm{IX}$ & Fina \\
\hline $\mathrm{X}$ & Fina \\
\hline $\mathrm{XI}$ & Grossa \\
\hline $\mathrm{XII}$ & Fina \\
\hline \hline
\end{tabular}

Com o apoio do Departamento de Geotecnia da Escola de Engenharia de São Carlos-SP, foi realizado o levantamento granulométrico, de todas as areias, de acordo com a NBR 7181/1984.

\subsubsection{Material Suporte Escolhido}

No início de janeiro de 2008, foi acrescentada uma camada de areia de aproximadamente 50 t para a complementação do leito do reator.

Devido à grande quantidade de material a ser transportado a uma altura de aproximadamente $18 \mathrm{~m}$, houve a necessidade da utilização de guindaste (modelo MD-30) para a realização do serviço. A areia foi colocada em sacos flexíveis de polipropileno (chamados comercialmente de big bags) para facilitar o seu transporte até a parte superior do reator.

Nas Figuras 4.3 e 4.4 são mostrados os big bags com areia e o transporte dos mesmos até o topo do reator, respectivamente. 


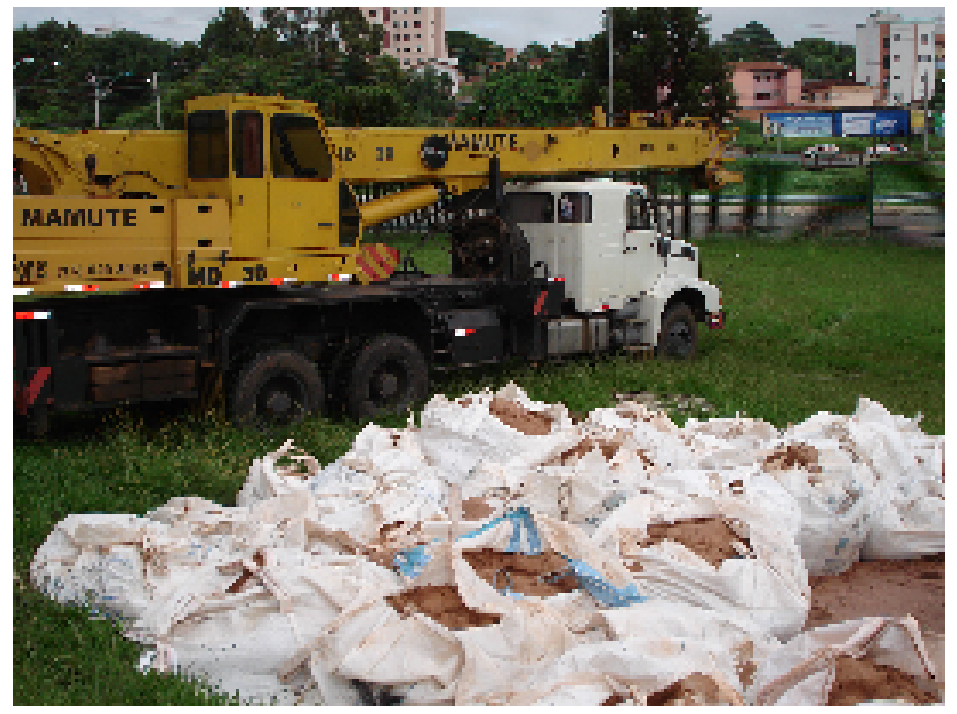

Figura 4.3 Areia disposta nos big bags

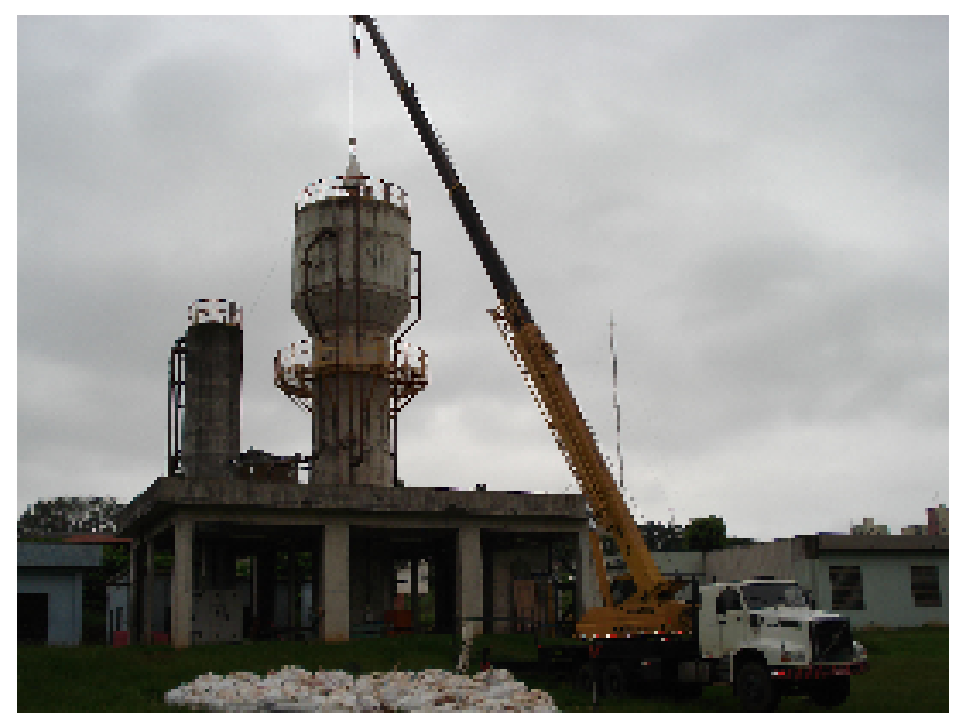

Figura 4.4 Transporte da areia nos big bags até a parte superior do reator de leito expandido

\subsection{Sistema de Aeração}

Nas pesquisas anteriores (MENDONÇA, 2004; SIMAN, 2007), a aeração foi efetuada com o fornecimento de oxigênio puro por meio de tanques criogênicos (White Martins TM 1500). 
Ao longo das pesquisas, foi verificado que essa alternativa foi pouco atraente economicamente, visto pelos elevados custos do oxigênio puro. Além disso, o sistema de injeção de oxigênio puro requer manutenção constante de equipe técnica especializada.

Por isso, optou-se por mudar o sistema de aeração, substituindo o fornecimento de oxigênio puro por ar atmosférico, através de um compressor.

Foi instalado um compressor de parafuso (Figura 4.5), modelo PS20D, do fabricante Puma System do Brasil. Na Tabela 4.2, pode-se observar os dados técnicos do compressor.

Tabela 4.2 Informações técnicas do compressor

\begin{tabular}{ll}
\hline \hline Pressão & $\mathbf{8 , 0}$ bar - 116 psi \\
Vazão efetiva unitária & $\mathbf{7 5}$ PCM - 2.124 L.min ${ }^{-1}$ \\
Potência do motor elétrico & $20 \mathrm{HP}-15 \mathrm{~kW}$ \\
Tensão de Alimentação & $\mathbf{2 2 0} \mathrm{V} / \mathbf{3}$ / $60 \mathrm{~Hz}$ \\
Acionamento & Estrela - Triângulo Automática \\
Transmissão & Acoplamento Direto \\
\hline \hline
\end{tabular}

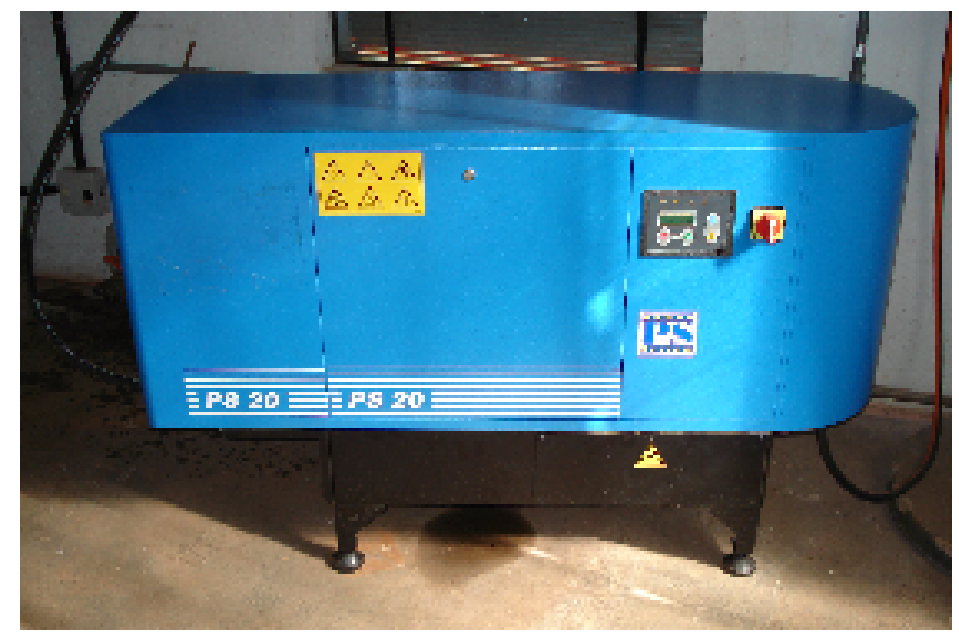

Figura 4.5 Compressor de parafuso, modelo PS20D 
A tubulação para a passagem do ar até o reator foi executada em aço soldado ( $=75 \mathrm{~mm})$. Nessa tubulação foi instalado medidor de vazão de ar (SMC PF2A12H) para faixa de vazão nominal de 600 a 12.000 L.min ${ }^{-1}$.

\subsection{Reformas Realizadas Durante o Trabalho Experimental}

\subsubsection{Generalidades}

Durante o período experimental, houve a necessidade da realização de reformas corretivas, bem como de melhoria do sistema.

Houve a necessidade de correção de vazamentos no reator de leito expandido, que foram ocasionados pelo aumento da pressão no reator, decorrente da colocação da areia, para aumentar a camada suporte.

Além disso, foi modificado o sistema de tratamento preliminar. A grade, utilizada no sistema, foi substituída por micro peneira mecanizada.

\subsubsection{Correção dos Vazamentos no Reator de Leito Expandido}

Após a colocação da areia no reator de leito expandido, houve a fissuração do concreto próximo à base do reator, resultando em vários focos de vazamento.

Inicialmente, foi realizada a correção dos vazamentos na estrutura de concreto do reator, com aplicação de impermeabilizante químico cimentício e cimento de cura rápida. Essa solução não apresentou resultados, havendo a necessidade de uma segunda aplicação de impermeabilizante. 
Mesmo depois de realizado o serviço, grande parte dos vazamentos continuaram. Diante disso, por questões de segurança, houve a necessidade iminente em se reforçar a estrutura de concreto armado do reator. Como solução para esse problema, foi aplicada fibra de carbono à superfície do reator. Essas fibras (MC-DUR CF SHETS 300/300) foram colocadas em camadas duplas de 0,3 m, espaçadas em 0,7 m uma da outra, até a altura de 7,0 m. Na Figura 4.6 observa-se a disposição das fibras de carbono na superfície de concreto do reator.

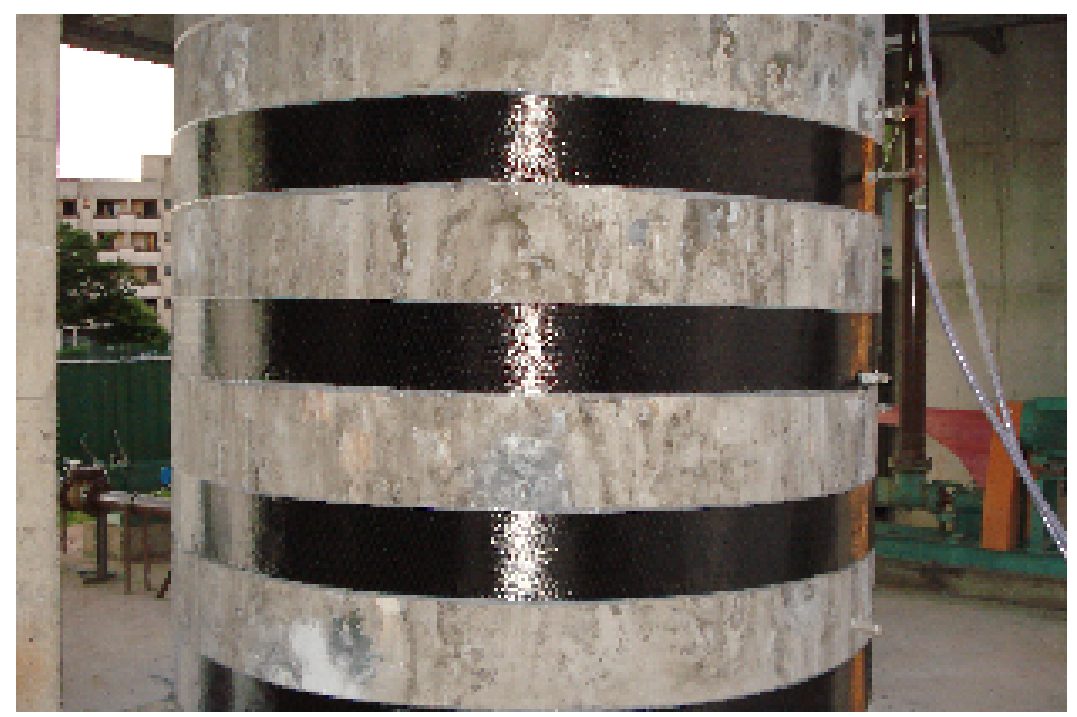

Figura 4.6 Disposição das fibras de carbono na superfície do reator de expandido

Para a realização desses serviços, por questões de segurança, houve a necessidade da interrupção do funcionamento do reator por aproximadamente dois meses.

\subsubsection{Mudança no Sistema de Tratamento Preliminar}

A remoção de sólidos grosseiros, realizada por meio de grade manual, com barras de $1 \times 2 \mathrm{~cm}^{2}$, espaçadas de $1 \mathrm{~cm}$, foi substituído por micro peneira de canal 
(PROMINAS MPC-300-01C) em aço inoxidável AISI 304, com abertura de tela de $1 \mathrm{~mm} ; 0,5 \mathrm{~m}$ de largura e $45^{\circ}$ de inclinação. Na foto da Figura 4.7 é mostrada a grade utilizada no tratamento preliminar, bem como a micro peneira.

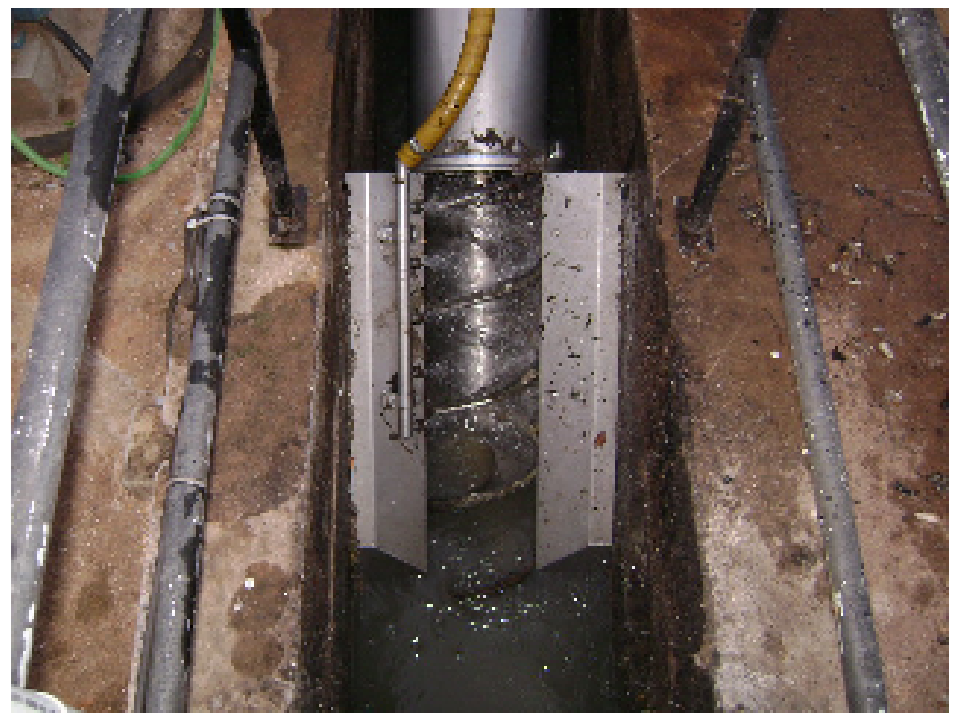

Figura 4.7 Micro peneira utilizada para remoção de sólidos grosseiros

\subsection{Controle Operacional do Sistema}

O controle operacional do sistema experimental, composto por sistema de tratamento preliminar (peneira e caixa de areia, estação elevatória de esgoto bruto, tanque pulmão e reator de leito expandido, foi realizado por meio de controlador lógico programável (CLP), e pelo software SCADAT\&S, desenvolvido em linguagem DELPHI 3.0, desenvolvido com a ajuda do técnico em eletrônica, Antonio Wagner Lamon do laboratório de tratamento avançado e reuso de águas, EESC-USP.

O esgoto proveniente do Campus I da USP de São Carlos, acrescentado de parcela oriunda de bairros próximos, era encaminhado por gravidade até a unidade preliminar de tratamento. Após passar pela peneira e caixa de areia era direcionado para o poço de sucção da estação elevatória de esgoto bruto. Quando o poço de 
sucção atingisse um nível de $30 \%$ do seu volume, o CLP acionava o conjunto motobomba da estação elevatória para o recalque de esgoto para o tanque pulmão, até que seu nível atingisse $97 \%$ da capacidade do tanque pulmão, ou até que o poço de sucção atingisse um nível de $15 \%$ do seu volume.

A partir do tanque pulmão, o esgoto era bombeado (bomba B1) para a base do reator, onde passava por tratamento biológico na zona de reação, atingindo a zona de sedimentação, onde era clarificado e, posteriormente lançado para o corpo receptor.

O controle da vazão da bomba de alimentação (B1) era feito por intermédio de medidor instalado na calha de coleta de efluente tratado. Já para as bombas de recirculação anaeróbia (B2) e aeróbia (B1), o controle foi feito pelo ajuste da porcentagem de vazão de trabalho no software SCADAT\&S, cujo valor fora obtido pela relação da rotação do motor e da curva característica das bombas, conforme é visualizado na Figura 4.8.

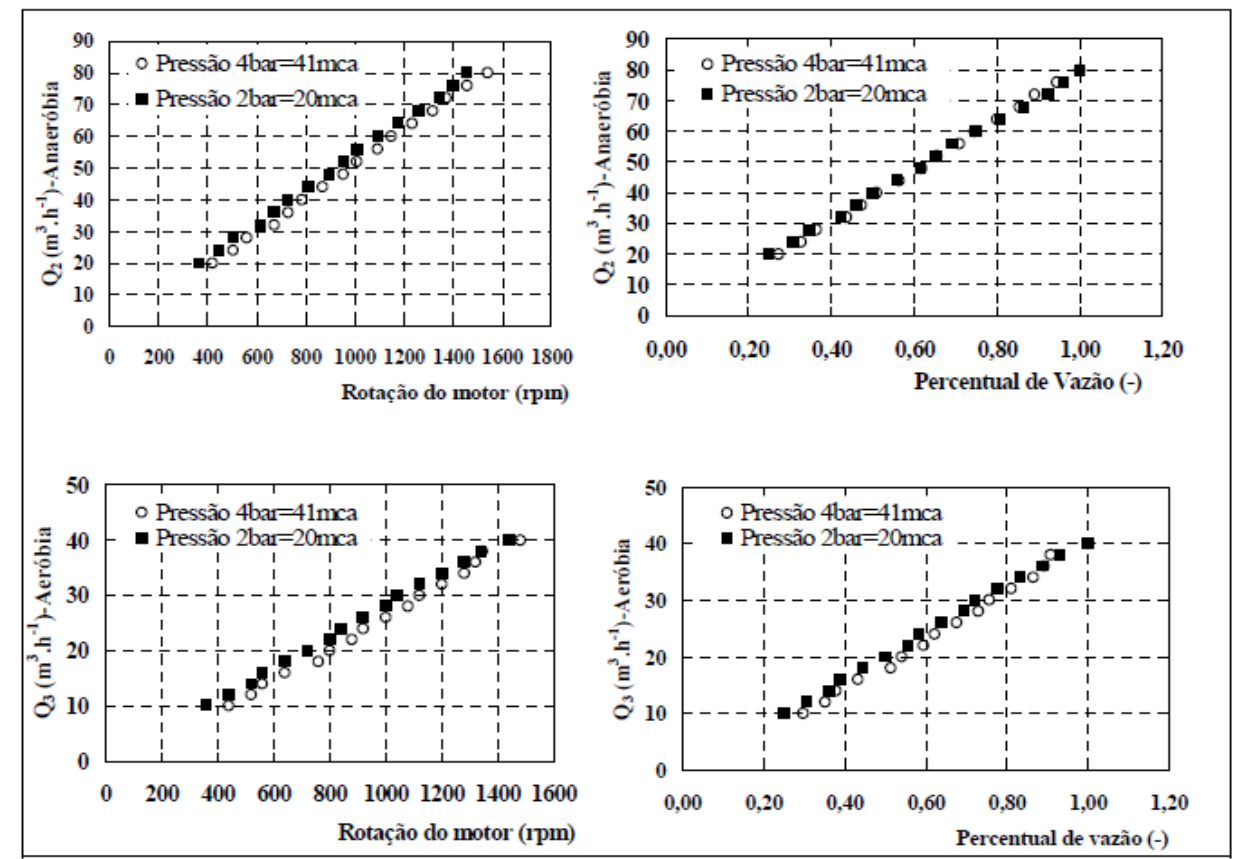

Figura 4.8 Relação ente a vazão e a rotação do motor das bombas de recirculação anaeróbia (B2) e aeróbia (B1)

Fonte: Mendonça (2004) 
Além de monitorar as unidades de tratamento mencionadas, o software SCADAT\&S realizava a aquisição de dados como: nível do tanque pulmão, vazão efluente, status, número de horas de funcionamento, potência e freqüência dos conjuntos moto-bombas B1, B2 e B3 (Figura 4.9).

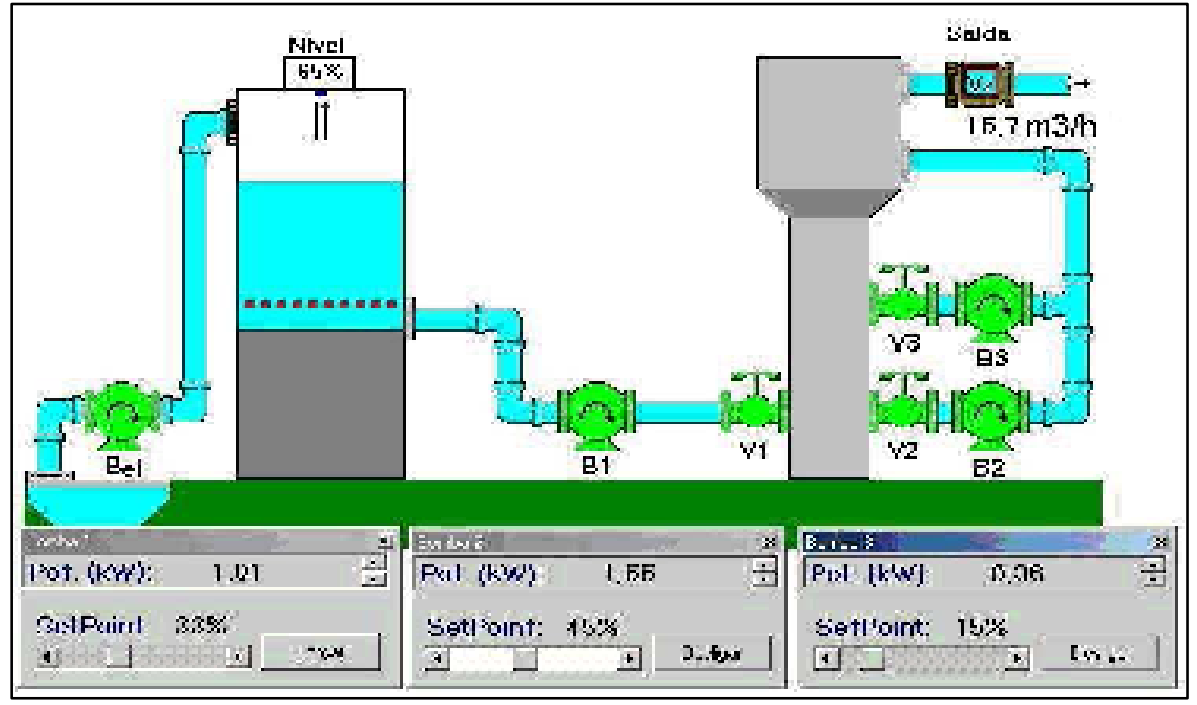

Figura 4.9 Interface do software SCADAT\&S

Fonte: Mendonça (2004)

Na Figura 4.10 é mostrado o diagrama de blocos da automação da estação elevatória de esgoto bruto, tanque pulmão e do reator de leito expandido.

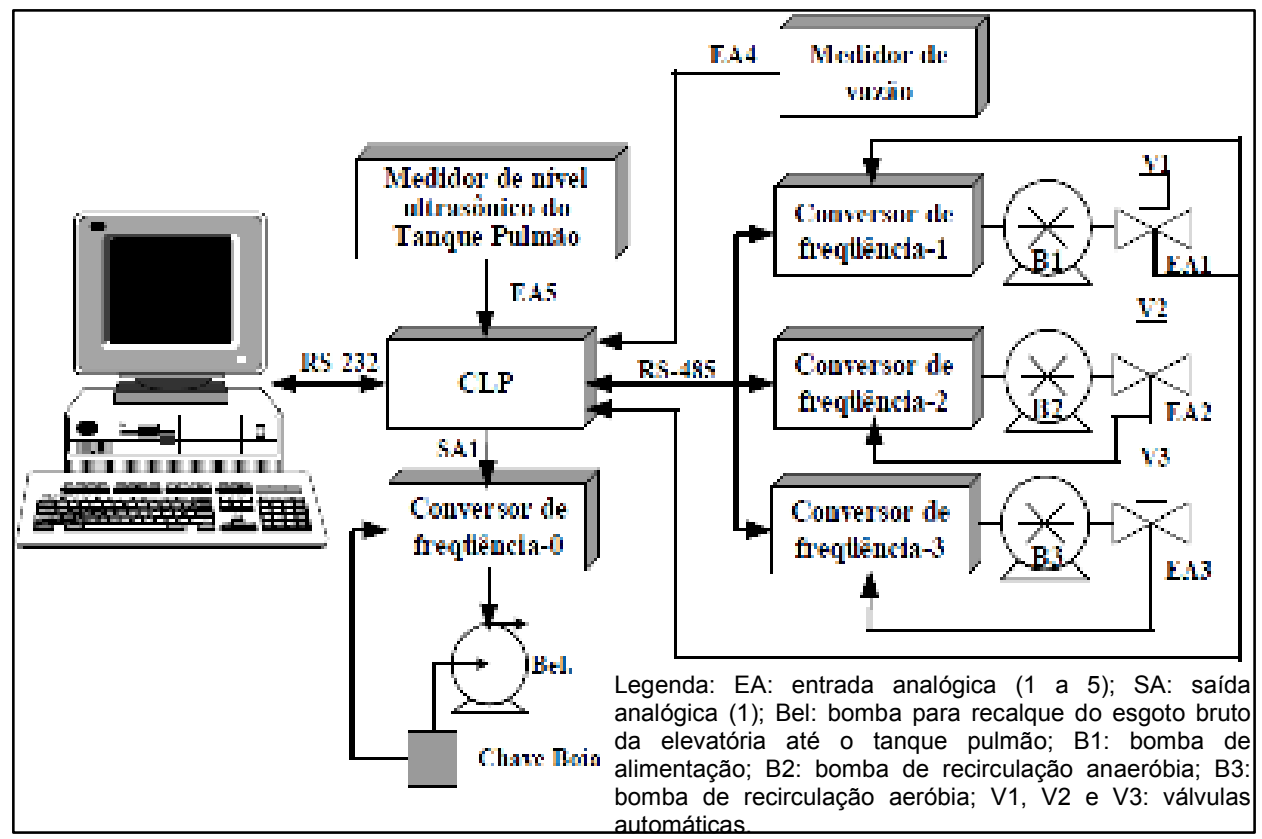

Figura 4.10 Diagrama de blocos da automação da estação elevatória de esgoto bruto, tanque pulmão e do reator de leito expandido

Fonte: Mendonça (2004) 
A comunicação entre o microcomputador e o CLP foi realizada por meio de interface serial RS232 e a comunicação entre os inversores de freqüência e o CLP via protocolo RS485. Foram utilizadas três entradas analógicas do CLP, sendo a primeira conectada ao medidor do tipo eletromagnético $(\varnothing 100 \mathrm{~mm}$ ) para leitura das medidas de vazão que é parte integrante do link de controle da vazão de saída do reator. A segunda entrada permitiu a verificação do estado da válvula de segurança da linha de alimentação do reator e a terceira, conectada ao inversor das bombas da estação elevatória para envio de comando on/off de acordo com o nível do tanque pulmão que é constantemente monitorado pelo software e medido por meio de medidor ultra-sônico de nível (LAMON et al., 2008).

Para a proteção do sistema, foram instalados dispositivos de segurança e de manutenção, tais como válvulas microprocessadas e bóia de nível no poço de sucção da estação elevatória de esgoto bruto e no tanque pulmão, responsáveis, respectivamente, pela interrupção do fluxo dos conjuntos moto bombas (B1, B2 e B3) e desligamento das bombas da elevatória quando o poço atingisse nível mínimo de trabalho.

\subsection{Etapas Experimentais}

O trabalho experimental foi dividido em duas Etapas, sendo que a primeira Etapa compreendeu o monitoramento da eficiência do tratamento de esgoto sanitário no reator de leito expandido operado somente sob condições anaeróbias. Na segunda Etapa, o reator foi operado sob as condições anaeróbia e aeróbia, sendo que a parte inferior do reator funcionou como anaeróbia e parte superior como 
aeróbia, por meio de injeção de ar, feito por compressor. Vale ressaltar, que cada etapa foi dividida em fases de acordo com o TDH adotado.

$\mathrm{Na}$ Tabela 4.3 observam-se as etapas de operação do sistema e as condições operacionais de cada fase.

Tabela 4.3 Variáveis de operação do reator de leito expandido: valores médios

\begin{tabular}{|c|c|c|c|c|c|c|c|c|c|}
\hline Etapa & Fase & $\begin{array}{c}Q_{\mathrm{afl}} \\
\left(\mathrm{m}^{3} \cdot \mathrm{h}^{-1}\right)\end{array}$ & $\begin{array}{l}Q_{\text {rec,ana }} \\
\left(m^{3} \cdot h^{-1}\right)\end{array}$ & $\begin{array}{l}Q_{\text {rec,aer }} \\
\left(m^{3} \cdot h^{-1}\right)\end{array}$ & $\begin{array}{l}\mathrm{V}_{\text {asc, ana }} \\
\left(\mathrm{m} \cdot \mathrm{h}^{-1}\right)\end{array}$ & $\begin{array}{l}\mathrm{V}_{\text {asc,aer }} \\
\left(\mathrm{m} \cdot \mathrm{h}^{-1}\right)\end{array}$ & $\begin{array}{c}\text { TDH }_{\text {total }} \\
\text { (h) }\end{array}$ & $\begin{array}{c}\mathrm{TDH}_{\mathrm{ana}} \\
\text { (h) }\end{array}$ & $\begin{array}{c}\mathrm{TDH}_{\text {aer }} \\
\text { (h) }\end{array}$ \\
\hline \multirow{2}{*}{$\begin{array}{l}\text { ( reator operado somente } \\
\text { na condição anaeróbia) }\end{array}$} & 1 & 11,4 & 22,8 & - & 4,8 & 4,8 & 14 & 8 & - \\
\hline & 2 & 19,9 & 39,8 & - & 8,5 & 8,5 & 8 & 4,6 & - \\
\hline \multirow{4}{*}{$\begin{array}{l}\text { Il (reator operado na } \\
\text { condição anaeróbia e } \\
\text { aeróbia sobrepostas) }\end{array}$} & 1 & 19,9 & 39,8 & 39,8 & 8,5 & 14 & 8 & 2,3 & 2,3 \\
\hline & 2 & 13,3 & 26,6 & 26,6 & 5,6 & 9,4 & 12 & 3,45 & 3,45 \\
\hline & 3 & 9,9 & - & 19,8 & 1,4 & 4,2 & 16 & 4,65 & 4,65 \\
\hline & 4 & 8,0 & - & 16 & 1,1 & 3,4 & 20 & 5,75 & 5,75 \\
\hline \multicolumn{10}{|l|}{$\overline{\overline{Q_{\text {aff: }}} \text { vazão afluente }}$} \\
\hline \multicolumn{10}{|c|}{$Q_{\text {rec,ana: }}$ vazão de recirculação na zona anaeróbia } \\
\hline \multicolumn{10}{|c|}{$Q_{\text {rec aer }}$ vazão de recirculação na zona aeróbia } \\
\hline \multicolumn{10}{|c|}{$\mathrm{V}_{\mathrm{asc}, \text { ana }}$ : velocidade ascensional na zona anaeróbia } \\
\hline \multicolumn{10}{|c|}{$\mathrm{V}_{\text {asc,aer }}:$ velocidade ascensional na zona aeróbia } \\
\hline \multicolumn{10}{|c|}{ TDH $_{\text {total: }}$ tempo de detenção hidráulica no reator de leito expandido } \\
\hline \multicolumn{10}{|c|}{$\mathrm{TDH}_{\text {ana: }}$ tempo de detenção hidráulica na zona anaeróbia } \\
\hline $\mathrm{TDH}_{\mathrm{aer}}$ : tem & . & . & & & & & & & \\
\hline
\end{tabular}

O TDH foi calculado com base na vazão afluente em relação ao volume total do reator vazio $\left(\mathrm{V}=159 \mathrm{~m}^{3}\right)$.

\subsection{Procedimento Experimental}

Durante o período de operação do reator de leito expandido foram coletadas amostras do esgoto afluente, bem como do efluente, com a finalidade de verificar a eficiência global dos processos biológicos do reator de leito expandido.

Semanalmente, foram realizadas coletas do afluente e do efluente, por meio de coletores automáticos da marca ISCO (modelo 6700F). Os equipamentos foram programados para preparar duas amostras compostas ao final de 24 horas, uma do esgoto afluente e outra do efluente. Ao final do período de coleta, essas amostras 
compostas eram encaminhadas para o laboratório para a realização de ensaios físico-químicos.

$\mathrm{Na}$ Tabela 4.4 enumeram-se as variáveis físicas e químicas que foram monitoradas durante o período de operação do reator, bem como os métodos utilizados. As análises foram realizadas de acordo com o Standard... (2005), com exceção dos ensaios para determinação das concentrações de AGVs, que foi feito segundo método proposto por Dilallo e Albertson (1961) e modificado por Ripley, Boyle e Converse (1986).

Tabela 4.4 Variáveis analisadas e métodos de análise

\begin{tabular}{|c|c|c|}
\hline Variável & Método & Protocolo APHA (2005) \\
\hline DBO total e filtrada $\left(\mathrm{mgO}_{2} \cdot \mathrm{L}^{-1}\right)$ & Mét. do Oxímetro & $5210(B)$ e 4500 - O (G) \\
\hline $\mathrm{DQO}$ total e filtrada $\left(\mathrm{mgO}_{2} \cdot \mathrm{L}^{-1}\right)$ & Colorimétrico & $5220(\mathrm{D})$ \\
\hline Alcalinidade $\left(\mathrm{mgCaCO}_{3} \cdot \mathrm{L}^{-1}\right)$ & Titulométrico & $2320(B)$ \\
\hline Ácidos voláteis $\left(\mathrm{mgHac} . \mathrm{L}^{-1}\right)$ & Titulométrico & Dilallo e Albertson (1961) \\
\hline Sólidos - série completa $\left(\mathrm{mg} \cdot \mathrm{L}^{-1}\right)$ & Gravimétrico & 2540 (B, D e E) \\
\hline $\mathrm{N}$-Amoniacal $\left(\mathrm{mgN} \cdot \mathrm{L}^{-1}\right)$ & Titulométrico & $4500-\mathrm{NH}_{3}(\mathrm{~B})$ \\
\hline N-NKT (mgN.L-1) & Titulométrico & $4500-\mathrm{N}_{\text {org }}(\mathrm{C})$ \\
\hline $\mathrm{N}-\mathrm{NO}_{2}^{-}\left(\mathrm{mgN} \cdot \mathrm{L}^{-1}\right)$ & $\mathrm{FIA}^{*}$ & $4500-\mathrm{NO}_{3}^{-}(\mathrm{I})$ \\
\hline $\mathrm{N}-\mathrm{NO}_{3}^{-}(\mathrm{mgN} \cdot \mathrm{L}-1)$ & $\mathrm{FIA}^{*}$ & $4500-\mathrm{NO}_{3}^{-}(\mathrm{I})$ \\
\hline Fósforo (mgP-PO $\left.{ }^{-3} \cdot \mathrm{L}^{-1}\right)$ & $\mathrm{FIA}^{*}$ & 4500 - $P(B 5)$ e $4500-P(G)$ \\
\hline
\end{tabular}

${ }^{*}$ FIA: Flow Injection Analysis

As concentrações de oxigênio dissolvido (OD), potencial oxi-redução (POR), $\mathrm{pH}$, temperatura e condutividade do afluente e efluente, foram medidas, através de sondas de multiparâmetros da marca YSI (modelo 600XL), adaptada com os referidos eletrodos. Esse tipo de equipamento utiliza software apropriado (EcoWatch for Windows) fornecido pela YSI Incorporated para acumulação dos dados e acompanhamento dos parâmetros em tempo real.

Além das coletas de amostras compostas do afluente e do efluente, foram levantados três perfis ao longo da altura do reator, um na Fase 1, da Etapa I e dois 
nas Fases 3 e 4, da Etapa II de operação do sistema. Na Figura 4.11 é mostrada em destaque a localização dos pontos de coleta de amostras ao longo da altura do reator.

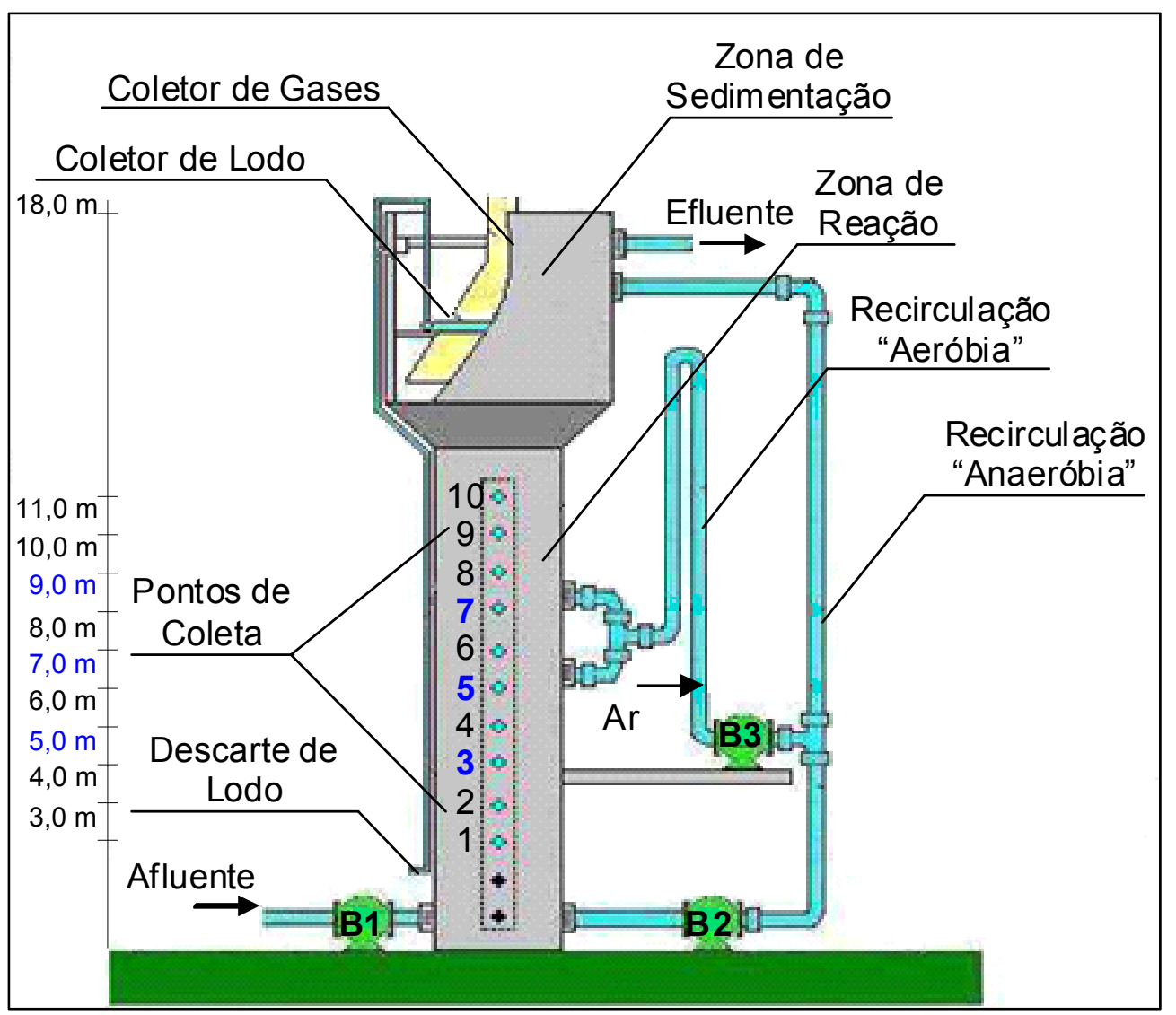

Figura 4.11 Localização dos pontos de coleta ao longo da altura do reator Fonte: adaptado de Siman (2007)

As amostras foram coletadas em balde, após ser descartado o residual que poderia estar acumulado na válvula ou, mesmo estagnado próximo ao ponto de coleta, no interior do reator

Depois de coletadas, as amostras foram filtradas em papel filtro qualitativo (com gramatura de $87 \mathrm{~g} \cdot \mathrm{m}^{-2}$ da marca VETEC) para a retenção do carvão mineral e areia. Foram realizados ensaios para determinação de $\mathrm{DBO}_{\text {filtrada, }} \mathrm{DQ} \mathrm{O}_{\text {filtrada, }}$ alcalinidade, ácidos voláteis, N-amoniacal, NKT, nitrito, nitrato e fósforo, conforme metodologia descrita na Tabela 4.3. Conjuntamente, no momento das coletas foram feitas análises de oxigênio dissolvido (OD), potencial oxi-redução (POR), pH, 
temperatura e condutividade das amostras, por meio da sonda de multiparâmetros da marca YSI (modelo 600XL).

Devido à dificuldade física encontrada na coleta de amostras somente nos pontos $3(5,0 \mathrm{~m}) ; 5(7,0 \mathrm{~m})$ e $7(9,0 \mathrm{~m})$ foi possível coletar amostras para o monitoramento do reator de leito expandido, ao longo da altura (Figura 4.11).

\subsection{Distribuição do Material Suporte ao Longo da Altura do Reator}

A determinação da distribuição do material suporte (CAG, CA e areia) foi realizada para se tentar verificar o comportamento do leito, após a colocação da areia no reator.

Foram realizados três perfis ao longo da altura do reator, um na Fase 1, da Etapa I e outros dois nas Fases 3 e 4, da Etapa II. As amostras do material suporte somente foram coletadas nos pontos $3(5,0 \mathrm{~m}) ; 5(7,0 \mathrm{~m})$ e $7(9,0 \mathrm{~m})$. Após a coleta, as amostras foram levadas para a estufa $\left(110^{\circ} \mathrm{C}\right)$ durante 24 horas para a secagem do material.

Para a realização deste ensaio, tentou-se separar as partículas de areia das partículas de carvão por meio de peneiramento. Tal fato foi possível, visto que Mendonça (1998), em revisão sobre algumas propriedades de materiais granulares para reatores de leito expandido, encontrou valores de diâmetro efetivo para a areia variando de 0,4 a 1,0 mm, relativamente distintos da faixa de variação para carvão ativado granular e carvão antracitoso que foi de 0,8 a 1,$5 ; 0,8$ a $1,4 \mathrm{~mm}$, respectivamente.

Vale ressaltar que, tanto o carvão ativado granular, quanto o antracitoso foram considerados como um único material, visto que apresentam diâmetros 
efetivos praticamente idênticos, concomitante a isto os dois materiais apresentam densidades relativamente próximas o que dificulta a separação física de ambos.

A areia e os carvões (ativado e antracitoso) foram separados, usando-se peneiras com malha próxima aos seus tamanhos efetivos. Depois de separados os materiais foram pesados individualmente. Para efeito de comparação da distribuição do material suporte ao longo da altura do reator, foi utilizado o conceito de densidade, visto que os materiais (areia e carvão) apresentavam densidades diferentes, impossibilitando a comparação física, por meio da massa de cada elemento.

Essas massas foram transformadas em volumes, de acordo com a densidade de cada material. A densidade da areia foi adotada igual a 2,69 $\mathrm{g} \cdot \mathrm{cm}^{-3}$, sendo que este índice foi determinado através do ensaio realizado de acordo com a NBR 6508/1984. Para o carvão, adotou-se valor determinado por Mendonça (1998) em estudos de caracterização de material suporte para reatores de leito expandido. O autor determinou a densidade do carvão ativado granular sendo igual a $1,71 \mathrm{~g} \cdot \mathrm{cm}^{-3} \mathrm{e}$ para o carvão antracitoso de $1,65 \mathrm{~g} \cdot \mathrm{cm}^{-3}$. Como esses dois materiais apresentam densidades semelhantes e foram considerados como um único material, adotou-se a média desses valores, ou seja, $1,69 \mathrm{~g} \cdot \mathrm{cm}^{-3}$.

Cabe comentar, que tal procedimento é relativamente grosseiro, no entanto, foi a melhor forma para se determinar a distribuição do material suporte ao longo da areia, e assim, avaliar a influência na colocação da areia. 


\subsection{Ensaio de Flotação}

Os ensaios de flotação foram realizados, a fim de se verificar se seria possível melhorar a qualidade do efluente do reator de leito expandido.

Para a realização dos ensaios foi utilizado equipamento denominado flotateste, desenvolvido por Reali (1991). O sistema, em escala de bancada, é composto por quatro colunas cilíndricas independentes entre si e interligadas a uma câmara de saturação. Cada coluna possui $60 \mathrm{~mm}$ de diâmetro interno, $900 \mathrm{~mm}$ de altura, $5 \mathrm{~mm}$ de parede de acrílico e capacidade útil de 2,5 litros.

Para efetuar a flotação, cada coluna é interligada a uma câmara de saturação construída a partir de tubo de acrílico com $10 \mathrm{~mm}$ de espessura de parede, $105 \mathrm{~mm}$ de diâmetro interno, $1000 \mathrm{~mm}$ de altura e 7 litros de volume útil. Para sua operação e controle, a câmara de saturação possui um manômetro, uma válvula de segurança, uma entrada de ar comprimido e uma entrada de água proveniente da rede de abastecimento público. O ar comprimido é fornecido por compressor de ar da marca Shultz, modelo MSI-2.6 VL40, C56 JZ, 1⁄2 CV, 850 rpm. A entrada de água saturada nas colunas de flotação é controlada por registros de agulha.

Para coleta de amostra líquida, cada coluna possui pequenos orifícios ao longo de sua altura. Na Figura 4.12 é mostrado o equipamento utilizado no ensaio de flotação. 


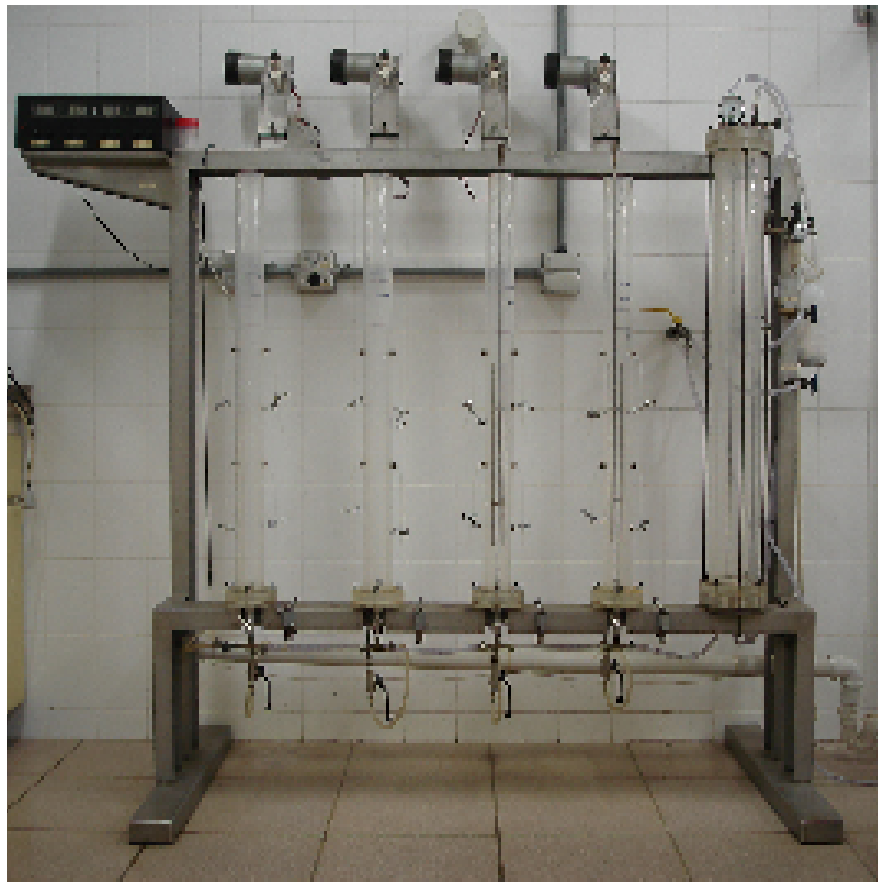

Figura 4.12 Equipamento de floculação/flotação em escala de laboratório (flotateste)

Para o ensaio de flotação foram estudadas quatros razões de recirculação, de $12 ; 14 ; 16$ e $18 \%$, que correspondem a concentrações de ar de 13,$1 ; 15,3 ; 17,5$ e 19,6 $\mathrm{mg}_{\mathrm{ar}} \mathrm{L}_{\mathrm{amostra}}{ }^{-1}$. Para cada razão de recirculação foram relacionadas três velocidades de flotação, $10 ; 14$ e $18 \mathrm{~cm} \cdot \mathrm{min}^{-1}$. A pressão de saturação utilizada foi de $500 \mathrm{kPa}$.

Na Tabela 4.5 são mostradas as variáveis analisadas e métodos de análise realizados na amostra bruta (efluente do reator) e nas amostras flotadas para cada condição do experimento.

Tabela 4.5 Variáveis analisadas e métodos de análise realizados no ensaio de flotação

\begin{tabular}{ccc}
\hline \hline Variável & Método & Protocolo APHA (2005) \\
\hline Cor & Colorimétrico & $2120(\mathrm{C})$ \\
Turbidez & Nefelométrico & $2130(\mathrm{~B})$ \\
$\mathrm{DQO}\left(\mathrm{mgO}_{2} \cdot \mathrm{L}^{-1}\right)$ & Colorimétrico & $5220(\mathrm{D})$ \\
Sólidos em Suspensão $\left(\mathrm{mg} \cdot \mathrm{L}^{-1}\right)$ & Gravimétrico & $2540(\mathrm{D} \mathrm{e} \mathrm{E})$ \\
Fósforo $\left(\mathrm{mgP}_{\mathrm{POO}}{ }^{-3} \cdot \mathrm{L}^{-1}\right)$ & $\mathrm{FIA}^{*}$ & $4500-\mathrm{P}(\mathrm{B} 5)$ e 4500 $-\mathrm{P}(\mathrm{G})$ \\
\hline \hline
\end{tabular}

"FIA: Flow Injection Analysis 


\section{RESULTADOS E DISCUSSÕES}

\subsection{Considerações Iniciais}

Neste capítulo são apresentados os resultados obtidos na fase experimental da pesquisa. Os resultados e discussões estão divididos nos seguintes itens:

- Areia utilizada para complementar o material suporte;

- Avaliação do desempenho do reator de leito expandido:

- Etapa I;

- Etapa II;

- Perfis ao longo da altura do reator.

Os resultados das análises e exames de rotina efetuados durante o período experimental são apresentados na forma de tabelas nos anexos.

No Anexo A estão inseridos os resultados referentes aos ensaios granulométricos realizados nas areias selecionadas para compor o material suporte.

No Anexo B e C estão inseridos os resultados referentes a operação do reator de leito expandido, durante as Etapas I e II, respectivamente.

No Anexo D são apresentados os resultados referentes aos perfis realizados ao longo da altura do reator.

No Anexo E são apresentados os resultados referentes aos ensaios de flotação realizados com o efluente do reator. 


\subsection{Areia Utilizada para Complementar o Material Suporte}

Mediante dos ensaios granulométricos foi possível determinar quais das areias estudadas apresentam maior porcentagem em massa para a faixa de diâmetro em 0,2 mm e 0,5 mm (Tabela 5.1).

Tabela 5.1 Porcentagem, em massa, de grãos de areia na faixa de 0,2 e $0,5 \mathrm{~mm}$

\begin{tabular}{cc}
\hline \hline Areia & $\begin{array}{c}\text { Massa referente a } \\
\text { faixa } \mathbf{0 , 2} \mathbf{a ~ 0 , 5} \mathbf{~} \mathbf{m m}\end{array}$ \\
\hline $\mathrm{I}$ & $\mathbf{2 8 \%}$ \\
\hline $\mathrm{II}$ & $62 \%$ \\
\hline $\mathrm{III}$ & $5 \%$ \\
\hline $\mathrm{IV}$ & $22 \%$ \\
\hline $\mathrm{V}$ & $50 \%$ \\
\hline $\mathrm{VI}$ & $53 \%$ \\
\hline $\mathrm{VII}$ & $56 \%$ \\
\hline $\mathrm{VIII}$ & $60 \%$ \\
\hline $\mathrm{IX}$ & $53 \%$ \\
\hline $\mathrm{X}$ & $4 \%$ \\
\hline $\mathrm{XI}$ & $35 \%$ \\
\hline $\mathrm{XII}$ & $65 \%$ \\
\hline \hline
\end{tabular}

Com esse levantamento, constatou-se que algumas areias comerciais atendem a potencialidade de uso como material suporte. Três areias estudadas apresentavam índice de massa superior ou igual a $60 \%$ para faixa determinada (II, VIII e XII).

Após essa seleção, deu-se inicio à escolha da areia dentre as três selecionadas. Como fatores limitantes apresentam-se o preço. A areia VIII foi descartada, pois apresentava custo $30 \%$ maior que as outras duas.

As areias de construção civil apresentam desvio muito grande na qualidade do produto fornecido por diferentes mineradoras.

A areia XII foi descartada, pois a mesma não se encontrava disponível para aquisição em volume suficiente para o complemento do leito, visto que, é altamente 
importante garantir que toda areia comprada seja similar àquela estudada no levantamento apresentado.

Por fim, efetuou-se a aquisição da areia II, pois foi a única areia que atendeu os requisitos anteriores. A curva granulométrica da areia II é mostrada na Figura 5.1.

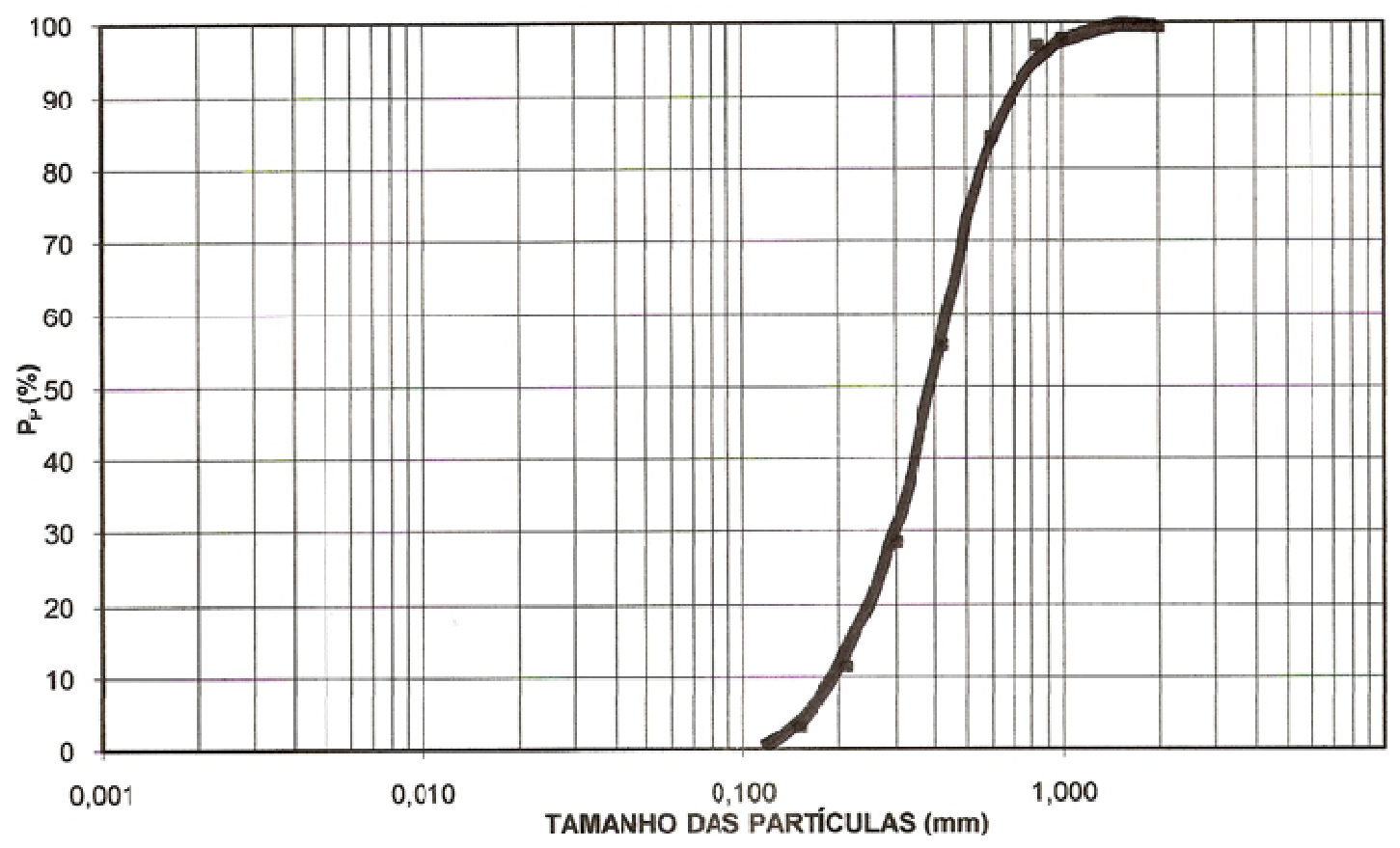

Figura 5.1 Curva granulométrica da areia II

A areia II apresentou diâmetro médio dos grãos igual a 0,69 mm e massa específica de $2690 \mathrm{~kg} \cdot \mathrm{m}^{-3}$.

\subsection{Avaliação do Desempenho do Reator de Leito Expandido}

A operação do reator de leito expandido foi dividida em duas etapas, que foram subdivididas em fases de acordo com o TDH de operação adotado.

A Etapa I objetivou a operação do reator de leito expandido somente sob condição anaeróbia, enquanto a Etapa II o reator foi operado sob condições anaeróbia e aeróbia sobrepostas. 


\subsubsection{Etapa I}

\subsubsection{Condições Operacionais - Etapa I}

As condições operacionais do reator de leito expandido, durante a Etapa I, são mostradas na Tabela 5.2.

Tabela 5.2 Variáveis de operação do reator de leito expandido: Etapa I

\begin{tabular}{ccc}
\hline \hline Etapa I & Fase 1 & Fase 2 \\
\hline $\mathbf{Q}_{\text {afl }}\left(\mathbf{m}^{3} \cdot \mathbf{h}^{-1}\right)$ & 11,4 & 19,9 \\
\hline $\mathbf{Q}_{\text {rec,ana }}\left(\mathbf{m}^{3} \cdot \mathbf{h}^{-1}\right)$ & 22,8 & 39,8 \\
\hline $\mathbf{Q}_{\text {rec,aer }}\left(\mathbf{m}^{3} \cdot \mathbf{h}^{-1}\right)$ & - & - \\
\hline $\mathbf{v}_{\text {asc,ana }}\left(\mathbf{m}^{-1} \mathbf{h}^{-1}\right)$ & 4,8 & 8,5 \\
\hline $\mathbf{v}_{\text {asc,aer }}\left(\mathbf{m}^{-1} \mathbf{h}^{-1}\right)$ & 4,8 & 8,5 \\
\hline $\mathbf{T D H}_{\text {total }}(\mathbf{h})$ & 14,0 & 8,0 \\
\hline $\mathbf{T D H}_{\text {ana }}(\mathbf{h})$ & 8,0 & 4,6 \\
\hline $\mathbf{T D H}_{\text {aer }}(\mathbf{h})$ & - & -
\end{tabular}

\begin{tabular}{l}
\hline \hline$Q_{\text {afl }}:$ vazão afluente \\
$\mathrm{Q}_{\mathrm{rec}, \text { ana }}:$ vazão de recirculação na zona anaeróbia \\
$\mathrm{Q}_{\mathrm{rec}}$ aer: vazão de recirculação na zona aeróbia \\
$\mathrm{V}_{\text {asc,ana: }}:$ velocidade ascensional na zona anaeróbia \\
$\mathrm{V}_{\mathrm{asc}, \mathrm{ae}}:$ velocidade ascensional na zona aeróbia \\
$\mathrm{TDH}_{\text {total }}:$ tempo de detenção hidráulica no reator \\
$\mathrm{TDH}_{\text {ana }}:$ tempo de detenção hidráulica zona anaeróbia \\
$\mathrm{TDH}_{\text {aer }}$ : tempo de detenção hidráulica zona aeróbia
\end{tabular}

A Etapa I teve duração de 77 dias, sendo que as Fases 1 e 2 duraram 56 e 21 dias, respectivamente. A Fase 2 teve duração relativamente pequena, por causa de problemas operacionais apresentado pela bomba de alimentação e, devido ao atraso no serviço de conserto da mesma, a referida fase foi encurtada, para que não ocorresse atrasos da Etapa II.

A razão de recirculação na zona anaeróbia, durante toda a Etapa I, foi mantida em $200 \%\left(Q_{r e c} / Q_{a f l}\right)$ para facilitar a expansão do leito do reator. 


\subsubsection{Resultados de Desempenho do Reator Anaeróbio de Leito Expandido}

Nas Figuras 5.2; 5.3 e 5.4 são apresentados, respectivamente, os resultados de $\mathrm{pH}$, alcalinidade e ácidos voláteis do afluente e efluente durante a Etapa I de operação do reator anaeróbio de leito expandido.

Vale ressaltar, que os pontos dos gráficos foram unidos para indicar tendências, embora isso não signifique que houve continuidade na variação dos parâmetros nos tempos intermediários.

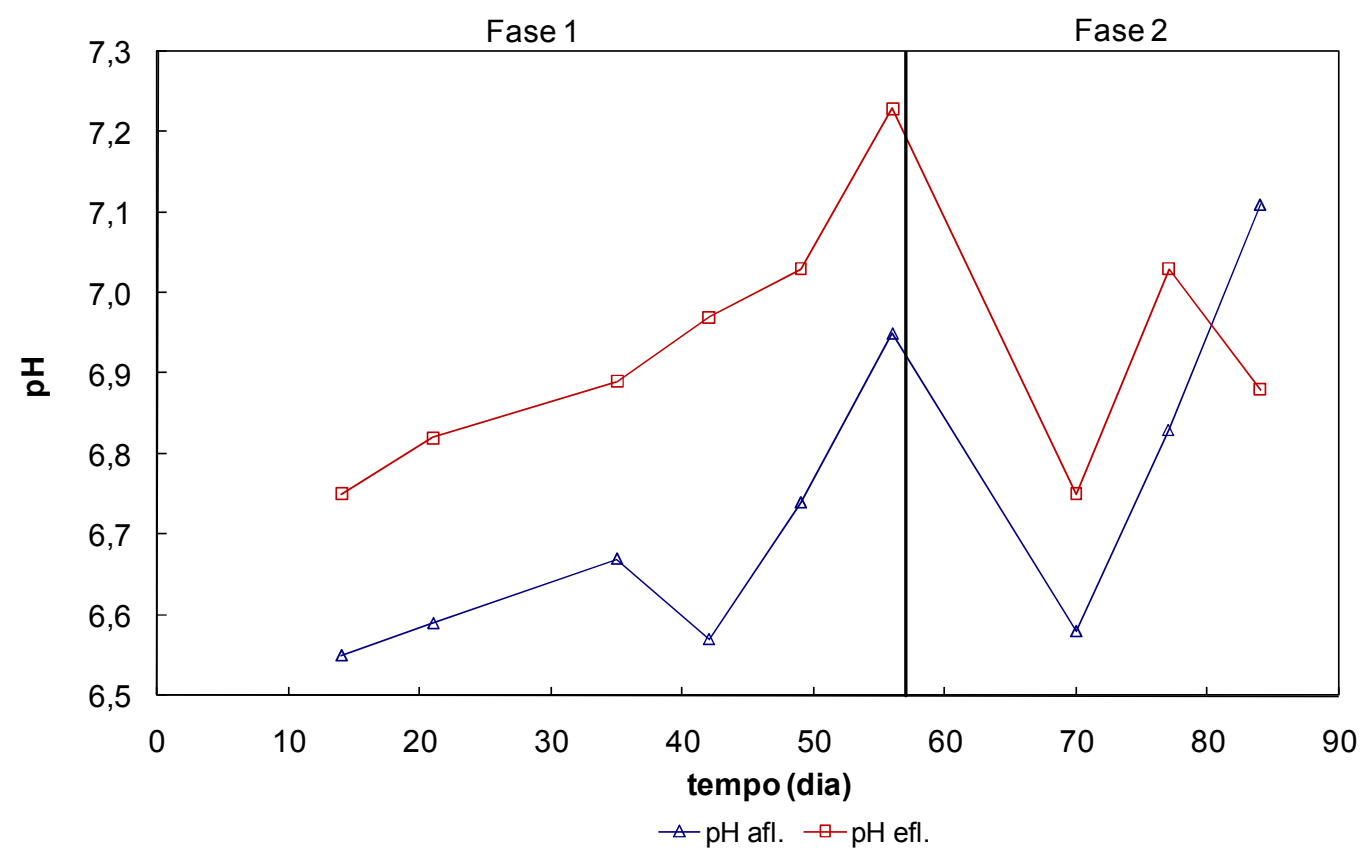

Figura 5.2 Resultados de $\mathrm{pH}$ do afluente e do efluente do reator anaeróbio de leito expandido, para as Fases 1 e 2 da Etapa I 


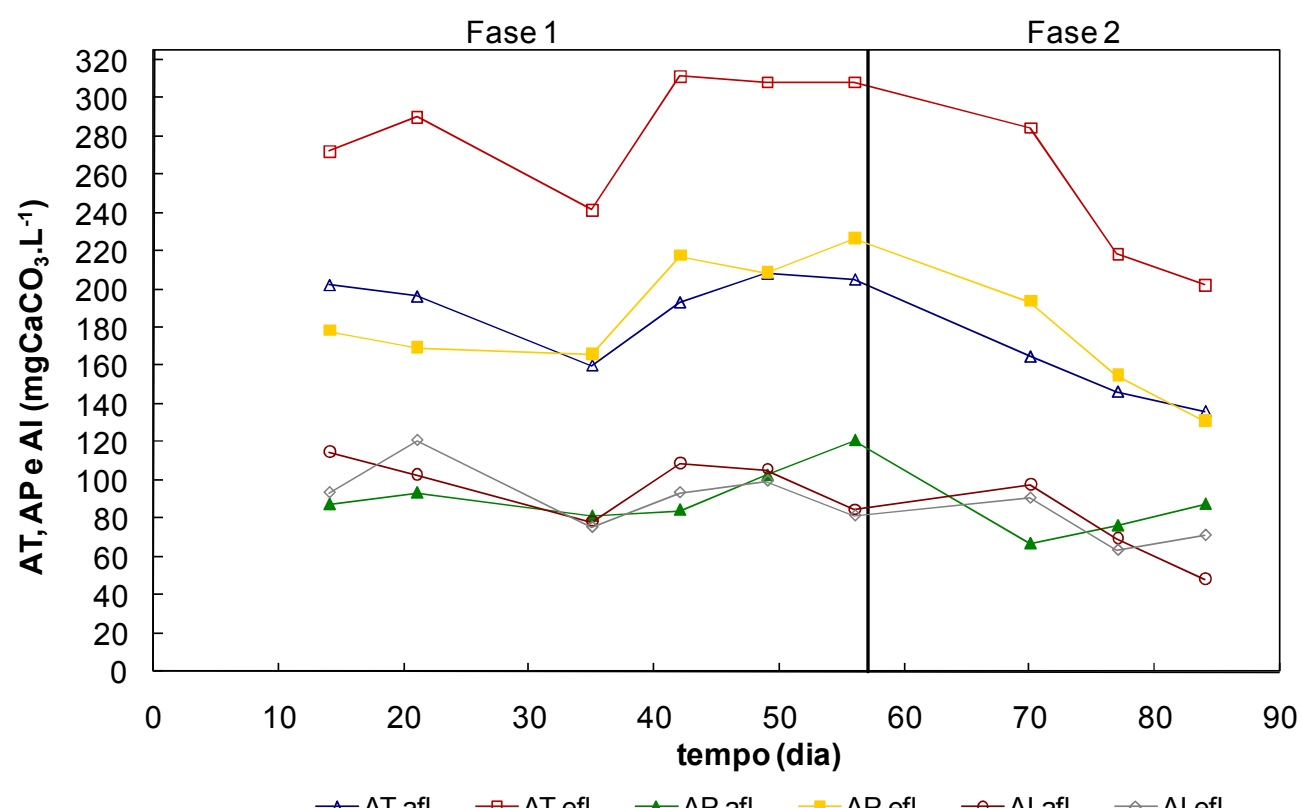

Figura 5.3 Resultados de AT (alcalinidade total), AP (alcalinidade parcial) e AI (alcalinidade intermediária) do afluente e do efluente do reator anaeróbio de leito expandido, para as Fases 1 e 2 da Etapa I

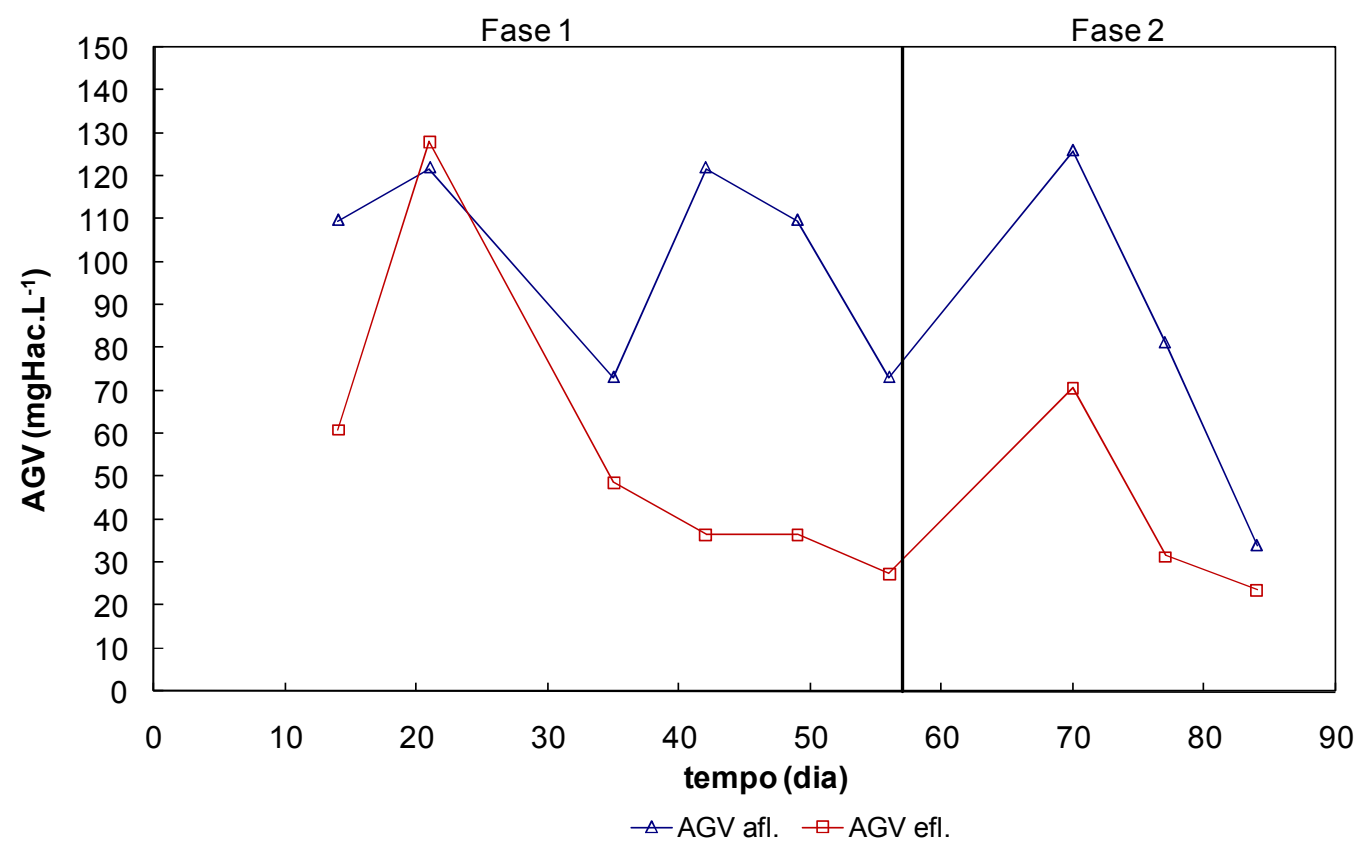

Figura 5.4 Resultados de AGV (ácidos graxos voláteis) do afluente e do efluente do reator anaeróbio de leito expandido, para as Fases 1 e 2 da Etapa I

Na Tabela 5.3 são apresentados os valores médios, desvios padrões, valores mínimos e máximos e número de dados considerados na análise estatística para os resultados de $\mathrm{pH}$, alcalinidade e AGV, da Etapa I. 
Tabela 5.3 Valores médios, desvios padrões, valores mínimos e máximos e números de dados analisados de $\mathrm{pH}$, AT (alcalinidade total), AP (alcalinidade parcial), Al (alcalinidade intermediária) e AGV (ácidos graxos voláteis) das Fases 1 e 2, da Etapa I

\begin{tabular}{|c|c|c|c|c|c|c|c|c|c|c|c|}
\hline \multirow[t]{2}{*}{ Fase } & \multirow[t]{2}{*}{ Variáveis } & \multicolumn{2}{|c|}{$\mathrm{pH}$} & \multicolumn{2}{|c|}{$\begin{array}{c}\mathrm{AP} \\
\left(\mathrm{mgCaCO}_{3} \cdot \mathrm{L}^{-1}\right)\end{array}$} & \multicolumn{2}{|c|}{$\begin{array}{c}\mathrm{Al} \\
\left(\mathrm{mgCaCO}_{3} \cdot \mathrm{L}^{-1}\right)\end{array}$} & \multicolumn{2}{|c|}{$\begin{array}{c}\mathrm{AT} \\
\left(\mathrm{mgCaCO}_{3} \cdot \mathrm{L}^{-1}\right)\end{array}$} & \multicolumn{2}{|c|}{$\begin{array}{c}\text { AGV } \\
\left(m g H A c . L^{-1}\right)\end{array}$} \\
\hline & & Afl. & Efl. & Afl. & Efl. & Afl. & Efl. & Afl. & Efl. & Afl. & Efl. \\
\hline \multirow{5}{*}{1} & Média: & 6,7 & 6,9 & 95 & 195 & 99 & 94 & 195 & 289 & 102 & 56 \\
\hline & Desvio padrão: & 0,2 & 0,2 & 15 & 26 & 14 & 16 & 18 & 27 & 23 & 37 \\
\hline & Mínimo: & 6,6 & 6,8 & 82 & 166 & 79 & 76 & 160 & 242 & 73 & 27 \\
\hline & Máximo: & 7,0 & 7,2 & 121 & 227 & 115 & 121 & 209 & 312 & 122 & 128 \\
\hline & № de amostras: & 6 & 6 & 6 & 6 & 6 & 6 & 6 & 6 & 6 & 6 \\
\hline \multirow{5}{*}{2} & Média: & 6,8 & 6,9 & 77 & 160 & 72 & 75 & 149 & 235 & 80 & 42 \\
\hline & Desvio padrão: & 0,3 & 0,1 & 10 & 32 & 25 & 14 & 15 & 44 & 46 & 25 \\
\hline & Mínimo: & 6,6 & 6,8 & 67 & 131 & 48 & 64 & 136 & 202 & 34 & 24 \\
\hline & Máximo: & 7,1 & 7,0 & 88 & 194 & 98 & 91 & 165 & 285 & 126 & 71 \\
\hline & $\mathrm{N}^{\circ}$ de amostras: & 3 & 3 & 3 & 3 & 3 & 3 & 3 & 3 & 3 & 3 \\
\hline
\end{tabular}

A alcalinidade total média do afluente foi de $195 \pm 18$ e $149 \pm 15 \mathrm{mgCaCO}_{3} . \mathrm{L}^{-1}$ para as Fases 1 e 2, respectivamente. Para esgoto sanitário valores de alcalinidade total na ordem de 150 a $350 \mathrm{mgCaCO}_{3} \cdot \mathrm{L}^{-1}$ são freqüentes, segundo HENZE, 1997. O efluente apresentou alcalinidade média de $289 \pm 27$ e $235 \pm 44$ mgCaCO $3 . \mathrm{L}^{-1}$, durante as Fases 1 e 2, respectivamente. Isso demonstra que houve geração de alcalinidade total, conforme esperado para sistemas anaeróbios. O aumento na alcalinidade está associado à neutralização de íons $\mathrm{H}^{+}$, o que favorece o aumento do $\mathrm{pH}$, conforme visualizado na Figura 5.2.

Durante a digestão anaeróbia, ocorre a interação da alcalinidade com os AGVs, fazendo com que a alcalinidade de sistemas em equilíbrio "neutralize" os ácidos presentes no processo. Isso foi observado, ao longo do período de monitoramento do sistema, pois concentração média de AGV no afluente, durante as Fases 1 e 2 , foi de $102 \pm 23$ e $80 \pm 46 \mathrm{mgHac}^{-1}$, respectivamente, e no efluente foi de $56 \pm 37$ e $42 \pm 25 \mathrm{mgHac} . \mathrm{L}^{-1}$, durante as Fases 1 e 2 , respectivamente.

Na Figura 5.5 são mostradas as relações AI/AP e AGVIAT para o efluente da Etapa I. 


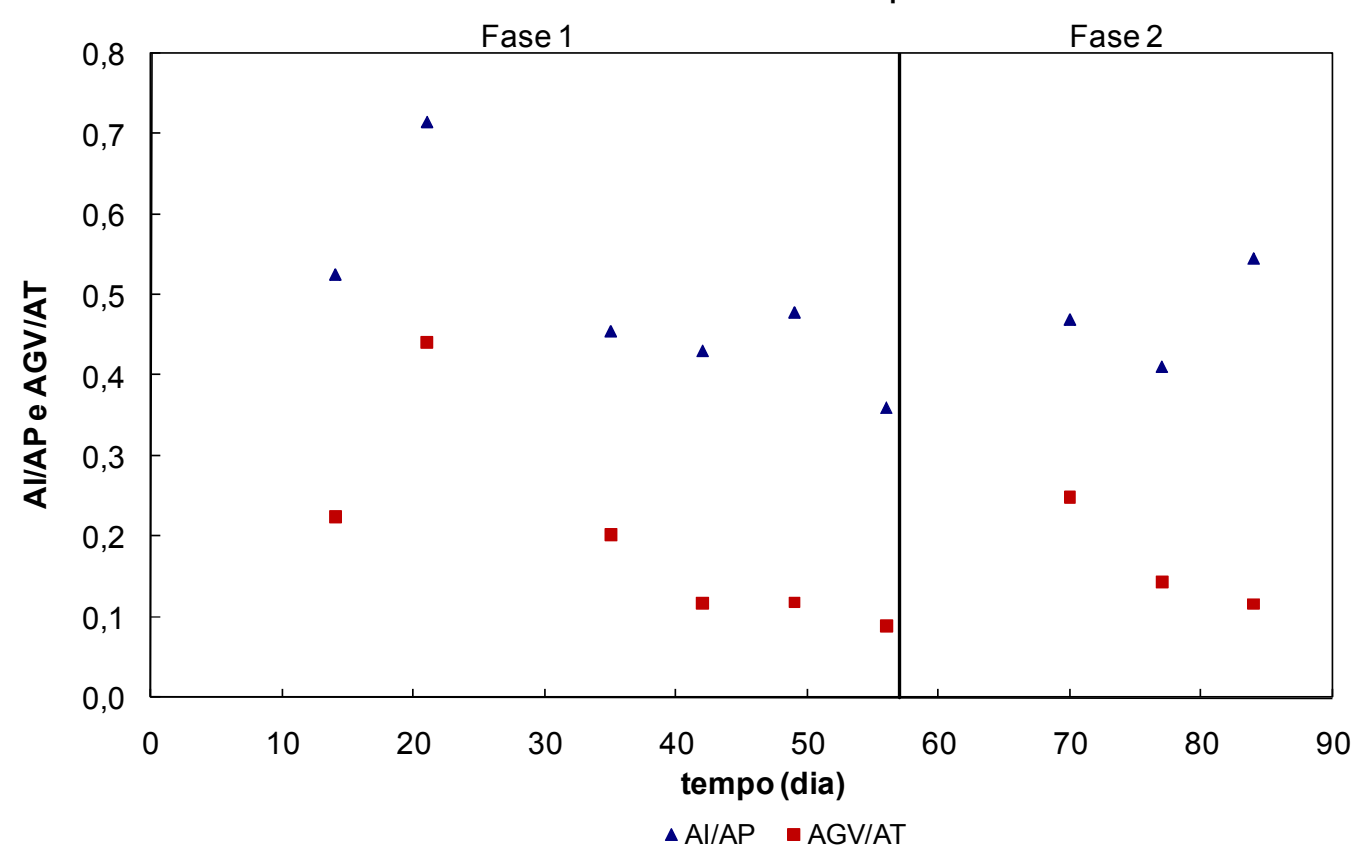

Figura 5.5 Relações Al/AP (alcalinidade intermediária/alcalinidade parcial) e AGVIAT (ácidos graxos voláteis/alcalinidade total) do efluente do reator anaeróbio de leito expandido, para as Fases 1 e 2 da Etapa I

As relações AI/AP e AGVIAT mantiveram-se, em média, em 0,5 e 0,2, respectivamente (Figura 5.5). A relação Al/AP apresentou-se acima de 0,3, valor usual para sistemas anaeróbios tratando esgoto sanitário. Enquanto a relação AGVIAT manteve-se entre 0,10 a 0,35 , faixa considerada típica de reatores com processos estáveis. É importante salientar, que apesar da relação Al/AP indicar menor estabilidade do sistema, isso não significa necessariamente que o sistema foi deficiente na remoção de matéria orgânica. Isso indica apenas, que a reserva de alcalinidade a bicarbonato (alcalinidade parcial) poderia ter sido insuficiente para neutralizar uma concentração

Na Figura 5.6 são apresentados os resultados da DQO da amostra bruta e da filtrada do afluente e do efluente, e na Figura 5.7, os resultados da eficiência de remoção de DQO total e filtrada afluente e efluente, para a Etapa I da operação do reator anaeróbio de leito expandido. 


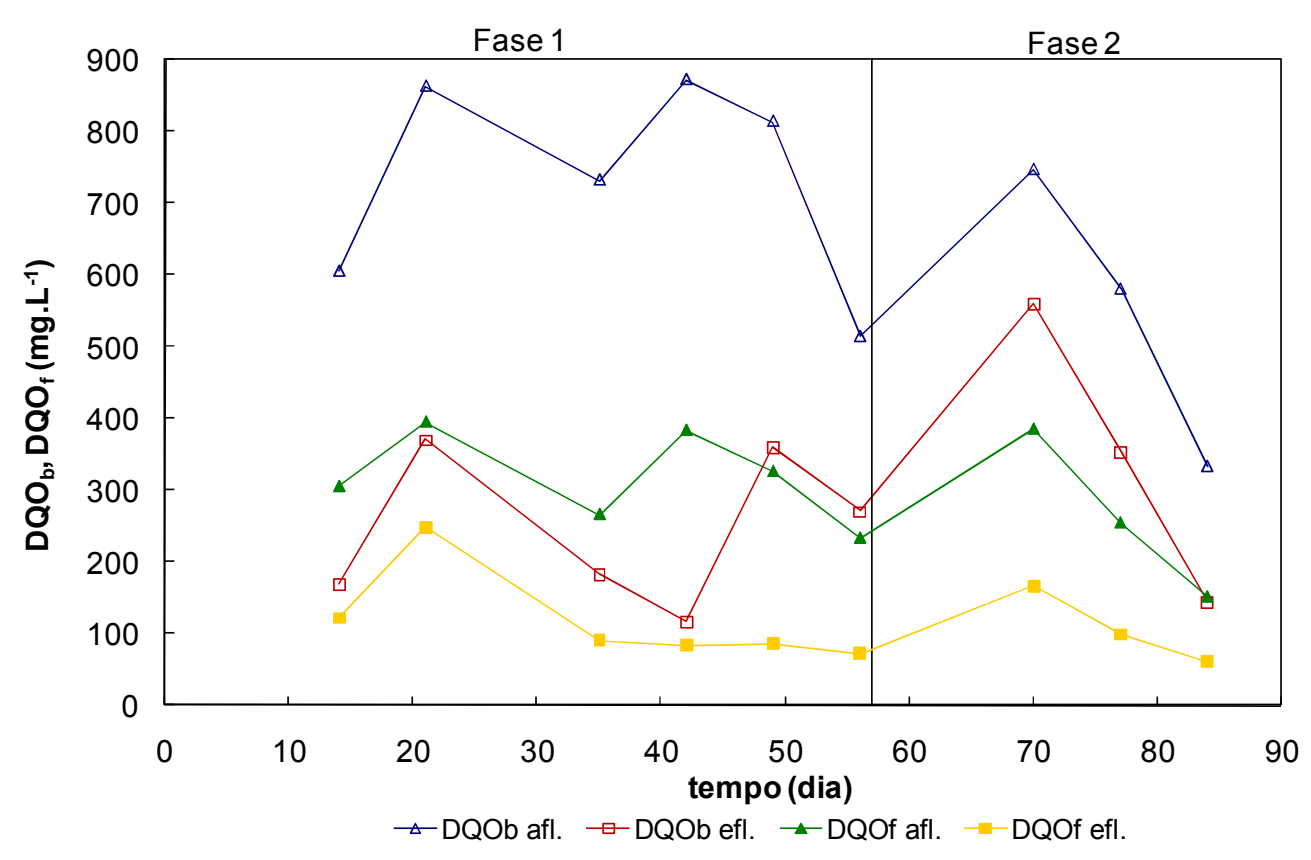

Figura 5.6 Resultados de DQO bruta e filtrada do afluente e do efluente do reator anaeróbio de leito expandido, para as Fases 1 e 2 da Etapa I

$\mathrm{Na}$ Tabela 5.4 são apresentados os valores médios, desvios padrões, valores mínimos e máximos e número de dados considerados na análise estatística para os resultados de DQO, da Etapa I.

Tabela 5.4 Valores médios, desvios padrões, valores mínimos e máximos e números de dados analisados de DQO das Fases 1 e 2, da Etapa I

\begin{tabular}{|c|c|c|c|c|c|c|c|}
\hline \multirow[t]{2}{*}{ Fase } & \multirow[t]{2}{*}{ Variáveis } & \multicolumn{2}{|c|}{$\begin{array}{l}\text { DQO }_{\text {bruta }} \\
\text { (mg. } \text { L }^{-1} \text { ) }\end{array}$} & \multirow{2}{*}{$\begin{array}{c}\varepsilon_{\mathrm{DQO}, \mathrm{t}} \\
(\%)\end{array}$} & \multicolumn{2}{|c|}{$\begin{array}{l}\text { DQO }_{\text {filt }} \\
\left(\mathrm{mg} \cdot \mathrm{L}^{-1}\right)\end{array}$} & \multirow{2}{*}{$\begin{array}{c}\varepsilon_{\mathrm{DQO}, \mathrm{f}} \\
(\%)\end{array}$} \\
\hline & & Afl. & Efl. & & Afl. & Efl. & \\
\hline \multirow{5}{*}{1} & Média: & 733 & 245 & 66 & 318 & 117 & 64 \\
\hline & Desvio padrão: & 146 & 106 & 15 & 64 & 67 & 15 \\
\hline & Mínimo: & 514 & 116 & 47 & 233 & 72 & 37 \\
\hline & Máximo: & 872 & 370 & 87 & 395 & 249 & 78 \\
\hline & № de amostras: & 6 & 6 & 6 & 6 & 6 & 6 \\
\hline \multirow{5}{*}{2} & Média: & 553 & 352 & 40 & 263 & 108 & 60 \\
\hline & Desvio padrão: & 208 & 208 & 16 & 117 & 54 & 2 \\
\hline & Mínimo: & 333 & 144 & 25 & 151 & 60 & 57 \\
\hline & Máximo: & 747 & 560 & 57 & 385 & 166 & 61 \\
\hline & $\mathrm{N}^{\circ}$ de amostras: & 3 & 3 & 3 & 3 & 3 & 3 \\
\hline
\end{tabular}

As médias dos valores de DQO bruta do afluente, para a duas fases foram $733 \pm 146$ (Fase 1) e $553 \pm 208 \mathrm{mg} \cdot \mathrm{L}^{-1}$ (Fase 2), enquanto os valores médios de DQO bruta do efluente foram $245 \pm 106$ e $352 \pm 208 \mathrm{mg} \cdot \mathrm{L}^{-1}$ para as Fases 1 e 2, 
respectivamente. Tanto a DQO bruta do afluente, quanto a do efluente apresentaram desvios relativamente grandes em relação à média, em ambas as fases.

Os valores médios de DQO filtrada do efluente foram praticamente semelhantes para as duas fases, $117 \pm 67 \mathrm{mg} \cdot \mathrm{L}^{-1}$ (Fase 1) e $108 \pm 54 \mathrm{mg} \cdot \mathrm{L}^{-1}$ (Fase 2), evidenciando que o aumento da carga orgânica volumétrica não influenciou diretamente este parâmetro.

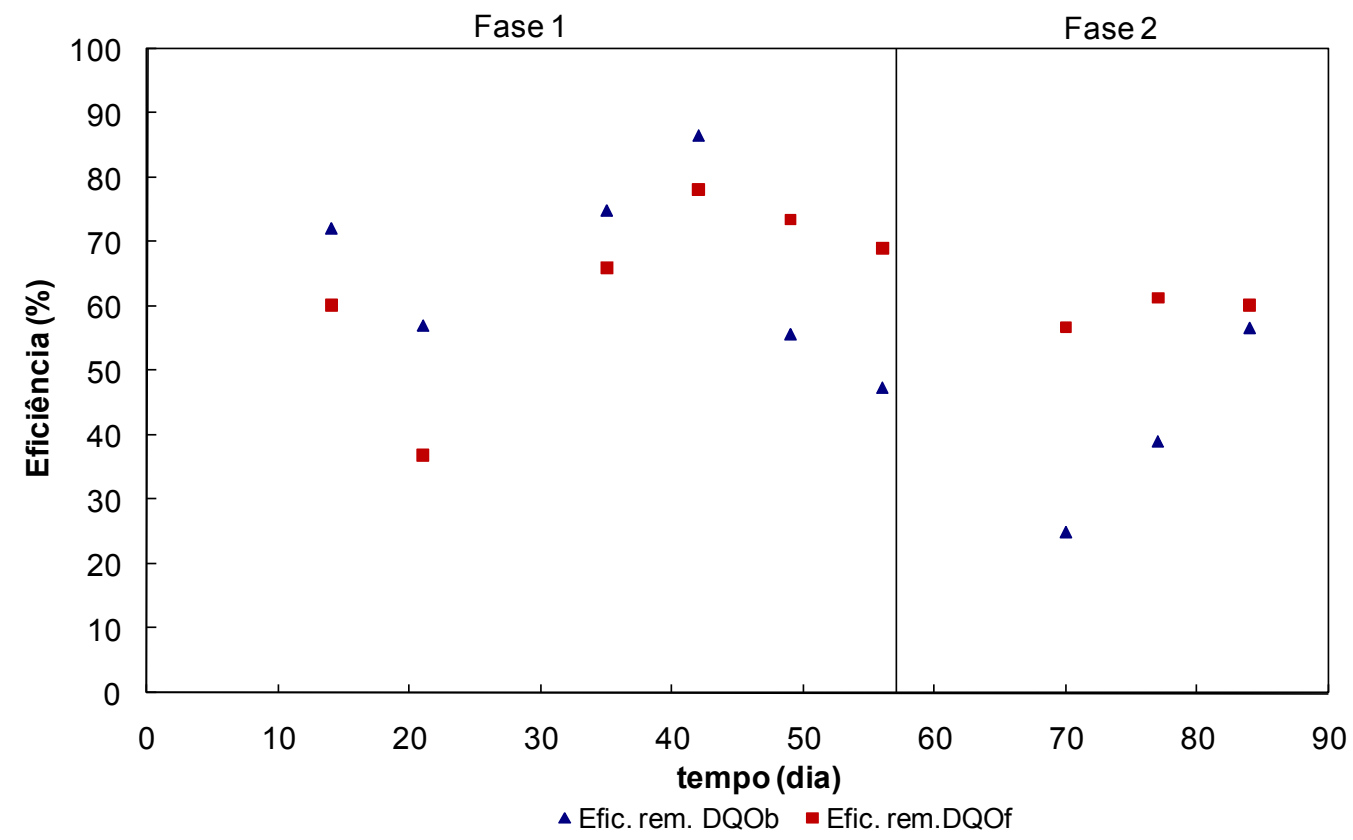

Figura 5.7 Resultados da eficiência de remoção de DQO bruta e filtrada, do reator anaeróbio de leito expandido, durante as Fases 1 e 2 da Etapa I

A eficiência média de remoção de DQO bruta na Fase 1 foi de $66 \%$. Isso ocorreu, quando o sistema foi operado com TDH na região anaeróbia de 8 horas e carga orgânica volumétrica (COV) média de 1,3 kgDQO $\cdot \mathrm{m}^{-3} \cdot \mathrm{dia}^{-1}$. Nestas condições, foi gerado efluente com valores médios de $245 \mathrm{mgDQO}_{\text {bruta. }} \mathrm{L}^{-1}$.

Na Fase 2, da Etapa I, houve redução na eficiência do sistema. O valor médio de remoção de matéria orgânica nesse período, em termos de $\mathrm{DQO}_{\text {bruta, }}$, foi de $40 \%$, para a COV média de 1,7 kgDQO. $\mathrm{m}^{-3} \cdot \mathrm{dia}^{-1}$ e TDH na região anaeróbia de 4,6 h. Foi gerado efluente com valores médios de $352 \mathrm{mgDQO}_{\text {bruta. }} \mathrm{L}^{-1}$. 
A eficiência média de remoção de $\mathrm{DQO}_{\text {filtrada }}$ não sofreu grande oscilação, visto que para Fase 1, a eficiência média de remoção de $\mathrm{DQO}_{\text {filtrada }}$ foi de $64 \%$ (efluente com valor médio de $117 \mathrm{mgDQO}_{\text {filtrada. }} \mathrm{L}^{-1}$ ), e para a Fase 2 , foi de $60 \%$ (efluente com valor médio de $108 \mathrm{mgDQO}_{\text {filtrada. }} \mathrm{L}^{-1}$ ). Isso é justificado, provavelmente, pelo fato de que, ao se reduzir o $\mathrm{TDH}$, ocorreu o aumento da velocidade ascensional do sistema, e conseqüentemente, favoreceu o "arraste" de sólidos, conforme mostrado na Figura 5.11.

Pereira (2000) monitorando um reator anaeróbio de leito expandido $\left(31,3 \mathrm{~m}^{3}\right)$, com altura de 14,9 m e diâmetro de 1,5 m, cujo leito foi composto por carvão ativado granular (CAG), obteve remoções de $\mathrm{DQO}_{\text {total }}$ e $\mathrm{DQO}_{\text {filt }}$ de $79,5 \%$ e $69,5 \%$, respectivamente, quando o sistema foi operado $\mathrm{TDH}$ médio de $3,1 \mathrm{~h}$. O efluente apresentou concentrações médias de $184 \mathrm{mgDQO}$ total $\cdot \mathrm{L}^{-1}$ e $98 \mathrm{mgDQO} \mathrm{filt}_{\mathrm{t}} \cdot \mathrm{L}^{-1}$.

Mendonça (2004) operando o mesmo reator desta pesquisa, somente na condição anaeróbia, com TDH médio de 2,69 h, obteve eficiências médias de remoção de $\mathrm{DQO}_{\text {total }}$ de $72 \%$, isso ocorreu, quando foi aplicada COV média de 3,4 kgDQO.m $\mathrm{m}^{-3} \cdot \mathrm{dia}^{-1}$. O efluente apresentou valor médio de $225 \mathrm{mgDQO} \mathrm{Otal}_{\mathrm{t}} \cdot \mathrm{L}^{-1}$.

Nas Figuras 5.8 e 5.9 são mostrados, respectivamente, os valores de DBO bruta e filtrada do afluente e do efluente e as eficiências de remoção de DBO bruta e filtrada do afluente e do efluente. 


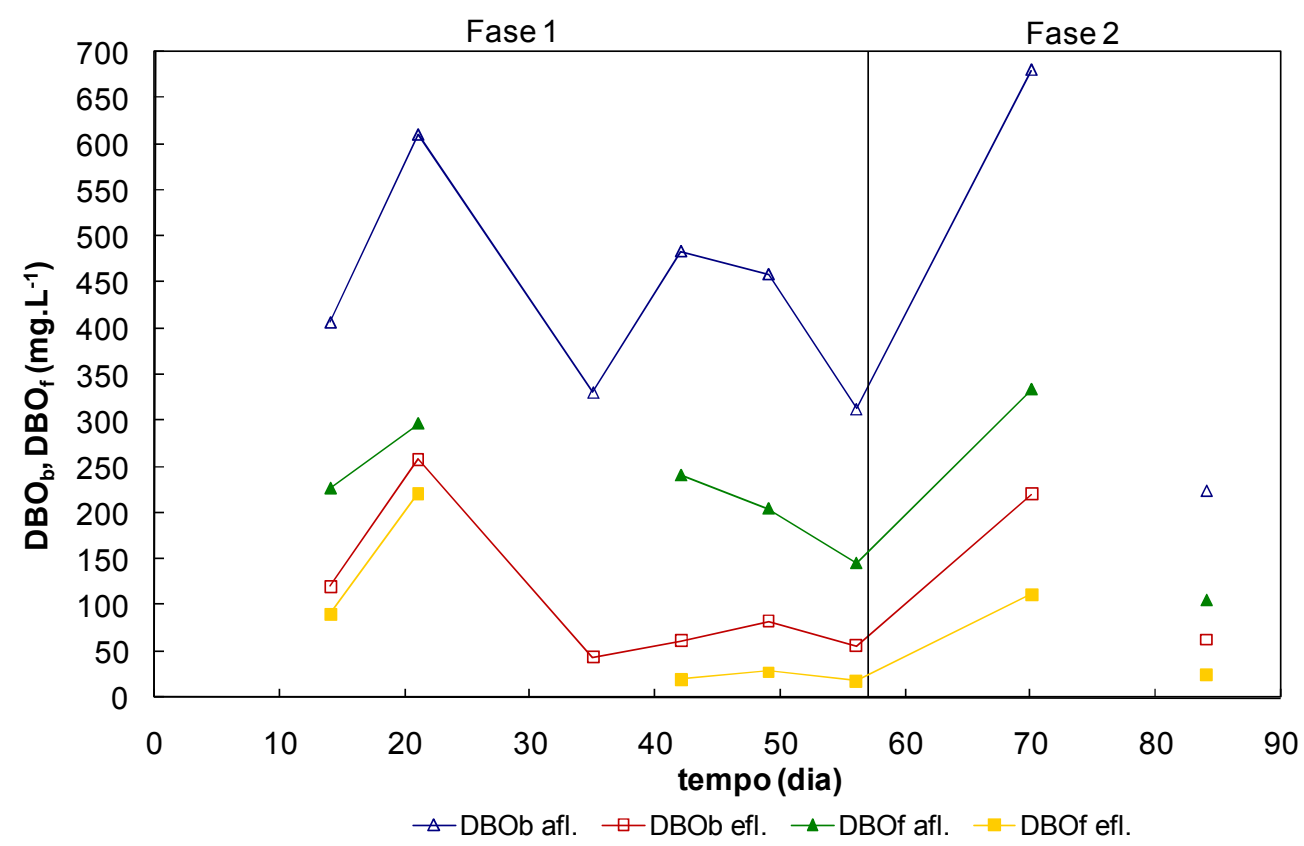

Figura 5.8 Resultados de DBO bruta e filtrada do afluente e do efluente do reator anaeróbio de leito expandido, para as Fases 1 e 2 da Etapa I

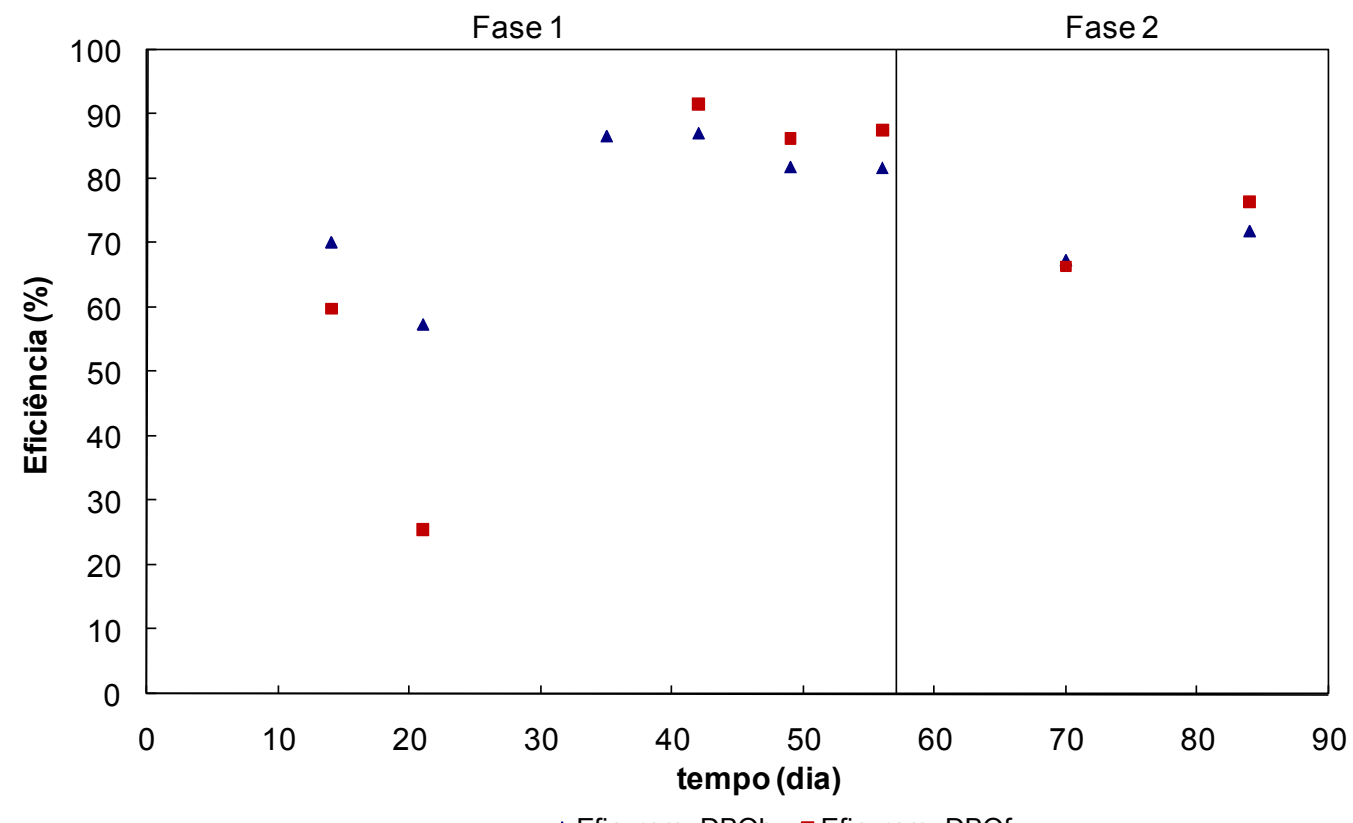

$\triangle$ Efic. rem. DBOb Efic. rem. DBOf

Figura 5.9 Resultados da eficiência de remoção de DBO bruta e filtrada do reator anaeróbio de leito expandido, durante as Fases 1 e 2 da Etapa I

Na Tabela 5.5 são apresentados os valores médios, desvios padrões, valores mínimos e máximos e número de dados considerados na análise estatística para os resultados de DBO, da Etapa I. 
Tabela 5.5 Valores médios, desvios padrões, valores mínimos e máximos e números de dados analisados de DBO das Fases 1 e 2, da Etapa I

\begin{tabular}{|c|c|c|c|c|c|c|c|}
\hline \multirow[t]{2}{*}{ Fase } & \multirow[t]{2}{*}{ Variáveis } & \multicolumn{2}{|c|}{$\begin{array}{l}\text { DBO }_{\text {bruta }} \\
\left(\mathrm{mg} \mathrm{L}^{-1}\right)\end{array}$} & \multirow[t]{2}{*}{$\begin{array}{c}\varepsilon_{\mathrm{DBO}, \mathrm{t}} \\
(\%)\end{array}$} & \multicolumn{2}{|c|}{$\begin{array}{l}\text { DBO }_{\text {filt }} \\
\left(\mathrm{mg}^{-L^{-1}}\right)\end{array}$} & \multirow[t]{2}{*}{$\begin{array}{c}\varepsilon_{\mathrm{DBO}, \mathrm{f}} \\
(\%)\end{array}$} \\
\hline & & Afl. & Efl. & & Afl. & Efl. & \\
\hline \multirow{5}{*}{1} & Média: & 434 & 104 & 78 & 223 & 76 & 70 \\
\hline & Desvio padrão: & 110 & 80 & 12 & 55 & 87 & 28 \\
\hline & Mínimo: & 313 & 44 & 58 & 146 & 18 & 26 \\
\hline & Máximo: & 610 & 259 & 87 & 297 & 221 & 92 \\
\hline & № de amostras: & 6 & 6 & 6 & 5 & 5 & 5 \\
\hline \multirow{5}{*}{2} & Média: & 453 & 142 & 70 & 220 & 69 & 71 \\
\hline & Desvio padrão: & 322 & 112 & 3 & 161 & 62 & 7 \\
\hline & Mínimo: & 225 & 63 & 68 & 106 & 25 & 66 \\
\hline & Máximo: & 680 & 221 & 72 & 334 & 112 & 76 \\
\hline & $\mathrm{N}^{\circ}$ de amostras: & 2 & 2 & 2 & 2 & 2 & 2 \\
\hline
\end{tabular}

Os valores de DBO bruta afluente e para o efluente, para as duas fases, mantiveram na média de $440 \mathrm{mg} \cdot \mathrm{L}^{-1}$ e $110 \mathrm{mg} \cdot \mathrm{L}^{-1}$, respectivamente. No início da Fase 2, ocorreu um aumento de aproximadamente de $50 \%$ do valor da $\mathrm{DBO}_{\text {bruta }}$ do efluente em relação à média observada na fase anterior, sendo que o mesmo fato foi verificado para a $\mathrm{DQO}_{\text {bruta }}$ do efluente no mesmo período.

As eficiências de $\mathrm{DBO}_{\text {bruta }}$ para as Fases 1 e 2 foram de 78 e $70 \%$, respectivamente. Essas eficiências foram observadas quando foi aplicada COV média de 0,75 e 1,4 kgDBO. $\mathrm{m}^{-3} \cdot \mathrm{dia}^{-1}$, respectivamente para as Fases 1 e $2 . \mathrm{A}$ eficiência de DBO filtrada efluente foi em média $70 \%$, sendo que o efluente apresentou valores médios de DBO filtrada de $71 \pm 7 \mathrm{mg} \cdot \mathrm{L}^{-1}$.

Pereira (2000) monitorando um reator anaeróbio de leito expandido $\left(31,3 \mathrm{~m}^{3}\right)$, com altura de 14,9 m e diâmetro de 1,5 m, cujo leito foi composto por carvão ativado granular (CAG), obteve remoções médias de DBO de $72,9 \%$, cujo valor médio no efluente foi de $118 \mathrm{mgDBO}_{\text {bruta. }} \mathrm{L}^{-1}$.

Mendonça (2004) operando o mesmo reator desta pesquisa, somente na condição anaeróbia, como TDH médio de 2,69 h, obteve eficiências médias de 
remoção de $\mathrm{DBO}_{\text {bruta }}$ de $76 \%$. O efluente apresentou concentrações média de 98 $\operatorname{mgDBO} \mathrm{brutal}_{\mathrm{L}} \mathrm{L}^{-1}$.

Os resultados de sólidos totais e sólidos em suspensão são mostrados nas Figuras 5.10 e 5.11, respectivamente.

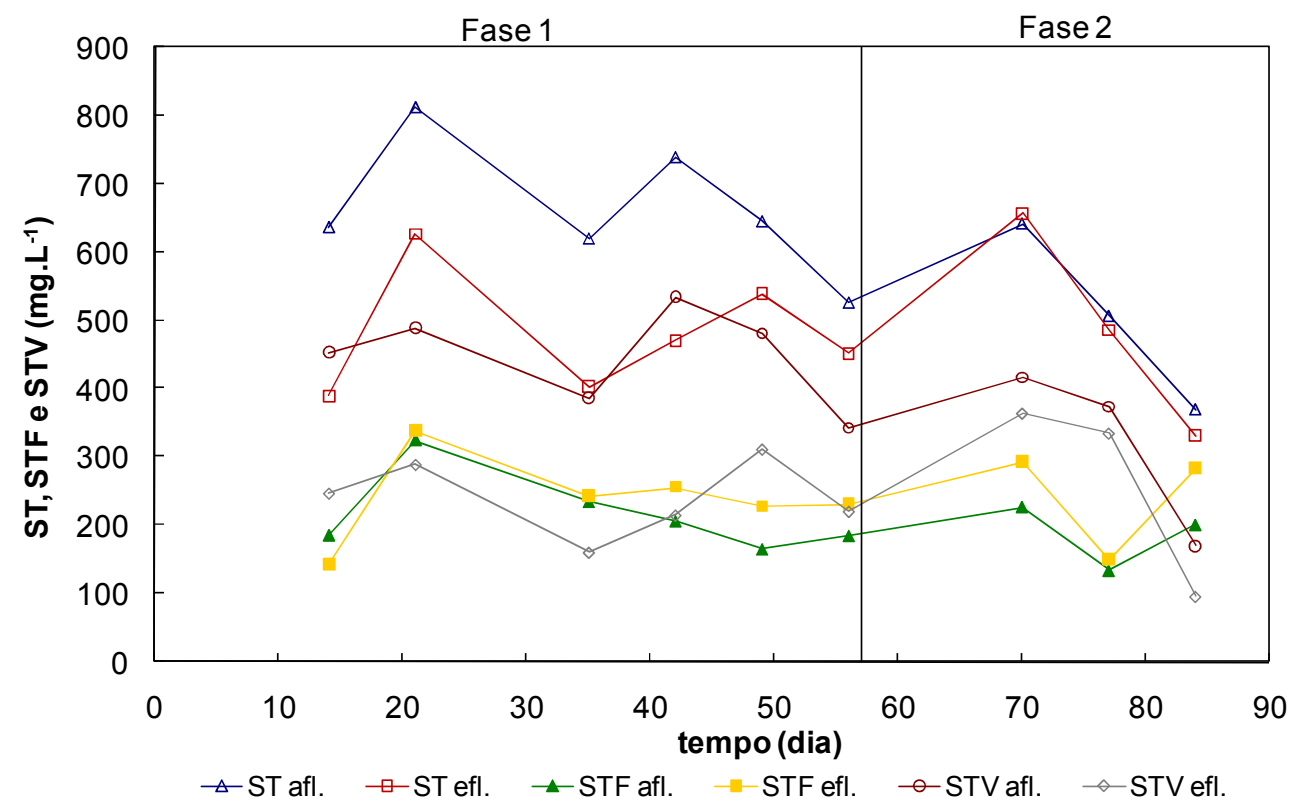

Figura 5.10 Resultados de ST (sólidos totais), STF (sólidos totais fixos) e STV (sólidos totais voláteis) do afluente e do efluente do reator anaeróbio de leito expandido, para as Fases 1 e 2 da Etapa I

$\mathrm{Na}$ Tabela 5.6 são apresentados os valores médios, desvios padrões, valores mínimos e máximos e número de dados considerados na análise estatística para os resultados de sólidos totais e sólidos em suspensão, da Etapa I.

Tabela 5.6 Valores médios, desvios padrões, valores mínimos e máximos e números de dados analisados de sólidos totais e sólidos em suspensão das Fases 1 e 2, da Etapa I

\begin{tabular}{|c|c|c|c|c|c|c|c|c|c|c|c|c|c|}
\hline \multirow[t]{2}{*}{ Fase } & \multirow[t]{2}{*}{ Variáveis } & \multicolumn{2}{|c|}{$\begin{array}{c}\text { ST } \\
\left(\mathrm{mg} \cdot \mathrm{L}^{-1}\right)\end{array}$} & \multicolumn{2}{|c|}{$\begin{array}{c}\text { STF } \\
\left(\mathrm{mg}^{\left.-L^{-1}\right)}\right.\end{array}$} & \multicolumn{2}{|c|}{$\begin{array}{c}\text { STV } \\
\left(\mathrm{mg}^{-L^{-1}}\right)\end{array}$} & \multicolumn{2}{|c|}{$\begin{array}{c}\text { SST } \\
\left(\mathrm{mg} \cdot \mathrm{L}^{-1}\right)\end{array}$} & \multicolumn{2}{|c|}{$\begin{array}{c}\text { SSF } \\
\left(\mathrm{mg} \cdot \mathrm{L}^{-1}\right)\end{array}$} & \multicolumn{2}{|c|}{$\begin{array}{c}\text { SSV } \\
\left(\mathrm{mg}^{-\mathrm{L}^{-1}}\right)\end{array}$} \\
\hline & & Afl. & Efl. & Afl. & Efl. & Afl. & Efl. & Afl. & Efl. & Afl. & Efl. & Afl. & Efl. \\
\hline \multirow{5}{*}{1} & Média: & 664 & 480 & 217 & 240 & 447 & 240 & 214 & 87 & 12 & 27 & 202 & 61 \\
\hline & Desvio padrão: & 100 & 90 & 58 & 63 & 71 & 55 & 48 & 61 & 4 & 17 & 48 & 44 \\
\hline & Mínimo: & 527 & 390 & 165 & 143 & 342 & 160 & 146 & 33 & 8 & 9 & 137 & 20 \\
\hline & Máximo: & 813 & 627 & 324 & 339 & 534 & 311 & 256 & 187 & 18 & 55 & 246 & 132 \\
\hline & o de amostras: & 6 & 6 & 6 & 6 & 6 & 6 & 6 & 6 & 6 & 6 & 6 & 6 \\
\hline \multirow{5}{*}{2} & Média: & 507 & 491 & 187 & 243 & 320 & 265 & 161 & 166 & 13 & 46 & 149 & 120 \\
\hline & Desvio padrão: & 136 & 163 & 48 & 79 & 132 & 147 & 51 & 115 & 4 & 35 & 48 & 80 \\
\hline & Mínimo: & 370 & 331 & 134 & 151 & 170 & 96 & 104 & 46 & 8 & 9 & 96 & 37 \\
\hline & Máximo: & 643 & 657 & 227 & 294 & 416 & 364 & 204 & 275 & 15 & 80 & 190 & 195 \\
\hline & $\mathrm{N}^{\circ}$ de amostras: & 3 & 3 & 3 & 3 & 3 & 3 & 3 & 3 & 3 & 3 & 3 & 3 \\
\hline
\end{tabular}


A eficiência de remoção de ST, para a Fase 1, foi em média de $30 \%$, sendo que o efluente apresentou concentração $480 \pm 90 \mathrm{mgST} . \mathrm{L}^{-1}$. Para a Fase 2, essa eficiência decaiu para $5 \%$, em média, embora o efluente apresentou concentração semelhante da fase anterior, $491 \pm 160 \mathrm{mgST} . \mathrm{L}^{-1}$, no entanto o desvio padrão foi superior.

A concentração de sólidos totais fixos no efluente foi maior que a do efluente. Este fato é justificável, provavelmente, pois a areia colocada no reator, para aumentar o volume de material suporte, continha partículas finas, fora da faixa apropriada para as velocidades ascensionais utilizadas nesta pesquisa, fato este, fez com que as partículas de areia mais finas, fossem carreadas para fora do sistema.

Pereira (2000) monitorando reator anaeróbio de leito expandido $\left(31,3 \mathrm{~m}^{3}\right)$, com altura de 14,9 m e diâmetro de 1,5 m, cujo leito foi composto por carvão ativado granular (CAG), obteve remoções de $59 \%$ de ST, sendo que o efluente apresentou concentração média de $265 \mathrm{mgST} . \mathrm{L}^{-1}$.

Em relação à parcela de sólidos voláteis, foram obtidas eficiências de remoção de STV na faixa de $45 \%$, durante a Fase 1, cujo efluente apresentou concentração média de $240 \pm 55 \mathrm{mgSTV} . \mathrm{L}^{-1}$. Essa eficiência relativamente baixa, provavelmente se deve ao fato de que ao mesmo tempo em que ocorreu remoção de material volátil, houve produção devida à liberação de produtos microbiológicos solúveis, bem como de subprodutos da hidrólise de material particulado e arraste de fragmentos de biofilme decorrente da ação de forças cisalhantes, ocasionadas pelo escoamento do líquido intersticial. 


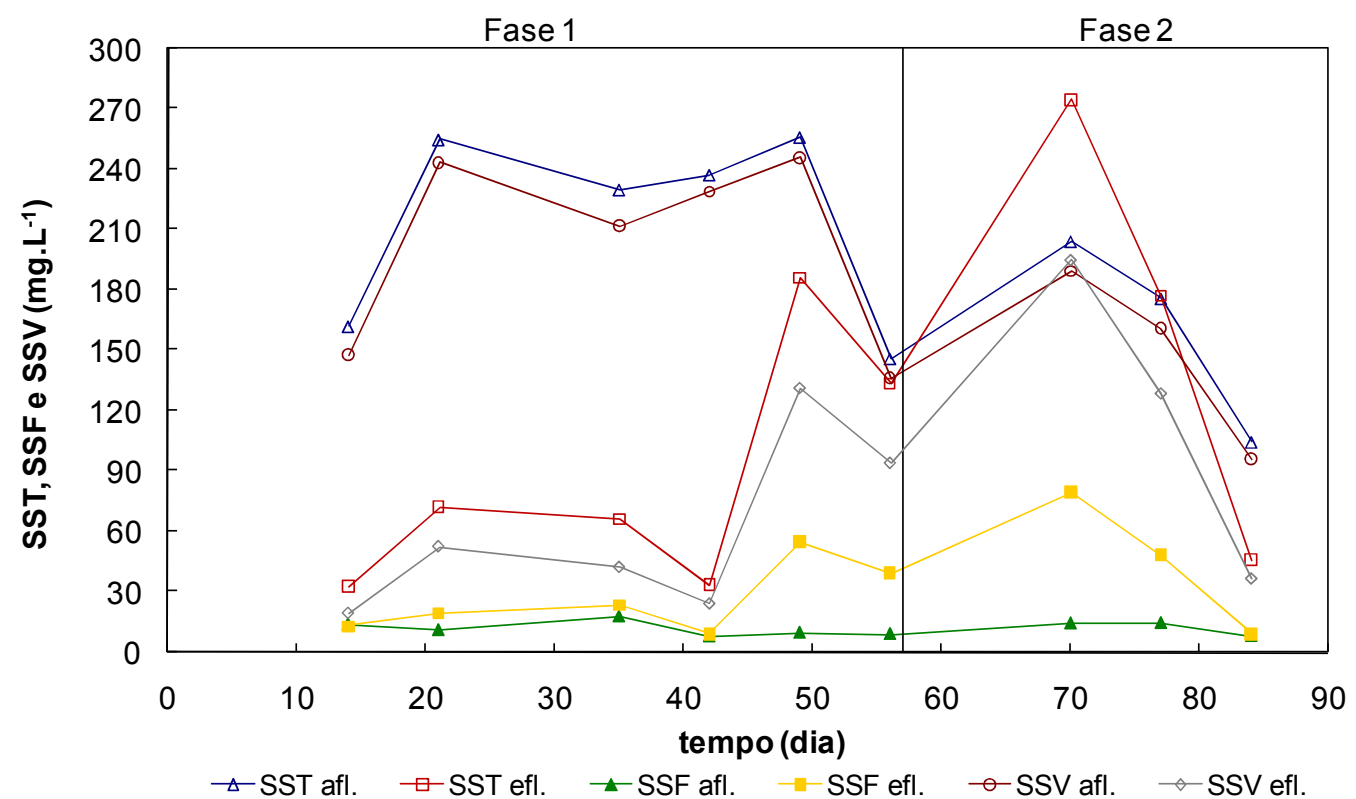

Figura 5.11 Resultados de SST (sólidos em suspensão totais), SSF (sólidos em suspensão fixos) e SSV (sólidos em suspensão voláteis) do afluente e do efluente do reator anaeróbio de leito expandido, para as Fases 1 e 2 da Etapa I

Durante a Fase 1, da Etapa I, o sistema apresentou eficiência de remoção de SST e de SSV de $58 \%$ e $69 \%$, respectivamente, apresentando um efluente com concentrações médias de $87 \pm 61$ mgSST.L ${ }^{-1}$ e $61 \pm 44$ mgSSV.L ${ }^{-1}$.

$\mathrm{Na}$ Fase 2, da mesma Etapa, houve queda sensível nas eficiências de remoção de sólidos em suspensão total e volátil. Ou seja, a eficiência média de remoção de SST e SSV foi de $7 \%$ e $26 \%$, sendo que o efluente apresentou concentrações médias de $166 \pm 115 \mathrm{mgSST} . \mathrm{L}^{-1}$ e $120 \pm 80 \mathrm{mgSSV} . \mathrm{L}^{-1}$ Isso ocorreu, como já observado anteriormente, pela redução no TDH do sistema, o que levou ao aumento na taxa de carregamento hidráulica, e conseqüentemente, o "arraste" de material particulado do sistema.

Na Figura 5.12 é mostrada a relação SSVISST para o afluente e o efluente, durante a Etapa I. 


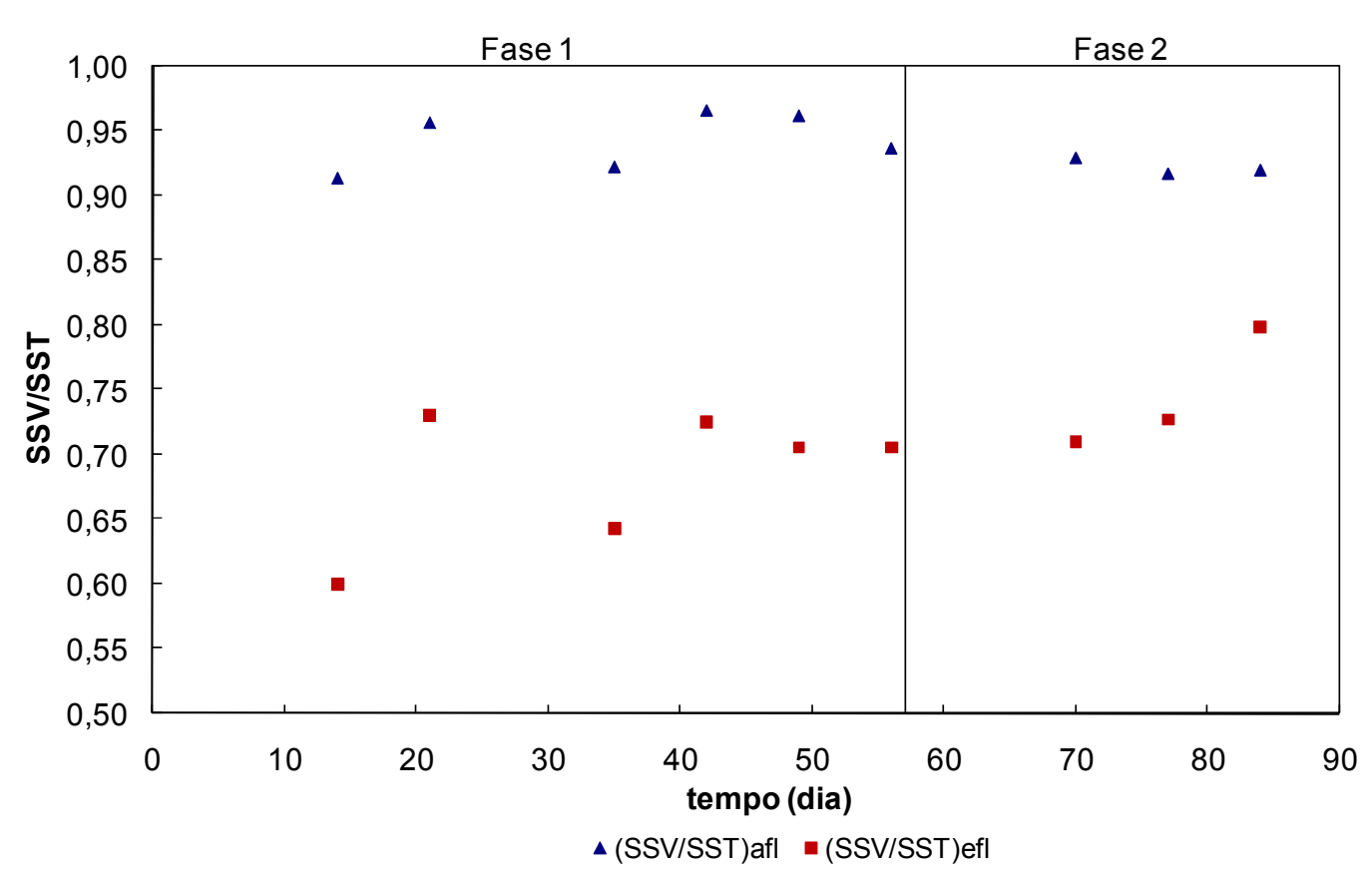

Figura 5.12 Relação SSVISST (sólidos em suspensão voláteis/sólidos em suspensão totais) do afluente e do efluente do reator anaeróbio de leito expandido, para as Fases 1 e 2 da Etapa I

Pela Figura 5.12, observa-se que aproximadamente $70 \%$ do SST é composto por material volátil, indicando que grande parcela da biomassa está sendo perdida pelo sistema, ou até mesmo parcela do afluente está passando direto pelo sistema.

Na Figura 5.13 são mostradas as concentrações de NKT, N-amon e N-org do afluente e do efluente, em função do tempo, para as Fases 1 e 2 do reator anaeróbio de leito expandido na Etapa I. Na Figura 5.14 é mostrada a relação $\mathrm{N}$-amon/NKT do afluente e do efluente. 


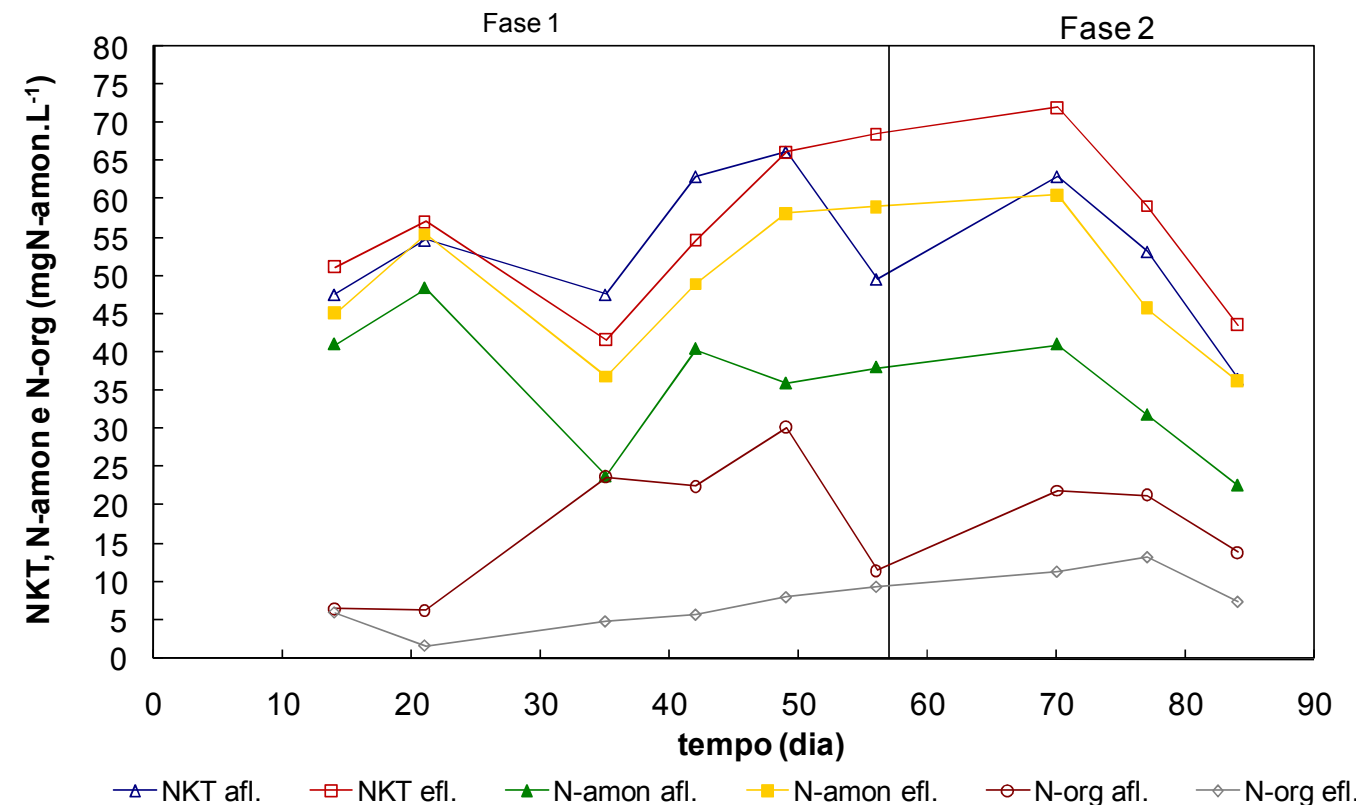

Figura 5.13 Resultados de NKT (nitrogênio Kjeldahl total), N-amon (nitrogênio amoniacal) e N-org (nitrogênio orgânico) do afluente e do efluente do reator anaeróbio de leito expandido, para as Fases 1 e 2 da Etapa I

Na Tabela 5.7 são apresentados os valores médios, desvios padrões, valores mínimos e máximos e número de dados considerados na análise estatística para os resultados de nitrogênio e fósforo, da Etapa I.

Tabela 5.7 Valores médios, desvios padrões, valores mínimos e máximos e números de dados analisados de nitrogênio e fósforo das Fases 1 e 2, da Etapa I

\begin{tabular}{|c|c|c|c|c|c|c|c|c|c|}
\hline \multirow[t]{2}{*}{ Fase } & \multirow[t]{2}{*}{ Variáveis } & \multicolumn{2}{|c|}{$\begin{array}{c}\text { NKT } \\
\left(\mathrm{mg}^{-L^{-1}}\right)\end{array}$} & \multicolumn{2}{|c|}{$\begin{array}{c}\mathrm{N} \text {-amoniacal } \\
\left(\mathrm{mg}^{-1} \mathrm{~L}^{-1}\right)\end{array}$} & \multicolumn{2}{|c|}{$\begin{array}{l}\text { N-orgânico } \\
\left(\mathrm{mg}^{-\mathrm{L}^{-1}}\right)\end{array}$} & \multicolumn{2}{|c|}{$\begin{array}{c}\mathbf{P} \\
\left(\mathrm{mg} \cdot \mathrm{L}^{-1}\right)\end{array}$} \\
\hline & & Afl. & Efl. & Afl. & Efl. & Afl. & Efl. & Afl. & Efl. \\
\hline \multirow{5}{*}{1} & Média: & 54,8 & 56,6 & 38,0 & 50,7 & 16,8 & 5,9 & 5,8 & 5,5 \\
\hline & Desvio padrão: & 8,1 & 9,9 & 8,1 & 8,6 & 10,0 & 2,7 & 1,1 & 1,2 \\
\hline & Mínimo: & 47,6 & 41,7 & 23,9 & 36,9 & 6,3 & 1,6 & 4,4 & 4,2 \\
\hline & Máximo: & 66,2 & 68,5 & 48,4 & 59,1 & 30,2 & 9,4 & 7,4 & 7,4 \\
\hline & № de amostras: & 6 & 6 & 6 & 6 & 6 & 6 & 6 & 6 \\
\hline \multirow{5}{*}{2} & Média: & 50,9 & 58,3 & 31,9 & 47,6 & 19,0 & 10,7 & 5,5 & 7,1 \\
\hline & Desvio padrão: & 13,3 & 14,2 & 9,2 & 12,2 & 4,5 & 3,0 & 1,9 & 2,1 \\
\hline & Mínimo: & 36,6 & 43,7 & 22,7 & 36,3 & 13,9 & 7,4 & 3,8 & 5,4 \\
\hline & Máximo: & 63,0 & 72,0 & 41,1 & 60,6 & 21,9 & 13,3 & 7,5 & 9,5 \\
\hline & $\mathrm{N}^{\circ}$ de amostras: & 3 & 3 & 3 & 3 & 3 & 3 & 3 & 3 \\
\hline
\end{tabular}

Analisando-se a Figura 5.13, observa-se que a remoção de NKT no reator anaeróbio de leito expandido foi insignificante, ocorrendo, provavelmente, a remoção 
devida à assimilação via metabolismo bacteriano, porém houve expressiva conversão de nitrogênio orgânico para nitrogênio amoniacal.

Observa-se que no $70^{\circ}$ dia, quando se reduziu o TDH do sistema de $14 \mathrm{~h}$ para $8 \mathrm{~h}$, a concentração de NKT do efluente foi superior a do afluente, isso ocorreu, provavelmente, devido à perda de sólidos biológicos, ocasionado pelo aumento da velocidade ascensional no reator e redução da eficiência na região de sedimentação.

A maior parcela de $\mathrm{N}$-orgânico presente no efluente, provavelmente está relacionada ao conteúdo de nitrogênio lentamente biodegradável, somado à parcela de sólidos biológicos arrastados do sistema.

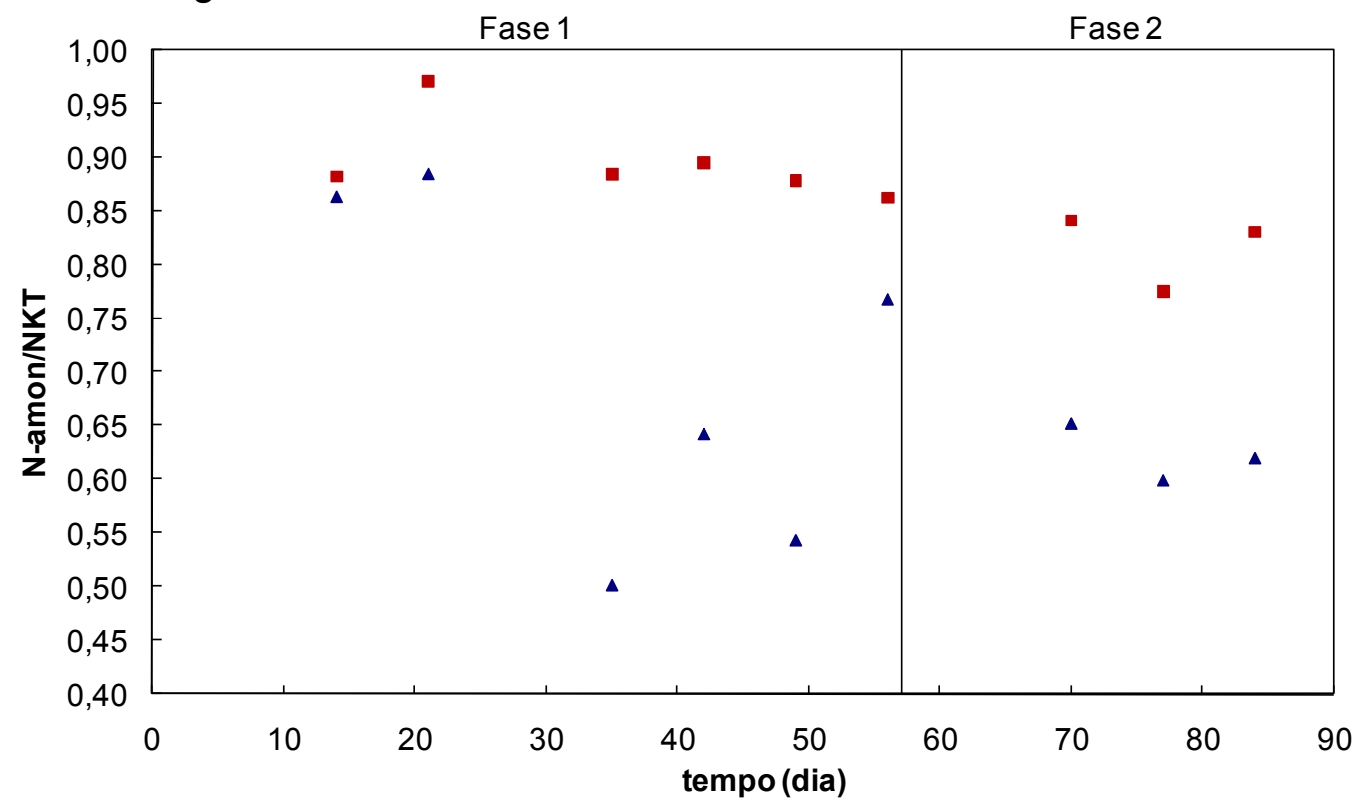

$\Delta(\mathrm{N}-\mathrm{amon} / \mathrm{NKT})$ afl $\quad(\mathrm{N}-\mathrm{amon} / \mathrm{NKT})$ efl

Figura 5.14 Relação N-amon/NKT (nitrogênio amoniacal/nitrogênio Kjeldahl total) do afluente e do efluente do reator anaeróbio de leito expandido, para as Fases 1 e 2 da Etapa I

Observa-se, pela Figura 5.14, que o sistema apresentou, durante a Fase 1 grau de amonificação de $90 \%$, isso ocorreu quando o sistema foi operado com TDH, na região anaeróbia, de 8 horas e carga média de carregamento de nitrogênio de $0,09 \mathrm{kgNKT} \cdot \mathrm{m}^{-3} \cdot \mathrm{dia}^{-1}$. Na fase 2, o grau de amonificação decaiu para $82 \%$. Isso 
ocorreu quando se aplicaram taxa média de carregamento de nitrogênio 0,15 kgNKT. $\mathrm{m}^{-3} \cdot \mathrm{dia}^{-1}$ e TDH na região anaeróbia de 4,6 horas.

Em ambas a fases, o grau de amonificação foi satisfatório, essa é uma característica positiva do sistema anaeróbio, pois atenua a necessidade de se amonificar, em reator subseqüente, para depois promover a nitrificação e, posterior, desnitrificação.

Mendonça (2004) operando o mesmo reator desta pesquisa, somente na condição anaeróbia, como TDH médio de $2,69 \mathrm{~h}$, obteve grau médio de amonificação de $82 \%$, quando foi aplicada ao sistema taxa de nitrogênio média de $0,27 \mathrm{kgNKT} \cdot \mathrm{m}^{-3} \cdot \mathrm{dia}^{-1}$.

Os resultados da concentração de fósforo no afluente e efluente são mostrados na Figura 5.15.

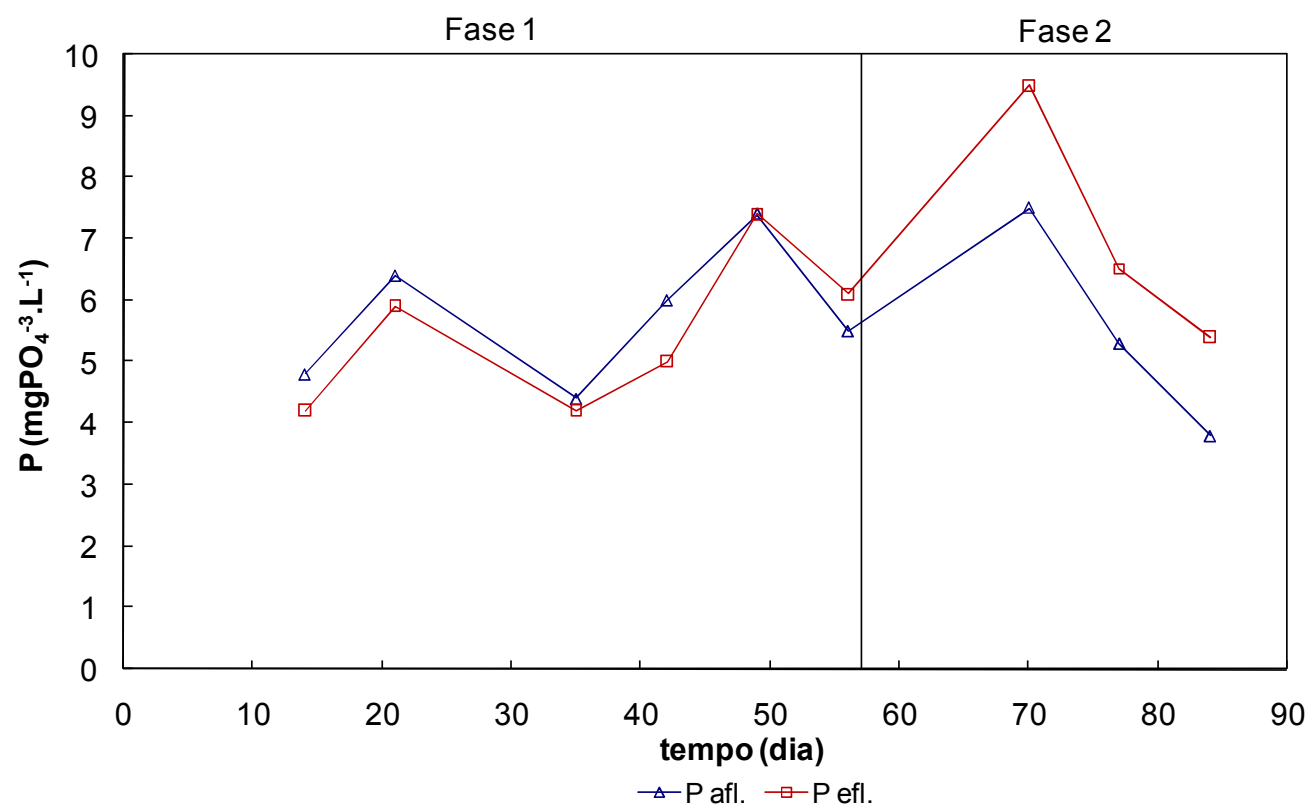

Figura 5.15 Resultados de P (fósforo) do afluente e do efluente do reator anaeróbio de leito expandido, para as Fases 1 e 2 da Etapa I

Pela Figura 5.15, pode-se observar que a fração de fósforo removida no sistema foi desprezível, comportamento típico do processo anaeróbio. 
Durante a Fase 1, o sistema obteve eficiências de remoção de fósforo de até $15 \%$, embora isso pode ser atribuído, devido à incorporação desse elemento no tecido celular da biomassa ou eventual adsorção na matriz polimérica do biofilme, conforme observado por Cuba Terán (1995).

Além disso, é visível o fato de que o processo anaeróbio isolado não apresenta capacidade de remoção de fósforo, podendo, em certos casos, propiciar o aumento nas concentrações efluentes, conforme observado na Fase 2 de operação do sistema (Figura 5.15).

Além Sobrinho e Kato (1999) citam que a remoção de fósforo em processos anaeróbios, somente será efetiva se forem utilizados produtos químicos para a precipitação dos mesmos.

\subsubsection{Análise Global dos Resultados Obtidos durante a Etapa I}

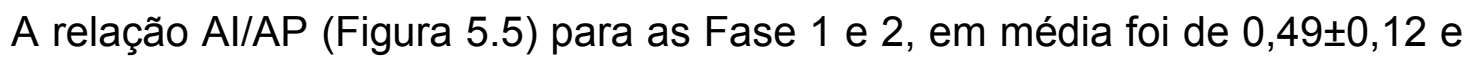
$0,48 \pm 0,07$, respectivamente. Embora, esses valores fossem superiores aos descritos na literatura para sistemas anaeróbios, que é de 0,3, o sistema em ambas as fases apresentou estabilidade adequada, visto pela remoção de matéria orgânica observada durante a Etapa I. Além disso, observa-se que o desvio padrão de ambas as fases foi relativamente pequeno, indicando a capacidade do sistema em se manter em equilíbrio.

A carga orgânica volumétrica média $\left(\mathrm{COV}_{\text {média }}\right)$ aplicada durante as Fases 1 e 2 foi de 1,26 e 1,66 kgDQO $\mathrm{bruta} \cdot \mathrm{m}^{-3} \cdot \mathrm{dia}^{-1}$, respectivamente. A COV média removida do sistema foi de $0,84 \mathrm{kgDQO}$ bruta $\cdot \mathrm{m}^{-3} \cdot \mathrm{dia}^{-1}$ para a Fase 1 e $0,64 \mathrm{kgDQO}$ bruta $\cdot \mathrm{m}^{-3} \cdot \mathrm{dia}^{-1}$ para a Fase 2. O sistema obteve maior eficiência na remoção de matéria orgânica, 
em termos de DQO, durante a Fase 1. A redução do TDH, durante a Fase 2, fez com que ocorresse a redução na eficiência de remoção de matéria orgânica, embora, provavelmente, o tempo de operação foi insuficiente para que o sistema se adaptasse ao aumento na taxa de carregamento orgânico e obtivesse equilíbrio dinâmico.

As eficiências de remoção de ST, nas Fases 1 e 2 foram de 30\% e 5\%, respectivamente. As concentrações de sólidos totais no efluente foram semelhantes

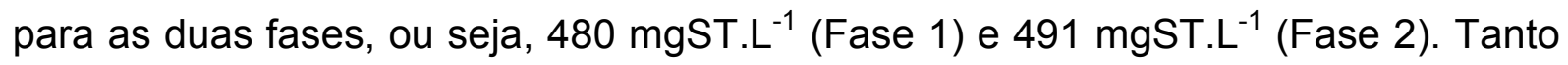
para a Fase 1, quanto para a Fase 2, as eficiências foram relativamente muito baixas, isso provavelmente pode ser explicado pelo baixo desempenho do sistema de decantação, mostrando que o mesmo não apresentou funcionabilidade adequada, visto que as taxas de aplicação hidráulica para as Fases 1 e 2 foram de 17,4 e $30,4 \mathrm{~m}^{3} \cdot \mathrm{m}^{-2} \cdot \mathrm{dia}^{-1}$, respectivamente, valores estes dentro do recomendado pela NBR 12209/1992, que determina que a taxa de escoamento superficial deve ser igual ou inferior a $36 \mathrm{~m}^{3} / \mathrm{m}^{2} . \mathrm{d}$, para decantador final.

As eficiências de remoção de SST, durante as Fases 1 e 2 foram de $58 \%$ e $7 \%$, respectivamente. A concentração de sólidos em suspensão totais no efluente foi 87 mgSST.L ${ }^{-1}$ (Fase 1) e 166 mgSST.L $^{-1}$ (Fase 2). Nota-se que com a redução do $\mathrm{TDH}$, de 14 horas para 8 horas, promoveu o aumento na velocidade ascensional, de $4,8 \mathrm{~m} \cdot \mathrm{h}^{-1}$ para $8,5 \mathrm{~m} \cdot \mathrm{h}^{-1} \mathrm{e}$ isso, ocasionou, provavelmente, o "arraste" de material particulado, reduzindo, assim de maneira significante a eficiência na remoção de SST, durante a Fase 2, da Etapa I.

O grau de amonificação obtido, durante as Fases 1 e 2, foi de $90 \%$ e $82 \%$, respectivamente. Isso evidencia a potenciabilidade do sistema na conversão de matéria nitrogenado orgânico em amoniacal. 


\subsubsection{Etapa II}

\subsubsection{Condições Operacionais - Etapa II}

As condições operacionais do reator de leito expandido, durante a Etapa I, são mostradas na Tabela 5.8.

Tabela 5.8 Variáveis de operação do reator de leito expandido: Etapa II

\begin{tabular}{ccccc}
\hline \hline Etapa II & Fase 1 & Fase 2 & Fase 3 & Fase 4 \\
\hline $\mathbf{Q}_{\text {afl }}\left(\mathbf{m}^{3} \cdot \mathbf{h}^{-1}\right)$ & 19,9 & 13,3 & 9,9 & 8,0 \\
\hline $\mathbf{Q}_{\text {rec,ana }}\left(\mathbf{m}^{\mathbf{3}} \cdot \mathbf{h}^{-1}\right)$ & 39,8 & 26,6 & - & - \\
\hline $\mathbf{Q}_{\text {rec,aer }}\left(\mathbf{m}^{\mathbf{3}} \cdot \mathbf{h}^{-1}\right)$ & 39,8 & 26,6 & 19,8 & 16 \\
\hline $\mathbf{v}_{\text {asc,ana }}\left(\mathbf{m}^{-1} \mathbf{h}^{-1}\right)$ & 8,5 & 5,6 & 1,4 & 1,1 \\
\hline $\mathbf{v}_{\text {asc,aer }}\left(\mathbf{m}^{-1} \mathbf{h}^{-1}\right)$ & 14,0 & 9,4 & 4,2 & 3,4 \\
\hline $\mathbf{T D H}_{\text {total }}(\mathbf{h})$ & 8,0 & 12,0 & 16,0 & 20,0 \\
\hline $\mathbf{T D H}_{\text {ana }}(\mathbf{h})$ & 2,3 & 3,45 & 4,65 & 5,75 \\
\hline $\mathbf{T D H}_{\text {aer }} \mathbf{( h )}$ & 2,3 & 3,45 & 4,65 & 5,75 \\
\hline \hline
\end{tabular}

\footnotetext{
Qafl vazão afluente

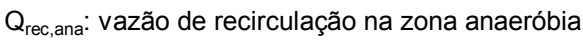

$Q_{\text {rec aer: }}$ vazão de recirculação na zona aeróbia

$v_{\text {asc,ana: }}$ velocidade ascensional na zona anaeróbia

$V_{\text {asc,aer: }}$ velocidade ascensional na zona aeróbia

$\mathrm{TDH}_{\text {total: }}$ tempo de detenção hidráulica no reator

$\mathrm{TDH}_{\text {ana: }}$ : tempo de detenção hidráulica zona anaeróbia

$\mathrm{TDH}_{\text {aer }}$ : tempo de detenção hidráulica zona aeróbia
}

A Etapa II teve duração de 126 dias, sendo que as Fases 1; 2; 3 e 4 duraram 21; 28; 28 e 49 dias, respectivamente.

A proposta inicial deste trabalho foi a remoção conjunta de matéria orgânica e nitrogênio em reator anaeróbio-aeróbio de leito expandido operado sob aeração intermitente.

Após estabilização aparente do sistema anaeróbio, iniciou-se a aeração de parte do sistema (zona aeróbia); vale lembrar que a zona aeróbia é sobreposta à anaeróbia, e que as zonas aparentemente tem o mesmo volume $\left(46 \mathrm{~m}^{3}\right)$. 
A aeração foi de forma contínua e durou cerca de 10 dias. Isso foi feito para que se tentasse promover o desenvolvimento de microrganismos aeróbios no sistema.

A partir disso, a aeração foi imposta de forma intermitente (zona aeróbia), com períodos de $2 \mathrm{~h}$ com aeração e de $1 \mathrm{~h}$ sem aeração. No entanto, ao longo da Fase 1, Etapa II, observou-se que o sistema não apresentou nenhuma eficiência na remoção do nitrogênio.

No primeiro momento acreditou-se que o sistema estava com déficit de oxigênio dissolvido, em média $0,4 \mathrm{mg} \cdot \mathrm{L}^{-1}$. Por isso, foi decidido aumentar o TDH do reator para 12 horas (Fase 2), visto que o compressor estava operando com capacidade máxima, não havendo a possibilidade de se aumentar a vazão do mesmo.

Durante a Fase 2, o sistema continuou não apresentando eficiências na remoção de nitrogênio. Perante essa situação, resolveu-se, aumentar novamente o TDH para 16 h (Fase 3) e além disso, desistiu-se da aeração intermitente, visto pelos resultados apresentados durante as Fases 1 e 2.

A partir desse momento, a aeração (zona aeróbia) passou a ser de forma contínua e a recirculação na zona anaeróbia foi desligada, para que se pudesse acompanhar o processo de nitrificação no sistema, caso o mesmo ocorresse a recirculação viria a ser religada.

Ao longo da Fase 3, o sistema começou a apresentar, nas primeiras semanas, remoção de nitrogênio. No entanto, o processo tornou-se instável. Finalmente, foi adotado TDH de $20 \mathrm{~h}$ (Fase 4), para se tentar requerer essa instabilidade e, eventualmente, elevar-se a remoção de nitrogênio. 
A razão de recirculação na zona anaeróbia, durante a Etapa II, com exceção das Fases 3 e 4, foi mantida em 200\% ( $\left.Q_{\text {rec }} / Q_{\text {afl }}\right)$ para facilitar a expansão do leito do reator. A mesma razão foi mantida para a zona aeróbia durante toda a Etapa II.

\subsubsection{Resultados de Desempenho do Reator Anaeróbio-Aeróbio de Leito Expandido}

Na Figura 5.16, 5.17 e 5.18 são apresentados, respectivamente, os resultados de $\mathrm{pH}$, alcalinidade e ácidos voláteis do afluente e do efluente, em função do tempo de operação, durante a Etapa II.

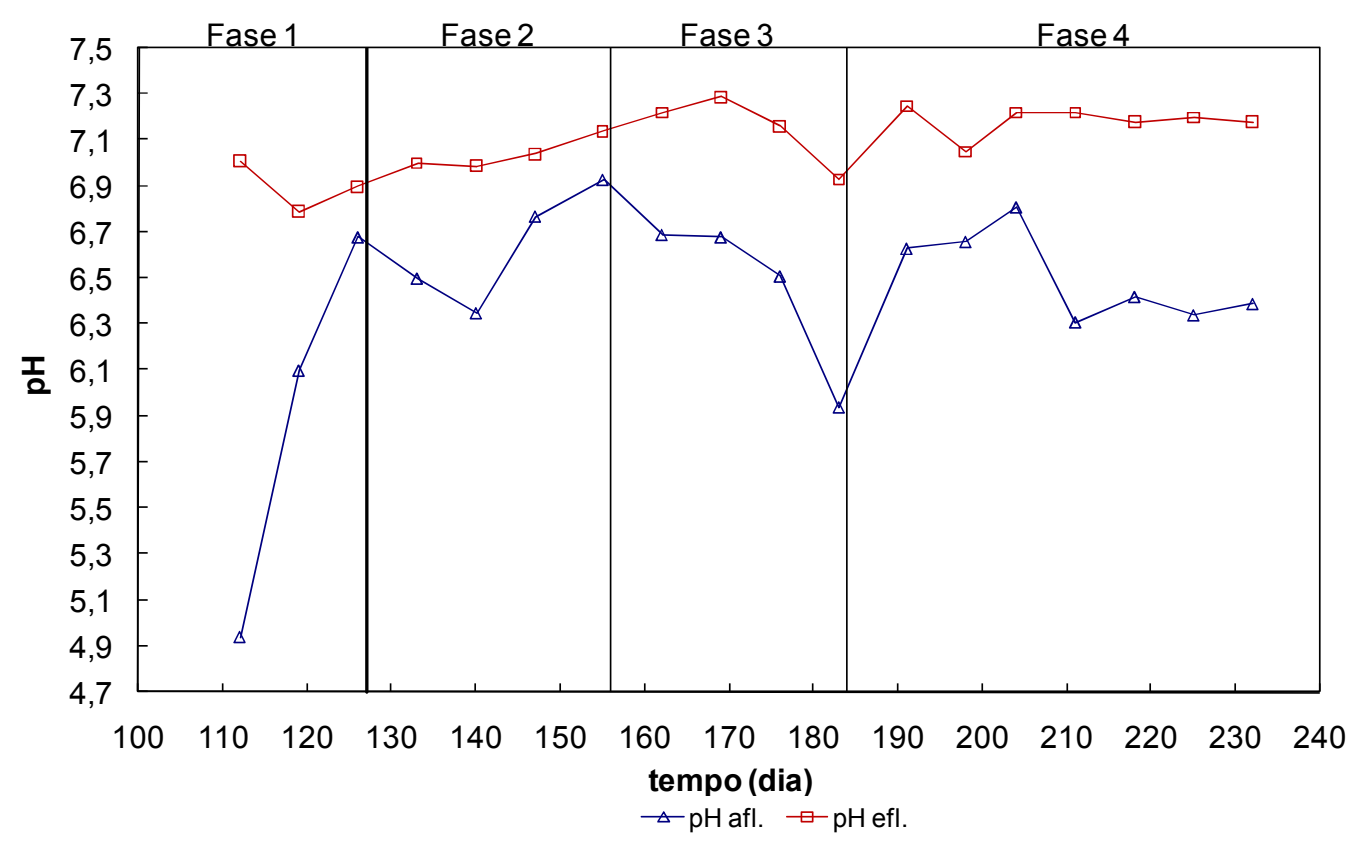

Figura 5.16 Resultados de pH do afluente e do efluente do reator anaeróbio-aeróbio de leito expandido, para as Fases 1; 2; 3 e 4 da Etapa II

Pela Figura 5.16, observa-se que, o pH do afluente variou de 4,9 a 6,9, enquanto o do efluente variou de 6,8 a 7,3 . 
Constata-se que o $\mathrm{pH}$ do efluente se manteve superior ao $\mathrm{pH}$ do afluente durante toda a Etapa II. Isso ocorreu, provavelmente, pela liberação de $\mathrm{CO}_{2}$ que se encontrava dissolvido no sistema.

Nota-se, pela Figura 5.16, que o pH do afluente no $112^{\circ}$ e no $183^{\circ}$ dia de operação do sistema, atingiu valores de 4,9 e 5,9, respectivamente. Isso ocorreu, devido à descarga ácida, de origem desconhecida, na rede coletora de esgoto da USP de São Carlos, área 1. Não foi possível avaliar o efeito direto do lançamento desse produto no sistema.

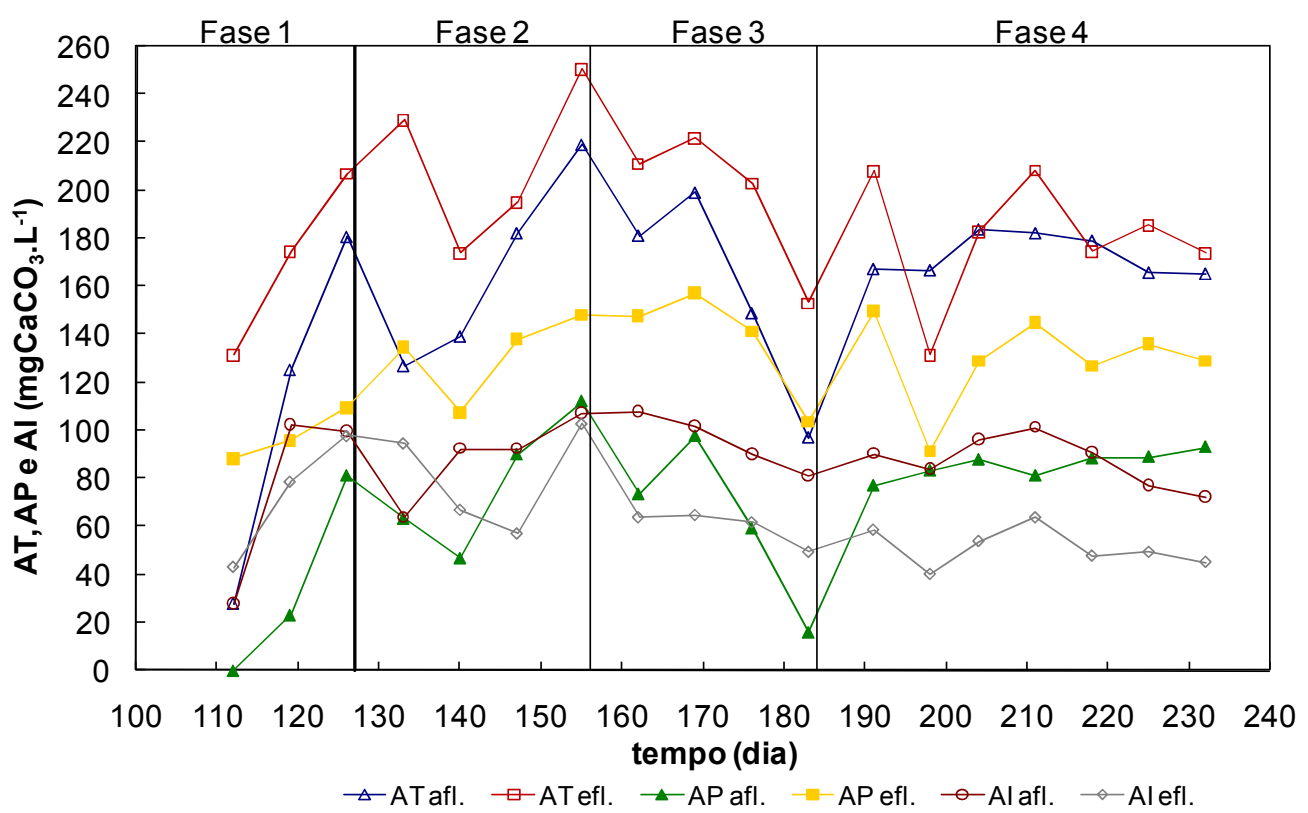

Figura 5.17 Resultados de AT (alcalinidade total), AP (alcalinidade parcial) e Al (alcalinidade intermediária) do afluente e do efluente do reator anaeróbio-aeróbio de leito expandido, para as Fases 1; 2; 3 e 4 da Etapa II 


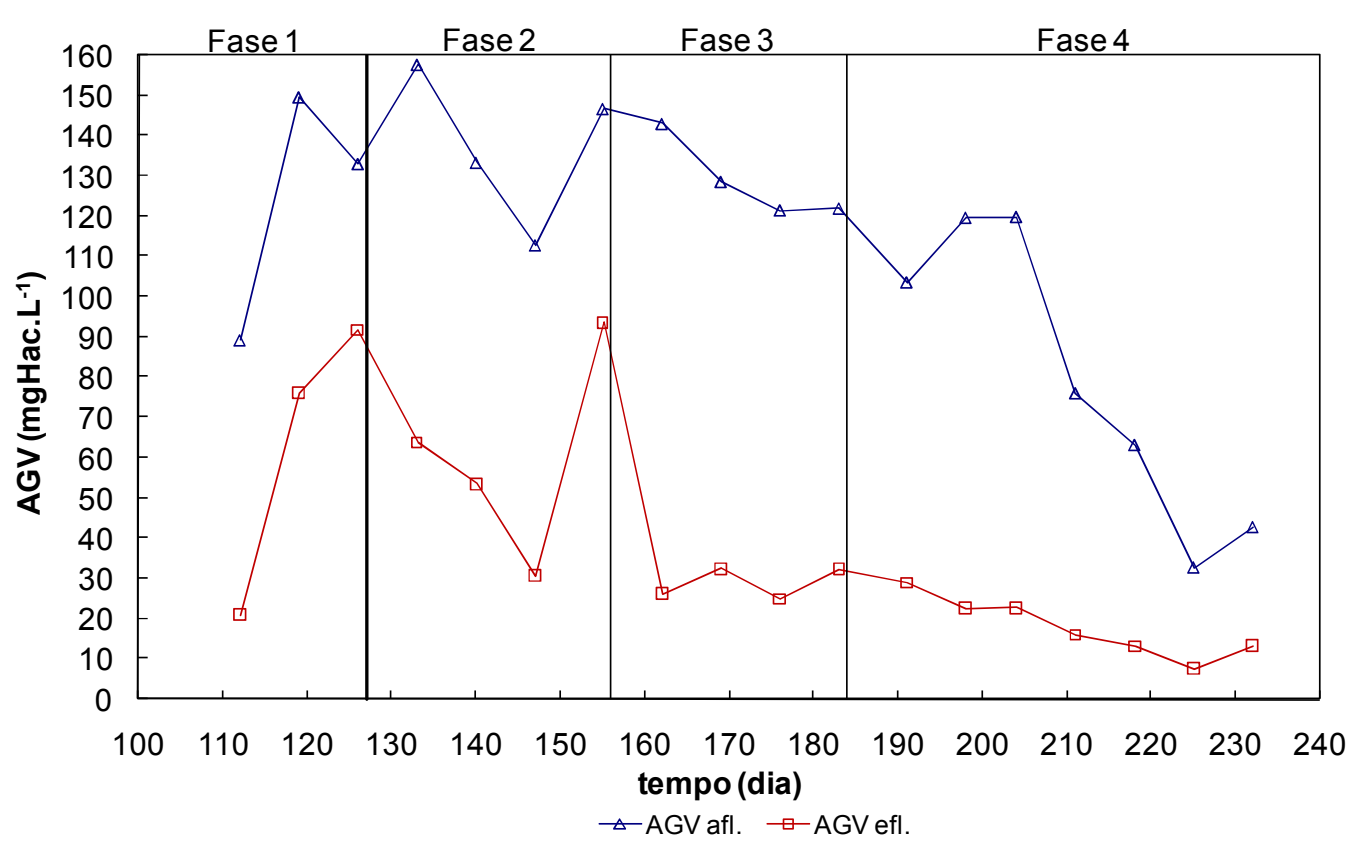

Figura 5.18 Resultados de AGV (ácidos graxos voláteis) do afluente e do efluente do reator anaeróbio-aeróbio de leito expandido, para as Fases 1; 2; 3 e 4 da Etapa II

$\mathrm{Na}$ Tabela 5.9 são apresentados os valores médios, desvios padrões, valores mínimos e máximos e número de dados considerados na análise estatística para os resultados de $\mathrm{pH}$, alcalinidade e AGV, da Etapa II.

Tabela 5.9 Valores médios, desvios padrões, valores mínimos e máximos e números de dados analisados de $\mathrm{pH}, \mathrm{AT}$ (alcalinidade total), AP (alcalinidade parcial), Al (alcalinidade intermediária) e AGV (ácidos graxos voláteis) das Fases 1; 2; 3 e 4, da Etapa II

\begin{tabular}{|c|c|c|c|c|c|c|c|c|c|c|c|}
\hline \multirow[t]{2}{*}{ Fase } & \multirow[t]{2}{*}{ Variáveis } & \multicolumn{2}{|c|}{ pH } & \multicolumn{2}{|c|}{$\begin{array}{c}\text { AP } \\
\left(\mathrm{mgCaCO}_{3} \cdot \mathrm{L}^{-1}\right)\end{array}$} & \multicolumn{2}{|c|}{$\begin{array}{c}\mathrm{Al} \\
\left(\mathrm{mgCaCO}_{3} \cdot \mathrm{L}^{-1}\right)\end{array}$} & \multicolumn{2}{|c|}{$\begin{array}{c}\text { AT } \\
\left(\mathrm{mgCaCO}_{3} \cdot \mathrm{L}^{-1}\right)\end{array}$} & \multicolumn{2}{|c|}{ 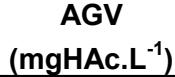 } \\
\hline & & Afl. & Efl. & Afl. & Efl. & Afl. & Efl. & Afl. & Efl. & Afl. & Efl. \\
\hline \multirow{5}{*}{1} & Média: & 5,9 & 6,9 & 35 & 98 & 77 & 73 & 111 & 171 & 124 & 63 \\
\hline & Desvio padrão: & 0,9 & 0,1 & 42 & 11 & 42 & 28 & 78 & 38 & 31 & 37 \\
\hline & Mínimo: & 4,9 & 6,8 & 0 & 88 & 28 & 43 & 28 & 132 & 89 & 21 \\
\hline & Máximo: & 6,7 & 7,0 & 81 & 109 & 102 & 98 & 181 & 207 & 150 & 92 \\
\hline & $\mathrm{N}^{\circ}$ de amostras: & 3 & 3 & 3 & 3 & 3 & 3 & 3 & 3 & 3 & 3 \\
\hline \multirow{5}{*}{2} & Média: & 6,6 & 7,0 & 78 & 132 & 89 & 80 & 167 & 212 & 138 & 60 \\
\hline & Desvio padrão: & 0,3 & 0,1 & 29 & 17 & 18 & 22 & 42 & 34 & 19 & 26 \\
\hline & Mínimo: & 6,4 & 7,0 & 47 & 107 & 64 & 57 & 127 & 174 & 113 & 31 \\
\hline & Máximo: & 6,9 & 7,1 & 112 & 148 & 107 & 103 & 219 & 251 & 158 & 94 \\
\hline & $\mathrm{N}^{\circ}$ de amostras: & 4 & 4 & 4 & 4 & 4 & 4 & 4 & 4 & 4 & 4 \\
\hline \multirow{5}{*}{3} & Média: & 6,5 & 7,2 & 62 & 137 & 95 & 60 & 157 & 197 & 129 & 29 \\
\hline & Desvio padrão: & 0,4 & 0,2 & 34 & 23 & 12 & 7 & 45 & 30 & 10 & 4 \\
\hline & Mínimo: & 5,9 & 6,9 & 16 & 104 & 81 & 49 & 97 & 153 & 122 & 25 \\
\hline & Máximo: & 6,7 & 7,3 & 98 & 157 & 108 & 65 & 199 & 222 & 143 & 33 \\
\hline & $\mathrm{N}^{\circ}$ de amostras: & 4 & 4 & 4 & 4 & 4 & 4 & 4 & 4 & 4 & 4 \\
\hline \multirow{5}{*}{4} & Média: & 6,5 & 7,2 & 86 & 130 & 87 & 51 & 173 & 181 & 80 & 18 \\
\hline & Desvio padrão: & 0,2 & 0,1 & 5 & 19 & 10 & 8 & 8 & 26 & 36 & 7 \\
\hline & Mínimo: & 6,3 & 7,1 & 77 & 91 & 72 & 40 & 165 & 132 & 33 & 8 \\
\hline & Máximo: & 6,8 & 7,3 & 93 & 150 & 101 & 64 & 184 & 209 & 120 & 29 \\
\hline & $\mathrm{N}^{\circ}$ de amostras: & 7 & 7 & 7 & 7 & 7 & 7 & 7 & 7 & 7 & 7 \\
\hline
\end{tabular}


Pela Figura 5.17, observa-se que, durante a Etapa II, a alcalinidade média do afluente foi de $112 ; 167 ; 157$ e $173 \mathrm{mgCaCO}_{3} \cdot \mathrm{L}^{-1}$, para as Fase $1 ; 2 ; 3$ e 4 , respectivamente. Enquanto que para o efluente, a alcalinidade média das Fases 1; 2; 3 e 4 foi de $171 ; 212 ; 197$ e $181 \mathrm{mgCaCO}_{3} \cdot \mathrm{L}^{-1}$, respectivamente. Nota-se que a alcalinidade total do efluente foi superior ao do efluente. Isso pode ter sido ocasionado, provavelmente, pela degradação de compostos orgânicos nitrogenados, resultando no aumento da alcalinidade do sistema.

Siman (2007) operando o mesmo reator desta pesquisa, sob condições anaeróbia-aeróbia sobrepostas, com TDH médio na zona de reação de 8,8 h, sendo que o TDH na zona anaeróbia e aeróbia foi de 6,5 e 2,3 h, respectivamente, obteve para o efluente alcalinidade total média de $250 \mathrm{mgCaCO} \cdot \mathrm{L}^{-1}$.

As concentrações médias de ácidos voláteis no afluente foram de $124 ; 138$; 129 e 80 mgHac. $\mathrm{L}^{-1}$ durante as Fases 1; 2; 3 e 4, respectivamente. Já para o efluente foram de 63; 60; 29 e $18 \mathrm{mgHac}^{-1}$, conforme Figura 5.18.

Nota-se que durante toda a Etapa II, o sistema foi capaz de "neutralizar" os ácidos presentes no meio.

Na Figura 5.19 são representados os resultados das análises de DQO das amostras brutas e filtradas do afluente e do efluente, em função do tempo de operação, para a Etapa II, e na Figura 5.20 são mostradas as eficiências na remoção de DQO total e filtrada. 


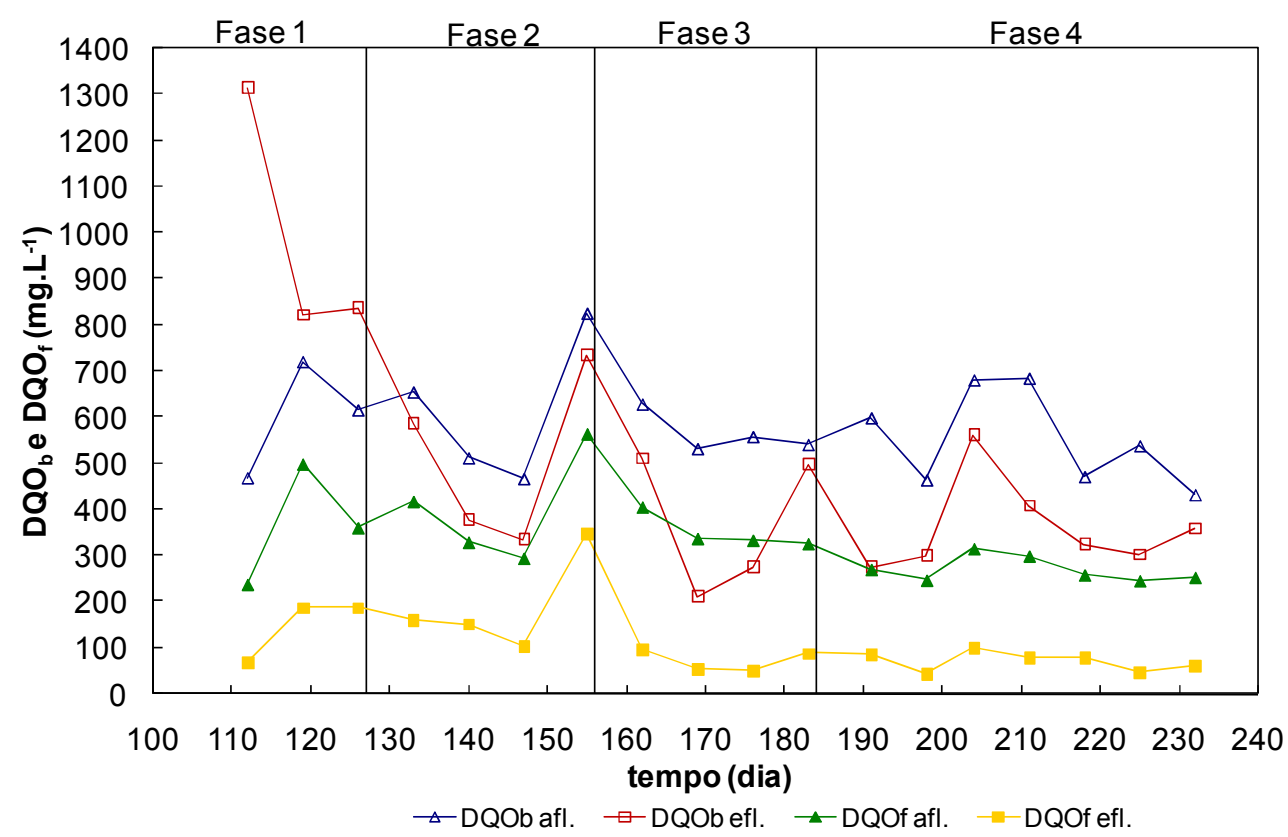

Figura 5.19 Resultados de DQO bruta e filtrada do afluente e do efluente do reator anaeróbio-aeróbio de leito expandido, para as Fases 1; 2; 3 e 4 da Etapa II

$\mathrm{Na}$ Tabela 5.10 são apresentados os valores médios, desvios padrões, valores mínimos e máximos e número de dados considerados na análise estatística para os resultados de DQO, da Etapa II.

Tabela 5.10 Valores médios, desvios padrões, valores mínimos e máximos e números de dados analisados de DQO das Fases 1; 2; 3 e 4, da Etapa II

\begin{tabular}{|c|c|c|c|c|c|c|c|}
\hline \multirow[t]{2}{*}{ Fase } & \multirow[t]{2}{*}{ Variáveis } & \multicolumn{2}{|c|}{$\begin{array}{l}\text { DQO }_{\text {bruta }} \\
\left(\mathrm{mg}^{-\mathrm{L}^{-1}}\right)\end{array}$} & \multirow[t]{2}{*}{$\begin{array}{c}\varepsilon_{\mathrm{DQO}, \mathrm{t}} \\
(\%)\end{array}$} & \multicolumn{2}{|c|}{$\begin{array}{c}\text { DQO }_{\text {filt }} \\
\left(\mathrm{mg} \cdot \mathrm{L}^{-1}\right)\end{array}$} & \multirow[t]{2}{*}{$\begin{array}{c}\varepsilon_{\mathrm{DQO}, \mathrm{f}} \\
(\%)\end{array}$} \\
\hline & & Afl. & Efl. & & Afl. & Efl. & \\
\hline \multirow{5}{*}{1} & Média: & 602 & 991 & -77 & 365 & 147 & 61 \\
\hline & Desvio padrão: & 127 & 281 & 90 & 130 & 69 & 12 \\
\hline & Mínimo: & 469 & 821 & -180 & 238 & 68 & 48 \\
\hline & Máximo: & 721 & 1315 & -14 & 498 & 187 & 71 \\
\hline & $\mathrm{N}^{\circ}$ de amostras: & 3 & 3 & 3 & 3 & 3 & 3 \\
\hline \multirow{5}{*}{2} & Média: & 615 & 507 & 19 & 401 & 191 & 55 \\
\hline & Desvio padrão: & 162 & 187 & 10 & 120 & 108 & 12 \\
\hline & Mínimo: & 467 & 334 & 11 & 294 & 103 & 38 \\
\hline & Máximo: & 826 & 734 & 28 & 563 & 348 & 65 \\
\hline & $\mathrm{N}^{\circ}$ de amostras: & 4 & 4 & 4 & 4 & 4 & 4 \\
\hline \multirow{5}{*}{3} & Média: & 565 & 373 & 35 & 350 & 72 & 80 \\
\hline & Desvio padrão: & 44 & 154 & 25 & 37 & 24 & 6 \\
\hline & Mínimo: & 532 & 210 & 8 & 326 & 50 & 73 \\
\hline & Máximo: & 629 & 510 & 61 & 405 & 97 & 85 \\
\hline & $\mathrm{N}^{\circ}$ de amostras: & 4 & 4 & 4 & 4 & 4 & 4 \\
\hline \multirow{5}{*}{4} & Média: & 553 & 361 & 34 & 270 & 70 & 74 \\
\hline & Desvio padrão: & 104 & 99 & 14 & 27 & 21 & 6 \\
\hline & Mínimo: & 432 & 275 & 17 & 246 & 43 & 69 \\
\hline & Máximo: & 685 & 561 & 54 & 315 & 99 & 83 \\
\hline & $\mathrm{N}^{\circ}$ de amostras: & 7 & 7 & 7 & 7 & 7 & 7 \\
\hline
\end{tabular}


A DQO bruta do afluente, durante a Etapa II variou de 432 a $826 \mathrm{mg} \cdot \mathrm{L}^{-1}$, enquanto para o efluente, variou 210 a $1315 \mathrm{mg} \cdot \mathrm{L}^{-1}$.

Durante a Fase 1, observa-se pela Figura 5.19, que a DQO bruta do efluente foi superior a do afluente. Durante essa fase, houve perda excessiva de material de difícil biodegradabilidade no sistema, devido ao período inicial de aeração, que carreou grande parte do material biológico sedimentado, no decantador do reator, para fora do sistema. Além disso, nesse período houve praticamente a adaptação do sistema, ou seja, a transição da Etapa I para a Etapa II, não conseguindo chegar à estabilidade.

A DQO das amostras filtradas do afluente variou de 238 a $405 \mathrm{mg} \cdot \mathrm{L}^{-1}$, enquanto que para o efluente, a variação foi de 43 a $348 \mathrm{mg} \cdot \mathrm{L}^{-1}$. Nota-se, pela Figura 5.19, que durante as Fases 3 e 4, houve estabilização da DQO filtrada do efluente, sendo que o mesmo não foi observado para a DQO bruta do efluente.

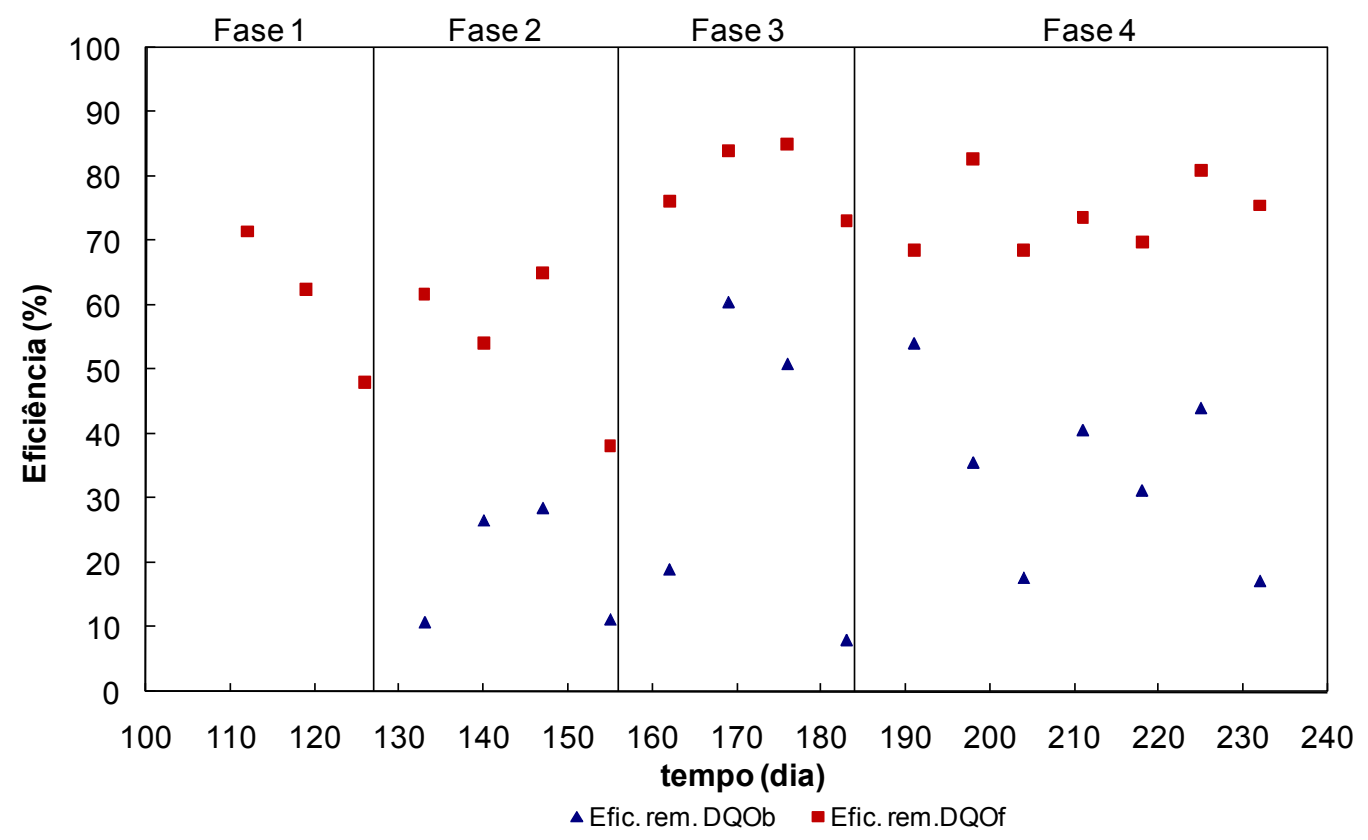

Figura 5.20 Resultados da eficiência de remoção de DQO bruta e filtrada, do reator anaeróbio-aeróbio de leito expandido, durante as Fases 1; 2; 3 e 4 da Etapa II

As eficiências médias de remoção de DQO bruta foram de 19; 35 e 35\%, para as Fases 2; 3 e 4, respectivamente. Isso ocorreu quando foram aplicadas cargas de 
carregamento médias de 1,23 (Fase 2), 0,84 (Fase 3) e 0,67 kgDQO.m ${ }^{-3} \cdot \mathrm{dia}^{-1}$ (Fase 4). Já as eficiências de remoção média de DQO das amostras filtradas para as Fases 2, 3 e 4 foram de 55; 80 e 75\%, respectivamente.

A eficiência de remoção de DQO filtrada na Fase 4 foi menor em relação a Fase 3, embora a qualidade do efluente da Fase 4 fosse melhor. Isso ocorreu, pois durante a Fase 4, o afluente apresentou menores valores de DQO, tanto bruta quanto filtrada, em relação às outras fases. Isso pode ser explicado, pois durante esta fase, ocorreram muitas chuvas, principalmente no dia da coleta, o que levou a uma diluição do esgoto sanitário, visto que muitas ligações da rede pluvial são interligadas ao sistema de coleta de esgotos.

Siman (2007) operando o mesmo reator, sob condições anaeróbia-aeróbia sobrepostas, com TDH médio na zona de reação de $8,8 \mathrm{~h}$, sendo que o TDH na zona anaeróbia e aeróbia foi de 6,5 e 2,3 h, respectivamente, obteve eficiências médias de remoção de $\mathrm{DQO}_{\text {total }}$ e $\mathrm{DQO}_{\text {filtrada }}$ de $68 \%$ e $78 \%$, quando se aplicou COV média de 0,95 $\mathrm{kgDQO}_{\text {total }} \cdot \mathrm{m}^{-3} \cdot \mathrm{dia}^{-1}$ e $0,46 \quad \mathrm{kgDQO}$ filtrada. $\mathrm{m}^{-3} \cdot \mathrm{dia}^{-1}$. O efluente apresentou concentrações médias de $108 \mathrm{mgDQO}_{\text {total. }} \mathrm{L}^{-1}$ e $37 \mathrm{mgDQO} \mathrm{O}_{\text {filtrada. }} \mathrm{L}^{-1}$.

Houve grande discrepância em relação aos valores de DQO bruta e filtrada para o efluente, conforme é mostrado na Figura 5.21 . 


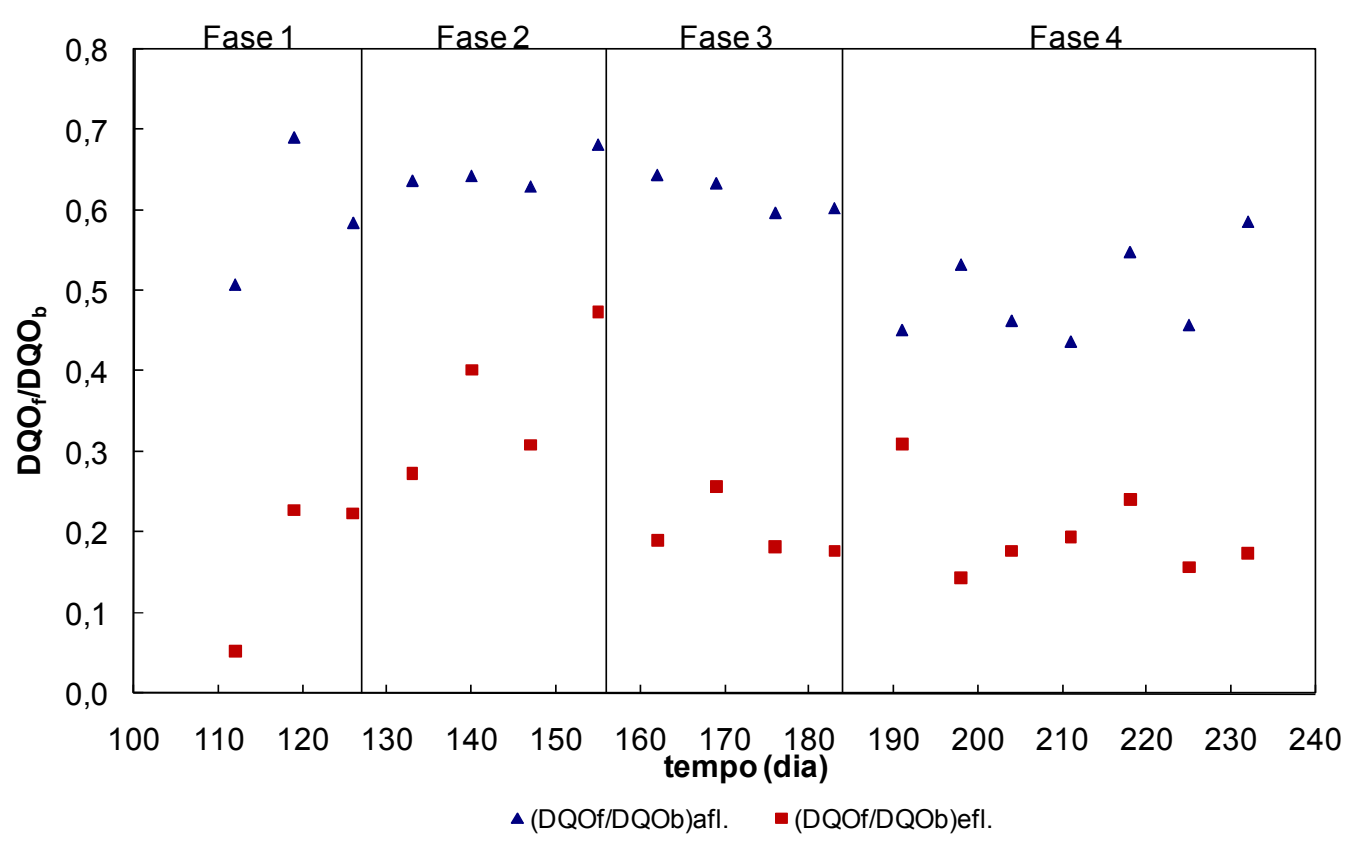

Figura 5.21 Relação $D Q O_{f} / D Q O_{b}$ afluente e do efluente do reator anaeróbio-aeróbio de leito expandido, para as Fases 1; 2; 3 e 4 da Etapa II

Isso ocorreu, pois a quantidade necessária de ar a ser injetada ao sistema, para que se tivesse oxigênio dissolvido para o sistema biológico, foi muito grande. Isso fez com que, esse grande volume de ar carreasse material sedimentado no decantador do reator anaeróbio-aeróbio de leito expandido, fazendo com que o mesmo saísse junto com o efluente tratado.

Nas Figuras 5.22 e 5.23 são mostrados os resultados das análises de DBO das amostras brutas e filtradas do afluente e do efluente e as eficiências na remoção de DBO total e filtrada, respectivamente. 


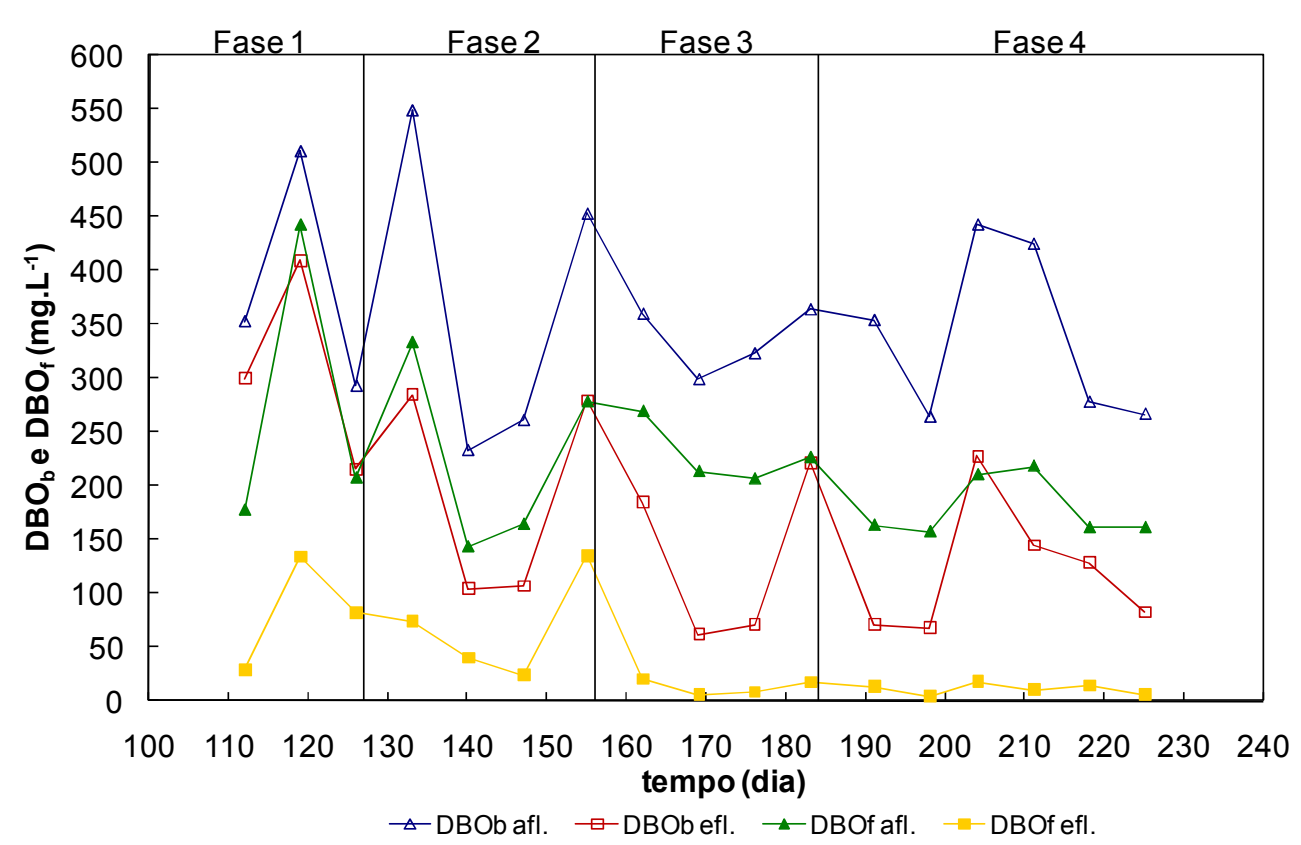

Figura 5.22 Resultados de DBO bruta e filtrada do afluente e do efluente do reator anaeróbio-aeróbio de leito expandido, para as Fases 1; 2; 3 e 4 da Etapa II

Ao contrário do ocorrido com a DQO, a DBO no efluente durante a Fase 1, foi menor que a do afluente, mostrando que o sistema foi eficiente na remoção de material facilmente biodegradável.

Na Tabela 5.11 são apresentados os valores médios, desvios padrões, valores mínimos e máximos e número de dados considerados na análise estatística para os resultados de DBO, da Etapa II.

As médias da DBO bruta no efluente foram de 309; 194; 135 e $121 \mathrm{mg} \cdot \mathrm{L}^{-1}$, para as Fases 1; 2; 3 e 4, respectivamente. Já para a DBO filtrada do efluente, os valores obtidos foram de 74; 68; 13 e $11 \mathrm{mg}^{\mathrm{L}} \mathrm{L}^{-1}$, para as Fase 1; 2; 3 e 4, conforme mostrado na Figura 5.22. 
Tabela 5.11 Valores médios, desvios padrões, valores mínimos e máximos e números de dados analisados de DBO das Fases 1; 2; 3 e 4, da Etapa II

\begin{tabular}{|c|c|c|c|c|c|c|c|}
\hline \multirow[t]{2}{*}{ Fase } & \multirow[t]{2}{*}{ Variáveis } & \multicolumn{2}{|c|}{$\begin{array}{l}\text { DBO }_{\text {bruta }} \\
\left(\mathrm{mg} \mathrm{L}^{-1}\right)\end{array}$} & \multirow[t]{2}{*}{$\begin{array}{c}\varepsilon_{\mathrm{DBO}, \mathrm{t}} \\
(\%)\end{array}$} & \multicolumn{2}{|c|}{$\begin{array}{l}\mathrm{DBO}_{\text {filt }} \\
\left(\mathrm{mg} \cdot \mathrm{L}^{-1}\right)\end{array}$} & \multirow{2}{*}{$\begin{array}{c}\varepsilon_{\mathrm{DBO}, \mathrm{f}} \\
(\%)\end{array}$} \\
\hline & & Afl. & Efl. & & Afl. & Efl. & \\
\hline \multirow{5}{*}{1} & Média: & 386 & 309 & 20 & 275 & 82 & 71 \\
\hline & Desvio padrão: & 113 & 97 & 6 & 145 & 53 & 12 \\
\hline & Mínimo: & 293 & 216 & 15 & 177 & 29 & 60 \\
\hline & Máximo: & 511 & 410 & 26 & 442 & 134 & 84 \\
\hline & $\mathrm{N}^{\circ}$ de amostras: & 3 & 3 & 3 & 3 & 3 & 3 \\
\hline \multirow{5}{*}{2} & Média: & 374 & 194 & 50 & 230 & 68 & 72 \\
\hline & Desvio padrão: & 152 & 102 & 9 & 91 & 49 & 15 \\
\hline & Mínimo: & 233 & 105 & 38 & 143 & 24 & 51 \\
\hline & Máximo: & 549 & 285 & 59 & 333 & 135 & 85 \\
\hline & $\mathrm{N}^{\circ}$ de amostras: & 4 & 4 & 4 & 4 & 4 & 4 \\
\hline \multirow{5}{*}{3} & Média: & 337 & 135 & 61 & 229 & 13 & 95 \\
\hline & Desvio padrão: & 31 & 81 & 20 & 28 & 7 & 2 \\
\hline & Mínimo: & 299 & 62 & 39 & 206 & 6 & 92 \\
\hline & Máximo: & 364 & 222 & 79 & 269 & 20 & 97 \\
\hline & $\mathrm{N}^{\circ}$ de amostras: & 4 & 4 & 4 & 4 & 4 & 4 \\
\hline \multirow{5}{*}{4} & Média: & 339 & 121 & 65 & 178 & 11 & 94 \\
\hline & Desvio padrão: & 81 & 61 & 12 & 28 & 5 & 3 \\
\hline & Mínimo: & 264 & 68 & 49 & 157 & 4 & 91 \\
\hline & Máximo: & 443 & 228 & 80 & 218 & 18 & 97 \\
\hline & $\mathrm{N}^{\circ}$ de amostras: & 6 & 6 & 6 & 6 & 6 & 6 \\
\hline
\end{tabular}

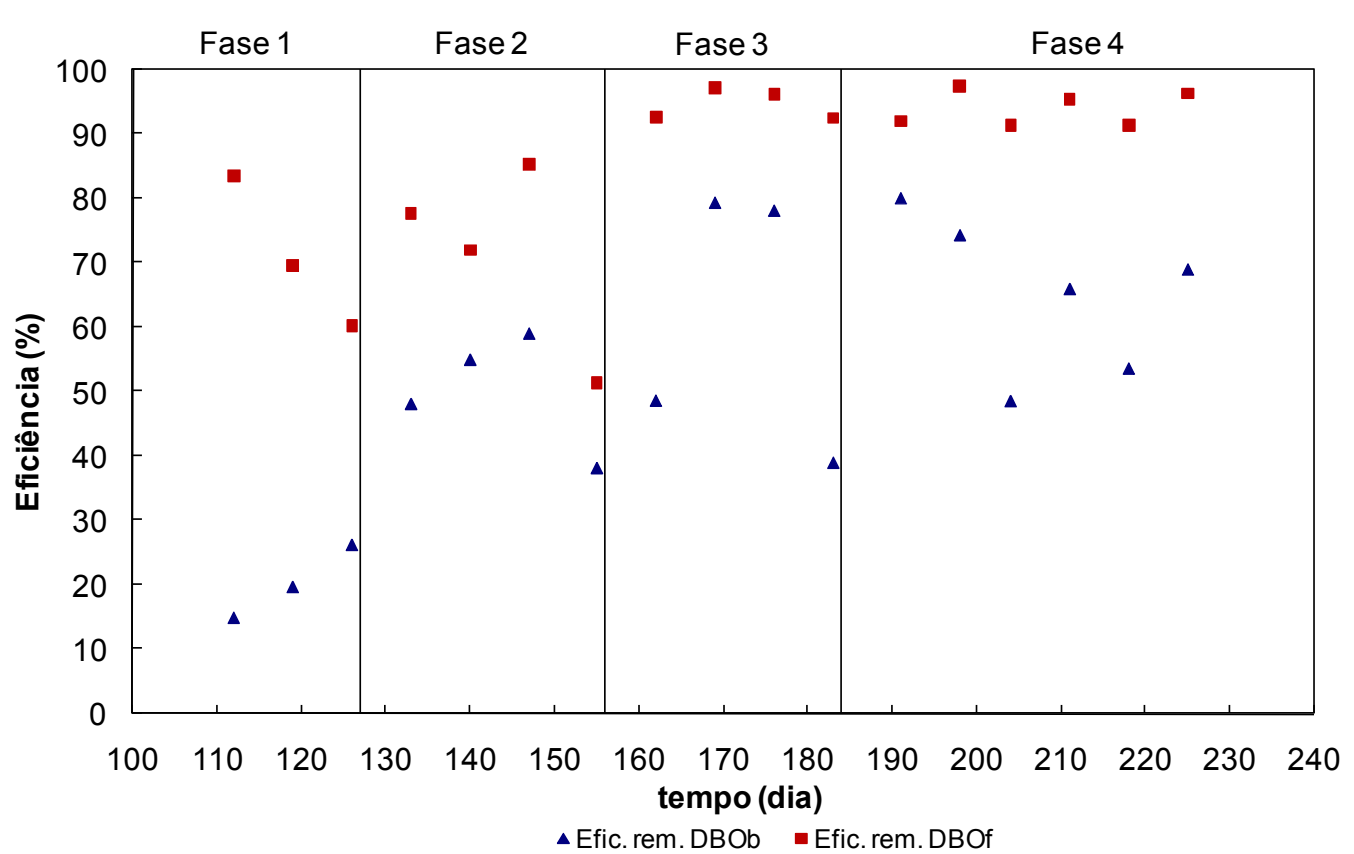

Figura 5.23 Resultados da eficiência de remoção de DBO total e filtrada do reator anaeróbio-aeróbio de leito expandido, durante as Fases 1; 2; 3 e 4 da Etapa II

O sistema alcançou eficiências médias de remoção de DBO total, durante as Fase 1; 2; 3 e 4 de 20,50, 60 e 65\%, respectivamente. Sendo que o efluente chegou a apresentar DBO total de $62 \mathrm{mg} \cdot \mathrm{L}^{-1}$ (Fase 3). Já para a DBO filtrada do efluente as 
eficiências médias foram de 71, 72, 95 e 94\%, para as Fases 1, 2, 3 e 4, respectivamente. O efluente chegou apresentar concentração de 4 mg.L ${ }^{-1}$ (Fase 4) de DBO filtrada.

Na Figura 5.24 e 5.25 são mostrados, respectivamente, os resultados dos sólidos totais e sólidos em suspensão, do afluente e do efluente, durante a Etapa II de operação do reator anaeróbio-aeróbio de leito expandido.

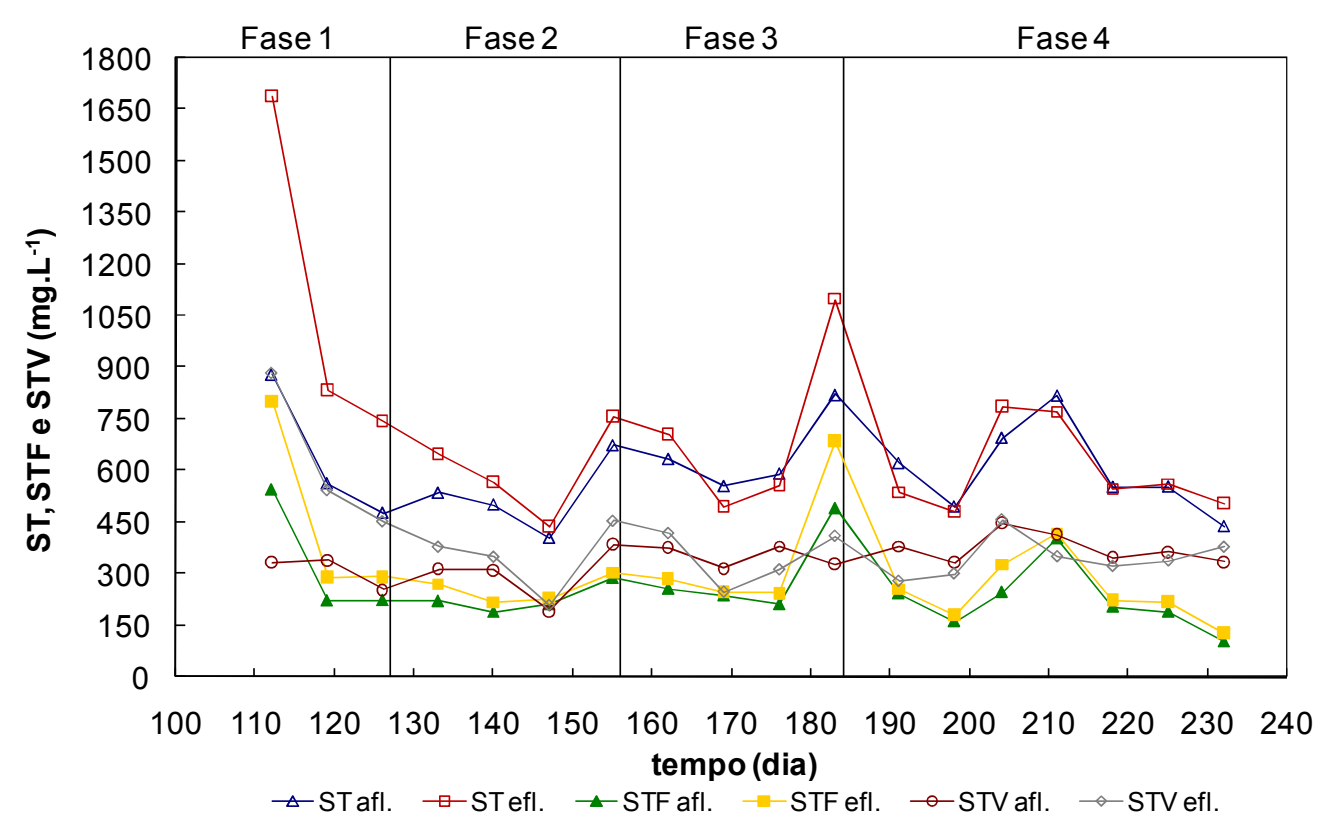

Figura 5.24 Resultados de ST (sólidos totais), STF (sólidos totais fixos) e STV (sólidos totais voláteis) do afluente e do efluente do reator anaeróbio-aeróbio de leito expandido, para as Fases 1; 2; 3 e 4 da Etapa II

Na Tabela 5.12 são apresentados os valores médios, desvios padrões, valores mínimos e máximos e número de dados considerados na análise estatística para os resultados de sólidos totais e sólidos em suspensão, da Etapa II. 
Tabela 5.12 Valores médios, desvios padrões, valores mínimos e máximos e números de dados analisados de sólidos totais e sólidos em suspensão das Fases 1; 2; 3 e 4, da Etapa II

\begin{tabular}{|c|c|c|c|c|c|c|c|c|c|c|c|c|c|}
\hline \multirow[t]{2}{*}{ Fase } & \multirow[t]{2}{*}{ Variáveis } & \multicolumn{2}{|c|}{$\begin{array}{c}\mathrm{ST} \\
\left(\mathrm{mg} \cdot \mathrm{L}^{-1}\right)\end{array}$} & \multicolumn{2}{|c|}{$\begin{array}{c}\text { STF } \\
\left(\mathrm{mg} \cdot \mathrm{L}^{-1}\right) \\
\end{array}$} & \multicolumn{2}{|c|}{$\begin{array}{c}\text { STV } \\
\left(\mathrm{mg}^{\left.-\mathrm{L}^{-1}\right)}\right.\end{array}$} & \multicolumn{2}{|c|}{$\begin{array}{c}\text { SST } \\
\left(\mathrm{mg} . \mathrm{L}^{-1}\right)\end{array}$} & \multicolumn{2}{|c|}{$\begin{array}{c}\text { SSF } \\
\left(\mathrm{mg} \cdot \mathrm{L}^{-1}\right)\end{array}$} & \multicolumn{2}{|c|}{$\begin{array}{c}\text { SSV } \\
\left(\mathrm{mg} \cdot \mathrm{L}^{-1}\right)\end{array}$} \\
\hline & & Afl. & Efl. & Afl. & Efl. & Afl. & Efl. & Afl. & Efl. & Afl. & Efl. & Afl. & Efl. \\
\hline \multirow{5}{*}{1} & Média: & 640 & 1089 & 331 & 462 & 309 & 627 & 119 & 651 & 7 & 203 & 112 & 448 \\
\hline & Desvio padrão: & 212 & 522 & 187 & 297 & 48 & 228 & 10 & 379 & 1 & 169 & 9 & 210 \\
\hline & Mínimo: & 477 & 745 & 223 & 291 & 253 & 453 & 108 & 419 & 6 & 105 & 102 & 314 \\
\hline & Máximo: & 880 & 1690 & 547 & 805 & 340 & 885 & 127 & 1088 & 9 & 398 & 120 & 690 \\
\hline & $\mathrm{N}^{\circ}$ de amostras: & 3 & 3 & 3 & 3 & 3 & 3 & 3 & 3 & 3 & 3 & 3 & 3 \\
\hline \multirow{5}{*}{2} & Média: & 528 & 602 & 228 & 254 & 300 & 348 & 118 & 211 & 7 & 34 & 111 & 177 \\
\hline & Desvio padrão: & 112 & 135 & 43 & 39 & 80 & 103 & 19 & 66 & 4 & 18 & 16 & 49 \\
\hline & Mínimo: & 404 & 437 & 190 & 217 & 192 & 209 & 100 & 145 & 4 & 18 & 96 & 127 \\
\hline & Máximo: & 674 & 757 & 289 & 302 & 385 & 455 & 144 & 274 & 12 & 58 & 132 & 222 \\
\hline & $\mathrm{N}^{\circ}$ de amostras: & 4 & 4 & 4 & 4 & 4 & 4 & 4 & 4 & 4 & 4 & 4 & 4 \\
\hline \multirow{5}{*}{3} & Média: & 650 & 714 & 300 & 366 & 350 & 348 & 120 & 226 & 7 & 28 & 112 & 198 \\
\hline & Desvio padrão: & 118 & 271 & 129 & 215 & 32 & 82 & 8 & 90 & 3 & 12 & 6 & 79 \\
\hline & Mínimo: & 555 & 496 & 213 & 244 & 316 & 249 & 111 & 127 & 5 & 16 & 106 & 111 \\
\hline & Máximo: & 821 & 1099 & 493 & 688 & 378 & 419 & 126 & 306 & 11 & 40 & 120 & 270 \\
\hline & $\mathrm{N}^{\circ}$ de amostras: & 4 & 4 & 4 & 4 & 4 & 4 & 4 & 4 & 4 & 4 & 4 & 4 \\
\hline \multirow{5}{*}{4} & Média: & 596 & 597 & 223 & 250 & 374 & 348 & 153 & 218 & 13 & 25 & 140 & 193 \\
\hline & Desvio padrão: & 128 & 126 & 94 & 97 & 43 & 59 & 49 & 49 & 5 & 5 & 44 & 48 \\
\hline & Mínimo: & 438 & 481 & 104 & 127 & 333 & 280 & 105 & 175 & 7 & 18 & 98 & 148 \\
\hline & Máximo: & 819 & 785 & 405 & 418 & 448 & 459 & 217 & 316 & 22 & 33 & 200 & 293 \\
\hline & $\mathrm{N}^{\circ}$ de amostras: & 7 & 7 & 7 & 7 & 7 & 7 & 7 & 7 & 7 & 7 & 7 & 7 \\
\hline
\end{tabular}

Conforme a Figura 5.24, o sistema, de modo geral, não baixa eficiência na remoção de sólidos totais, fixos e voláteis. Geralmente, o efluente apresentou concentrações superiores de sólidos totais, fixos e voláteis, em relação ao afluente. Algumas vezes, o sistema apresentou eficiências na remoção de totais voláteis, mas isso chegou a ser desprezível.

No caso dos sólidos totais fixos, ocorria o carreamento de partículas de areia com densidades menores, visto que o material acrescentado ao sistema para aumentar o material suporte não foi classificado previamente.

Fdz-Polanco; Real e Garcia (1994) comentaram que sistemas leito fluidificado/expandido aeróbio e, principalmente para os casos nos quais ocorrem ambientes anaeróbio e aeróbio sobrepostos, é comum serem relatados arrastes significativos de sólidos junto com o efluente, devido à aplicação de altas taxas superficiais. 


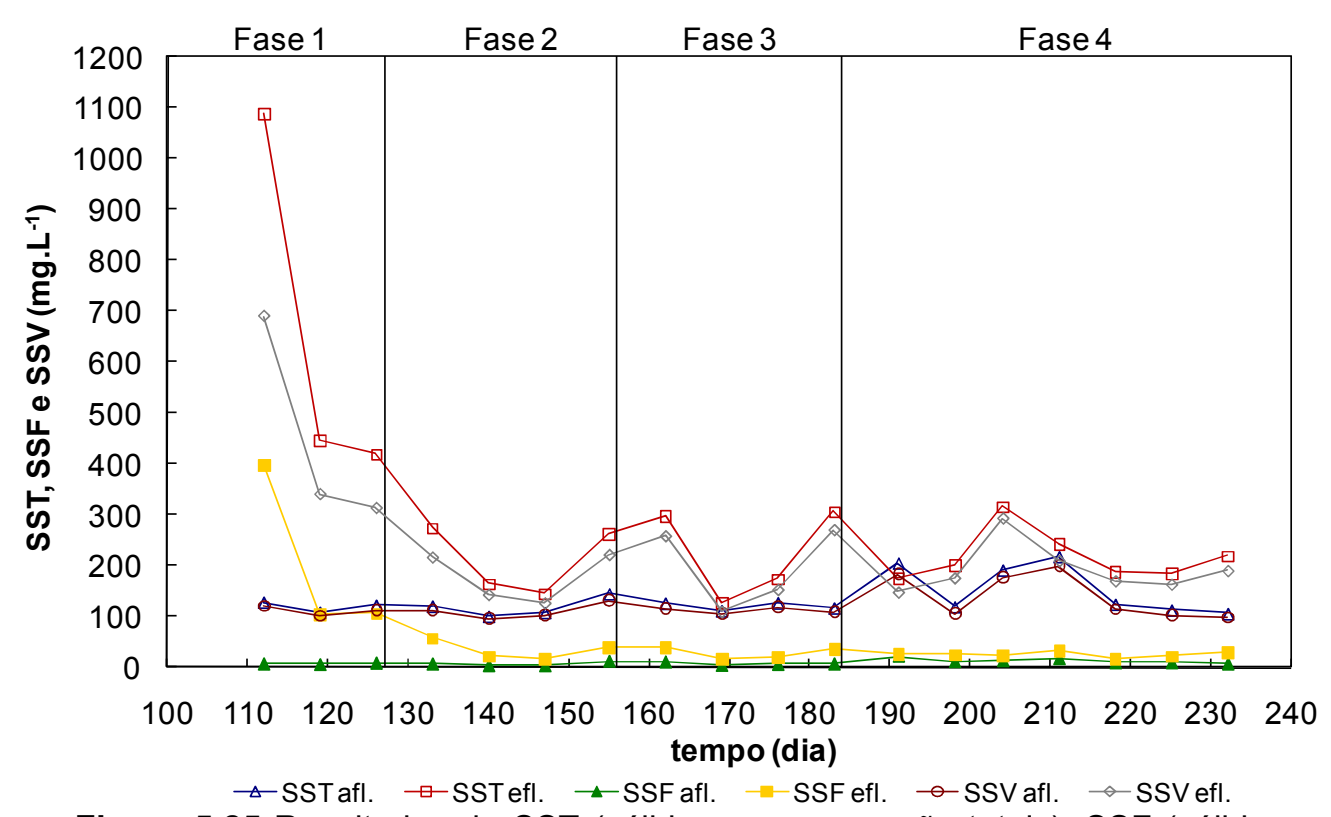

Figura 5.25 Resultados de SST (sólidos em suspensão totais), SSF (sólidos em suspensão fixos) e SSV (sólidos em suspensão voláteis) do afluente e do efluente do reator anaeróbio-aeróbio de leito expandido, para as Fases 1; 2; 3 e 4 da Etapa II

O mesmo fato ocorreu para os sólidos em suspensão, conforme mostrado na Figura 5.25, o sistema não apresentou baixa eficiência na remoção de sólidos em suspensão totais, fixos e voláteis.

Observa-se que aproximadamente $85 \%$ dos sólidos em suspensão são formados por material orgânico, de acordo com a Figura 5.26, em que se mostra a relação SSVISST para o afluente e efluente. Ou seja, nota-se, que o decantador não está sendo eficiente na sedimentação do lodo biológico. 


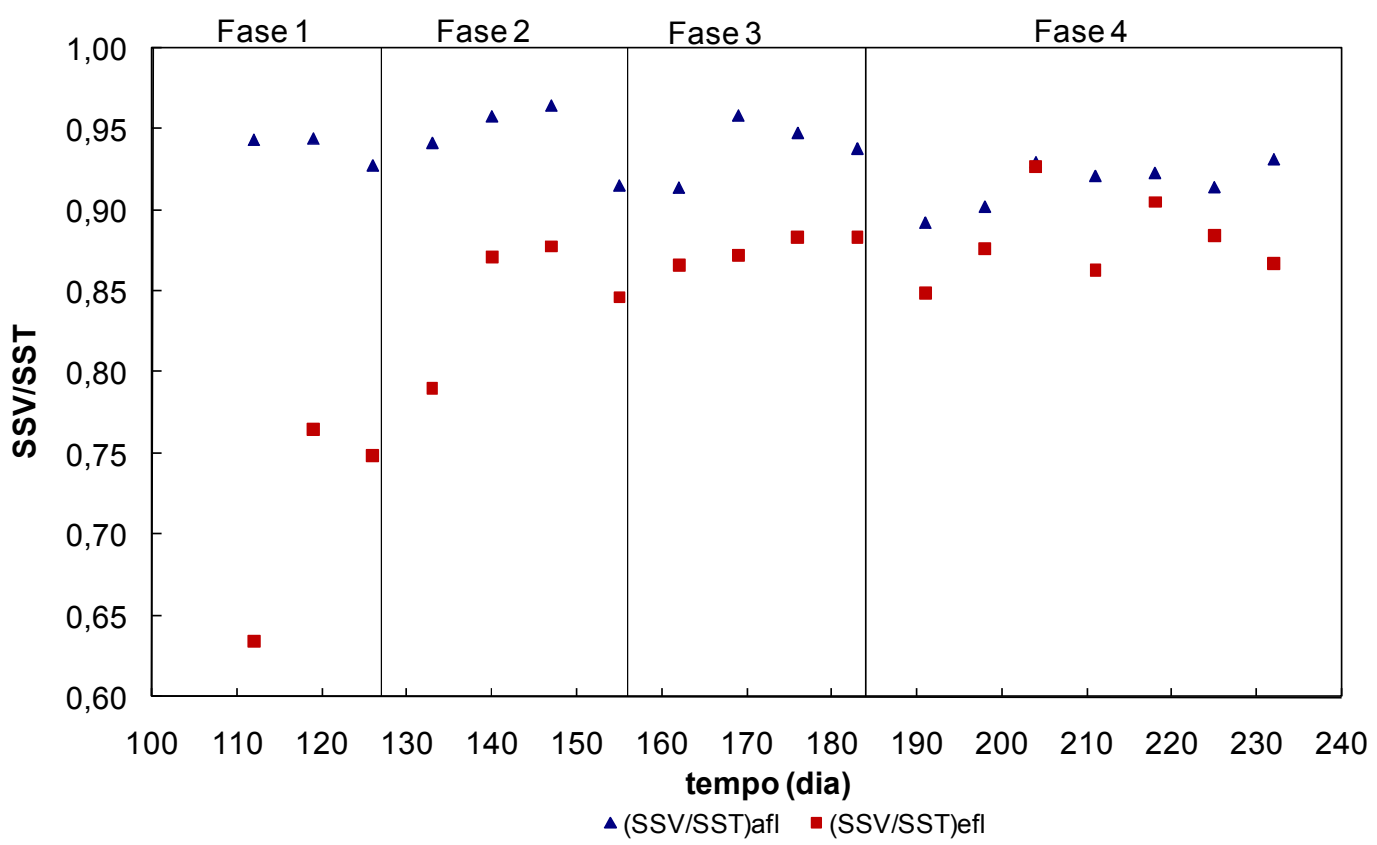

Figura 5.26 Relação SSVISST (sólidos em suspensão voláteis/sólidos em suspensão totais) do afluente e do efluente do reator anaeróbio-aeróbio de leito expandido, para as Fases 1; 2; 3 e 4 da Etapa II

As concentrações de NKT, N-amoniacal e N-orgânico, em função do tempo de operação, para o afluente e efluente, nas Fases 1; 2; 3 e 4 da Etapa II do reator anaeróbio-aeróbio de leito expandido, são apresentadas nas Figuras 5.27.

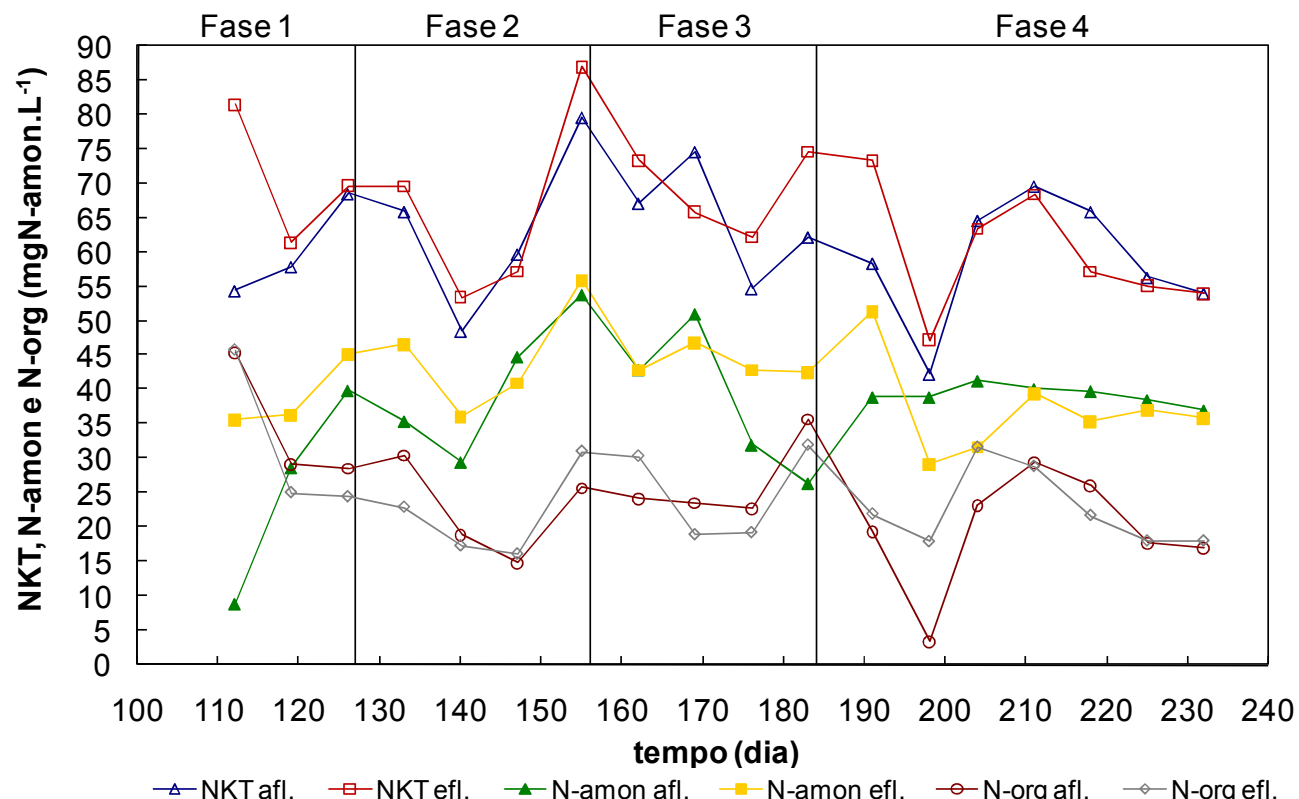

Figura 5.27 Resultados de NKT (nitrogênio Kjeldahl total), N-amon (nitrogênio amoniacal) e N-org (nitrogênio orgânico) do afluente e do efluente do reator anaeróbio-aeróbio de leito expandido, para as Fases 1; 2; 3 e 4 da Etapa II 
Na Tabela 5.13 são apresentados os valores médios, desvios padrões, valores mínimos e máximos e número de dados considerados na análise estatística para os resultados de nitrogênio e fósforo, da Etapa II.

Tabela 5.13 Valores médios, desvios padrões, valores mínimos e máximos e números de dados analisados de nitrogênio e fósforo das Fases 1; 2; 3 e 4, da Etapa II

\begin{tabular}{|c|c|c|c|c|c|c|c|c|c|c|c|}
\hline \multirow[t]{2}{*}{ Fase } & \multirow[t]{2}{*}{ Variáveis } & \multicolumn{2}{|c|}{$\begin{array}{c}\text { NKT } \\
\left(\mathrm{mg} \cdot \mathrm{L}^{-1}\right)\end{array}$} & \multicolumn{2}{|c|}{$\begin{array}{l}\mathrm{NKT}_{\text {filt }} \\
\left(\mathrm{mg} \cdot \mathrm{L}^{-1}\right)\end{array}$} & \multicolumn{2}{|c|}{$\begin{array}{c}\mathrm{N} \text {-amoniacal } \\
\left(\mathrm{mg} \cdot \mathrm{L}^{-1}\right)\end{array}$} & \multicolumn{2}{|c|}{$\begin{array}{c}\text { N-orgânico } \\
\left(\text { mg. }^{-1}\right)\end{array}$} & \multicolumn{2}{|c|}{$\begin{array}{c}\mathbf{P} \\
\left(\mathrm{mg} \cdot \mathrm{L}^{-1}\right)\end{array}$} \\
\hline & & Afl. & Efl. & Afl. & Efl. & Afl. & Efl. & Afl. & Efl. & Afl. & Efl. \\
\hline \multirow{5}{*}{1} & Média: & 60,3 & 70,9 & - & - & 25,8 & 39,1 & 34,4 & 31,8 & 6,3 & 7,8 \\
\hline & Desvio padrão: & 7,3 & 10,1 & - & - & 15,7 & 5,3 & 9,6 & 12,1 & 0,1 & 1,2 \\
\hline & Mínimo: & 54,4 & 61,4 & - & - & 8,9 & 35,7 & 28,6 & 24,5 & 6,1 & 6,8 \\
\hline & Máximo: & 68,5 & 81,5 & - & - & 39,9 & 45,2 & 45,5 & 45,8 & 6,4 & 9,0 \\
\hline & $\mathrm{N}^{\circ}$ de amostras: & 3 & 3 & - & - & 3 & 3 & 3 & 3 & 3 & 3 \\
\hline \multirow{5}{*}{2} & Média: & 63,4 & 66,8 & 51,2 & 52,3 & 40,9 & 44,9 & 22,6 & 21,9 & 6,2 & 6,0 \\
\hline & Desvio padrão: & 13,0 & 15,1 & 15,7 & 8,6 & 10,7 & 8,5 & 6,9 & 6,8 & 1,4 & 1,1 \\
\hline & Mínimo: & 48,5 & 53,5 & 34,8 & 43,5 & 29,5 & 36,1 & 14,9 & 16,2 & 4,6 & 4,6 \\
\hline & Máximo: & 79,6 & 87,0 & 70,9 & 63,4 & 53,8 & 55,9 & 30,5 & 31,1 & 7,9 & 7,2 \\
\hline & $\mathrm{N}^{\circ}$ de amostras: & 4 & 4 & 4 & 4 & 4 & 4 & 4 & 4 & 4 & 4 \\
\hline \multirow{5}{*}{3} & Média: & 64,7 & 69,0 & 55,3 & 51,0 & 38,1 & 43,8 & 26,6 & 25,2 & 6,2 & 6,4 \\
\hline & Desvio padrão: & 8,4 & 5,9 & 6,6 & 3,7 & 11,0 & 2,1 & 6,2 & 7,0 & 0,4 & 0,7 \\
\hline & Mínimo: & 54,7 & 62,2 & 47,2 & 47,2 & 26,4 & 42,6 & 22,7 & 19,0 & 5,7 & 5,8 \\
\hline & Máximo: & 74,6 & 74,6 & 63,4 & 55,9 & 51,0 & 46,9 & 35,8 & 32,0 & 6,5 & 7,4 \\
\hline & $\mathrm{N}^{\circ}$ de amostras: & 4 & 4 & 4 & 4 & 4 & 4 & 4 & 4 & 4 & 4 \\
\hline \multirow{5}{*}{4} & Média: & 58,7 & 59,8 & 49,2 & 43,9 & 39,2 & 37,1 & 19,5 & 22,7 & 5,6 & 5,9 \\
\hline & Desvio padrão: & 9,2 & 9,0 & 4,1 & 5,1 & 1,4 & 7,1 & 8,4 & 5,6 & 0,7 & 0,7 \\
\hline & Mínimo: & 42,3 & 47,2 & 41,3 & 38,5 & 37,0 & 29,2 & 3,4 & 18,0 & 4,6 & 4,9 \\
\hline & Máximo: & 69,6 & 73,3 & 53,5 & 52,2 & 41,3 & 51,3 & 29,5 & 31,7 & 6,3 & 6,7 \\
\hline & $\mathrm{N}^{\circ}$ de amostras: & 7 & 7 & 7 & 7 & 7 & 7 & 7 & 7 & 7 & 7 \\
\hline
\end{tabular}

A concentração de NKT do efluente foi, na maioria das vezes, superior a do afluente. Isso indica que ocorreu perda de material biológico no sistema, ocasionado, provavelmente, pelo arraste de sólidos retidos nos interstícios do leito.

De forma geral, o sistema apresentou baixa eficiência na oxidação do nitrogênio amoniacal. Durante a Fase 4 de operação do sistema, no $198^{\circ}$ dia, o reator apresentou eficiência de $25 \%$ de oxidação do nitrogênio amoniacal, as concentrações de nitrito e nitrato encontradas foram de aproximadamente 4,0 mgN-NO${ }_{2}^{-} \cdot \mathrm{L}^{-1}$ e $2,0 \mathrm{mgN}-\mathrm{NO}_{3}^{-} \cdot \mathrm{L}^{-1}$, respectivamente. O $\mathrm{pH}$ (Figura 5.16) mantevese no valor 7,0 , enquanto a alcalinidade neste período decaiu, conforme visualizada na Figura 5.17. Nas semanas seguintes, a eficiência oscilou consideravelmente, 
mostrando grande instabilidade no sistema. Durante este período apareceram apenas traços de nitrito e nitrato no efluente.

Na Figura 5.28 são mostradas as relações $\mathrm{N}$-amon/NKT do afluente e do efluente bruto e filtrado.

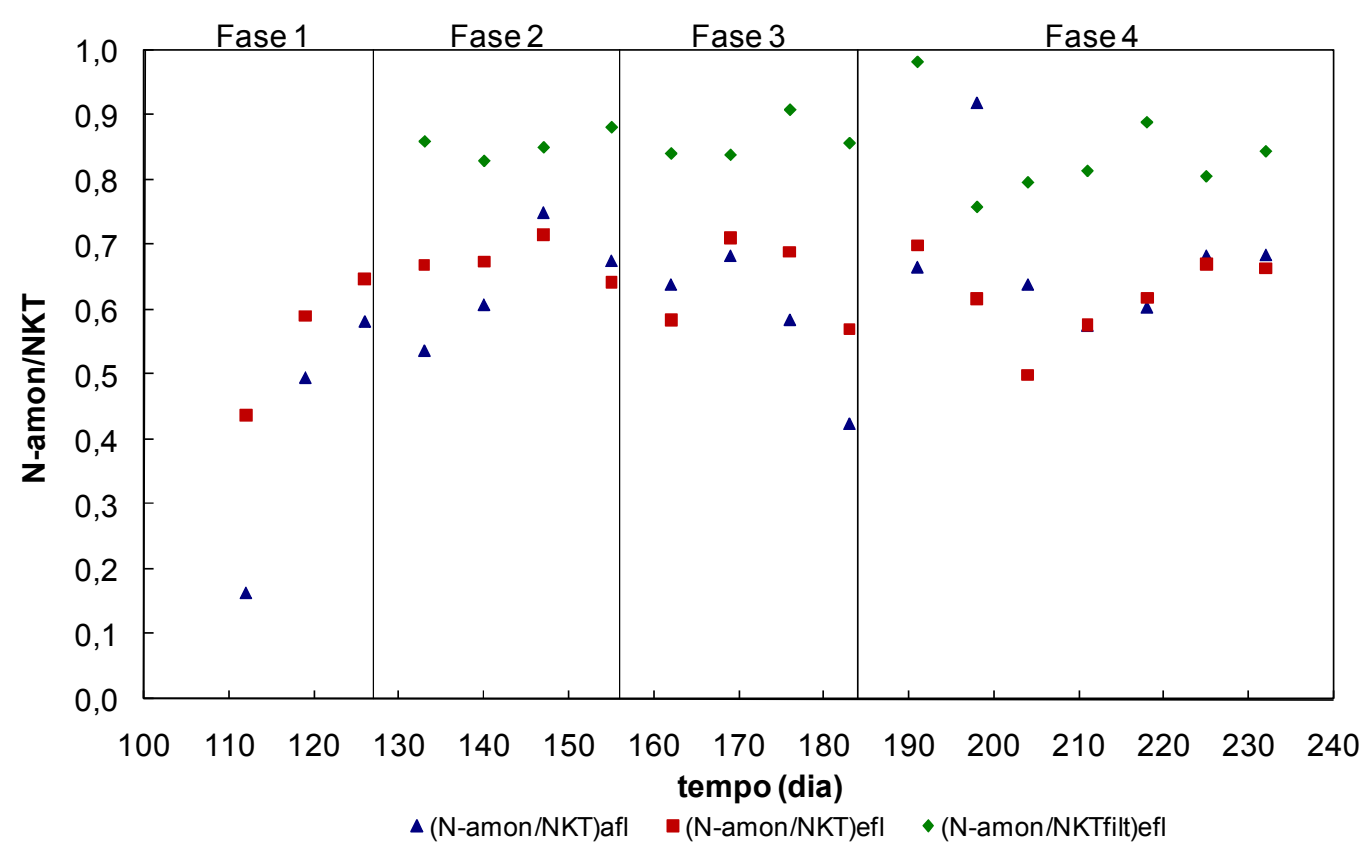

Figura 5.28 Relação N-amon/NKT (nitrogênio amoniacal/nitrogênio Kjeldahl total) do afluente e do efluente bruto e filtrado do reator anaeróbio-aeróbio de leito expandido, para as fases $1 ; 2 ; 3$ e 4 da etapa II

Pela Figura 5.28, observa-se que o grau de amonificação do sistema foi, em média, $65 \%$. Visto pela grande perda de sólidos no sistema, decidiu-se realizar a análise de NKT do efluente filtrado, para avaliar a interferência dos mesmos. Nota-se que, a partir desse procedimento, o grau de amonificação do sistema foi, em média de $85 \%$, indicando a grande interferência de material biológico "arrastado" no sistema.

Siman (2007) operando o mesmo reator desta pesquisa, sob condições anaeróbia-aeróbia sobrepostas, com TDH médio de $8,8 \mathrm{~h}$, obteve grau de amonificação de $89 \%$ quando o sistema foi operado sob carregamento médio volumétrico de $0,13 \mathrm{kgNKT} \cdot \mathrm{m}^{-3} \cdot \mathrm{dia}^{-1}$. O autor comenta que o sistema também não apresentou eficiência na nitrificação, ou seja, a ausência das formas oxidadas do 
nitrogênio $\left(\mathrm{NO}_{2}^{-}\right.$e $\left.\mathrm{NO}_{3}{ }^{-}\right)$. Isso ocorreu, provavelmente pela baixa concentração de oxigênio dissolvido no sistema aeróbio, visto que a concentração de OD na saída do sistema (decantador) era praticamente zero.

Na Figura 5.29 são mostrados os resultados de fósforo no afluente e no efluente do reator anaeróbio-aeróbio de leito expandido.

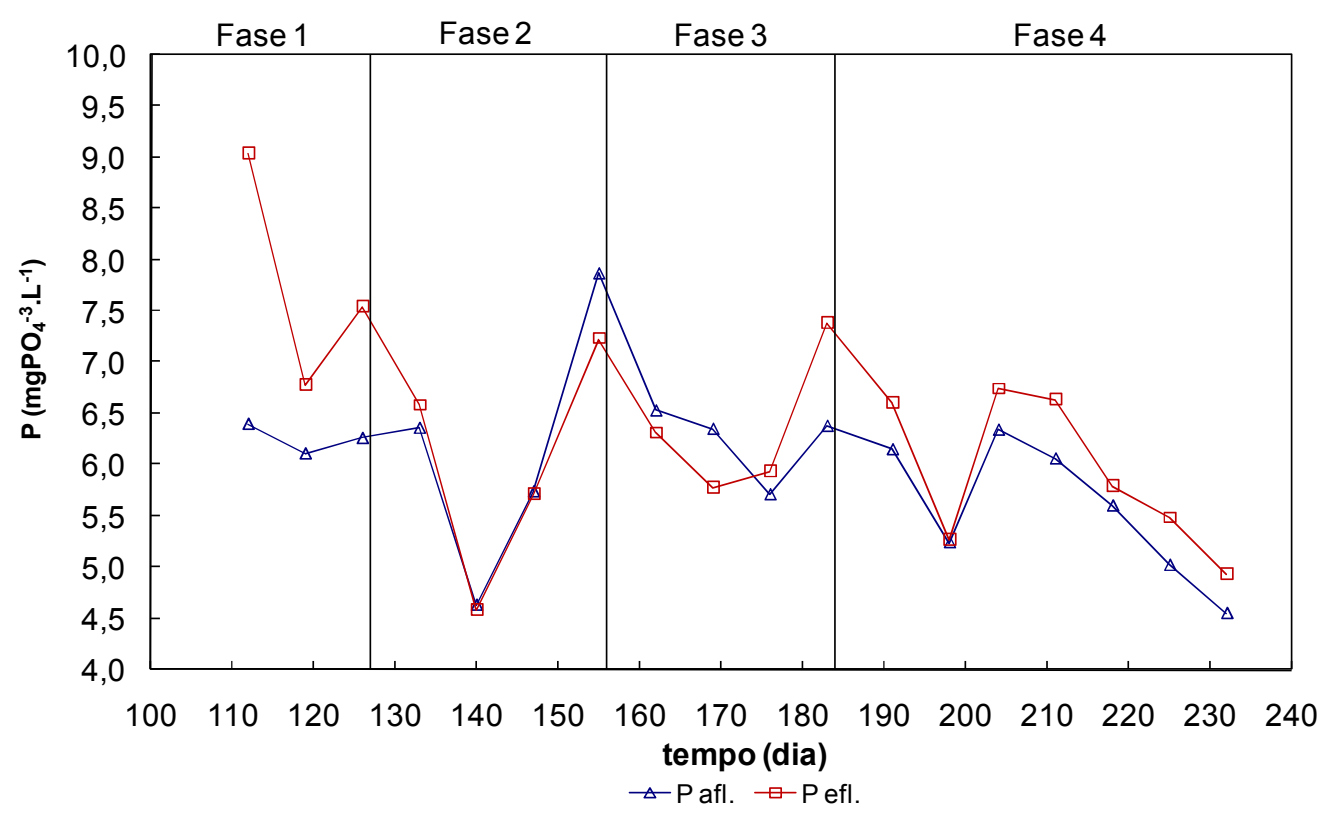

Figura 5.29 Resultados de $P$ (fósforo) do afluente e do efluente do reator anaeróbio-aeróbio de leito expandido, para as Fases 1; 2; 3 e 4 da Etapa II

A concentração média de fósforo no efluente foi de $6,5 \mathrm{mgP}-\mathrm{PO}_{4}{ }^{-3} \cdot \mathrm{L}^{-1}$. O sistema apresentou eficiência relativamente baixa de remoção de fósforo. Ao passo que, houve períodos, cujas concentrações de fósforo no efluente foram maiores que as do afluente, devido ao arraste de sólidos biológicos. 


\subsubsection{Análise Global dos Resultados Obtidos durante a Etapa II}

Durante a Fase 1, da Etapa II, o sistema não apresentou eficiência na remoção de matéria orgânica, em termos de DQO, visto pela provável perda de material biológico de difícil degradabilidade.

As cargas orgânicas volumétricas médias ( $\left.\mathrm{COV}_{\text {média }}\right)$ aplicadas durante as Fases 2; 3 e 4 foram de 1,23; 0,84 e 0,67 kgDQO bruta. $\mathrm{m}^{-3} \cdot \mathrm{dia}^{-1}$, respectivamente. As $\mathrm{COVs}_{\text {médias }}$ removidas do sistema foram de $0,22 \mathrm{kgDQO}$ bruta. $\mathrm{m}^{-3} \cdot \mathrm{dia}^{-1}$ (Fase 2), 0,29 kgDQO $\mathrm{bruta} \cdot \mathrm{m}^{-3} \cdot \mathrm{dia}^{-1}$ (Fase 3) e 0,23 kgDQO $\mathrm{kruta} \cdot \mathrm{m}^{-3} \cdot \mathrm{dia}^{-1}$ (Fase 4). Nota-se, que o sistema obteve maior eficiência na remoção de matéria orgânica, em termos de DQO, durante a Fase 3.

Em termos de DBO, as COVs $s_{\text {médias }}$ durante a Fase 1; 2; 3 e 4 foram de 1,16; 0,$75 ; 0,50$ e $0,41 \mathrm{kgDBO}$ bruta. $\mathrm{m}^{-3} \cdot \mathrm{dia}^{-1}$, respectivamente. Ao contrário do ocorrido com a DQO, houve remoção de matéria orgânica, em termos de DBO, durante a Fase 1, da Etapa II. A COV média removida foi de $0,23 \mathrm{kgDBO}_{\text {bruta }} \cdot \mathrm{m}^{-3} \cdot \mathrm{dia}^{-1}$. Já para a Fase 2; 3 e 4 as COVs $_{\text {médias }}$ removidas foram de 0,36; 0,30 e 0,26 $\mathrm{kgDBO}_{\text {bruta. }} \mathrm{m}^{-3} \cdot \mathrm{dia}^{-1}$, respectivamente.

Durante a Etapa II, o sistema apresentou baixa eficiência na remoção de sólidos totais e sólidos em suspensão. As taxas de aplicação hidráulica durante as Fases $1 ; 2 ; 3$ e 4 foram de 30,$4 ; 20,3 ; 15,1$ e $12,2 \mathrm{~m}^{3} \cdot \mathrm{m}^{-2} \cdot \mathrm{dia}^{-1}$, respectivamente. Mesmo com a redução da taxa de aplicação hidráulica, o decantador foi incapaz de desempenhar sua função. Além disso, foi visível o efeito da aplicação de ar no sistema, que veio maximizar o problema da sedimentação do material sólido no decantador, pois devido à quantidade de ar aplicada, criou-se turbulência na região de sedimentação do sistema, não permitindo a retenção de sólidos biológicos. 
O grau de amonificação obtido, durante as Fases 2; 3 e 4, da Etapa II, foi de $86 \%$. Isso evidenciou a capacidade do sistema em promover a amonificação do esgoto sanitário.

\subsubsection{Comparação dos Resultados da Etapa I e II}

O sistema obteve maior eficiência de remoção de matéria orgânica, em termos de DQO, durante a Fase 1, da Etapa I, sendo que a $\mathrm{COV}_{\text {média }}$ removida foi de $0,84 \mathrm{kgDQO}$ bruta. $\mathrm{m}^{-3} \cdot \mathrm{dia}^{-1}$, quando se aplicou $\mathrm{COV}_{\text {média }}$ de $1,26 \mathrm{kgDQO}$ bruta. $\mathrm{m}^{-3} \cdot \mathrm{dia}^{-1}$. Esse valor foi bem superior ao apresentado pela melhor fase da Etapa II, Fase 3, que foi de $0,29 \quad \mathrm{kgDQO}$ bruta $\cdot \mathrm{m}^{-3} \cdot \mathrm{dia}^{-1}$, quando se aplicou $\mathrm{COV}_{\text {média }}$ de $0,84 \mathrm{kgDQO}$ bruta. $\mathrm{m}^{-3} \cdot \mathrm{dia}^{-1}$.

Segundo Wastewater... (2003) a COV aplicada em reatores de leito fluidificado/expandido varia de 1 a $30 \mathrm{kgDQO} \cdot \mathrm{m}^{-3} \cdot \mathrm{dia}^{-1}$. Comparando-se essa faixa com as COVs aplicadas nas duas etapas de operação do sistema, nota-se, que a COV aplicada na Etapa I está próxima ao valor mínimo, enquanto que a COV aplicada na Etapa II, foi inferior à faixa utilizada para reatores com essa configuração. A título de comparação, a COV para reatores UASB é de 2,4 a 12 kgDQO.m $\mathrm{m}^{-3} \cdot \mathrm{dia}^{-1}$ (WASTEWATER..., 2003), ou seja, tanto para a Etapa I, quanto para a Etapa II as COVs aplicadas ao sistema foi inferior à faixa utilizada em reatores de manta de lodo.

Durante a Etapa II houve baixíssima eficiência na remoção de sólidos totais, ao contrário do ocorrido, durante a Etapa I, que mesmo que relativamente pequena, o sistema apresentou eficiências de remoção de sólidos totais de $30 \%$. Observa-se que durante as duas etapas de operação do sistema, o decantador não 
desempenhou sua função de maneira satisfatória, sendo que isso foi intensificado com a aplicação de ar, durante a Etapa II, prejudicando, ainda mais a sedimentação dos sólidos, pois se observou a criação de uma zona de turbulência na região de sedimentação, maximizando ainda mais a ineficiência do sistema de sedimentação de partículas.

O grau de amonificação obtido, durante a Etapa I foi de $90 \%$ e para a Etapa II, esse valor foi de $86 \%$. Isso demonstra que, durante as duas etapas de operação, o sistema foi eficiente no processo de amonificação do esgoto sanitário.

\subsubsection{Perfis de Amostras ao Longo da Altura do Reator}

Foram realizadas três coletas de amostras, em três pontos de amostragem distribuídos ao longo da altura do reator, conforme relatado anteriormente (item 4.7). Essas amostras foram úteis para verificar a presença de zonas reacionais anaeróbia e aeróbia no reator de leito expandido.

Como citado anteriormente, o perfil 1, foi realizado no final da Fase 1 da Etapa I, já os perfis 2 e 3, foram realizados no final da Fase 3 e 4, da Etapa II, respectivamente.

Conforme comentado no item 4.7, para a realização dos perfis ao longo da altura do reator, foram escolhidos os pontos 3; 5 e 7 para a coleta de amostras pontuais. Os pontos 3; 5 e 7 ficam localizados 5,0; 7,0 e 9,0 m das base do reator (Figura 4.11).

Nas Figuras $5.30 ; 5.31$ e 5.32 são representados os resultados de $\mathrm{pH}$, alcalinidade e AGV obtidos nos perfis realizados ao longo da altura do reator, respectivamente. 


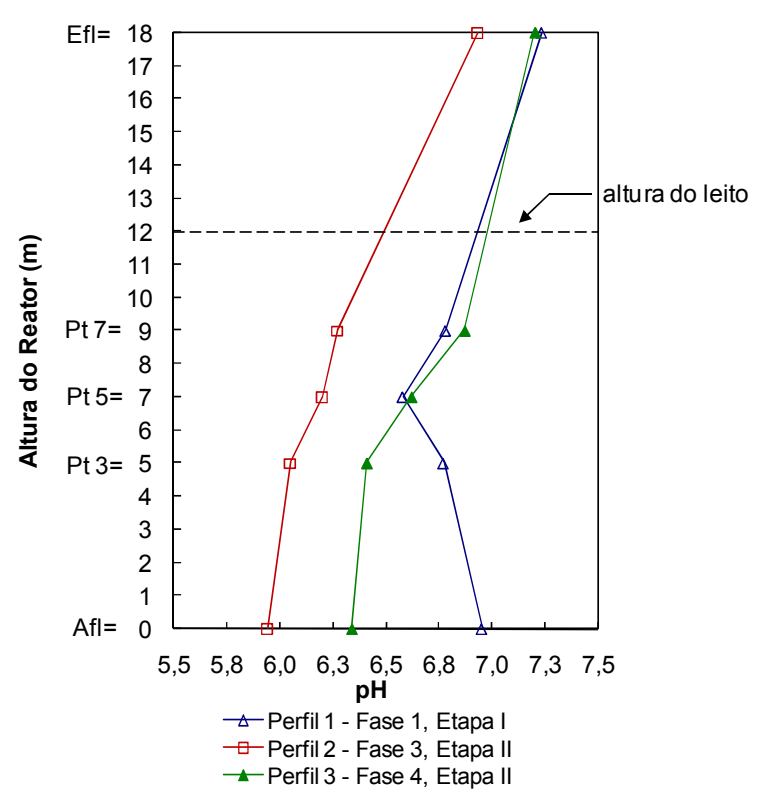

Figura 5.30 Resultados de pH do perfil 1; 2 e 3

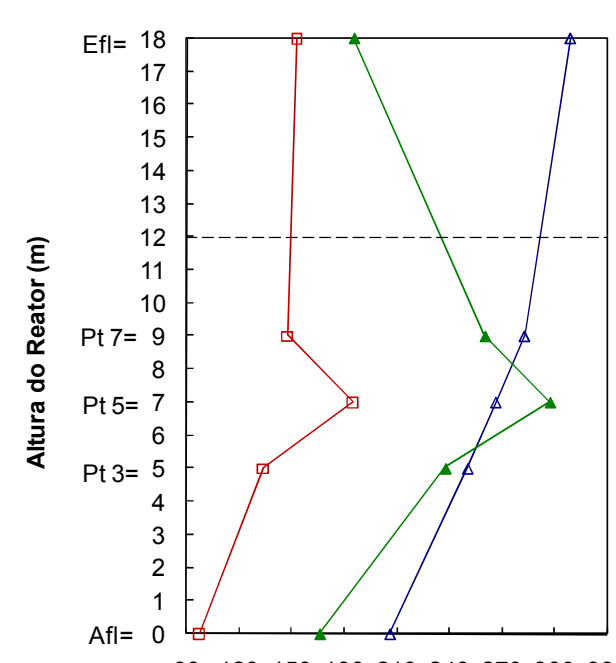

$9012015018021024027030033 C$ AT $\left(\mathrm{mgCaCO}_{3} \cdot \mathrm{L}^{-1}\right)$

(a)

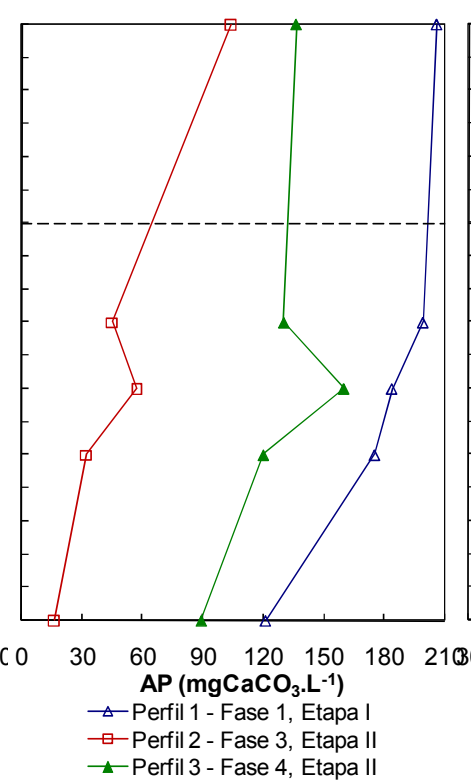

(b)

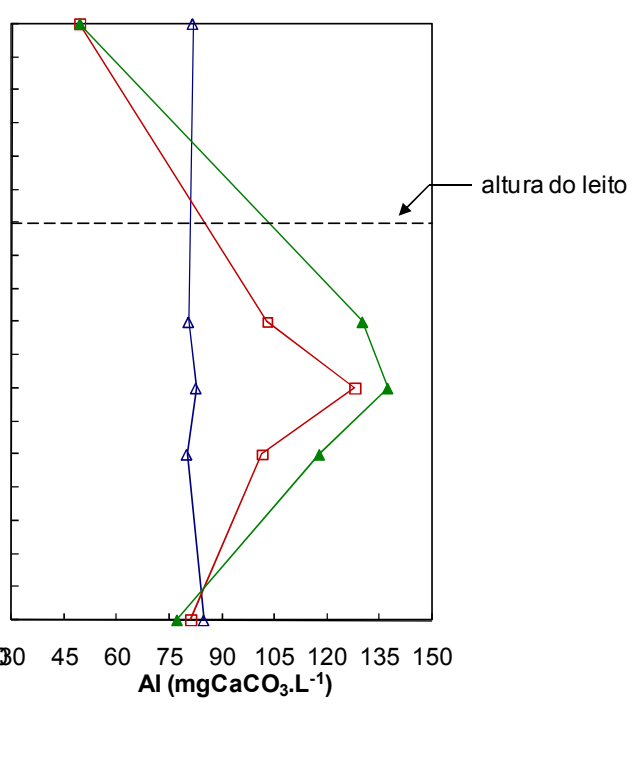

(c)

Figura 5.31 Resultados de alcalinidade total (a), alcalinidade parcial (b) e alcalinidade intermediária (c) do perfil 1; 2 e 3

$\mathrm{O} \mathrm{pH}$ no perfil 1, realizado no final da Fase 1, da Etapa I, quando o reator foi operado somente sob a fase anaeróbia, variou de 6,9 a 7,2.

Vale ressaltar, que as coletas do afluente e do efluente foram compostas de alíquotas coletadas ao longo de 24 horas, enquanto que as coletas dos perfis (ponto 3; 5 e 7) foram amostras pontuais. 
Observa-se na Figura 5.31, que houve produção de alcalinidade, durante os perfis 2 e 3 na região anaeróbia (ponto 3), realizados, respectivamente, no final das Fases 3 e 4, da Etapa II. Enquanto na região aeróbia (ponto 5 e 7) houve consumo de alcalinidade total.

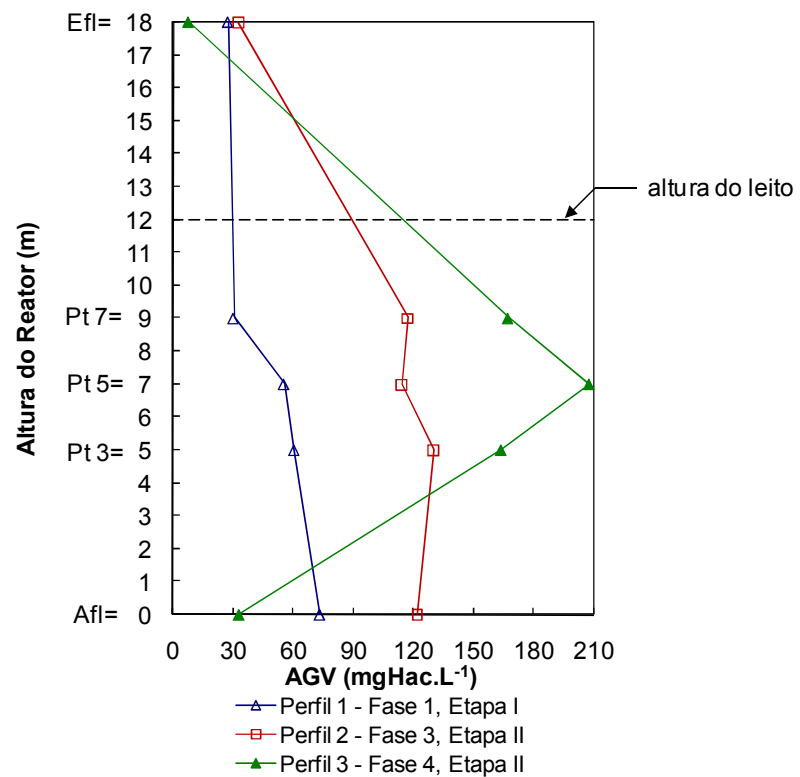

Figura 5.32 Resultados de AGV (ácidos graxos voláteis) do perfil 1; 2 e 3

Pela Figura 5.32, nota-se que houve consumo de AGV obtido durante os perfis 1 e 2. Enquanto houve geração do mesmo, ao longo da altura, no perfil 3, embora avaliando somente o afluente e o efluente do sistema, observa-se que houve consumo de AGV. Essa geração de AGV pode ter sido ocasionada pela coleta de amostra que estivesse estagnada em uma zona morta dentro do reator.

$\mathrm{Na}$ Figura 5.33 são mostradas as curvas de variação dos resultados de $\mathrm{DQO}_{\text {filtrada }}$ e $\mathrm{DBO}_{\text {filtrada }}$ obtidos durantes os perfis $1 ; 2$ e 3. 


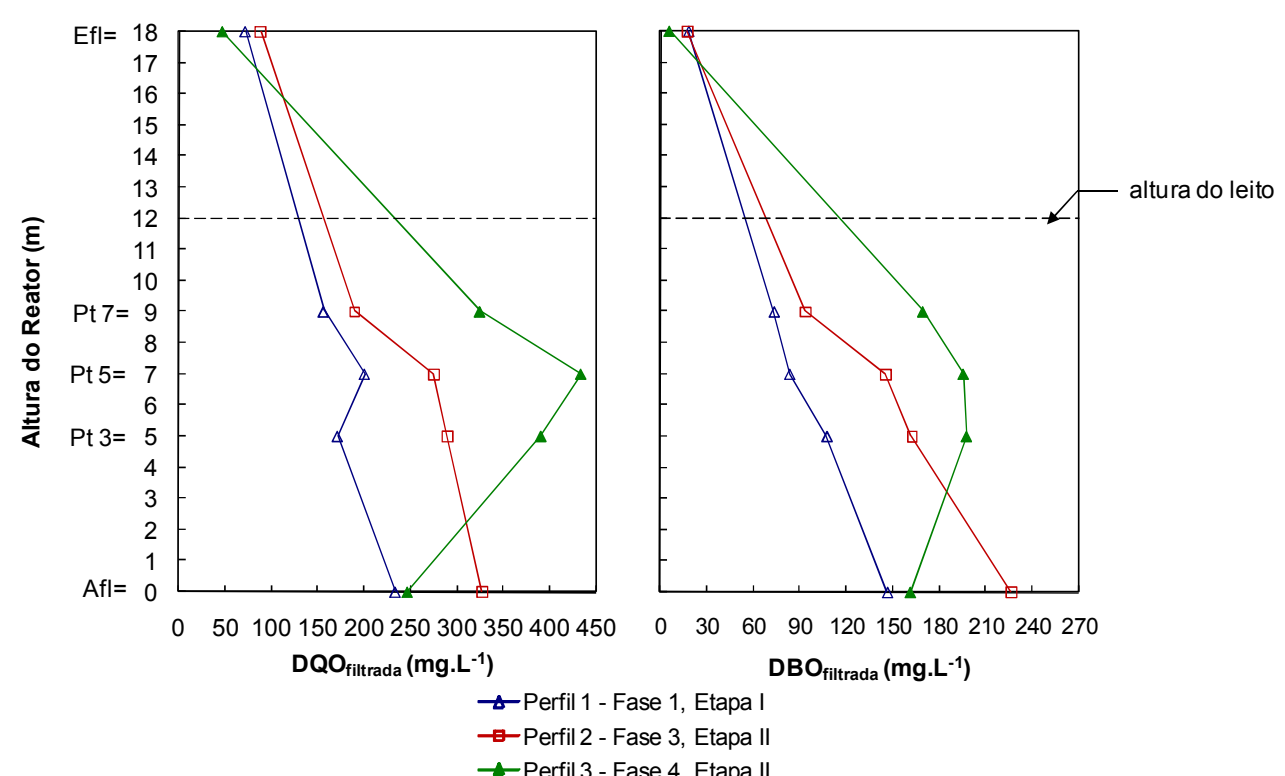

(a)

(b)

Figura 5.33 Resultados de $\mathrm{DQO}_{\text {filtrada }}$ (a) e $\mathrm{DBO}_{\text {filtrada }}$ do perfil $1 ; 2$ e 3

Durante o levantamento dos perfis 1 e 2 , houve decaimento, tanto da $D Q O_{\text {filtrada, }}$ quanto da $\mathrm{DBO}_{\text {filtrada. }}$. Como ocorrido com o $\mathrm{AGV}$, o perfil 3 da $\mathrm{DQO}_{\text {filtrada }} \mathrm{e}$ $\mathrm{DBO}_{\text {filtrada }}$ apresentou certas incongruências. Conforme, a Figura 5.33, ocorre o aumento da $\mathrm{DQO}_{\text {filtrada }}$ e da $\mathrm{DBO}_{\text {filtrada }}$ na região anaeróbia, enquanto na região aeróbia tende ocorrer a redução dos mesmos parâmetros, sendo que o valor no efluente, no perfil 3, é de $47 \mathrm{mgDQO}_{\text {fitt }} \mathrm{L}^{-1}$ e $6 \mathrm{mgDBO}_{\text {fitt }} \mathrm{L}^{-1}$.

De um modo geral, a relação $\mathrm{DBO} / \mathrm{DQO}$ tendeu a decrescer ao longo da altura do reator, durante os três perfis. Em média, a relação DBO/DQO no ponto 3 foi de 0,55 , enquanto que, para o ponto 7 , foi de 0,45 . Isso indica que o líquido ao longo da altura do reator foi se tornando mais lentamente biodegradável, visto que a relação DBO/DQO do efluente foi em média 0,20.

Nas Figuras 5.34 e 5.35 são mostrados, respectivamente, os resultados das concentrações de nitrogênio e de fósforo, durante os perfis realizados ao longo da altura do reator. 


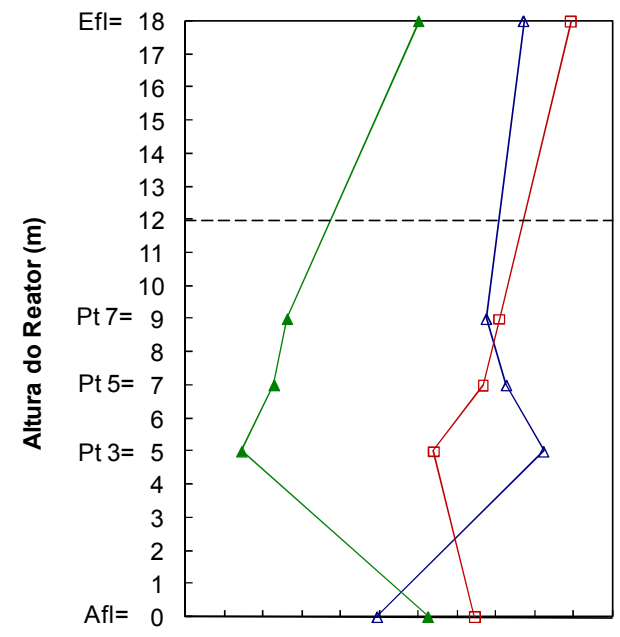

253035404550556065
NKT (mgN-amon.L-1)

(a)

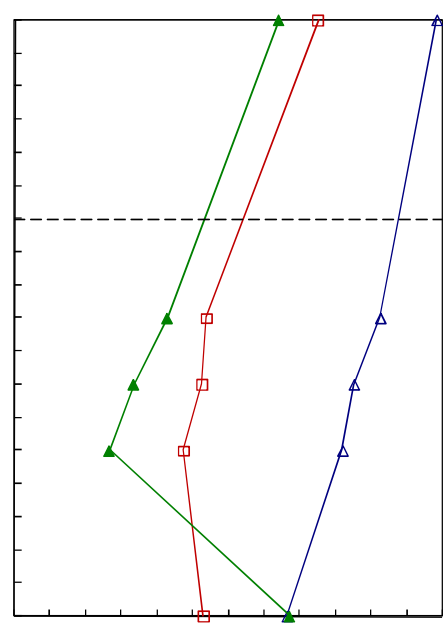

1015202530354045505560 $\mathrm{N}$-amon (mgN-amon. $\left.\mathbf{L}^{-1}\right)$
$\triangle$ Perfil 1 - Fase 1, Etapa I

$\triangle$ Perfil 1 - Fase 1, Etapa I
$\square$ Perfil 2 - Fase 3, Etapa II

$\rightarrow$ Perfil 3 - Fase 4, Etapa II

(b)

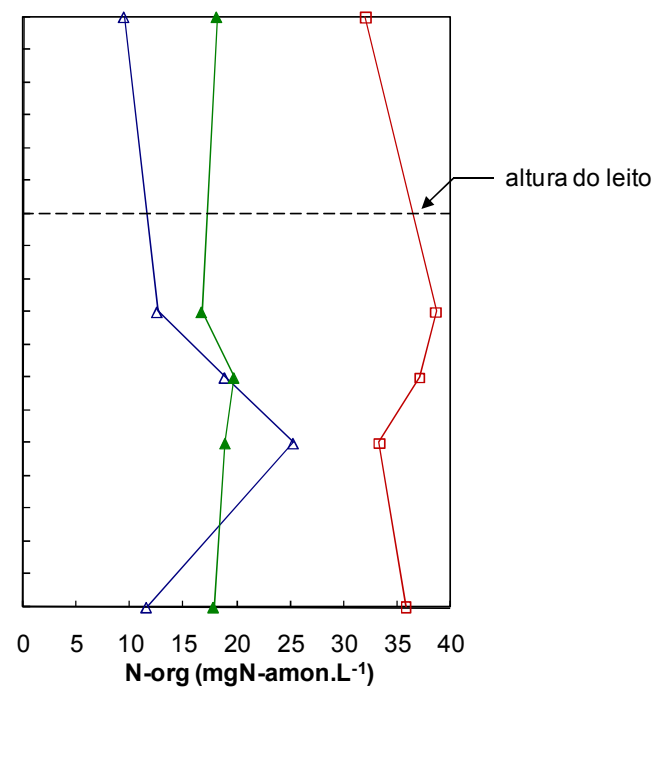

(c)

Figura 5.34 Resultados de nitrogênio Kjeldahl total (a), nitrogênio amoniacal (b) e nitrogênio orgânico (c) do perfil 1; 2 e 3

O grau de amonificação, no perfil 1, foi crescente, conforme Figura 5.34. No ponto 3 , houve $65 \%$ de amonificação, enquanto no ponto 7 esse valor foi de $80 \%$. Já no perfil 2, esse valor tornou-se aproximadamente constante, com valor de $40 \%$.

No perfil 3, inicialmente houve queda na concentração do nitrogênio, que voltou a se estabilizar a partir do ponto 5 , isso pode ter ocorrido, provavelmente, como comentado nos resultados de $\mathrm{AGV}, \mathrm{DQO}_{\text {filtrada }}$ e $\mathrm{DBO}_{\text {filtrada, }}$ a coleta de amostra estagnada em uma possível zona morta dentro reator.

Nos perfis 2 e 3, observa-se, que não houve nitrificação no sistema, visto que não foi encontrado nitrogênio na forma de nitrito nem de nitrato. Além disso, nota-se que a concentração de $\mathrm{N}$-amon ao longo da altura do reator tendeu-se a aumentar, indicando a ocorrência do processo de amonificação.

No perfil 2, a relação DBO/NKT (ponto 5) foi de aproximadamente 2,3. Segundo Wastewater... (2003), quando os valores da relação DBO/NKT são menores que 3, ocorre predominantemente o processo de nitrificação. Essa relação 
foi observada no sistema, durante a Fase 3, da Etapa II (perfil 2), embora no sistema não foi observado a ocorrência de tal processo.

A concentração do N-org, com exceção do perfil 1, manteve-se aproximadamente constante ao longo da altura do reator (Figura 5.34).

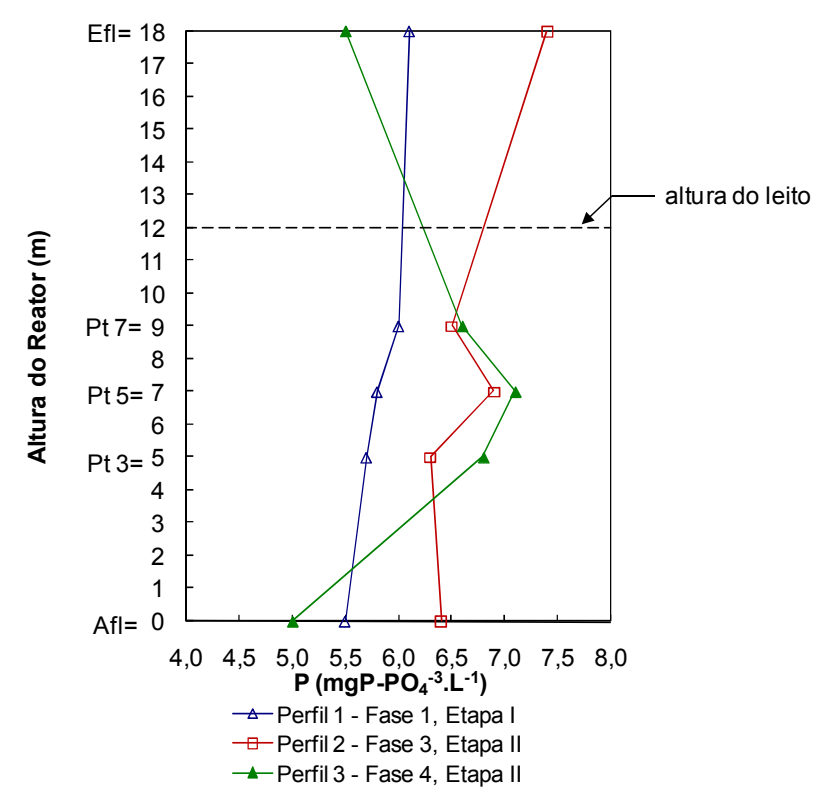

Figura 5.35 Resultados de $\mathrm{P}$ (fósforo) do perfil 1; 2 e 3

Pela Figura 5.35 observa-se que, durante os três perfis realizados ao longo da altura do reator não houve a remoção do fósforo, pelo contrário, houve liberação de fósforo no meio.

\subsubsection{Distribuição do Material Suporte}

Conforme comentado no item 4.8, foram coletadas três amostras ao longo da altura do reator para verificar a distribuição do material suporte, após a colocação da areia no sistema. As amostras foram coletadas a 5,0 m (ponto 3); 7,0 m (ponto 5) e 9,0 m (ponto 7) da base do reator em três oportunidades diferentes, denominadas por amostragem 1 (Fase 1, Etapa I); 2 (Fase 3, Etapa II) e 3 (Fase 4, Etapa II). 
$\mathrm{Na}$ Tabela 5.14 são apresentadas as proporções em relação ao volume de cada material suporte ao longo da altura do reator nas três amostragens distintas.

Tabela 5.14 Proporção em relação ao volume de carvão ativado granular (CAG), carvão antracitoso (CA) e areia ao longo da altura do reator

\begin{tabular}{|c|c|c|c|c|c|c|c|c|c|}
\hline \multirow{3}{*}{$\begin{array}{l}\text { Material } \\
\text { Suporte }\end{array}$} & \multicolumn{9}{|c|}{ Proporção em relação ao volume de material suporte (\%) } \\
\hline & \multicolumn{3}{|c|}{ Ponto $3(5,0 \mathrm{~m})$} & \multicolumn{3}{|c|}{ Ponto 5 (7,0 m) } & \multicolumn{3}{|c|}{ Ponto $7(9,0 \mathrm{~m})$} \\
\hline & Am. 1 & Am. 2 & Am. 3 & Am. 1 & Am. 2 & Am. 3 & Am. 1 & Am. 2 & Am. 3 \\
\hline CAG + CA & 73,8 & 75,9 & 54,8 & 89,1 & 56,4 & 51,9 & 77,3 & 62,9 & 65,6 \\
\hline AREIA & 26,2 & 24,1 & 45,2 & 10,9 & 43,6 & 48,1 & 22,7 & 37,1 & 34,4 \\
\hline
\end{tabular}

CAG: carvão ativado granular

CA: carvão antracitoso

Am. 1: Amostragem 1 (Fase 1, Etapa I)

Am. 2: Amostragem 2 (Fase 3, Etapa II)

Am. 3: Amostragem 3 (Fase 4, Etapa II)

Pela análise da Tabela 5.14, observa-se que, inicialmente, na amostragem 1, a proporção de CAG + CA foi superior em relação à areia, nos diferentes pontos de coleta (pontos 3; 5 e 7). Sendo que essa proporção tendeu a se reduzir ao longo das amostragens 2 e 3 .

Ao longo do tempo, a areia tendeu-se a se localizar mais próximo a base do reator, provavelmente por sua maior densidade $\left(2,69 \mathrm{~g} \cdot \mathrm{cm}^{-3}\right)$ em relação ao CAG + CA $\left(1,69 \mathrm{~g} \cdot \mathrm{cm}^{-3}\right)$, conforme verificado no ponto 3 , ao longo das amostragens 2 e 3 .

Conforme comentado, era de se esperar que a proporção de areia na base do reator fosse maior, quando comparada com o CAG + CA. No entanto, esse fato não foi observado, provavelmente pelo fato de que as características do fluxo não estariam adequadas, ou seja, a vazão de recirculação não estaria proporcionando a fluidificação/expansão do leito de partículas. Este fato é corroborado, visto que a recirculação na fase anaeróbia, durante as Fases 3 e 4, da Etapa II, estava desligada, conforme discutido no item 5.3.2.5.

Contudo, nota-se que as proporções de CAG + CA em relação à areia já estavam praticamente se igualando, como observado nos pontos 3 e 5 , durante a terceira amostragem. Além disso, a proporção de areia próxima ao topo (ponto 7) 
tendeu a se reduzir, ao longo da segunda e terceira amostragens, indicando a acomodação da areia, em direção à base do reator.

\subsubsection{Resultados do Ensaio de Flotação}

Os ensaios de flotação, conforme já mencionado item 4.8, foram realizados com a finalidade em se tentar a possibilidade de melhorar a qualidade do efluente, visto que, o decantador do sistema não desempenhou sua função de forma eficiente.

Reali, Penetra e Campos (2001) e Penetra, Reali e Campos (2002) corroboram com tal possibilidade, visto que os autores avaliaram o uso da flotação por ar dissolvido (FAD) no pós-tratamento do efluente de reator anaeróbio de leito expandido $\left(32 \mathrm{~m}^{3}\right)$. De acordo com os autores, o sistema RALEx-FAD foi capaz de produzir efluente com DQO de 53 mg.L $\mathrm{L}^{-1}$ (94,4\% de remoção); 9 mgSST.L ${ }^{-1}$; turbidez de 12,9 uT e $0,8 \mathrm{mgPO}_{3}^{-4} \cdot \mathrm{L}^{-1}(87 \%$ de remoção) com o auxílio de coagulante.

Vale ressaltar, que não houve coagulação nem floculação prévia da amostra, apenas a flotação da mesma. Isso foi feito, de tal forma, a simular uma situação de campo, ou seja, a possibilidade na transformação do decantador do sistema num flotador.

Nas Figuras 5.36; 5.37 e 5.38 são apresentadas as eficiências de remoção de sólidos em suspensão totais, fixos e voláteis, respectivamente em função das concentrações de ar fornecidas durante o ensaio. 


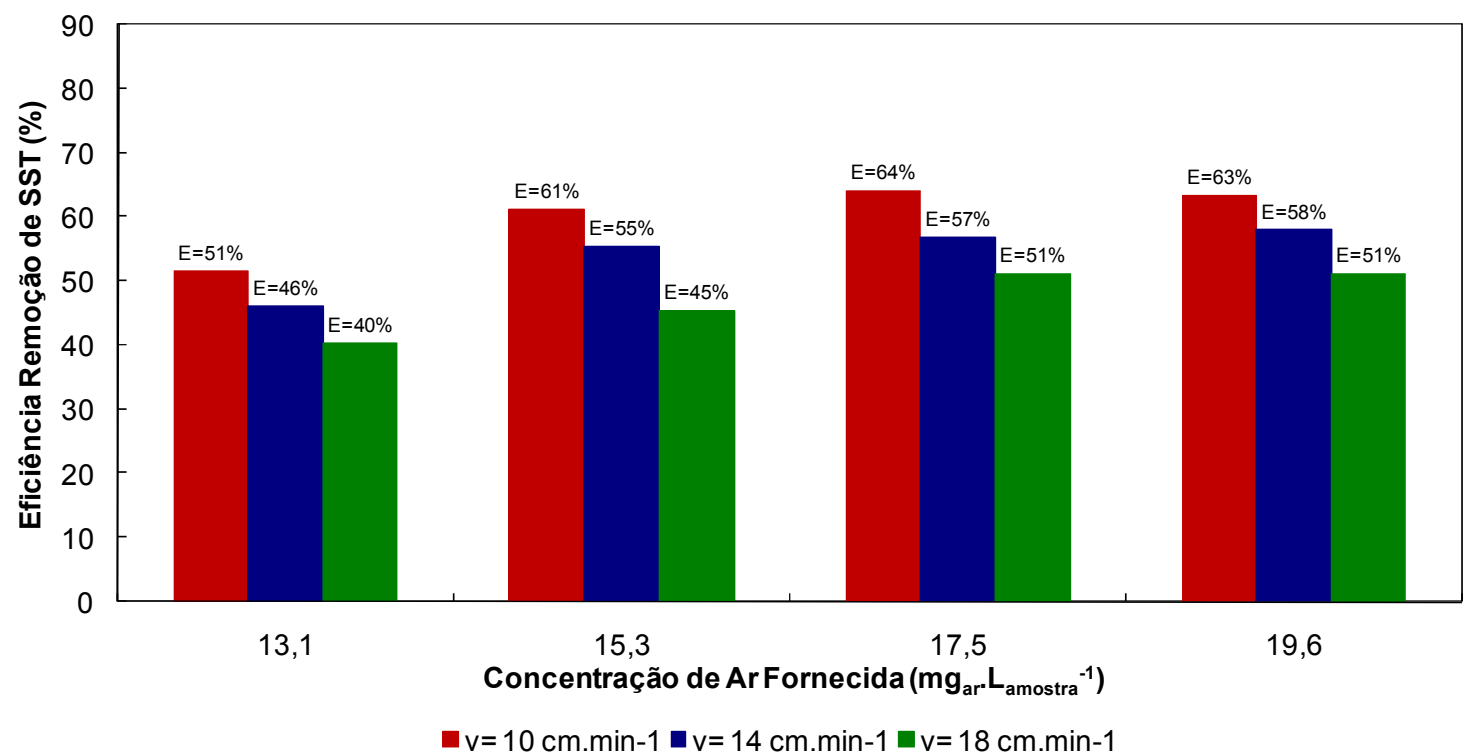

Figura 5.36 Eficiência na remoção de SST (sólidos em suspensão totais) em função das concentrações de ar fornecidas durante o ensaio de flotação

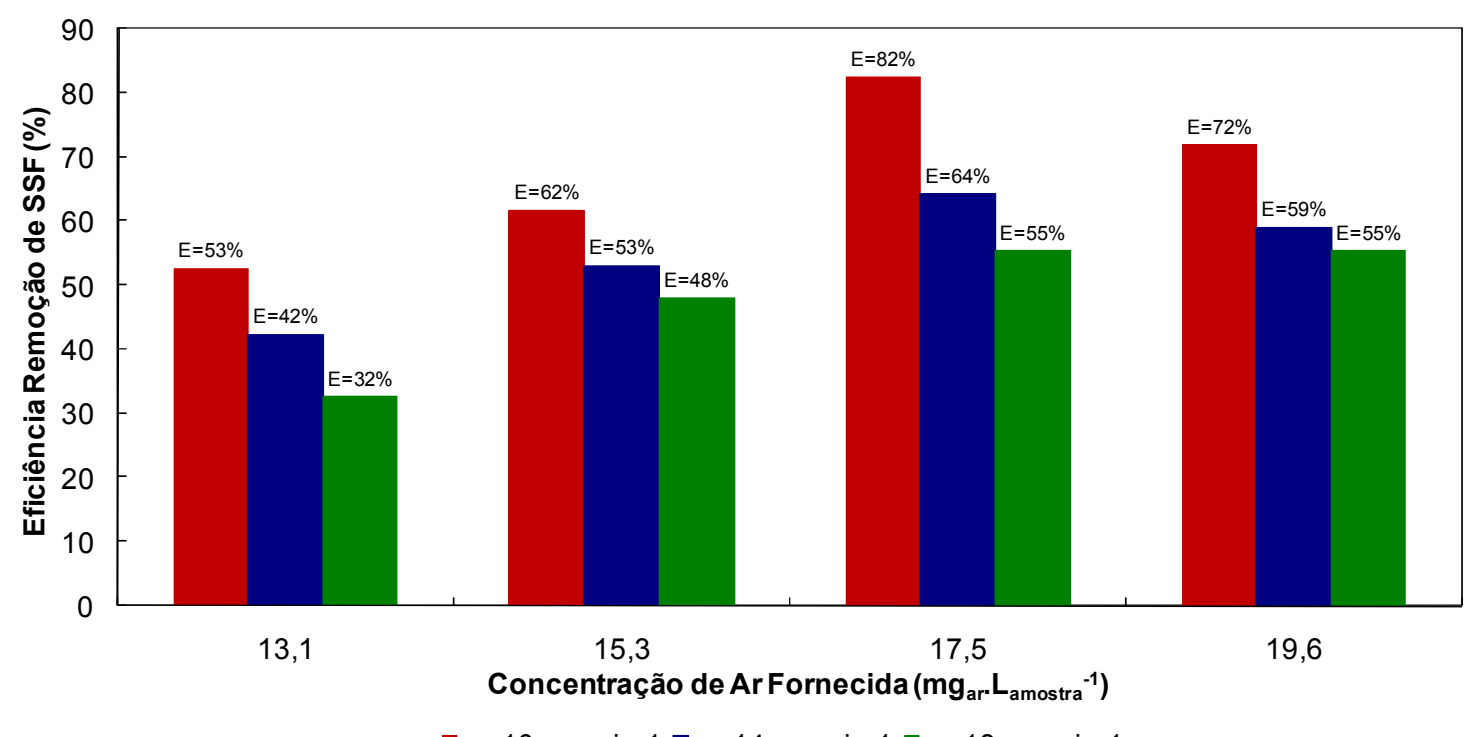

Figura 5.37 Eficiência na remoção de SSF (sólidos em suspensão fixos) em função das concentrações de ar fornecidas durante o ensaio de flotação 


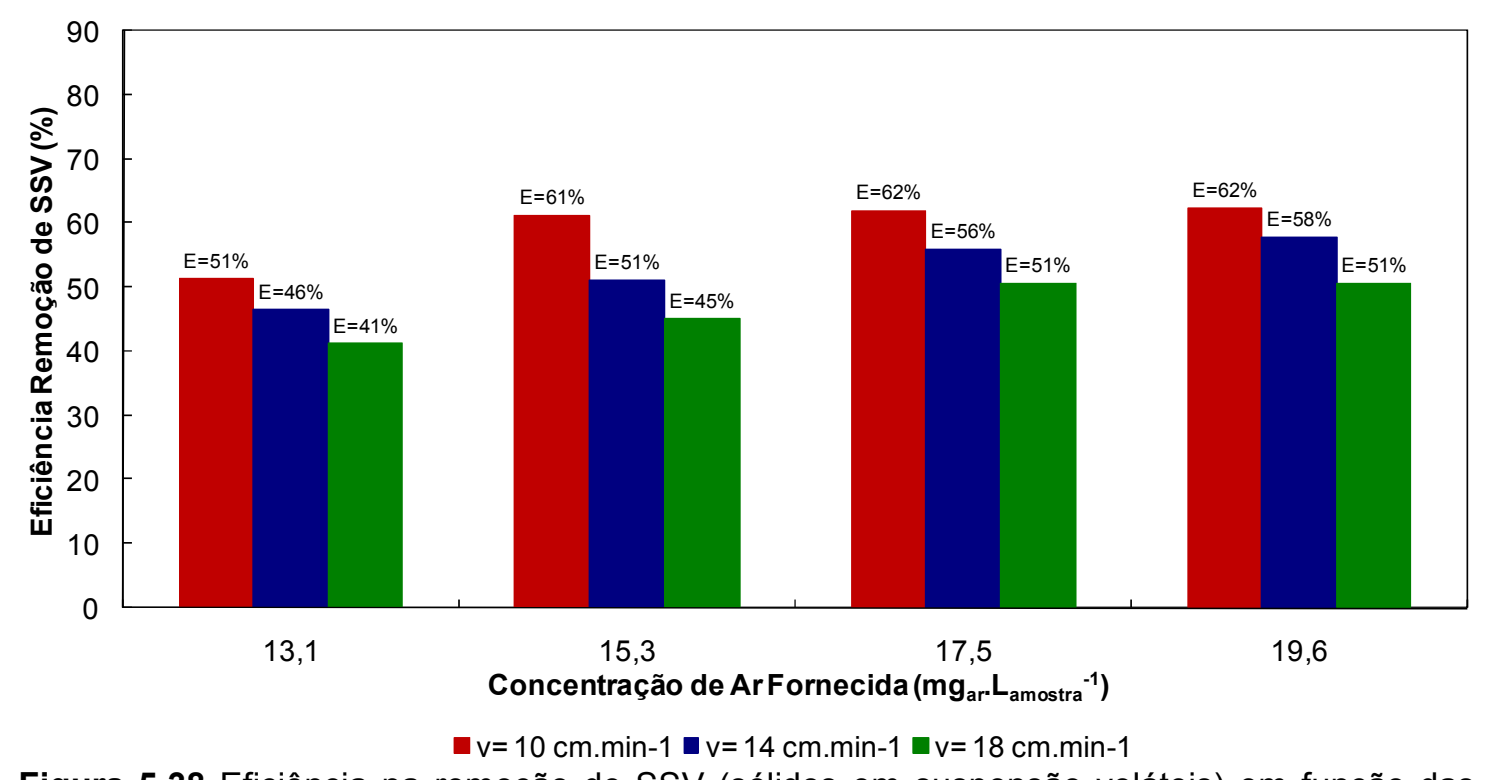

Figura 5.38 Eficiência na remoção de SSV (sólidos em suspensão voláteis) em função das concentrações de ar fornecidas durante o ensaio de flotação

Pela análise das Figuras 5.36; 5.37 e 5.38, observa-se que as maiores eficiências de remoção de sólidos em suspensão totais, fixos e voláteis ocorreram quando foi aplicada recirculação com concentração de ar de $17,5 \mathrm{mg}_{\mathrm{ar}} \mathrm{L}_{\mathrm{amostra}}{ }^{-1}$, que corresponde a razão de recirculação de $16 \%$ e velocidade ascensional de flotação de $10 \mathrm{~cm} \cdot \mathrm{min}^{-1}$. As eficiências de remoção de SST; SSF e SSV obtidas foram de 64; 82 e $62 \%$, respectivamente. O efluente flotado apresentou concentrações de 63 mgSST.L ${ }^{-1} ; 5$ mgSSF.L ${ }^{-1}$ e 59 mgSSV.L ${ }^{-1}$, sendo que a amostra bruta apresentava concentrações de 174 mgSST.L ${ }^{-1} ; 18$ mgSSF.L ${ }^{-1}$ e 156 mgSSV.L ${ }^{-1}$.

Nota-se que as eficiências de remoção de sólidos em suspensão totais, fixos e voláteis quando foram aplicadas recirculações com concentrações de ar de 17,5 e 19,6 mgar. $\mathrm{L}_{\mathrm{amostra}}{ }^{-1}$ foram semelhantes. Vale lembrar, que quanto menor a quantidade de ar for fornecida ao sistema, menor serão os gastos com energia, o que favorece o aumento da potencialidade do sistema, visto que ele se torna mais economicamente favorável. 
Pereira (2000) tentou simular, em escala de laboratório, a flotação do efluente de reator anaeróbio de leito expandido $\left(32 \mathrm{~m}^{3}\right)$. Ao se aplicar razão de recirculação de $20 \%$, sem a utilização de coagulante, o autor obteve eficiência na remoção de SST de $77 \%$, o efluente apresentou concentração de $23 \mathrm{mgSST} . \mathrm{L}^{-1}$, sendo que a amostra bruta apresentava concentração de 98 mgSST.L $L^{-1}$.

Niciura (2005) tentou simular também, em escala de laboratório, a flotação do efluente do mesmo reator de Pereira (2000). O autor obteve eficiências de remoção de SST; SSF e SSV de 47; 65 e 41\%, respectivamente, quando foi aplicada razão de recirculação de $18 \%$ e velocidade ascensional de flotação de $12,5 \mathrm{~cm} \cdot \mathrm{min}^{-1}$. Vale ressaltar, que não houve coagulação nem floculação prévia da amostra. O efluente apresentou concentrações de 49 mgSST.L ${ }^{-1} ; 9$ mgSSF.L ${ }^{-1}$ e 40 mgSSV.L ${ }^{-1}$, sendo que a amostra bruta apresentava concentrações de 92 mgSST.L $L^{-1} ; 25$ mgSSF.L $L^{-1}$ e 68 mgSSV.L $L^{-1}$.

Na Figura 5.39 são apresentadas as eficiências de remoção de DQO em função das concentrações de ar fornecidas durante o ensaio.

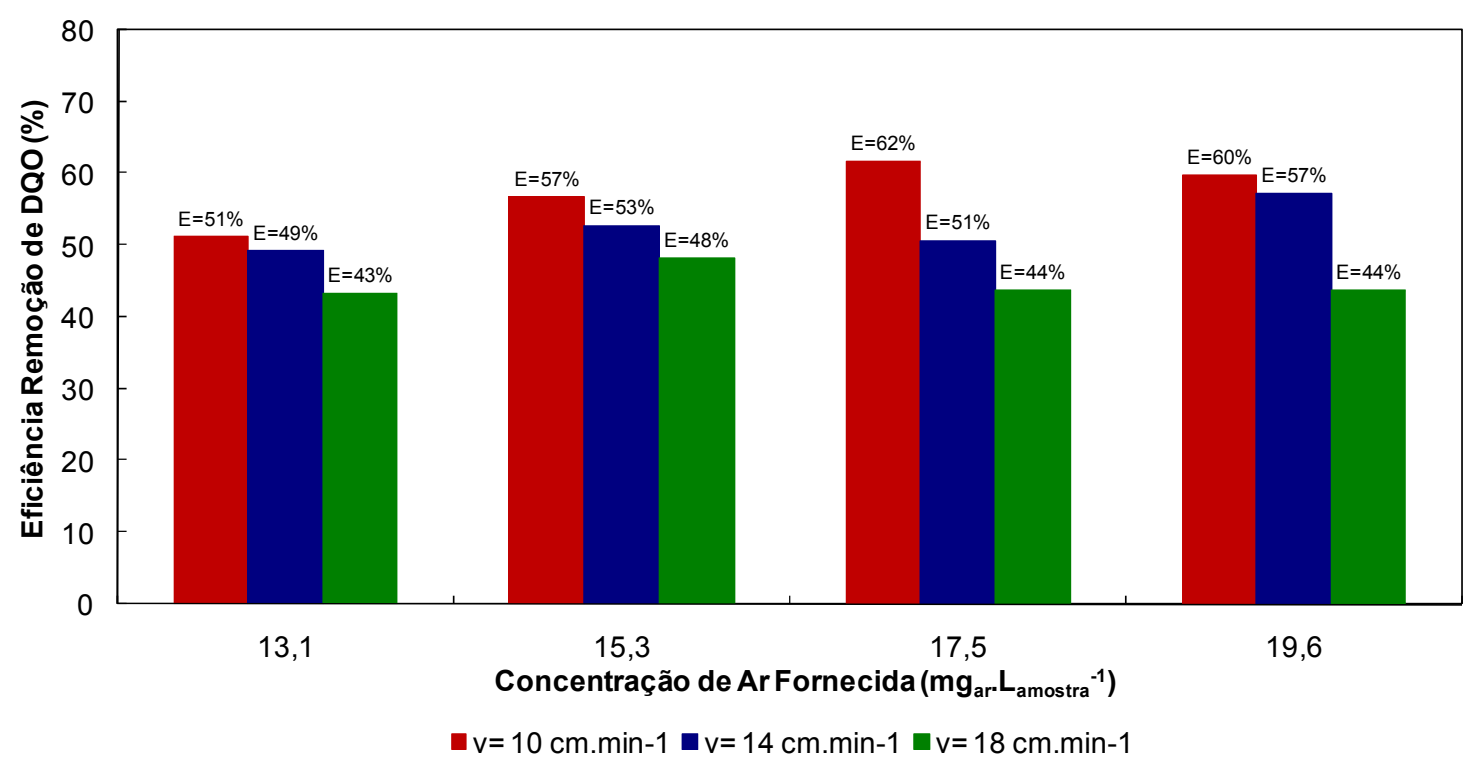

Figura 5.39 Eficiência na remoção de DQO (demanda química de oxigênio) em função das concentrações de ar fornecidas durante o ensaio de flotação 
A maior eficiência de remoção de DQO, conforme a Figura 5.39 ocorreu quando foi aplicada recirculação com concentração de ar de $17,5 \mathrm{mg}_{\mathrm{ar}} \mathrm{L}_{\mathrm{amostra}}{ }^{-1}$, que corresponde a razão de recirculação de $16 \%$ e velocidade ascensional de flotação de $10 \mathrm{~cm} \cdot \mathrm{min}^{-1}$. A eficiência de remoção de DQO foi de $62 \%$. O efluente flotado apresentou 127 mgDQO $\mathrm{bruta}_{\mathrm{L}} \mathrm{L}^{-1}$, sendo que a amostra bruta apresentava $331 \mathrm{mgDQ} \mathrm{O}_{\text {bruta. }} \mathrm{L}^{-1}$.

Pereira (2000), em escala de laboratório, tentou a flotação do efluente de reator anaeróbio de leito expandido $\left(32 \mathrm{~m}^{3}\right)$. O autor obteve eficiência na remoção de DQO de $61 \%$, ao se aplicar razão de recirculação de $20 \%$, sem a utilização de coagulante. O efluente apresentou $120 \mathrm{mgDQO}$ bruta. $\mathrm{L}^{-1}$, sendo que a amostra bruta apresentava $311 \mathrm{mgDQO}$ bruta. $\mathrm{L}^{-1}$.

Niciura (2005) simulou também, em escala de laboratório, a flotação do efluente do mesmo reator de Pereira (2000). Quando foi aplicada razão de recirculação de $18 \%$ e velocidade ascensional de flotação de $12,5 \mathrm{~cm} \cdot \mathrm{min}^{-1}$, sem a utilização de coagulante, o autor obteve eficiência de remoção de DQO de $29 \%$. O efluente apresentou $173 \mathrm{mgDQO}_{\text {bruta }} \mathrm{L}^{-1}$, sendo que a amostra bruta apresentava $242 \mathrm{mgDQO}$ bruta. $\mathrm{L}^{-1}$.

Nas Figuras 5.40 e 5.41 são apresentadas as eficiências de remoção de cor e turbidez em função das concentrações de ar fornecidas durante o ensaio. 


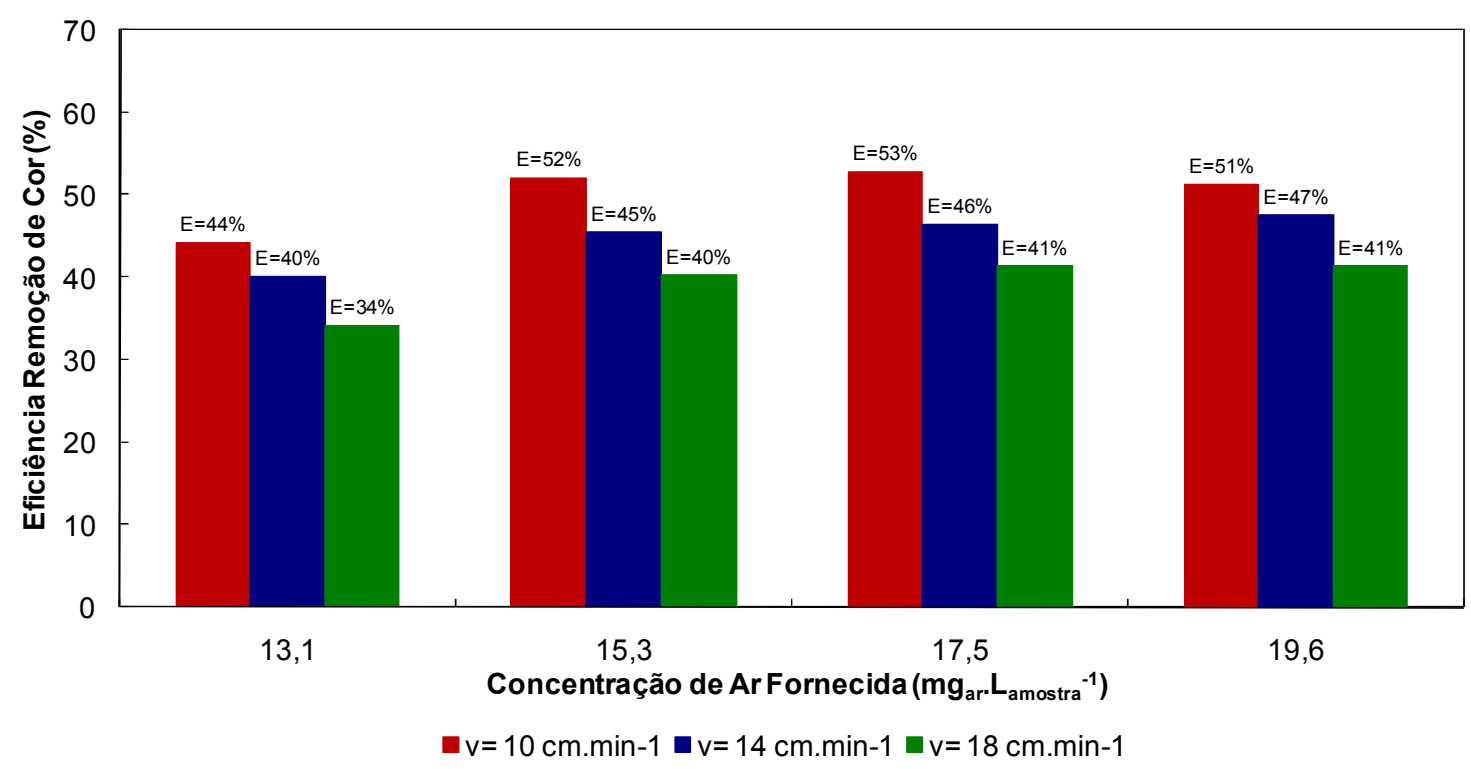

Figura 5.40 Eficiência na remoção de cor em função das concentrações de ar fornecidas durante o ensaio de flotação

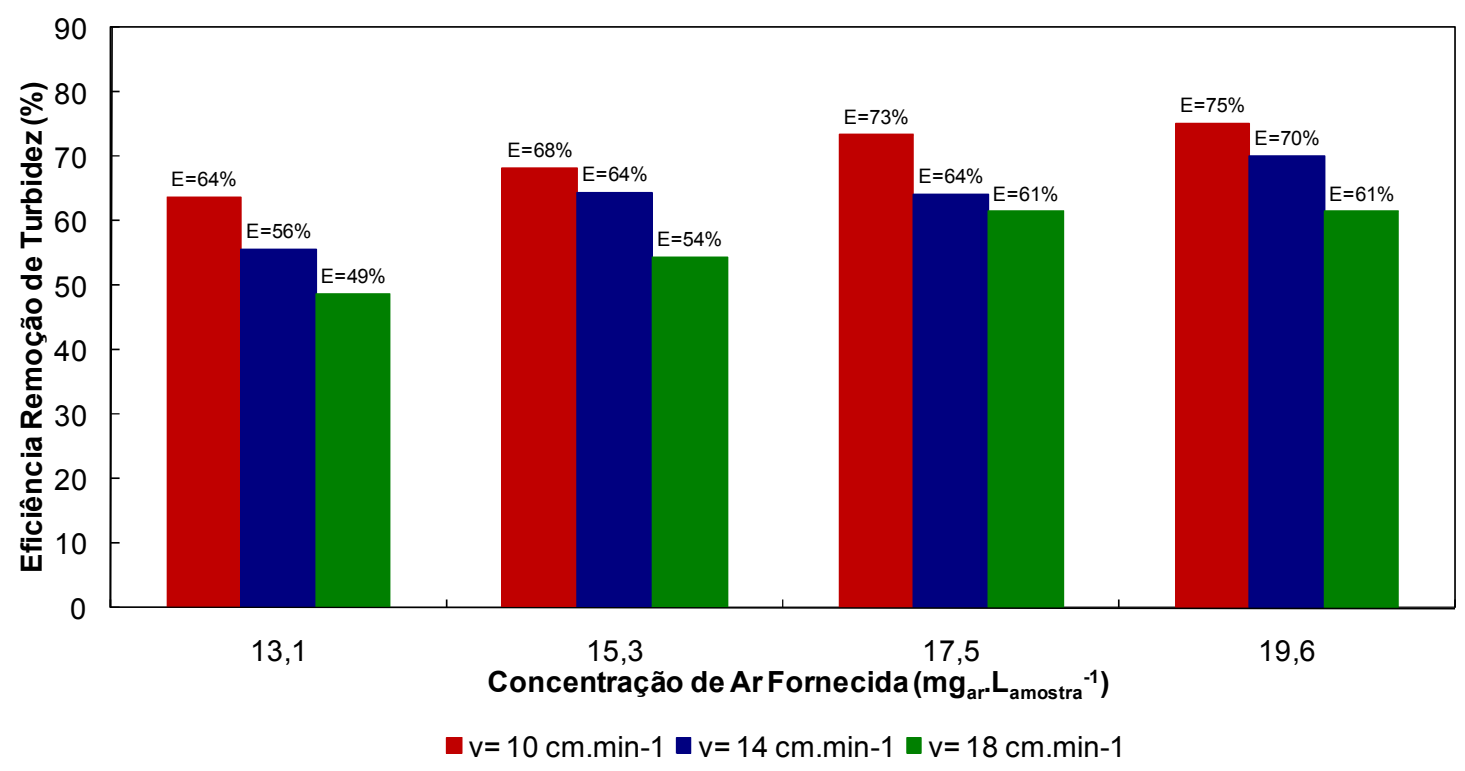

Figura 5.41 Eficiência na remoção de turbidez em função das concentrações de ar fornecidas durante o ensaio de flotação

De acordo com as Figuras 5.40 e 5.41, as maiores eficiências de remoção de cor e turbidez, ocorreram quando foi aplicada recirculação com concentração de ar de $17,5 \mathrm{mgar}_{\mathrm{a}} \mathrm{L}_{\mathrm{amostra}}{ }^{-1}$, que corresponde a razão de recirculação de $16 \%$ e velocidade ascensional de flotação de $10 \mathrm{~cm} \cdot \mathrm{min}^{-1}$. As eficiências de cor e turbidez foram de 53 e $73 \%$, respectivamente. O efluente flotado apresentou cor de $431 \mathrm{uC}$ e turbidez de 29 uT, sendo que a amostra bruta apresentava cor de 9121 uC e turbidez de 109 uT. 
Pereira (2000) simulando, em escala de laboratório, a flotação do efluente de reator anaeróbio de leito expandido $\left(32 \mathrm{~m}^{3}\right)$. Ao se aplicar razão de recirculação de $20 \%$, sem a utilização de coagulante, o autor obteve eficiência na remoção de cor e turbidez de 60 e $67 \%$, respectivamente. O efluente flotado apresentou cor de 308 uC e turbidez de 31 uT, sendo que a amostra bruta apresentava cor de 776 uC e turbidez de 92 uT.

Na Figura 5.42 são apresentadas as eficiências de remoção de fósforo em função das concentrações de ar fornecidas durante o ensaio.

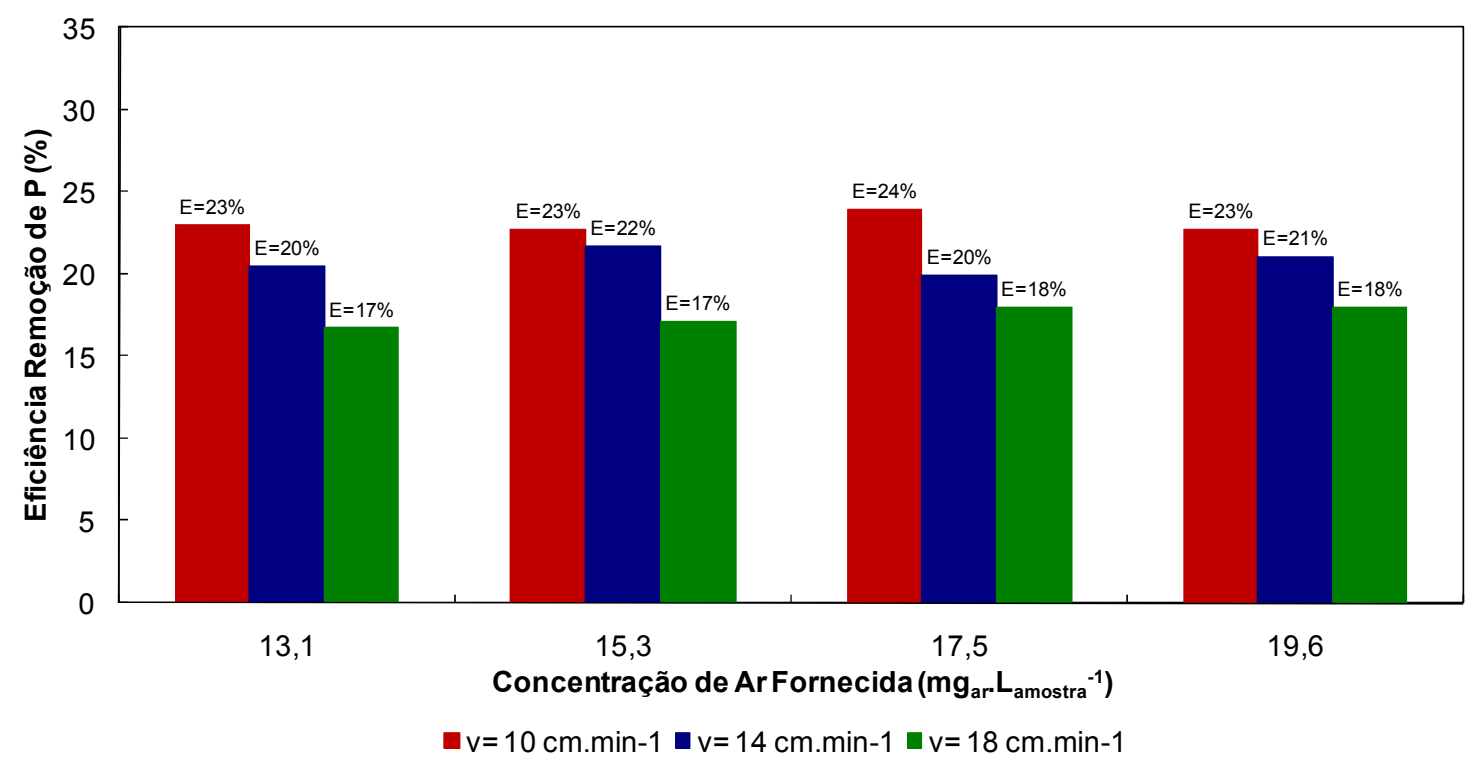

Figura 5.42 Eficiência na remoção de $P$ (fósforo) em função das concentrações de ar fornecidas durante o ensaio de flotação

A maior eficiência de remoção de $\mathrm{P}$, conforme a Figura 5.42 ocorreu quando foi aplicada recirculação com concentração de ar de $17,5 \mathrm{mg}_{\mathrm{ar}} \mathrm{L}_{\mathrm{amostra}}{ }^{-1}$, que corresponde a razão de recirculação de $16 \%$ e velocidade ascensional de flotação de $10 \mathrm{~cm} \cdot \mathrm{min}^{-1}$. A eficiência de remoção de $\mathrm{P}$ foi de $24 \%$. O efluente flotado apresentou $4,1 \quad \mathrm{mgPO}_{4}^{-3} \cdot \mathrm{L}^{-1}$, sendo que a amostra bruta apresentava $5,4 \mathrm{mgPO}_{4}^{-3} \cdot \mathrm{L}^{-1}$. 
A eficiência da remoção de fósforo foi baixa, mas vale lembrar, que não houve o processo de coagulação nem de floculação durante o ensaio.

Pereira (2000) simulando, em escala de laboratório, a flotação do efluente de reator anaeróbio de leito expandido $\left(32 \mathrm{~m}^{3}\right)$. O autor obteve eficiência na remoção de $\mathrm{P}$ de $10 \%$, ao se aplicar razão de recirculação de $20 \%$, sem a utilização de coagulante. $\mathrm{O}$ efluente apresentou $18 \mathrm{mgPO}_{4}{ }^{-3} \cdot \mathrm{L}^{-1}$, sendo que a amostra bruta apresentava $20 \mathrm{mgPO}_{4}^{-3} \cdot \mathrm{L}^{-1}$.

Niciura (2005) simulou também, em escala de laboratório, a flotação do efluente do mesmo reator de Pereira (2000). Quando foi aplicada razão de recirculação de $18 \%$ e velocidade ascensional de flotação de $12,5 \mathrm{~cm} \cdot \mathrm{min}^{-1}$, sem a utilização de coagulante, o autor obteve eficiência de remoção de $\mathrm{P}$ de $44 \%$. efluente apresentou $6,1 \mathrm{mgPO}_{4}^{-3} \cdot \mathrm{L}^{-1}$, sendo que a amostra bruta apresentava $10,9 \mathrm{mgPO}_{4}^{-3} \cdot \mathrm{L}^{-1}$

Ambos os autores obtiverem eficiências baixas na remoção de fósforo. A título de curiosidade, quando foi realizada a coagulação e floculação das amostras, Pereira (2000) obteve eficiência na remoção de fósforo de 98\%, quando foi aplicado dosagem de cloreto férrico de $65 \mathrm{mg} \cdot \mathrm{L}^{-1}$, sendo que o efluente apresentou concentração residual de $0,34 \mathrm{mgPO}_{4}^{-3} \cdot \mathrm{L}^{-1}$. Niciura (2005) obteve eficiência de $80 \%$ na remoção de fósforo (efluente com residual de $2 \mathrm{mgPO}_{4}{ }^{-3} \cdot \mathrm{L}^{-1}$ ), quando foi aplicado uma dosagem de coagulante de $50 \mathrm{mg} \cdot \mathrm{L}^{-1}$.

Torna-se imprescindível ressaltar o fato de que o ensaio de flotação foi realizado somente para estimar a eficiência do processo RALEx-FAD, tendo em vista que a avaliação consistente dessa associação exigiria estudo aprofundado, com a aplicação e otimização de condições de mistura rápida e floculação, além da escolha da dosagem e tipo de coagulante e polímero utilizados. 


\section{CONCLUSÕES}

Em relação ao período em que o reator foi operado somente na condição anaeróbia, Etapa I, conclui-se que:

- O sistema obteve maior eficiência na remoção de matéria orgânica, em termos de DQO, durante a Fase 1, TDH de 14 horas, quando foi removido $0,84 \mathrm{kgDQO}$ bruta. $\mathrm{m}^{-3} \cdot \mathrm{dia}^{-1}$, sendo que foi aplicado 1,26 $\mathrm{kgDQO}$ bruta. $\mathrm{m}^{-3} \cdot \mathrm{dia}^{-1}$.

- As eficiências médias de remoção de $\mathrm{DQO}_{\text {bruta, }} \mathrm{DQO}_{\text {filtrada, }} \mathrm{DBO}_{\text {bruta }} \mathrm{e}$ $\mathrm{DBO}_{\text {filtrada }}$ foram de $65 \% ; 64 \% ; 80 \%$ e $70 \%$, respectivamente. $\mathrm{O}$ efluente apresentou, em média, $245 \mathrm{mgDQO}_{\text {bruta. }} \mathrm{L}^{-1}, 117 \mathrm{mgDQO}_{\text {filtrada. }} \mathrm{L}^{-1}$, $104 \mathrm{mgDBO}$ bruta. $\mathrm{L}^{-1}$ e $76 \mathrm{mgDBO}_{\text {filtrada. }} \mathrm{L}^{-1}$;

- As eficiências médias de remoção de SST e SSV foram de $58 \%$ e $69 \%$, respectivamente. A concentração média no efluente foi de $88 \mathrm{mgSST}^{-\mathrm{L}^{-1} \mathrm{e}}$ 69 mgSSV.L L $^{-1}$

- A redução do TDH, de 14 horas para 8 horas, promoveu o aumento na velocidade ascensional, de 4,8 $\mathrm{m} \cdot \mathrm{h}^{-1}$ para $8,5 \mathrm{~m} \cdot \mathrm{h}^{-1} \mathrm{e}$ isso, ocasionou, provavelmente, o "arraste" de material particulado, reduzindo, assim de maneira significante a eficiência na remoção de SST;

- O aumento da taxa de carregamento orgânico de 1,3 para 1,7 $\mathrm{kgDQO}_{\text {bruta. }} \mathrm{m}^{-3} \cdot \mathrm{dia}^{-1}$, promoveu o carreamento de sólidos junto ao efluente; 
- O grau de amonificação no sistema foi de $90 \%$, evidenciando a potenciabilidade do sistema na conversão de material nitrogenado orgânico em amoniacal;

- É possível a utilização desta configuração de reator operado somente sob a fase anaeróbia, desde que haja a substituição do decantador convencional por outra unidade que melhore o desempenho do sistema na separação sólido/líquido.

Do período em que o reator foi operado nas fases anaeróbia e aeróbias sobrepostas, Etapa II, conclui-se que:

- A maior eficiência na remoção de matéria orgânica, em termos de DQO, foi obtida durante a Fase 3, TDH de 16 horas, quando foi removido 0,29 kgDQO $\mathrm{bruta} \cdot \mathrm{m}^{-3} \cdot \mathrm{dia}^{-1}$, sendo que foi aplicado 0,84 $\mathrm{kgDQO}$ bruta $\cdot \mathrm{m}^{-3} \cdot \mathrm{dia}^{-1}$.

- As maiores eficiências médias de remoção de $D Q O_{\text {filtrada }}$ e $D B O_{\text {filtrada }}$ foram de $80 \%$ e $95 \%$, respectivamente. O efluente apresentou, em média, $72 \mathrm{mgDQO} \mathrm{f}_{\text {filtrada. }} \mathrm{L}^{-1}$, e $13 \mathrm{mgDBO}$ filtrada. $\mathrm{L}^{-1}$;

- Não houve sedimentação adequada do material biológico no decantador do sistema, isso provavelmente pode ter sido ocasionado pela quantidade de ar injetada no sistema, visto que foi criada uma turbulência na região de sedimentação do sistema;

- O sistema obteve grau de amonificação de $85 \%$, evidenciando a capacidade do sistema em promover a amonificação do esgoto sanitário de forma satisfatória; 
- O sistema apresentou baixa eficiência na oxidação do $\mathrm{N}$-amoniacal, no máximo $25 \%$, sendo que as concentrações máximas de nitrito e nitrato foram de $4 \mathrm{mgN}-\mathrm{NO}_{2}^{-} \cdot \mathrm{L}^{-1}$ e $2 \mathrm{mgNO}_{3}^{-} \cdot \mathrm{L}^{-1}$, respectivamente;

- Há grande dificuldade para se conseguir o domínio sob os processos biológicos em reatores com essa configuração, sendo mais interessante a utilização de reatores separados, de tal forma que se consiga o controle do processo.

A partir dos resultados obtidos em relação à escolha do material suporte para complementar o leito do reator, conclui-se que:

- A areia escolhida para complementar o leito possuía diâmetro médio dos grãos igual a 0,69 mm e massa específica de $2690 \mathrm{~kg} \cdot \mathrm{m}^{-3}$;

- O uso da areia comercial como alternativa para compor o leito de partículas do reator de leito expandido, em comparação à areia classificada, pode vir a reduzir o custo de execução desse tipo de sistema.

Sobre a distribuição do material suporte, conclui-se que:

- A proporção de CAG + CA foi superior em relação à areia, nos diferentes pontos de coleta, sendo que essa proporção tendeu a se reduzir ao longo das amostragens;

- As características do fluxo não estão adequadas para proporcionar a fluidificação/expansão do leito de partículas. 
A partir dos resultados do ensaio de flotação, conclui-se que:

- Os melhores resultados do ensaio de flotação foram obtidos quando foi aplicada recirculação com concentração de ar de $17,5 \mathrm{mg}_{\mathrm{ar}} \mathrm{L}_{\mathrm{amostra}}{ }^{-1}$, que corresponde à razão de recirculação de $16 \%$ e velocidade ascensional de flotação de $10 \mathrm{~cm} \cdot \mathrm{min}^{-1}$;

- As eficiências de remoção de SST; SSF e SSV obtidas foram de 64; 82 e $62 \%$, respectivamente. O efluente flotado apresentou concentrações de 63 mgSST.L ${ }^{-1} ; 5$ mgSSF.L ${ }^{-1}$ e 59 mgSSV.L ${ }^{-1}$;

- As eficiências de remoção de DQO, cor e turbidez foram de 62; 53 e 73\%, respectivamente. O efluente flotado apresentou $127 \mathrm{mgDQO}_{\text {bruta. }} \mathrm{L}^{-1}$, cor de 431 uC e turbidez de 29 uT;

- Pela simulação da flotação do efluente, foi demonstrado que o uso da flotação, ao invés da decantação, forneceria maior eficiência ao sistema. 


\section{REFERÊNCIAS}

AKUTSU, J. (1984). Emprego de reator de leito fluidificado para tratamento biológico de efluente de uma indústria de conservas vegetais. $88 \mathrm{f}$. Dissertação (Mestrado) - Escola de Engenharia de São Carlos, Universidade de São Paulo, São Carlos, 1984.

ALÉM SOBRINHO, P.; KATO, M.T. (1999). Análise crítica do uso do processo anaeróbio para o tratamento de esgotos sanitários. In: CAMPOS, J.R. (Coord.). Tratamento de esgotos sanitários por processo anaeróbio e disposição controlada no solo. Rio de Janeiro: ABES. Cap.12, p.301-320.

ARAUJO, J.C. (1995). Caracterização e evolução do biofilme em reator anaeróbio de leito fluidificado alimentado com esgoto sanitário sintético. 150p. Dissertação (Mestrado) - Escola de Engenharia de São Carlos, Universidade de São Paulo, São Carlos, 1995.

ASLAN, S.; DAHAB, M. (2008). Nitritation and denitritation of ammonium-rich wastewater using fluidized-bed biofilm reactors. Jornal of Hazardous Materials, Amsterdam, v.156, n.1/3, p.56-63, Aug.

ASSOCIAÇÃO BRASILEIRA DE NORMAS TÉCNICAS (1984a). NBR 6508: Solo determinação da massa específica. Rio de Janeiro.

de Janeiro.

(1984b). NBR 7181: Solo - análise granulométrica: método de ensaio. Rio

(1992). NBR 12209: Projeto de estações de tratamento de esgoto sanitário. Rio de Janeiro.

BARROS, F.G. (1989). Emprego de reator aeróbio de leito fluidificado para nitrificação de efluentes de tratamento secundário. 188 f. Dissertação (Mestrado) - Escola de Engenharia de São Carlos, Universidade de São Paulo, São Carlos, 1990.

BRASIL. Ministério do Meio Ambiente. Conselho Nacional do Meio Ambiente. (2005). Resolução $n^{\circ} 357$, de 17 de março de 2005, dispõe sobre a classificação dos corpos d'água e diretrizes ambientais para o seu enquadramento, bem como estabelece as condições e padrões de lançamento de efluentes, e dá outras providências. Diário Oficial da União, Brasília, DF, 18 mar. 2005. 
BRASIL. Ministério do Meio Ambiente. Conselho Nacional do Meio Ambiente. (2008). Altera o inciso II do $\S 4^{\circ}$ e a tabela $X$ do $\S 5^{\circ}$, ambos do art. 34 da resolução do Conselho Nacional do Meio Ambiente - CONAMA n 357, de 2005, que dispõe sobre a classificação dos corpos d'água e diretrizes ambientais para o seu enquadramento, bem como estabelece as condições e padrões de lançamento de efluentes, resolução CONAMA n 397, 03 de abril de 2008. Diário Oficial da União, Brasília, DF, 7 abr. 2008. Seção 1, p.68.

BRATBY J. et al. (2003). Mitigating the cost of denitrification in fixed film plant with nitrate recycle. In: WATER ENVIRONMENT FEDERATION, 2003, Los Angeles. Proceedings... Los Angeles: Los Angeles Convention Center.

CAMPOS, J.R. (1989). Remoção de DQO e de nitrogênio em um sistema de três reatores biológicos de filme fixo em série. 189 p. Tese (Livre Docência) - Escola de Engenharia de São Carlos, Universidade de São Paulo, São Carlos, 1989.

CAMPOS, J.R.; PEREIRA, J.A.R. (1999). Reator anaeróbio de leito expandido/fluidificado. In: CAMPOS, J.R. (Coord.). Tratamento de esgotos sanitários por processo anaeróbio e disposição controlada no Solo. Rio de Janeiro: ABES. Cap.8, p.199-220.

CHENG, S.S.; CHEN, W.C.; HWANG, H.H. (1997). Biofilm formation: the effects of hydrodynamic and substrate feeding patterns in three phase draft-tube fluidized bed for nitrification process. Water Science \& Technology, Oxford, v.36, n.12, p.83-90.

CHOUWDHURY, N.; NAKLA, G.; ZHU, J. (2008). Load maximization of a liquid-solid circulation fluidized bed bioreactor for nitrogen removal from synthetic municipal wastewater. Chemosphere, Oxford, v.71, n.5, p.807-815, May.

COSTA, S.R.A. (1994). Remoção de fenol em reator anaeróbio de leito fluidizado de carvão ativado. 199p. Tese (Doutorado) - Escola de Engenharia de São Carlos, Universidade de São Paulo, São Carlos, 1994.

CRESSON, R. et al. (2006). Biofilm formation during the start-up period of an anaerobic biofilm reactor: impact of nutrient complementation. Biochemical Engineering Journal, Amsterdam, v.30, n.1, p.55-62, May.

CUBA TERÁN, F. (1990). Conversão de nitrogênio amoniacal mediante reator de leito fluidificado como pré-tratamento de água para abastecimento. 166p. Dissertação (Mestrado) - Escola de Engenharia de São Carlos, Universidade de São Paulo, São Carlos, 1990.

(1995). Tratamento de esgoto sintético empregando reator anaeróbio de leito fluidificado: desempenho do reator e estudo do biofilme. 243p. Tese (Doutorado) - Escola de Engenharia de São Carlos, Universidade de São Paulo, São Carlos, 1995. 
DEMPSEY, M.J. et al. (2006). The Expanded bed biofilter: combined nitrification, solids destruction and removal of bacteria. Water Science and Technology, Oxford, v.54, n.8, p.37-46.

DESIGN of wastewater treatment plants. (1998). $4^{\text {th }}$ ed. Alexandria: Water Environmental Federation; American Society of Civil engineering. (Manual of practice, 8; ASCE Manual and Report on Engineering Practice, 76).

DILALLO, R.; ALBERTSON, O.E. (1961). Volatile acids by direct titration. Journal of Water Pollution Control Federation, New York, v.33, n.4, p.357-365.

FDZ-POLANCO, F.; REAL, F.J.; GARCIA, P.A. (1994). Behavior of an anaerobic/aerobic pilot scale fluidized bed for the simultaneous removal of carbon and nitrogen. Water Science \& Technology, Oxford, v.29, n.10-11, p.339-346.

FORD, D.L.; CHURCHWELL, J. (1980). Comprehensive analysis of nitrification of chemical processing wastewater. Journal Water Pollution Control Federation, New York, v.52, n.11, p.2726-2746.

HA, J.H.; ONG, S.K. (2007). Nitrification and denitrification in partially aerated biological aerated filter (BAF) with dual size sand media. Water Science \& Technology, Oxford, v.55, n.1, p.9-17.

HAMADA, J. (1992). Emprego de reatores biológicos de leito fluidificado no prétratamento de águas de abastecimento. 230p. Tese (Doutorado) - Escola de Engenharia de São Carlos, Universidade de São Paulo, São Carlos, 1992.

HENZE, M. et al. (1997). Wastewater treatment biological and chemical processes. $2^{\text {nd }}$ ed. Berlim: Springer.

HIBIYA, K. et al. (2004). Simple prediction of oxygen penetration depth in biofilms for wastewater treatment. Biochemical Engineering Journal, Amsterdam, v.19, n.1, p.61-68, July.

JENKINS, D.; RICHARD, M.G.; DAIGGER, G.T. (2003). Manual on the causes and control of activated sludge bulking, foaming, and other solids separation problems. $3^{\text {rd }}$ ed. Boca Raton: Lewis.

JEWELL, W.J. et al. (1981). Municipal wastewater treatment with anaerobic attached microbial film expanded bed process. Journal of Water Pollution Control Federation, New York, v.53, n.4, p.482-490.

KUNII, D.; LEVENSPIEL, O. (1969). Engineering fluidization. New York: John Wiley.

LAMON, A.W. et al. (2008). Automação de reator de leito expandido em escala plena com zonas anaeróbia e aeróbia sobrepostas para tratamento de esgoto sanitário. Tecno-Lógica, Santa Cruz do Sul, v.12, n.2, p.17-24. 
LASSMAN, A.A. et al. (2006). Simultaneous removal of carbon and nitrogen in an anaerobic inverse fluidized bed reactor. Water Science and Technology, Oxford, v.54, n.2, p.111-117.

LENS, P. et al. (Ed.). Biofilms in medicine, industry and environmental biotechnology: characteristics, analysis and control. London: IWA.

LING, J.; CHEN, S. (2005). Impacting of organic carbon and nitrification performance of different biofilters. Aquacultural Engineering, London, v.33, n.2, p.150-162, Aug.

MARAGNO, A.L.F.C. (1988). Tratamento de águas residuárias de baixa concentração de matéria orgânica em reator anaeróbio de leito fluidificado. 117p. Dissertação (Mestrado) - Escola de Engenharia de São Carlos, Universidade de São Paulo, São Carlos, 1988.

MENDONÇA, N.M. (1998). Caracterização do material suporte e estudo da partida em um reator anaeróbio de leito expandido utilizado no tratamento de esgoto sanitário. 189p. Dissertação (Mestrado) - Escola de Engenharia de São Carlos, Universidade de São Paulo, São Carlos, 1998.

(2004). Remoção simultânea de DQO e N em único reator de leito expandido com zonas anaeróbia e aeróbia. 204p. Tese (Doutorado) - Escola de Engenharia de São Carlos, Universidade de São Paulo, São Paulo, 2004.

MICHAUD, L. et al. (2006). Effect of particulate organic carbon on heterotrophic bacterial population and nitrification efficiency in biological filters. Aquacultual Engineering, London, v.34, n.3, p.224-233, May.

NICIURA, C.L. (2005). Avaliação do uso de banda de rodagem de pneus inservíveis triturada como suporte ao desenvolvimento de biofilmes em reator anaeróbio de leito expansível. 171 p. Tese (Doutorado) - Escola de Engenharia de São Carlos, Universidade de São Paulo, São Carlos, 2005.

NICOLELLA, C. et al. (1997). Mechanisms of biofilm detachment in bed reactors. Water Science \& Technology, Oxford, v.36, n.1, p.229-235.

PATEL, A.; ZHU, J.; NAKHLA, G. (2006). Simultaneous carbon, nitrogen and phosphorus removal from municipal wastewater in a circulating fluidized bed bioreactor. Chemosphere, Oxford, v.65, n.7, p.1103-1112, Nov.

PENETRA, R.G.; REALI, M.A.P.; CAMPOS, J.R. (2002). Influence of flocculation conditions in the performance of an experimental domestic sewage treatment plant consisting of an anaerobic expanded bed reactor followed by dissolved air flotation. In: TALLER Y SIMPÓSIO LATINO-AMERICANO SOBRE DIGESTÃO ANAERÓBIA, 7., 2002, Mérida. Proceedings... Mérida: IWA. p.503-510. 
PEREIRA, J.A.R. (2000). Concepção, construção e operação de reator anaeróbio de leito expandido, em escala real, para o tratamento de esgoto sanitário. 339 p. Tese (Doutorado) - Escola de Engenharia de São Carlos, Universidade de São Paulo, São Carlos, 2000.

RABAH, F.K.J.; DAHAB, M.F. (2004). Biofilm and biomass characteristics in highperformance fluidized-bed biofilm reactors. Water Research, New York, v.38, n.19, p.4252-4270, Nov.

REALI, M.A.P. (1991). Avaliação de um sistema original para clarificação de águas de abastecimento utilizando o processo de flotação e filtração por taxa declinante. 373p. Tese (Doutorado) - Escola de Engenharia de São Carlos, Universidade de São Paulo, São Carlos, 1991.

REALI, M.A.P.; PENETRA, R.G.; CAMPOS, J.R. (2001). Sewage treatment by anaerobic biological process associated with dissolved air flotation. Water Science \& Technology, Oxford, v.8, n.43, p.91-98.

RIPLEY, L.E.; BOYLE, W.C.; CONVERSE, J.C. (1986). Improved alkalimetric monitoring anaerobic digestion of high-strenght wastes. Journal of Water Pollution Control Federation, vol. 58, p.406-411.

SALVETTI, R. et al. (2006). Effects of temperature on tertiary nitrification in movingbed biofilm reactors. Water Research, New York, v.40, n.15, p.2981-2993, Aug.

SANTOS, P.I.A. (2001). Aplicação de coagulantes no afluente do reator anaeróbio de leito expandido alimentado com esgoto sanitário, 129 p. Dissertação (Mestrado) - Escola de Engenharia de São Carlos, Universidade de São Paulo, São Carlos, 2001.

SEDLAK, R.I. (Ed.). (1991). Phosphorus and nitrogen removal from municipal wastewater: principles and practice. $2^{\text {nd }} e d$. New York: Lewis.

SILVA, E.L. (1995). Tratamento aeróbio de fenol em reator de leito fluidificado trifásico. 248 p. Tese (Doutorado) - Escola de Engenharia de São Carlos, Universidade de São Paulo, São Carlos, 1995.

SIMAN, R.R. (2007). Reator de leito expandido em escala plena com zonas anaeróbia e aeróbia sobrepostas: remoção conjunta de matéria orgânica e nutrientes e estudo do comportamento microbiológico do biofilme, por respirometria e microsensor de OD. 256 p. Tese (Doutorado) - Escola de Engenharia de São Carlos, Universidade de São Paulo, São Carlos, 2007.

SOWMEYAN, R.; SWAMINATHAN, G. (2008). Performance of inverse anaerobic fluidized bed reactor for treating high strength organic wastewater during star-up phase. Bioresource Technology, Essex, v.99, n.14, p.6280-6284, Sept.

SPEECE, R.E. (1995). Anaerobic biotechnology for industrial wastewaters. Nashville: Archae. p.393, 1995. 
STANDARD methods for the examination of water and wastewater. (2005). 21.ed. Washington, DC: American Public Health Association, American Water Works Association, Water Environment Federation. Paginação irregular.

STOODLEY, P. et al. (1999). Evolving perspectives of biofilm structure. Biofouling, Chur, v.14, n.1, p.75-90.

SUMMERFELT, S.T. (2006). Design and management of conventional fluidized-sand biofilters. Aquacultural Engineering, London, v.34, n.3, p.275-302, May.

SUMRAMPALLI, R. et al. (1997). Nitrification, denitrification and phosphorus removal in sequential batch reactors. Bioresoruce Technology, Esses, v.61, n.2, p.151-157, Aug.

THEREZO, P.E.A. (1993). Avaliação do desempenho de um reator anaeróbio de leito expandido operado sob condições instáveis de carregamento orgânico e hidráulico. 109 p. Dissertação (Mestrado) - Escola de Engenharia de São Carlos, Universidade de São Paulo, São Carlos, 2003.

VELUCHAMY, R.R.A.; BEYENAL, H.; LEWANDOWSKI, Z. (2008). Characterizing temporal development biofilm porosity using artificial neural networks. Water Science \& Technology, Oxford, v.57, n.12, p.1867-1872.

VERSTRAETE, W.; PHILIPS, S. (1998). Nitrification-denitrification process and technologies in new contexts. Environmental Pollution, London, v.102, n.1 (Suppl.1), p.717-726, Mar.

VIEIRA, L.T.G. (2000). Desenvolvimento de sistema misto de leito fixo para remoção de nitrogênio de esgoto sanitário pré-tratado em reator anaeróbio. 144 p. Tese (Doutorado) - Escola de Engenharia de São Carlos, Universidade de São Paulo, São Carlos, 2000.

VIEIRA, M.B.S. (1989). Avaliação do desempenho de um reator anaeróbio de leito fluidificado no tratamento de efluentes líquidos apresentando baixa concentração de DQO. 249 p. Dissertação (Mestrado) - Escola de Engenharia de São Carlos, Universidade de São Paulo, São Carlos, 1989.

WANG, X.C. et al. (2007). Fluidized pellet bed bioreactor: a promising technology for onsite wastewater treatment and reuse. Water Science \& Technology, Oxford, v.55, n.1-2, p.59-67.

WASTEWATER engineering: treatment, disposal, reuse. (2003). $4^{\text {th }}$ ed. Revisada por G.Tchobanoglous; F.Burton; H.D.Stensel. New York: McGraw-Hill. (McGraw-Hill Series in Civil and Environmental Engineering).

XAVIER, J.B.C.; PICIOREANU, J.S.; ALMEIDA, M.C.M. (2005). Monitorização e modelação da estrutura de biofilmes. Boletim de Tecnologia, Porto, n.76, dez. 
YOOCHATCHAVAL, W. et al. (2008). Influence of effluent-recirculation condition on the process performance of expanded granular sludge bed reactor for treating low strength wastewater. Water Science \& Technology, Oxford, v.57, n.6, p.869-873.

ZANG, K. et al. (2006). Identifying Pioneer bacterial species responsible for biofouling membrane bioreactors. Environmental Microbiology, Malden, v.8, n.3, p.433-440, Mar.

ZHOU, D. et al. (2008). Biofilm performance in aerobic fluidized bed reactor during the start-up period. In: INTERNATIONAL CONFERENCE ON BIOINFORMATICS AND BIOMEDICAL ENGINEERING, 2008, Shangai. Proceedings... New York: IEEE. p.3100-3105. 
Página intencionalmente deixada em branco. 
ANEXO A - ENSAIOS GRANULOMÉTRICOS REALIZADOS COM AREIAS PARA ESCOLHA DE MATERIAL SUPORTE 
Tabela A1 Curva granulométrica: areia grossa - Itaporanga

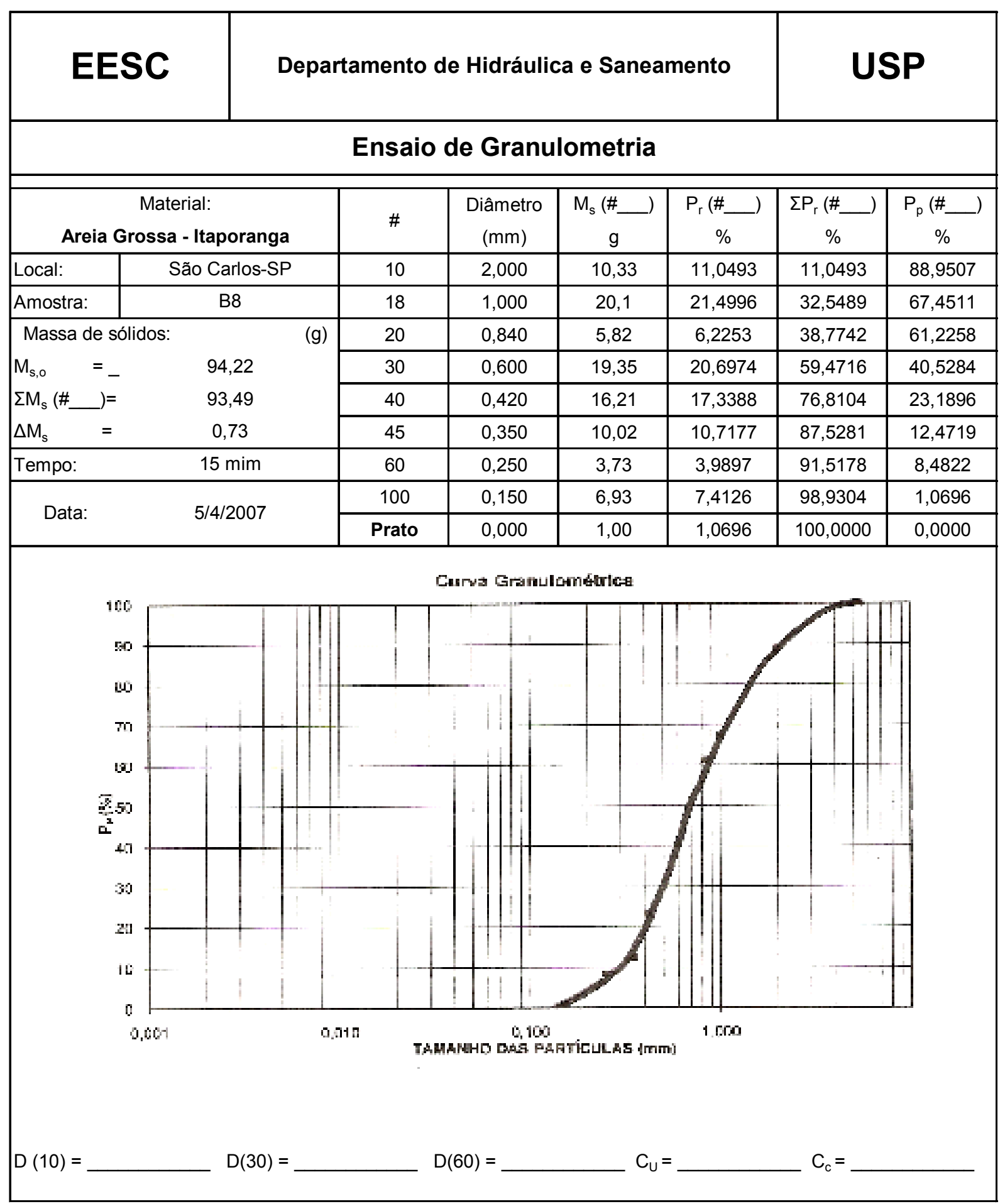


Tabela A2 Curva granulométrica: areia média - Itaporanga

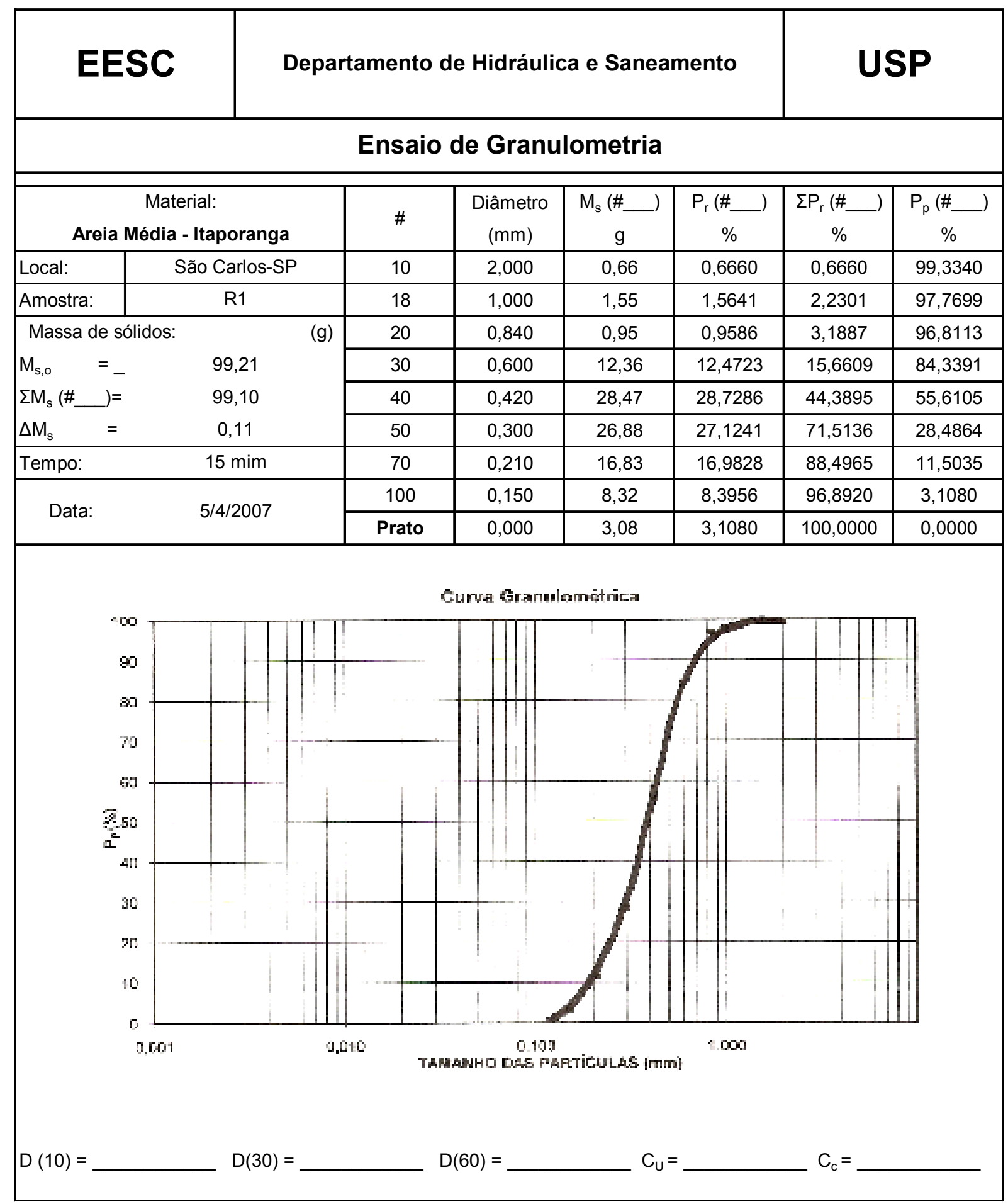


Tabela A3 Curva granulométrica: areia grossa, tipo I - Descalvado

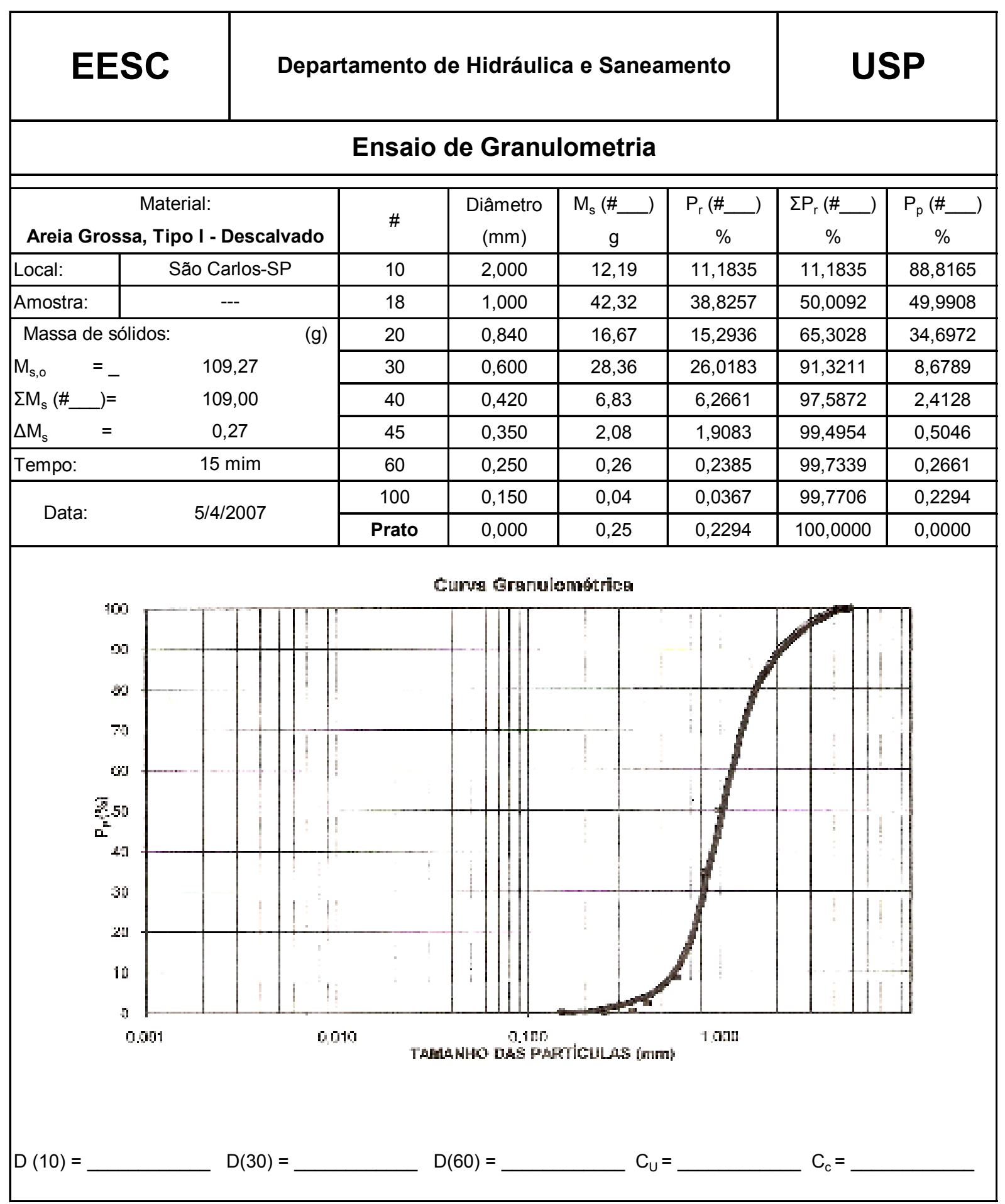


Tabela A4 Curva granulométrica: areia grossa, tipo II - Descalvado

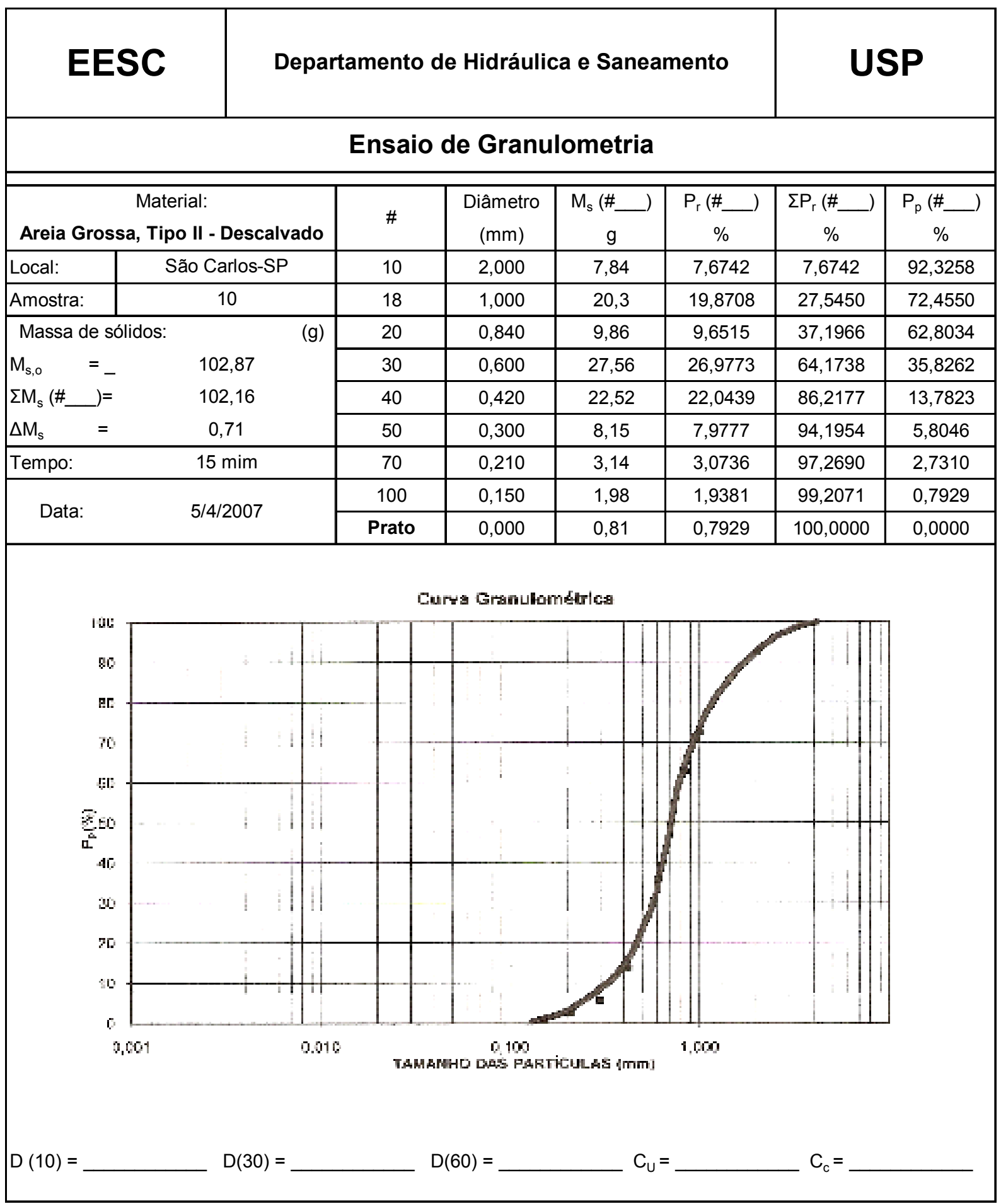


Tabela A5 Curva granulométrica: areia média - Descalvado

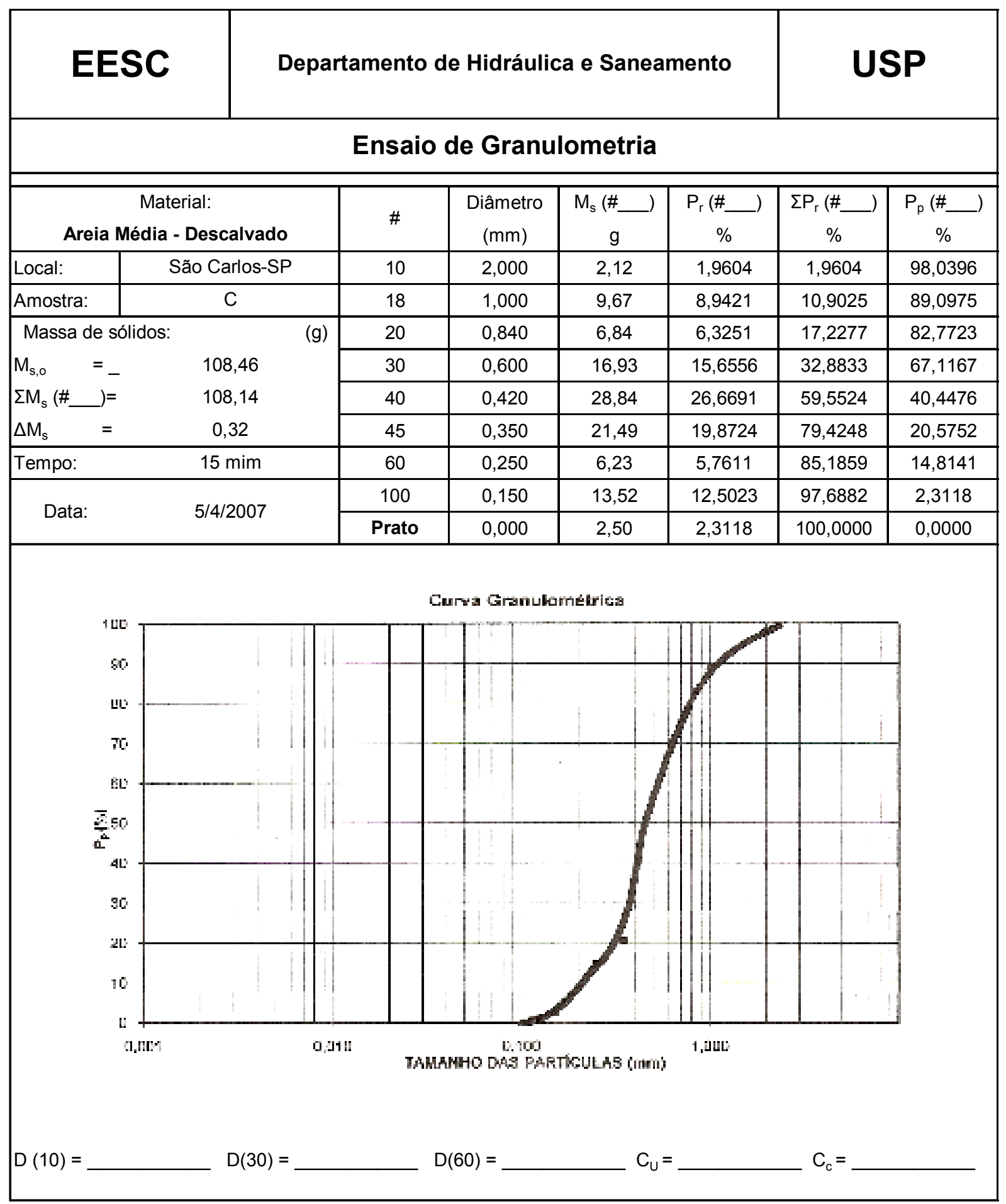


Tabela A6 Curva granulométrica: areia fina - Descalvado

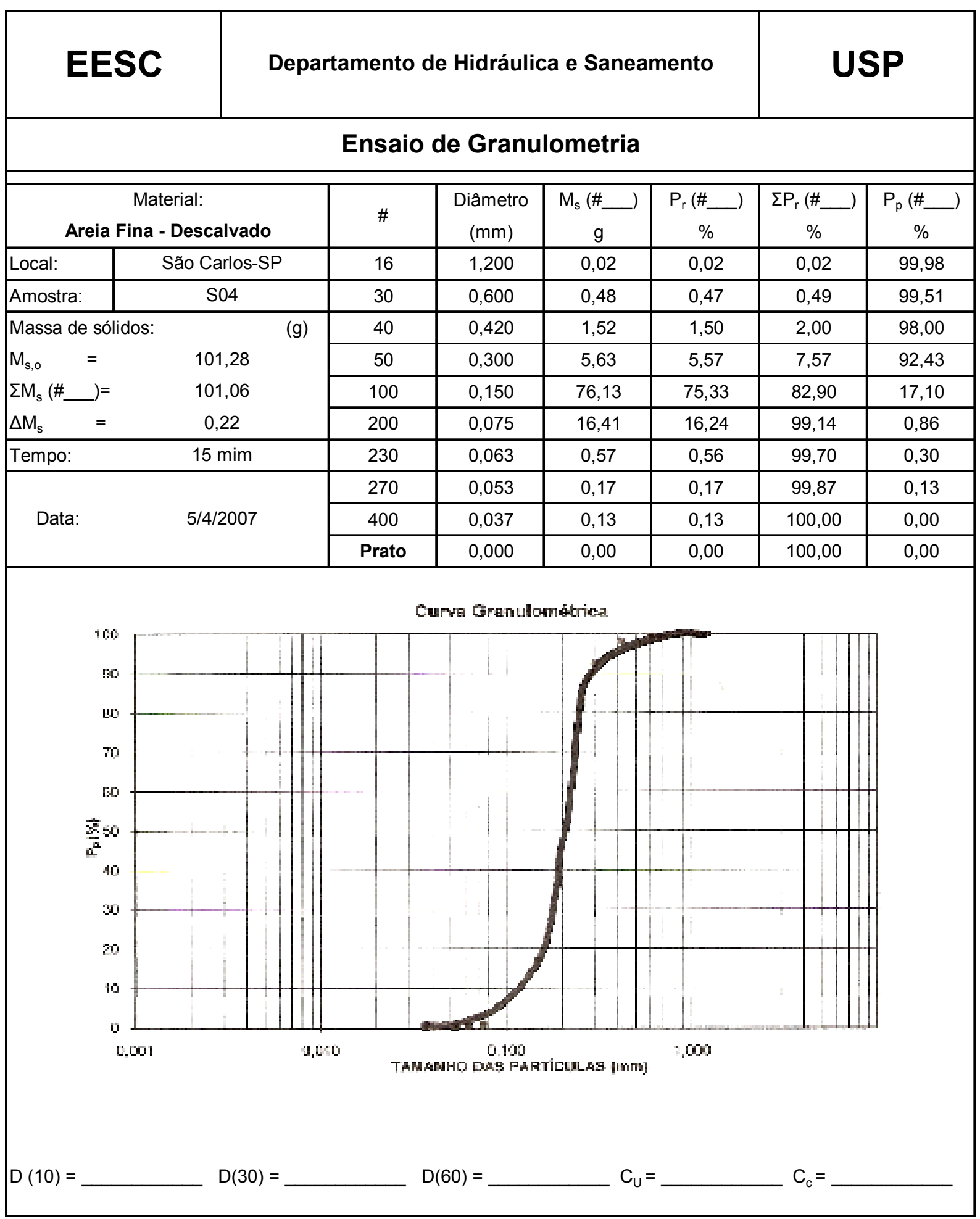


Tabela A7 Curva granulométrica: areia grossa - Mojam

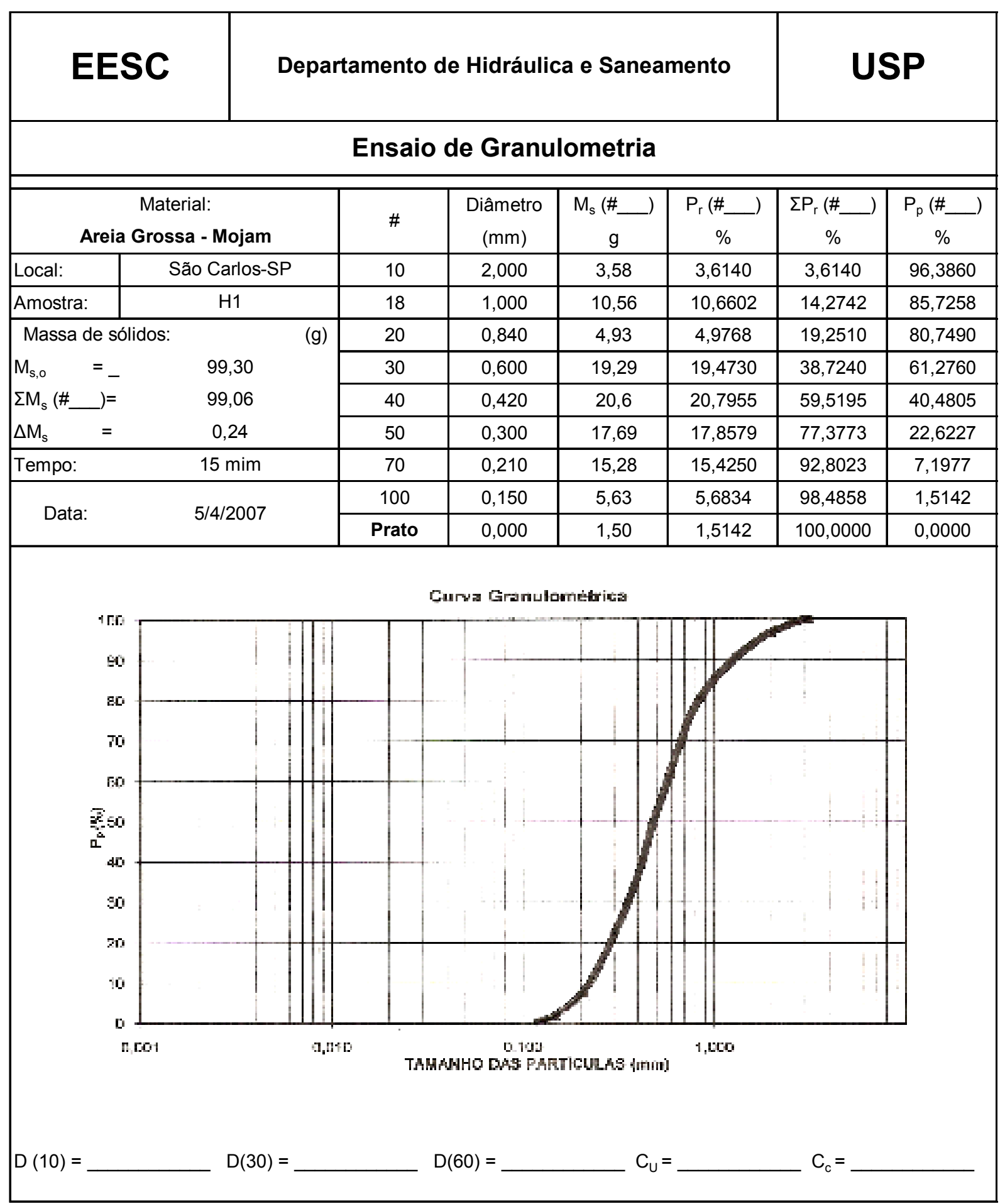


Tabela A8 Curva granulométrica: MIG - Humaitá

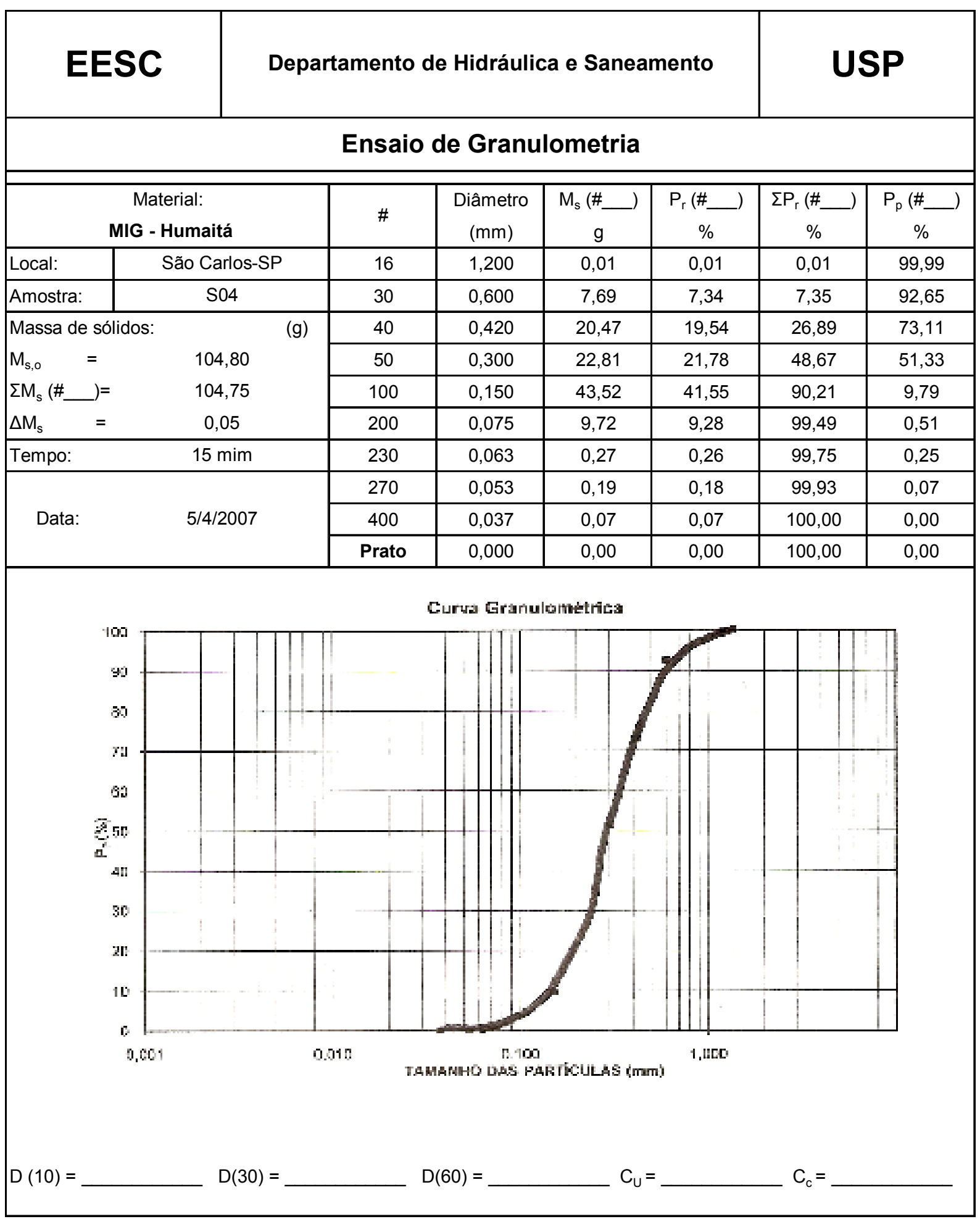


Tabela A9 Curva granulométrica: F5 - Humaitá

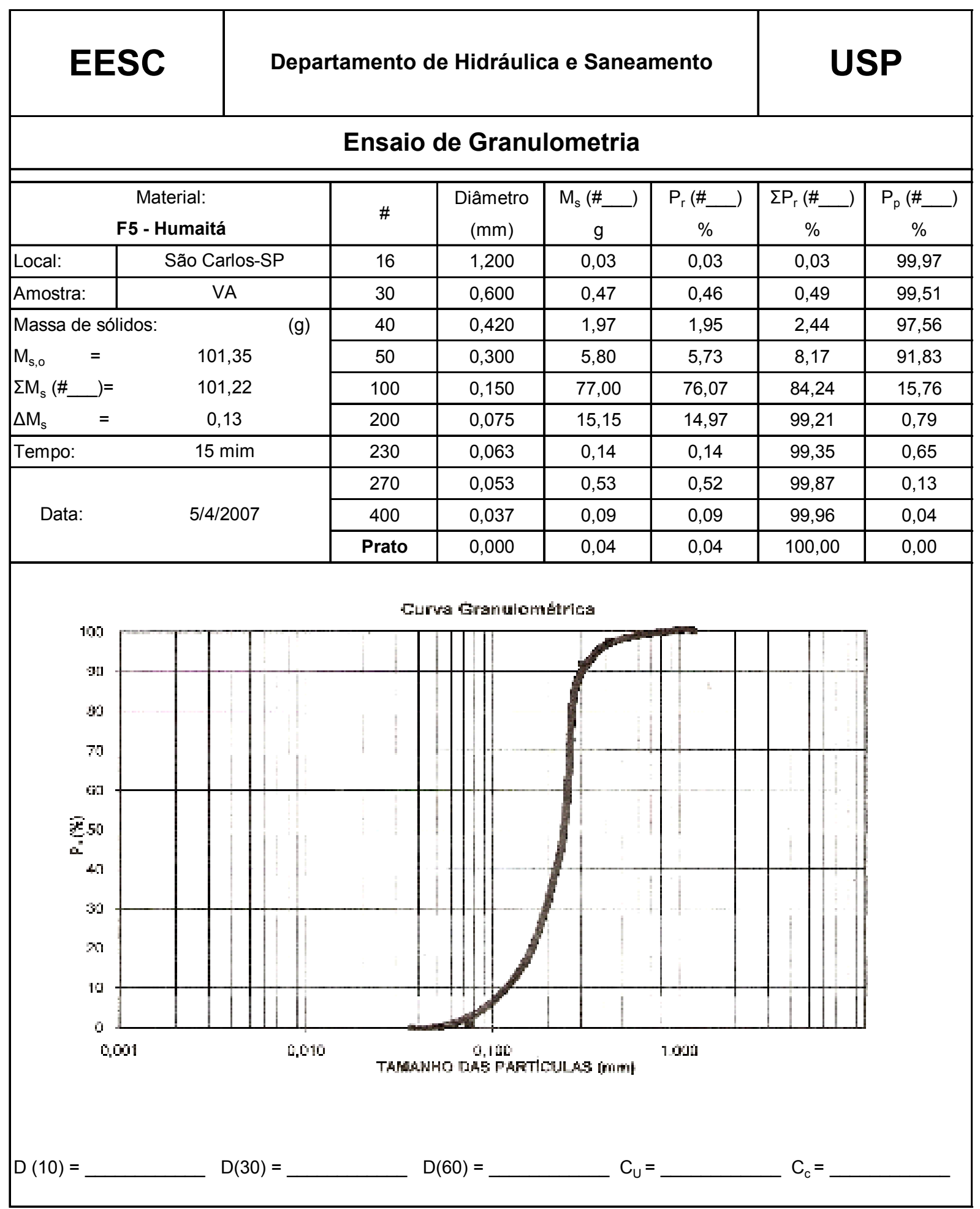


Tabela A10 Curva granulométrica: F100 - Humaitá

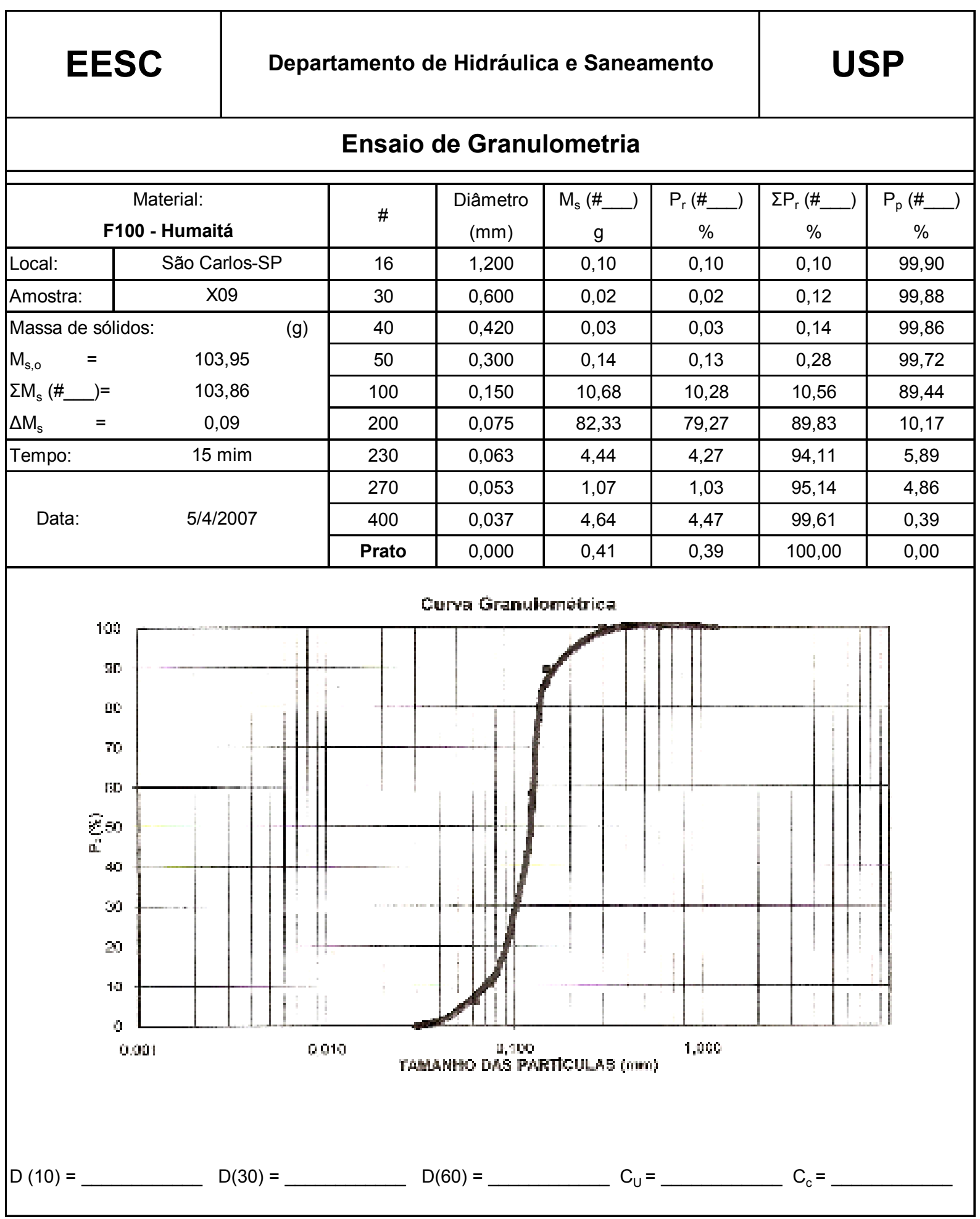


Tabela A11 Curva granulométrica: areia grossa - Água Fria

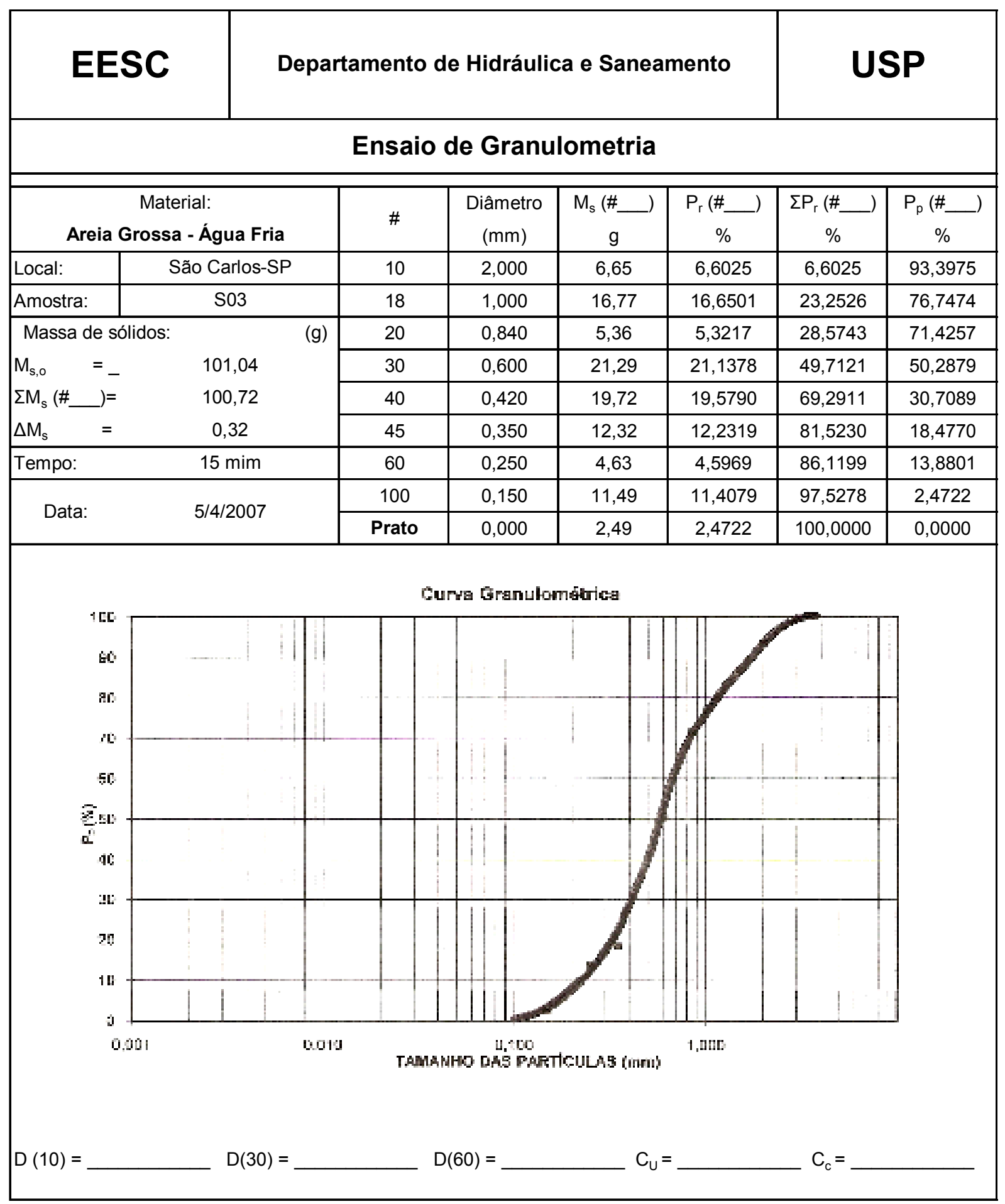


Tabela A12 Curva granulométrica: areia fina - Água Fria

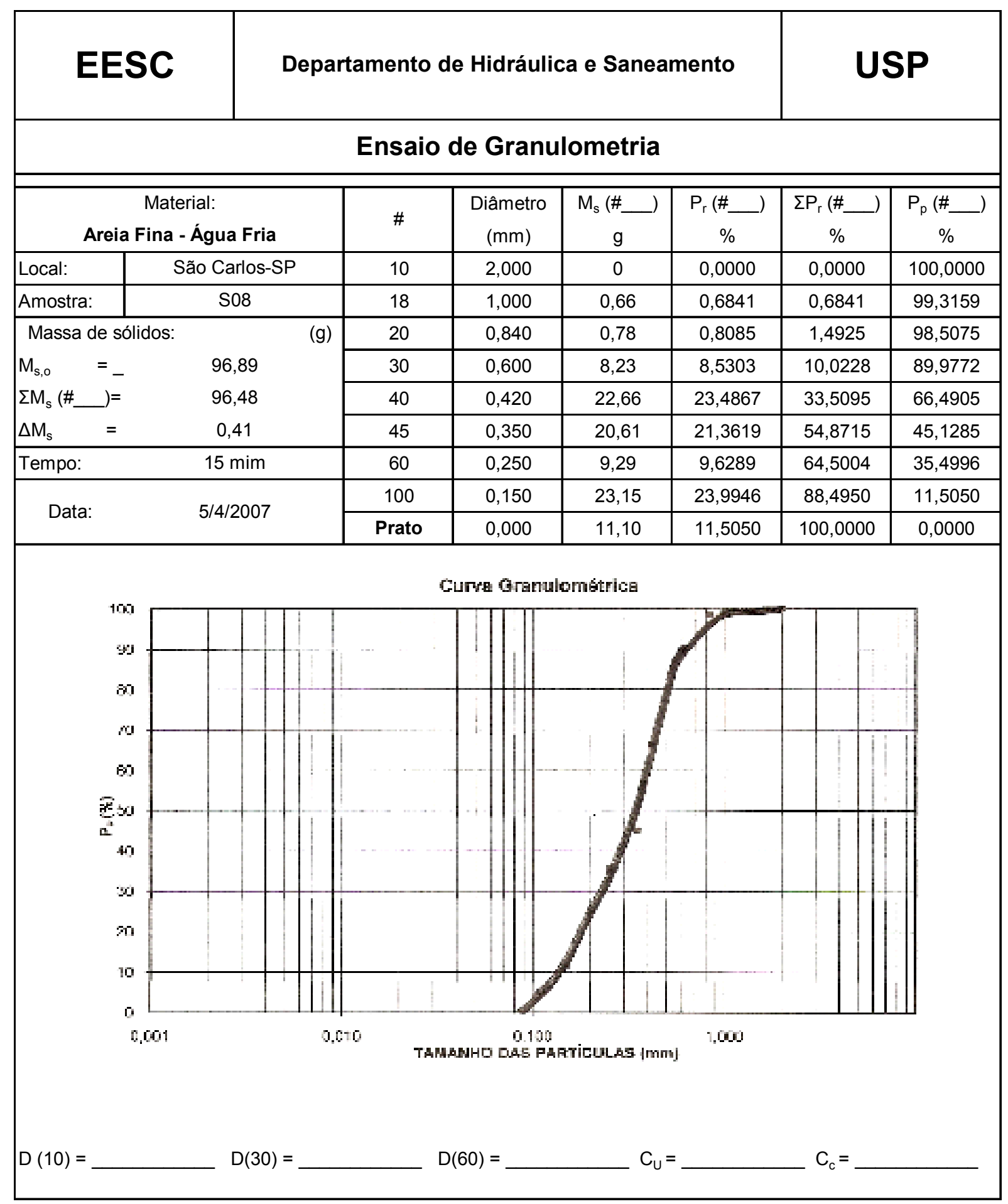


Página intencionalmente deixada em branco. 
ANEXO B - RESULTADOS DE ANÁLISES E DETERMINAÇÕES:

ETAPA I 
Tabela B1 Valores de temperatura, potencial de oxi-redução (POR) e condutividade do afluente e do efluente do reator de leito expandido na Etapa I

\begin{tabular}{|c|c|c|c|c|c|c|c|c|c|}
\hline \multirow[t]{2}{*}{ Fase } & \multirow[t]{2}{*}{ Data } & \multirow{2}{*}{$\begin{array}{c}\text { Tempo em } \\
\text { Operação } \\
\text { (d) }\end{array}$} & \multirow{2}{*}{$\begin{array}{l}\text { TDH } \\
\text { (h) }\end{array}$} & \multicolumn{2}{|c|}{$\begin{array}{l}\text { Temp. } \\
\left({ }^{\circ} \mathrm{C}\right)\end{array}$} & \multicolumn{2}{|c|}{$\begin{array}{l}\text { POR } \\
(\mathrm{mV})\end{array}$} & \multicolumn{2}{|c|}{$\begin{array}{c}\text { Cond. } \\
\left(\mathrm{mS}^{\left.-\mathrm{cm}^{-1}\right)}\right.\end{array}$} \\
\hline & & & & Afl. & Efl. & Afl. & Efl. & Afl. & Efl. \\
\hline \multirow{11}{*}{1} & $06 / 05 / 08$ & 14 & \multirow{6}{*}{14} & 22,9 & 22,0 & -115 & -273 & 0,716 & 0,699 \\
\hline & $13 / 05 / 08$ & 21 & & 22,9 & 22,5 & -287 & -326 & 0,774 & 0,801 \\
\hline & $27 / 05 / 08$ & 35 & & 23,4 & 23,0 & -361 & -256 & 0,625 & 0,643 \\
\hline & 03/06/08 & 42 & & 22,7 & 21,9 & -342 & -266 & 0,677 & 0,828 \\
\hline & $10 / 06 / 08$ & 49 & & 23,5 & 23,3 & -297 & -248 & 0,820 & 0,849 \\
\hline & $17 / 06 / 08$ & 56 & & 22,4 & 22,1 & -341 & -143 & 0,447 & 0,847 \\
\hline & & \multirow{5}{*}{\multicolumn{2}{|c|}{$\begin{array}{r}\text { Média: } \\
\text { Desvio padrão: } \\
\text { Mínimo: } \\
\text { Máximo: } \\
\text { No de Amostras: }\end{array}$}} & 23,0 & 22,5 & -291 & -252 & 0,677 & 0,778 \\
\hline & & & & 0,4 & 0,6 & 91 & 60 & 0,132 & 0,086 \\
\hline & & & & 22,4 & 21,9 & -361 & -326 & 0,447 & 0,643 \\
\hline & & & & 23,5 & 23,3 & -115 & -143 & 0,820 & 0,849 \\
\hline & & & & 6 & 6 & 6 & 6 & 6 & 6 \\
\hline \multirow{8}{*}{2} & $01 / 07 / 08$ & 70 & \multirow{3}{*}{8} & 22,7 & 22,5 & -147 & -161 & 0,601 & 0,897 \\
\hline & $07 / 07 / 08$ & 77 & & 22,7 & 22,5 & -376 & -181 & 0,630 & 0,678 \\
\hline & $15 / 07 / 08$ & 84 & & 22,1 & 21,5 & -227 & -206 & 0,502 & 0,617 \\
\hline & & \multicolumn{2}{|c|}{ Média: } & 22,5 & 22,2 & -250 & -183 & 0,578 & 0,731 \\
\hline & & \multirow{2}{*}{\multicolumn{2}{|c|}{$\begin{array}{r}\text { Desvio padrão: } \\
\text { Mínimo: }\end{array}$}} & 0,3 & 0,6 & 116 & 23 & 0,067 & 0,147 \\
\hline & & & & 22,1 & 21,5 & -376 & -206 & 0,502 & 0,617 \\
\hline & & \multicolumn{2}{|c|}{ Máximo: } & 22,7 & 22,5 & -147 & -161 & 0,630 & 0,897 \\
\hline & & \multicolumn{2}{|c|}{$\mathrm{N}^{\circ}$ de Amostras: } & 3 & 3 & 3 & 3 & 3 & 3 \\
\hline
\end{tabular}


Tabela B2 Valores de pH, alcalinidade parcial (AP), intermediária (AI) e total (AT), ácidos voláteis (AGV) e relações Al/AP e AGV/AT do afluente e do efluente do reator de leito expandido na Etapa I

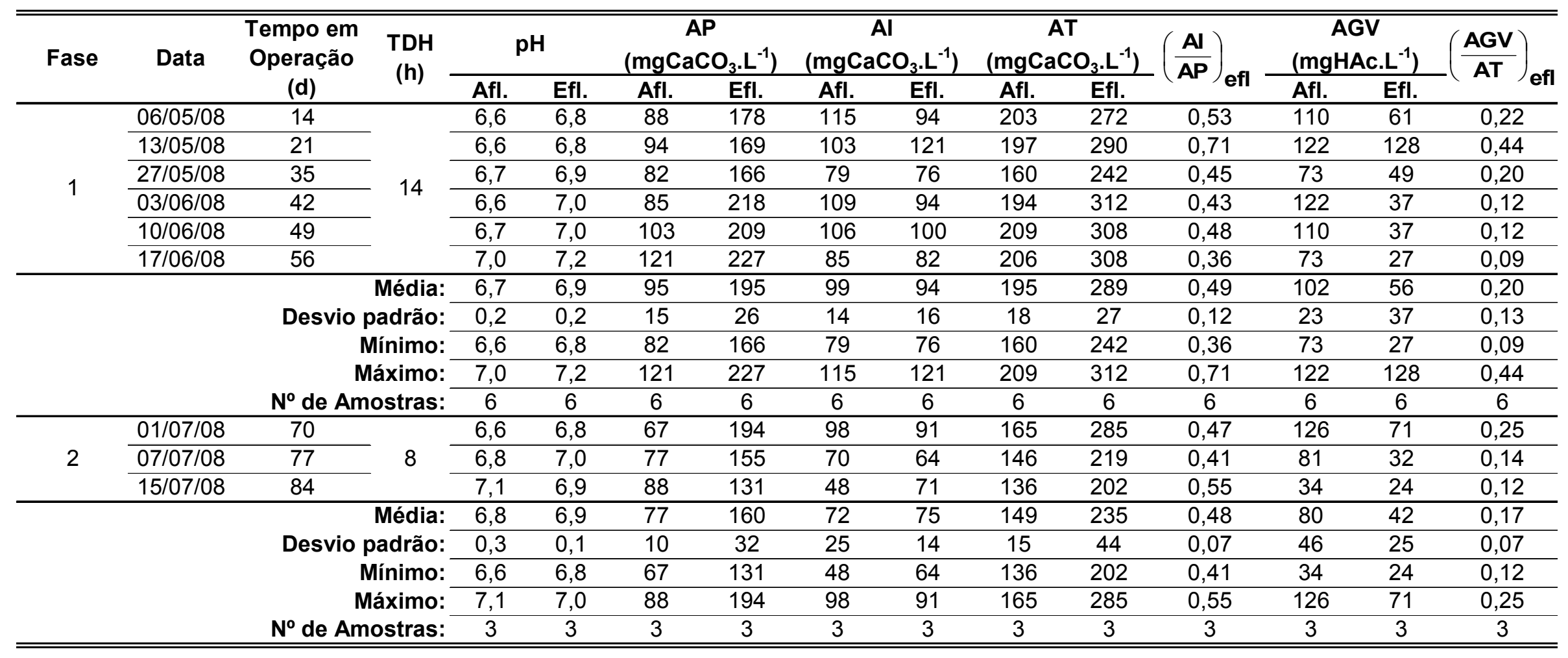


Tabela B3 Valores e eficiências de sólidos totais (ST), fixos (STF) e voláteis (STV) e relação STV/ST do afluente e do efluente do reator de leito expandido na Etapa I

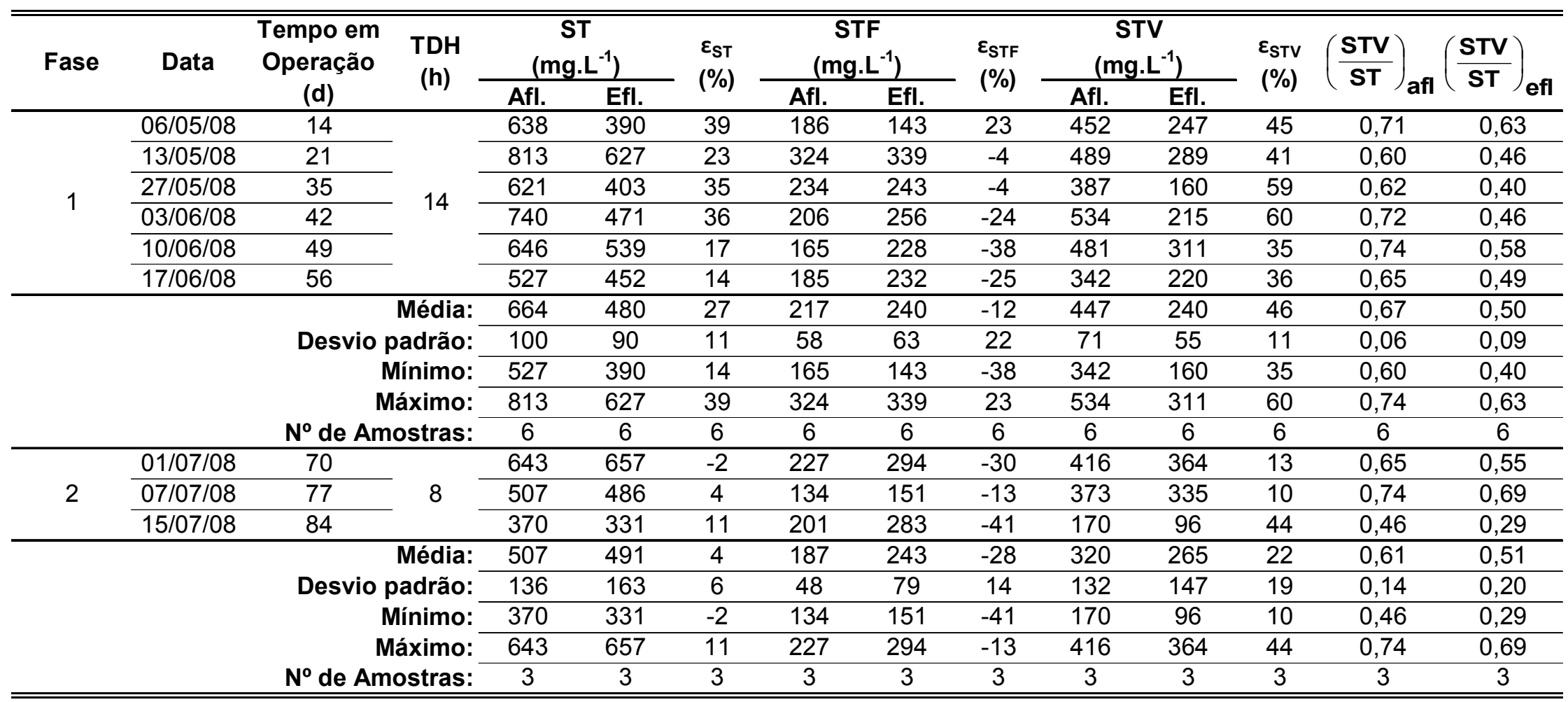


Tabela B4 Valores e eficiências de sólidos em suspensão totais (SST), fixos (SSF) e voláteis (SSV) e relação SSV/SST do afluente e do efluente do reator de leito expandido na Etapa I

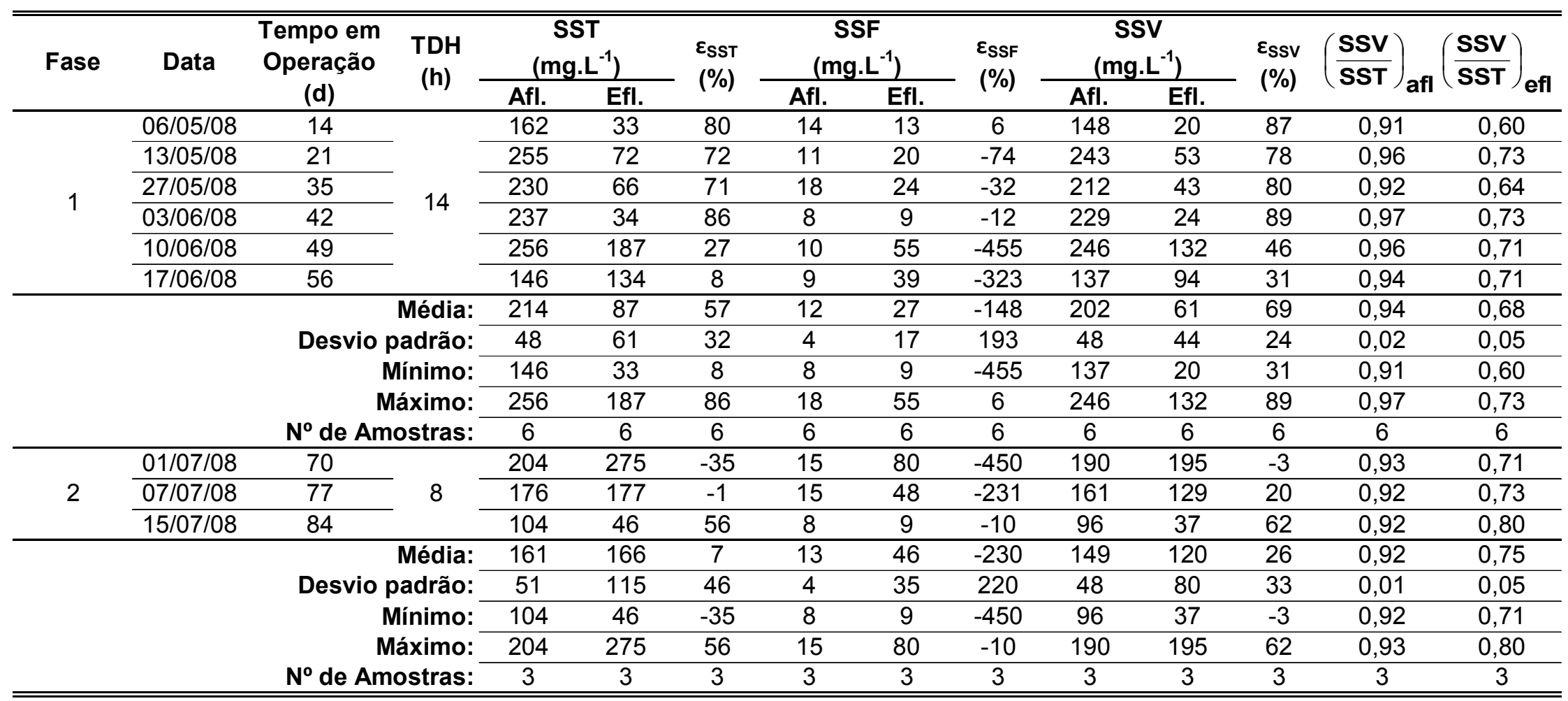


Tabela B5 Valores e eficiência de demanda química de oxigênio total (DQObruta) e filtrada (DQOfilt), cargas orgânicas volumétricas (COV) e relação DQOf/DQOb do afluente e do efluente do reator de leito expandido na Etapa I

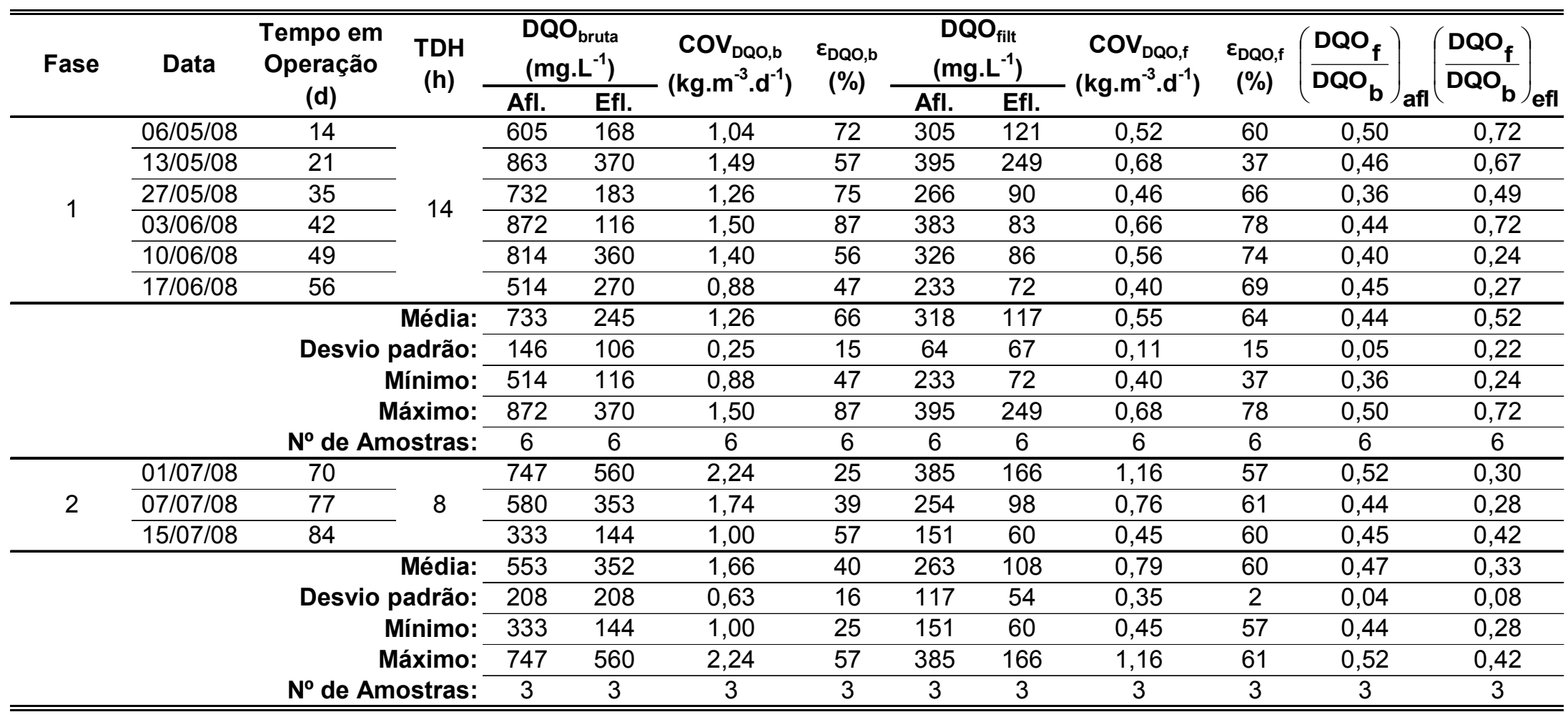


Tabela B6 Valores e eficiência de demanda bioquímica de oxigênio total (DBObruta) e filtrada (DBOfilt), cargas orgânicas volumétricas (COV) e relação DBOf/DBOb do afluente e do efluente do reator de leito expandido na Etapa I

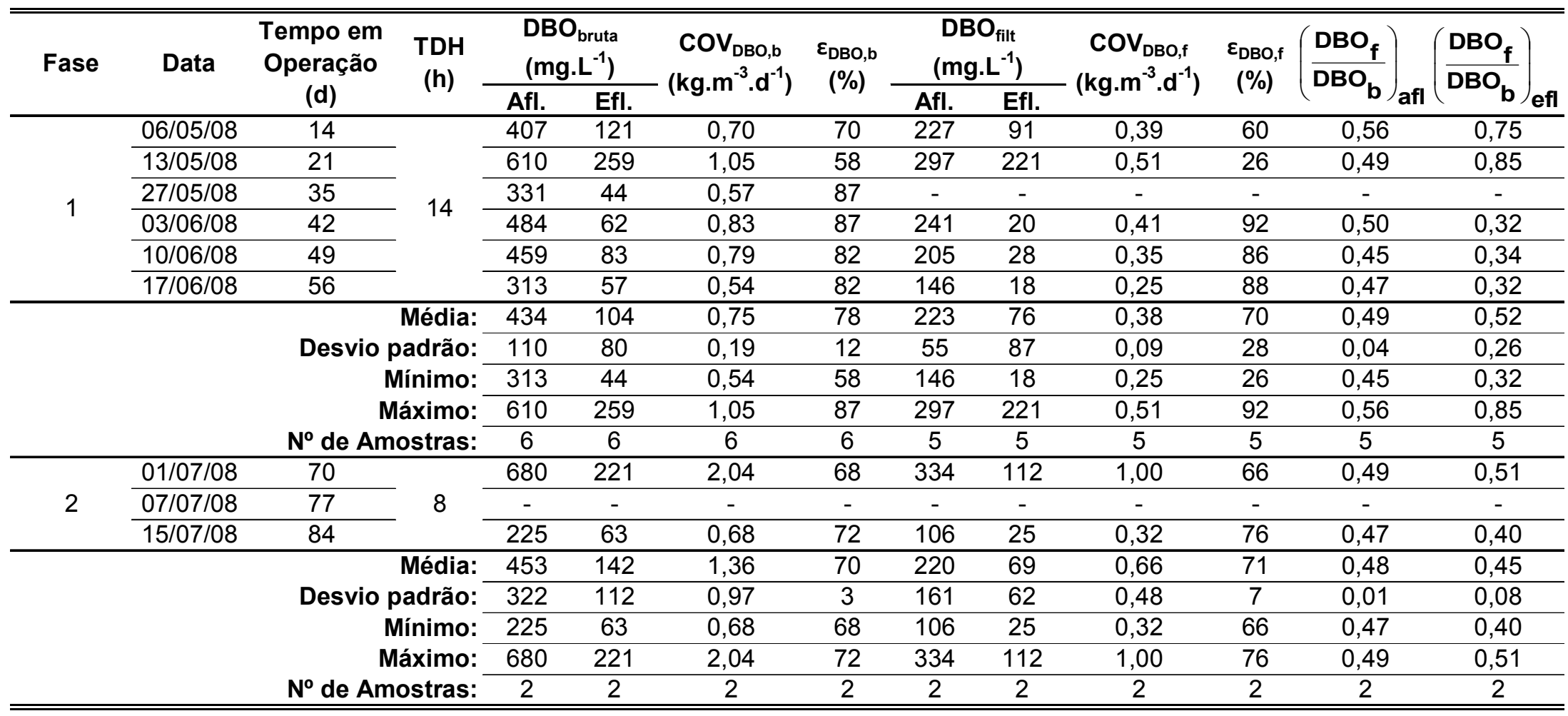


Tabela B7 Valores das relações DBOb/DQOb e DBOf/DQOf do afluente e do efluente do reator de leito expandido na Etapa I

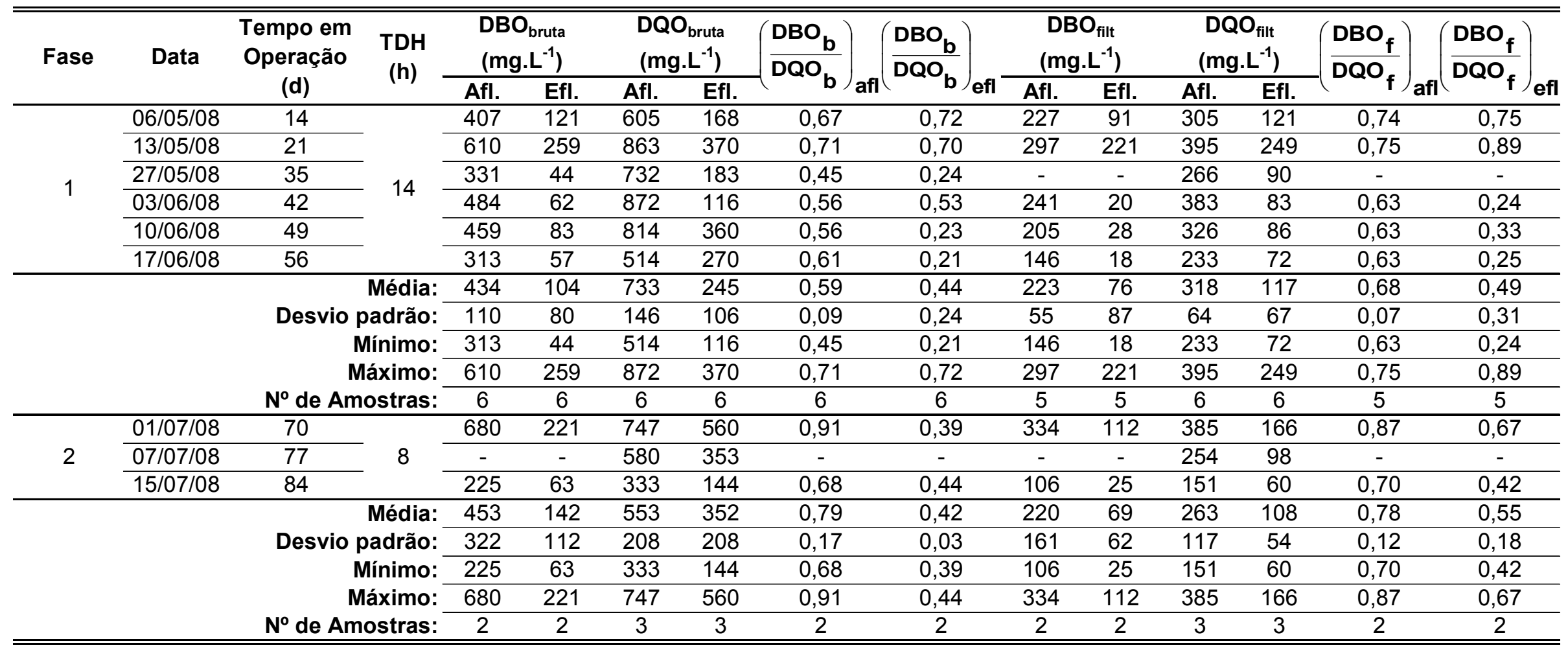


Tabela B8 Valores e eficiências de nitrogênio Kjedhal total (NKT), amoniacal ( $\mathrm{N}$-amon) e orgânico ( $\mathrm{N}$-org), cargas de nitrogênio volumétricas (CNV) e relação $\mathrm{N}$-amon/NKT do afluente e do efluente do reator de leito expandido na Etapa I

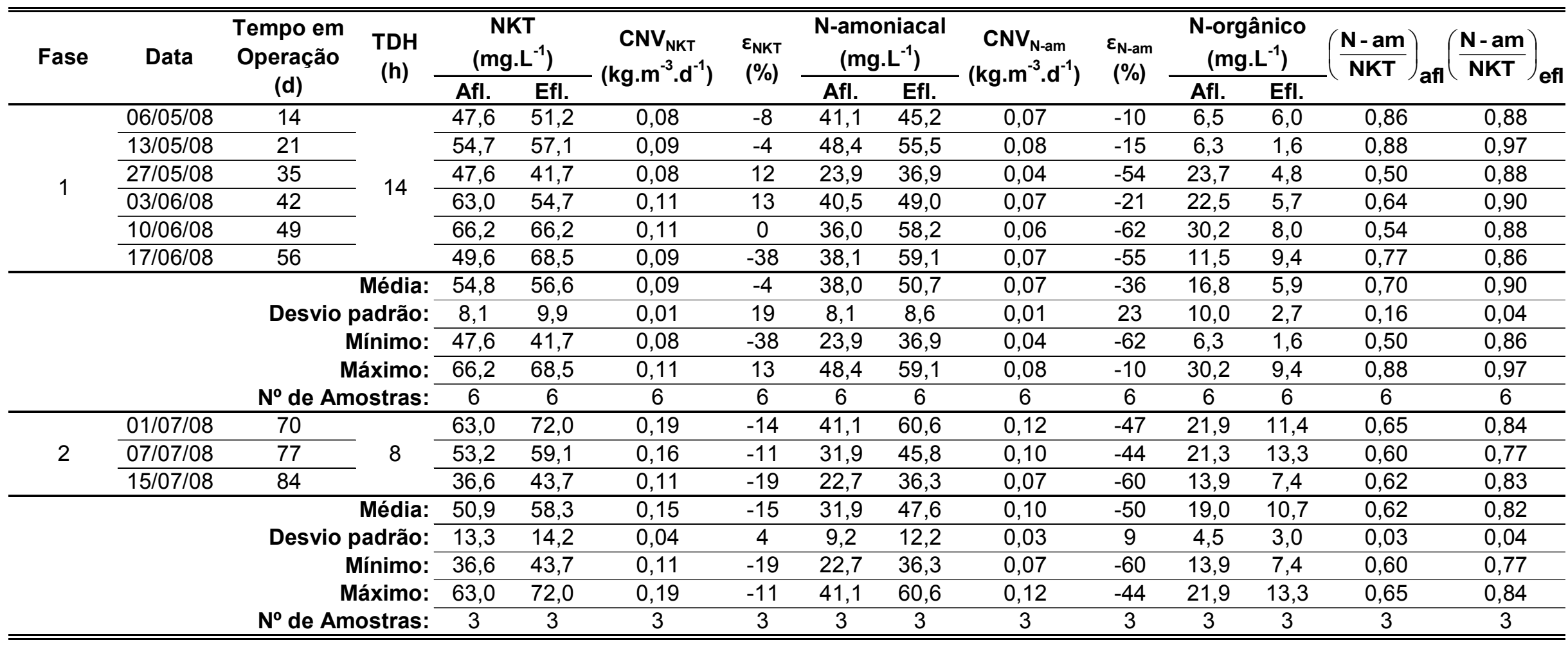


Tabela B9 Valores e eficiências de fósforo $(\mathrm{P})$ e cargas de fósforo volumétrica (CNP) do afluente e do efluente do reator de leito expandido na Etapa I

\begin{tabular}{|c|c|c|c|c|c|c|c|}
\hline \multirow[t]{2}{*}{ Fase } & \multirow[t]{2}{*}{ Data } & \multirow{2}{*}{$\begin{array}{c}\text { Tempo em } \\
\text { Operação } \\
\text { (d) }\end{array}$} & \multirow[t]{2}{*}{$\begin{array}{l}\text { TDH } \\
\text { (h) }\end{array}$} & \multicolumn{2}{|c|}{$\begin{array}{c}\mathrm{P} \\
\left(\mathrm{mgPO}_{4}^{-3} \cdot \mathrm{L}^{-1}\right)\end{array}$} & \multirow{2}{*}{$\begin{array}{c}\text { CPV } \\
\left(\mathrm{kg} \cdot \mathrm{m}^{-3} \cdot \mathrm{d}^{-1}\right)\end{array}$} & \multirow[t]{2}{*}{$\begin{array}{l}\varepsilon_{\mathrm{P}} \\
(\%)\end{array}$} \\
\hline & & & & Afl. & Efl. & & \\
\hline \multirow{11}{*}{1} & $06 / 05 / 08$ & 14 & \multirow{6}{*}{14} & 4,8 & 4,2 & 0,01 & 13 \\
\hline & $13 / 05 / 08$ & 21 & & 6,4 & 5,9 & 0,01 & 8 \\
\hline & $27 / 05 / 08$ & 35 & & 4,4 & 4,2 & 0,01 & 5 \\
\hline & 03/06/08 & 42 & & 6,0 & 5,0 & 0,01 & 17 \\
\hline & $10 / 06 / 08$ & 49 & & 7,4 & 7,4 & 0,01 & 0 \\
\hline & $17 / 06 / 08$ & 56 & & 5,5 & 6,1 & 0,01 & -11 \\
\hline & & & Média: & 5,8 & 5,5 & 0,01 & 5 \\
\hline & & Desvio & adrão: & 1,1 & 1,2 & 0,00 & 10 \\
\hline & & & inimo: & 4,4 & 4,2 & 0,01 & -11 \\
\hline & & & iximo: & 7,4 & 7,4 & 0,01 & 17 \\
\hline & & $N^{0}$ de Am & stras: & 6 & 6 & 6 & 6 \\
\hline \multirow{8}{*}{2} & $01 / 07 / 08$ & 70 & \multirow{3}{*}{8} & 7,5 & 9,5 & 0,02 & -27 \\
\hline & $07 / 07 / 08$ & 77 & & 5,3 & 6,5 & 0,02 & -23 \\
\hline & $15 / 07 / 08$ & 84 & & 3,8 & 5,4 & 0,01 & -42 \\
\hline & & \multirow{2}{*}{\multicolumn{2}{|c|}{$\begin{array}{r}\text { Média: } \\
\text { Desvio padrão: }\end{array}$}} & 5,5 & 7,1 & 0,02 & -30 \\
\hline & & & & 1,9 & 2,1 & 0,01 & 10 \\
\hline & & \multirow{3}{*}{\multicolumn{2}{|c|}{$\begin{array}{l}\text { Mínimo: } \\
\text { Máximo: }\end{array}$}} & 3,8 & 5,4 & 0,01 & -42 \\
\hline & & & & 7,5 & 9,5 & 0,02 & -23 \\
\hline & & & & 3 & 3 & 3 & 3 \\
\hline
\end{tabular}


ANEXO C - RESULTADOS DE ANÁLISES E DETERMINAÇÕES:

ETAPA II 
Tabela C1 Valores de temperatura, potencial de oxi-redução (POR), condutividade e oxigênio dissolvido (OD) do afluente e do efluente do reator de leito expandido na Etapa II

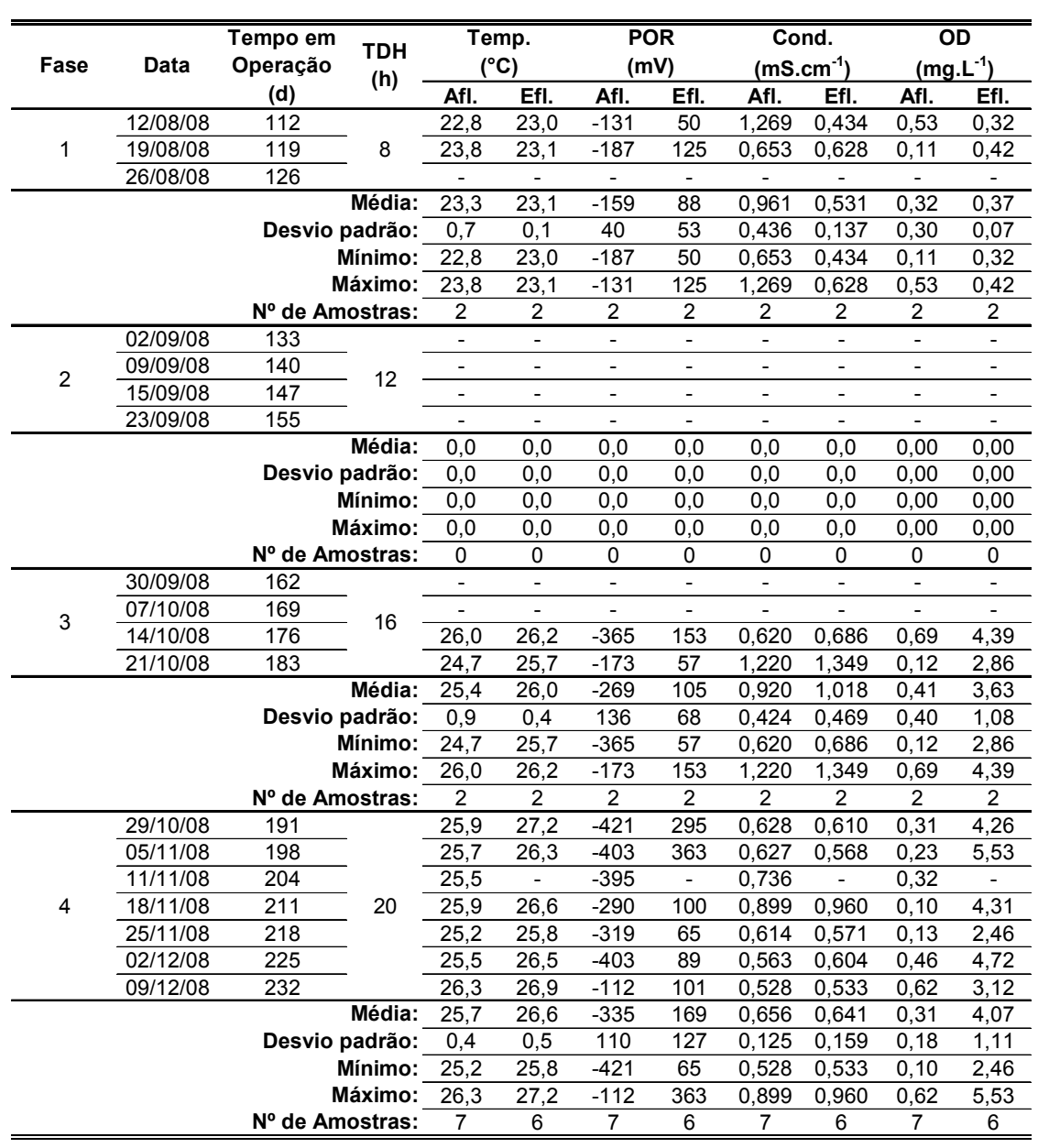


Tabela C2 Valores de pH, alcalinidade parcial (AP), intermediária (Al) e total (AT) e ácidos voláteis (AGV) do afluente e do efluente do reator de leito expandido na Etapa II

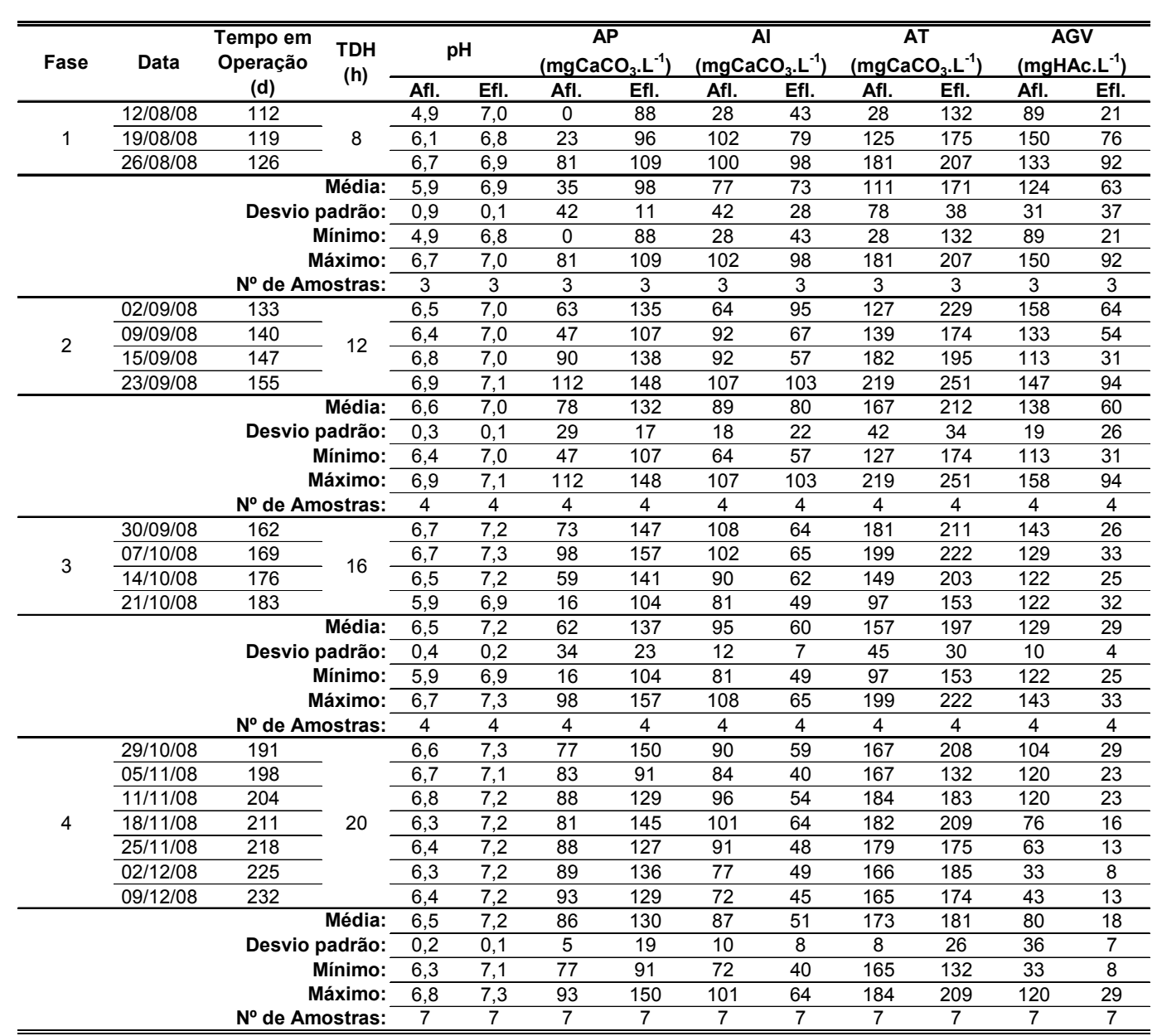


Tabela C3 Valores e eficiências de sólidos totais (ST), fixos (STF) e voláteis (STV) e relação STVIST do afluente e do efluente do reator de leito expandido na Etapa II

\begin{tabular}{|c|c|c|c|c|c|c|c|c|c|c|c|c|c|c|}
\hline \multirow[t]{2}{*}{ Fase } & \multirow[t]{2}{*}{ Data } & \multirow{2}{*}{$\begin{array}{l}\text { Tempo em } \\
\text { Operação } \\
\text { (d) }\end{array}$} & \multirow{2}{*}{$\begin{array}{l}\text { TDH } \\
\text { (h) }\end{array}$} & \multicolumn{2}{|c|}{$\begin{array}{c}\text { ST } \\
\left(\mathrm{mg} \cdot \mathrm{L}^{-1}\right)\end{array}$} & \multirow{2}{*}{$\begin{array}{l}\varepsilon_{S T} \\
(\%)\end{array}$} & \multicolumn{2}{|c|}{$\begin{array}{c}\text { STF } \\
\left(\mathrm{mg} \cdot \mathrm{L}^{-1}\right)\end{array}$} & \multirow{2}{*}{$\begin{array}{l}\varepsilon_{\text {STF }} \\
(\%)\end{array}$} & \multicolumn{2}{|c|}{$\begin{array}{c}\text { STV } \\
\left(\mathrm{mg}^{-L^{-1}}\right)\end{array}$} & \multirow{2}{*}{$\begin{array}{l}\varepsilon_{\text {STV }} \\
(\%)\end{array}$} & \multirow{2}{*}{$\left(\frac{\mathrm{STV}}{\mathrm{ST}}\right)_{\mathrm{afl}}$} & \multirow{2}{*}{$\left(\frac{\text { STV }}{\text { ST }}\right)_{\text {ef }}$} \\
\hline & & & & Afl. & Efl. & & Afl. & Efl. & & Afl. & Efl. & & & \\
\hline \multirow{8}{*}{1} & $12 / 08 / 08$ & 112 & \multirow{3}{*}{8} & 880 & 1690 & -92 & 547 & 805 & -47 & 333 & 885 & -166 & 0,38 & 0,52 \\
\hline & $19 / 08 / 08$ & 119 & & 563 & 834 & -48 & 223 & 291 & -30 & 340 & 544 & -60 & 0,60 & 0,65 \\
\hline & $26 / 08 / 08$ & 126 & & 477 & 745 & -56 & 224 & 292 & -30 & 253 & 453 & -79 & 0,53 & 0,61 \\
\hline & & & Média: & 640 & 1089 & -65 & 331 & 462 & -36 & 309 & 627 & -102 & 0,50 & 0,59 \\
\hline & & Desvio & adrão: & 212 & 522 & 23 & 187 & 297 & 10 & 48 & 228 & 56 & 0,12 & 0,07 \\
\hline & & & ínimo: & 477 & 745 & -92 & 223 & 291 & -47 & 253 & 453 & -166 & 0,38 & 0,52 \\
\hline & & & áximo: & 880 & 1690 & -48 & 547 & 805 & -30 & 340 & 885 & -60 & 0,60 & 0,65 \\
\hline & & $\mathrm{N}^{\circ}$ de $\mathrm{Am}$ & stras: & 3 & 3 & 3 & 3 & 3 & 3 & 3 & 3 & 3 & 3 & 3 \\
\hline \multirow{9}{*}{2} & $02 / 09 / 08$ & 133 & \multirow{4}{*}{12} & 535 & 648 & -21 & 222 & 269 & -21 & 314 & 379 & -21 & 0,59 & 0,59 \\
\hline & 09/09/08 & 140 & & 501 & 566 & -13 & 190 & 217 & -14 & 311 & 350 & -13 & 0,62 & 0,62 \\
\hline & $15 / 09 / 08$ & 147 & & 404 & 437 & -8 & 212 & 228 & -7 & 192 & 209 & -9 & 0,47 & 0,48 \\
\hline & $23 / 09 / 08$ & 155 & & 674 & 757 & -12 & 289 & 302 & -4 & 385 & 455 & -18 & 0,57 & 0,60 \\
\hline & & \multirow{5}{*}{\multicolumn{2}{|c|}{$\begin{array}{r}\text { Média: } \\
\text { Desvio padrão: } \\
\text { Mínimo: } \\
\text { Máximo: } \\
N^{\circ} \text { de Amostras: }\end{array}$}} & 528 & 602 & -14 & 228 & 254 & -12 & 300 & 348 & $\begin{array}{l}-15 \\
\end{array}$ & 0,56 & 0,57 \\
\hline & & & & 112 & 135 & 5 & 43 & 39 & 7 & 80 & 103 & 5 & 0,06 & 0,06 \\
\hline & & & & 404 & 437 & -21 & 190 & 217 & -21 & 192 & 209 & -21 & 0,47 & 0,48 \\
\hline & & & & 674 & 757 & -8 & 289 & 302 & -4 & 385 & 455 & -9 & 0,62 & 0,62 \\
\hline & & & & 4 & 4 & 4 & 4 & 4 & 4 & 4 & 4 & 4 & 4 & 4 \\
\hline \multirow{9}{*}{3} & $30 / 09 / 08$ & 162 & \multirow{4}{*}{16} & 634 & 705 & -11 & 258 & 286 & -11 & 377 & 419 & -11 & 0,59 & 0,59 \\
\hline & $07 / 10 / 08$ & 169 & & 555 & 496 & 11 & 239 & 248 & -4 & 316 & 249 & 21 & 0,57 & 0,50 \\
\hline & $14 / 10 / 08$ & 176 & & 591 & 557 & 6 & 213 & 244 & -15 & 378 & 313 & 17 & 0,64 & 0,56 \\
\hline & $21 / 10 / 08$ & 183 & & 821 & 1099 & -34 & 493 & 688 & -40 & 328 & 411 & -25 & 0,40 & 0,37 \\
\hline & \multirow{5}{*}{\multicolumn{3}{|c|}{$\begin{array}{r}\text { Média: } \\
\text { Desvio padrão: } \\
\text { Mínimo: } \\
\text { Máximo: } \\
\text { No de Amostras: }\end{array}$}} & 650 & 714 & -7 & 300 & 366 & $\begin{array}{l}-17 \\
\end{array}$ & 350 & 348 & 1 & 0,55 & 0,51 \\
\hline & & & & 118 & 271 & 20 & 129 & 215 & 16 & 32 & 82 & 22 & 0,10 & 0,10 \\
\hline & & & & 555 & 496 & -34 & 213 & 244 & -40 & 316 & 249 & -25 & 0,40 & 0,37 \\
\hline & & & & 821 & 1099 & 11 & 493 & 688 & -4 & 378 & 419 & 21 & 0,64 & 0,59 \\
\hline & & & & 4 & 4 & 4 & 4 & 4 & 4 & 4 & 4 & 4 & 4 & 4 \\
\hline \multirow{12}{*}{4} & $29 / 10 / 08$ & 191 & & 622 & 535 & 14 & 244 & 255 & -5 & 378 & 280 & 26 & 0,61 & 0,52 \\
\hline & $05 / 11 / 08$ & 198 & & 495 & 481 & 3 & 163 & 180 & -10 & 333 & 302 & 9 & 0,67 & 0,63 \\
\hline & $11 / 11 / 08$ & 204 & & 696 & 785 & -13 & 248 & 327 & -32 & 448 & 459 & -2 & 0,64 & 0,58 \\
\hline & $18 / 11 / 08$ & 211 & 20 & 819 & 770 & 6 & 405 & 418 & -3 & 414 & 352 & 15 & 0,51 & 0,46 \\
\hline & $25 / 11 / 08$ & 218 & & 553 & 546 & 1 & 206 & 223 & -8 & 347 & 323 & 7 & 0,63 & 0,59 \\
\hline & $02 / 12 / 08$ & 225 & & 554 & 559 & -1 & 191 & 220 & -15 & 363 & 340 & 6 & 0,66 & 0,61 \\
\hline & $09 / 12 / 08$ & 232 & & 438 & 506 & -15 & 104 & 127 & -22 & 335 & 379 & -13 & 0,76 & 0,75 \\
\hline & & & Média: & 596 & 597 & -1 & 223 & 250 & -14 & 374 & 348 & 7 & 0,64 & 0,59 \\
\hline & & Desvio & adrão: & 128 & 126 & 10 & 94 & 97 & 10 & 43 & 59 & 12 & 0,08 & 0,09 \\
\hline & & & ínimo: & 438 & 481 & -15 & 104 & 127 & -32 & 333 & 280 & -13 & 0,51 & 0,46 \\
\hline & & & áximo: & 819 & 785 & 14 & 405 & 418 & -3 & 448 & 459 & 26 & 0,76 & 0,75 \\
\hline & & $\mathrm{N}^{\circ}$ de $\mathrm{Am}$ & ostras: & 7 & 7 & 7 & 7 & 7 & 7 & 7 & 7 & 7 & 7 & 7 \\
\hline
\end{tabular}


Tabela C4 Valores e eficiências de sólidos em suspensão totais (SST), fixos (SSF) e voláteis (SSV) e relação SSVISST do afluente e do efluente do reator de leito expandido na Etapa II

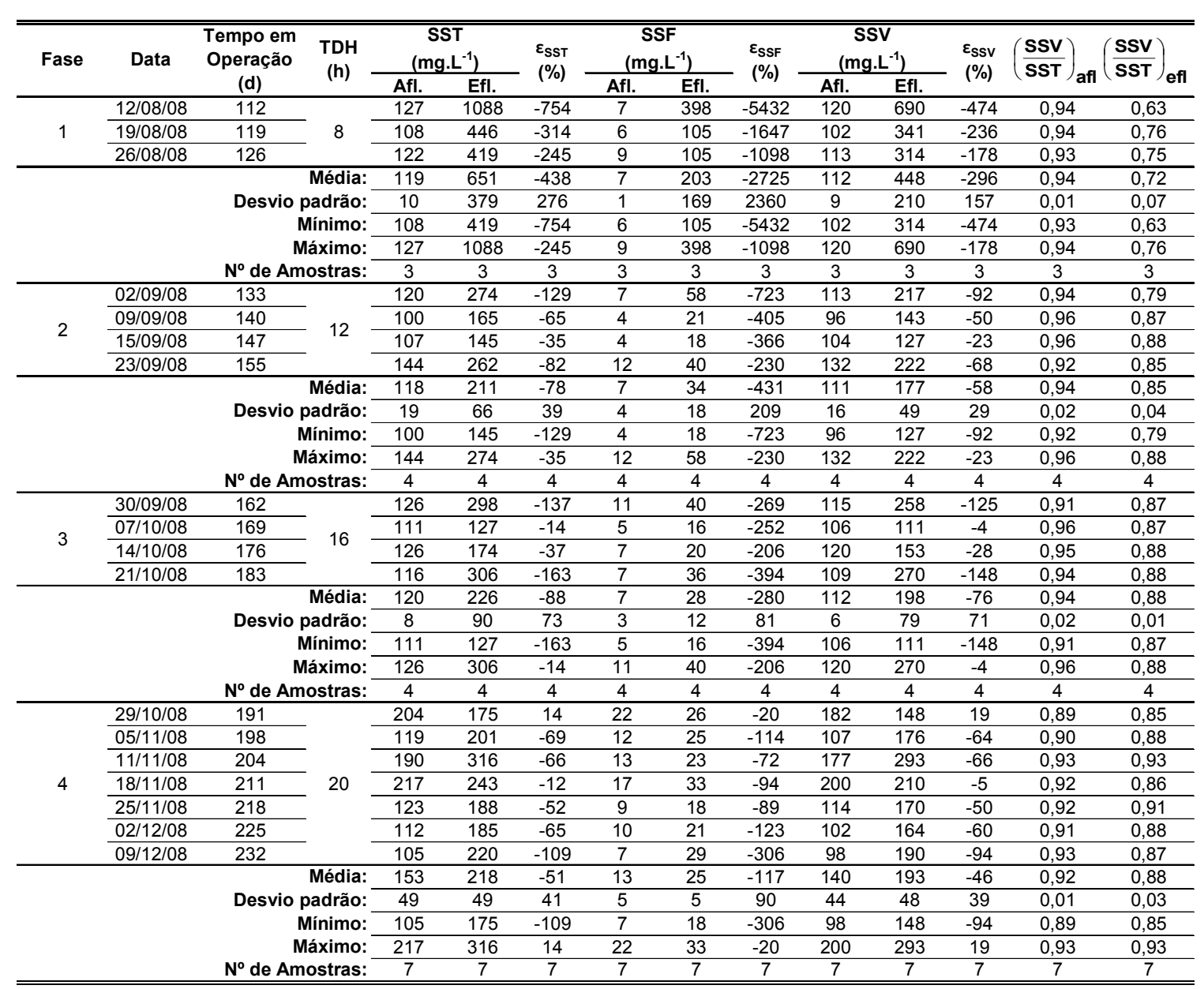


Tabela C5 Valores e eficiência de demanda química de oxigênio bruta (DQObruta) e filtrada (DQOfilt), cargas orgânicas volumétricas (COV) e relação DQOf/DQOb do afluente e do efluente do reator de leito expandido na Etapa II

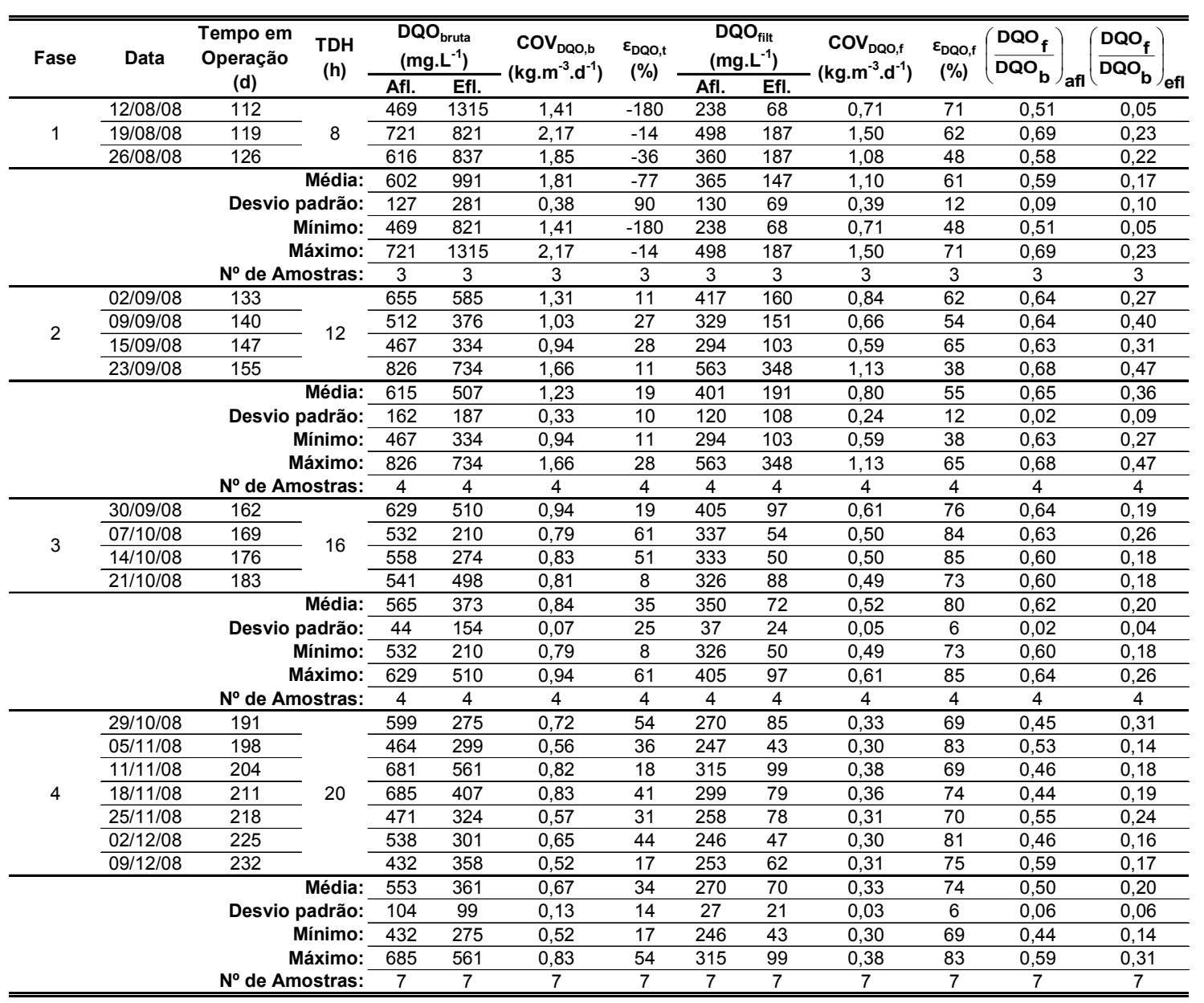


Tabela C6 Valores e eficiência de demanda bioquímica de oxigênio total (DBObruta) e filtrada (DBOfilt), cargas orgânicas volumétricas (COV) e relação DBOf/DBOb do afluente e do efluente do reator de leito expandido na Etapa II

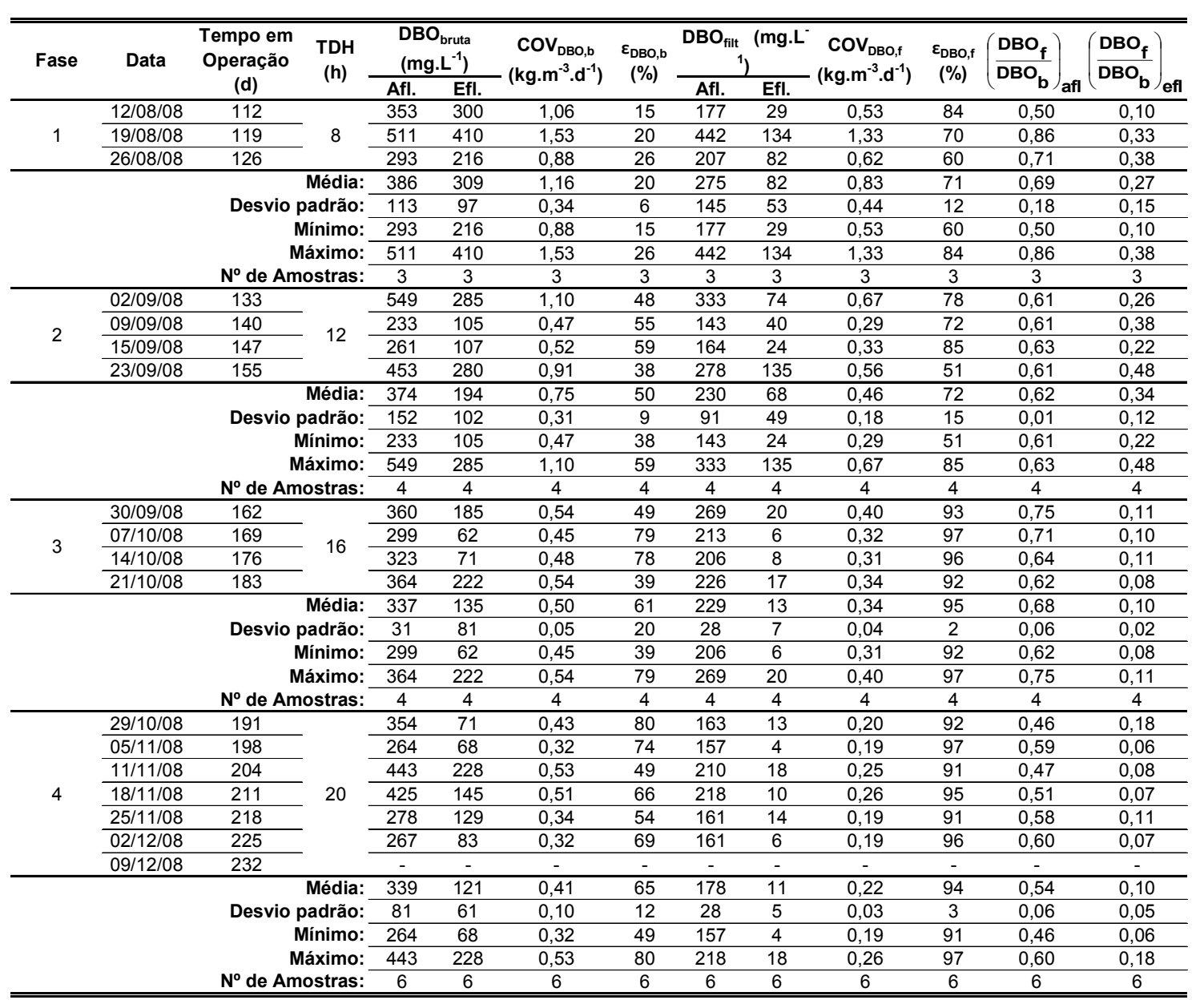


Tabela C7 Valores das relações DBOb/DQOb e DBOf/DQOf do afluente e do efluente do reator de leito expandido na Etapa II

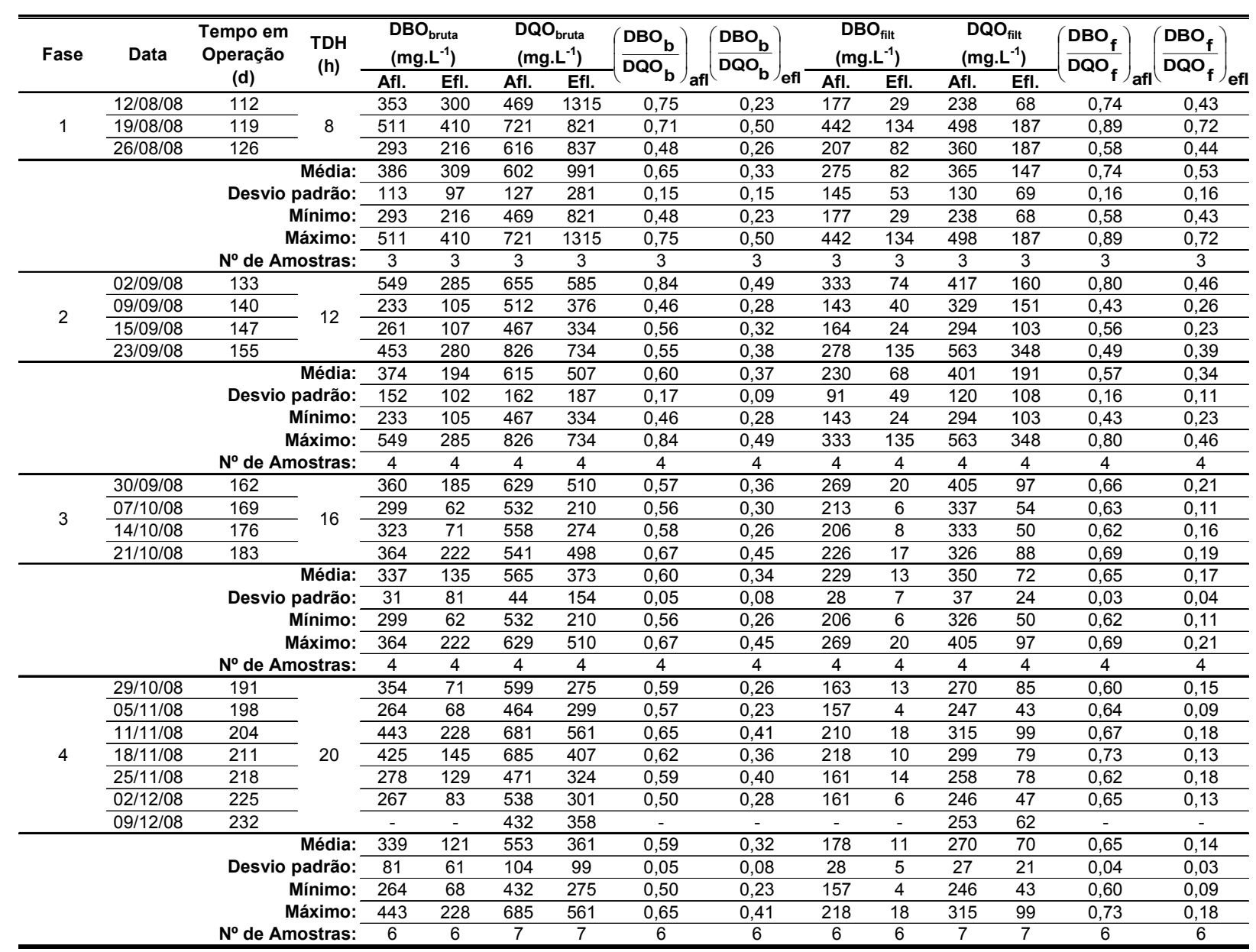


Tabela C8 Valores e eficiências de nitrogênio Kjedhal total (NKT), amoniacal ( $\mathrm{N}$-amon) e orgânico ( $\mathrm{N}$-org), nitrito, nitrato, cargas de nitrogênio volumétricas (CNV) e relação $\mathrm{N}$-amon/NKT do afluente e do efluente do reator de leito expandido na Etapa II

\begin{tabular}{|c|c|c|c|c|c|c|c|c|c|c|c|c|c|c|c|c|c|c|c|c|c|c|c|}
\hline \multirow[t]{2}{*}{ Fase } & \multirow[t]{2}{*}{ Data } & \multirow{2}{*}{$\begin{array}{l}\text { Tempo em } \\
\text { Operação } \\
\text { (d) }\end{array}$} & \multicolumn{2}{|c|}{$\begin{array}{c}\text { NKT } \\
\left(\mathrm{mg} \cdot \mathrm{L}^{-1}\right)\end{array}$} & \multicolumn{2}{|c|}{$\begin{array}{l}\mathrm{NKT}_{\text {filt }} \\
\left(\mathrm{mg}^{-\mathrm{L}^{-1}}\right)\end{array}$} & \multirow{2}{*}{$\begin{array}{c}\mathrm{CNV}_{\mathrm{NKT}} \\
\left(\mathrm{kg} \cdot \mathrm{m}^{-3} \cdot \mathrm{d}^{-1}\right)\end{array}$} & \multirow{2}{*}{$\begin{array}{l}\varepsilon_{\mathrm{NKT}} \\
(\%)\end{array}$} & \multicolumn{2}{|c|}{$\begin{array}{c}\mathrm{N} \text {-amoniacal } \\
\left(\mathrm{mg} \cdot \mathrm{L}^{-1}\right)\end{array}$} & \multirow{2}{*}{$\begin{array}{c}\mathrm{CNV}_{\mathrm{Nam}} \\
\left(\mathbf{k g} \cdot \mathrm{m}^{-3} \cdot \mathrm{d}^{-1}\right)\end{array}$} & \multirow{2}{*}{$\begin{array}{l}\varepsilon_{\mathrm{N}-\mathrm{am}} \\
(\%)\end{array}$} & \multicolumn{2}{|c|}{$\begin{array}{c}\text { N-orgânico } \\
\left(\mathrm{mg} \cdot \mathrm{L}^{-1}\right)\end{array}$} & \multicolumn{2}{|c|}{$\begin{array}{l}\text { Nitrito } \\
\left(\mathrm{mg}^{\left.-L^{-1}\right)}\right.\end{array}$} & \multicolumn{2}{|c|}{$\begin{array}{c}\text { Nitrato } \\
\left(\mathrm{mg}^{\left.-\mathrm{L}^{-1}\right)}\right.\end{array}$} & \multirow{2}{*}{$\left(\frac{\mathbf{N}-\mathbf{a m}}{\mathbf{N K T}}\right)$} & \multirow{2}{*}{ afl $\left(\frac{N-a m}{N K T}\right)_{\text {afl }}$} & \multirow{2}{*}{$\frac{\mathrm{N}-\mathrm{am}}{\mathrm{NKT_{ \text {filt } }}}$} & & $\frac{\mathrm{N}-\mathrm{am}}{\mathrm{NKT}}$ \\
\hline & & & Afl. & Efl. & Afl. & Efl. & & & Afl. & Efl. & & & Afl. & Efl. & Afl. & Efl. & Afl. & Efl. & & & & afl & \\
\hline & $12 / 08 / 08$ & 112 & 54,4 & 81,5 & - & - & 0,16 & -50 & 8,9 & 35,7 & 0,03 & -301 & 45,5 & 45,8 & 0,0 & 0,0 & 0,0 & 0,0 & 0,16 & 0,44 & - & & \\
\hline 1 & $19 / 08 / 08$ & 119 & 57,9 & 61,4 & - & - & 0,17 & -6 & 28,7 & 36,3 & 0,09 & -26 & 29,2 & 25,1 & 0,0 & 0,0 & 0,0 & 0,0 & 0,50 & 0,59 & - & & - \\
\hline & $26 / 08 / 08$ & 126 & 68,5 & 69,7 & - & - & 0,21 & -2 & 39,9 & 45,2 & 0,12 & -13 & 28,6 & 24,5 & 0,0 & 0,0 & 0,0 & 0,0 & 0,58 & 0,65 & 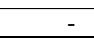 & & - \\
\hline & & Média: & 60,3 & 70,9 & - & - & 0,18 & -19 & 25,8 & 39,1 & 0,08 & -114 & 34,4 & 31,8 & 0,0 & 0,0 & 0,0 & 0,0 & 0,41 & 0,56 & - & & - \\
\hline & & Desvio padrão: & 7,3 & 10,1 & - & - & 0,02 & 27 & 15,7 & 5,3 & 0,05 & 163 & 9,6 & 12,1 & 0,0 & 0,0 & 0,0 & 0,0 & 0,22 & 0,11 & - & & - \\
\hline & & Mínimo: & 54,4 & 61,4 & - & - & 0,16 & -50 & 8,9 & 35,7 & 0,03 & -301 & 28,6 & 24,5 & 0,0 & 0,0 & 0,0 & 0,0 & 0,16 & 0,44 & - & & - \\
\hline & & Máximo: ${ }^{-}$ & 68,5 & 81,5 & - & - & 0,21 & -2 & 39,9 & 45,2 & 0,12 & -13 & 45,5 & 45,8 & 0,0 & 0,0 & 0,0 & 0,0 & 0,58 & 0,65 & - & & - \\
\hline & & $\mathrm{N}^{\circ}$ de Amostras: & 3 & 3 & - & - & 3 & 3 & 3 & 3 & 3 & 3 & 3 & 3 & 3 & 3 & 3 & 3 & 3 & 3 & & & - \\
\hline & $02 / 09 / 08$ & 133 & 65,9 & 69,6 & 43,2 & 54,2 & 0,13 & -6 & 35,4 & 46,6 & 0,07 & -32 & 30,5 & 23,0 & 0,0 & 0,0 & 0,0 & 0,0 & 0,54 & 0,67 & 0,82 & & 0,86 \\
\hline & 09/09/08 & 140 & 48,5 & 53,5 & 34,8 & 43,5 & 0,10 & -10 & 29,5 & 36,1 & 0,06 & -22 & 19,0 & 17,4 & 0,0 & 0,0 & 0,0 & 0,0 & 0,61 & 0,67 & 0,85 & & 0,83 \\
\hline 2 & $15 / 09 / 08$ & 147 & 59,7 & 57,2 & 56,0 & 48,2 & 0,12 & 4 & 44,8 & 41,0 & 0,09 & 8 & 14,9 & 16,2 & 0,0 & 0,0 & 0,0 & 0,0 & 0,75 & 0,72 & 0,80 & & 0,85 \\
\hline & $23 / 09 / 08$ & 155 & 79,6 & 87,0 & 70,9 & 63,4 & 0,16 & -9 & 53,8 & 55,9 & 0,11 & -4 & 25,8 & 31,1 & 0,0 & 0,0 & 0,0 & 0,0 & 0,68 & 0,64 & 0,76 & & 0,88 \\
\hline & & Média: & 63,4 & 66,8 & 51,2 & 52,3 & 0,13 & -5 & 40,9 & 44,9 & 0,08 & -12 & 22,6 & 21,9 & 0,0 & 0,0 & 0,0 & 0,0 & 0,64 & 0,68 & 0,81 & & 0,86 \\
\hline & & Desvio padrão: & 13,0 & 15,1 & 15,7 & 8,6 & 0,03 & 7 & 10,7 & 8,5 & 0,02 & 18 & 6,9 & 6,8 & 0,0 & 0,0 & 0,0 & 0,0 & 0,09 & 0,03 & 0,04 & & 0,02 \\
\hline & & Mínimo: & 48,5 & 53,5 & 34,8 & 43,5 & 0,10 & -10 & 29,5 & 36,1 & 0,06 & -32 & 14,9 & 16,2 & 0,0 & 0,0 & 0,0 & 0,0 & 0,54 & 0,64 & 0,76 & & 0,83 \\
\hline & & Máximo: & 79,6 & 87,0 & 70,9 & 63,4 & 0,16 & 4 & 53,8 & 55,9 & 0,11 & 8 & 30,5 & 31,1 & 0,0 & 0,0 & 0,0 & 0,0 & 0,75 & 0,72 & 0,85 & & 0,88 \\
\hline & & $N^{\circ}$ de Amostras: & 4 & 4 & 4 & 4 & 4 & 4 & 4 & 4 & 4 & 4 & 4 & 4 & 4 & 4 & 4 & 4 & 4 & 4 & 4 & & 4 \\
\hline & $30 / 09 / 08$ & 162 & 67,1 & 73,3 & 55,9 & 51,0 & 0,10 & -9 & 42,9 & 42,9 & 0,06 & 0 & 24,2 & 30,4 & 0,0 & 0,0 & 0,0 & 0,0 & 0,64 & 0,59 & 0,77 & & 0,84 \\
\hline & $07 / 10 / 08$ & 169 & 74,6 & 65,9 & 63,4 & 55,9 & 0,11 & 12 & 51,0 & 46,9 & 0,08 & 8 & 23,6 & 19,0 & 0,0 & 0,0 & 0,0 & 0,0 & 0,68 & 0,71 & 0,80 & & 0,84 \\
\hline 3 & $14 / 10 / 08$ & 176 & 54,7 & 62,2 & 47,2 & 47,2 & 0,08 & -14 & 32,0 & 42,9 & 0,05 & -34 & 22,7 & 19,3 & 0,0 & 0,0 & 0,0 & 0,0 & 0,59 & 0,69 & 0,68 & & 0,91 \\
\hline & $21 / 10 / 08$ & 183 & 62,2 & 74,6 & 54,7 & 49,7 & 0,09 & -20 & 26,4 & 42,6 & 0,04 & -61 & 35,8 & 32,0 & 0,0 & 0,0 & 0,0 & 0,0 & 0,42 & 0,57 & 0,48 & & 0,86 \\
\hline & & Média: & 64,7 & 69,0 & 55,3 & 51,0 & 0,10 & -8 & 38,1 & 43,8 & 0,06 & -22 & 26,6 & 25,2 & 0,0 & 0,0 & 0,0 & 0,0 & 0,58 & 0,64 & 0,68 & & 0,86 \\
\hline & & Desvio padrão: & 8,4 & 5,9 & 6,6 & 3,7 & 0,01 & 14 & 11,0 & 2,1 & 0,02 & 32 & 6,2 & 7,0 & 0,0 & 0,0 & 0,0 & 0,0 & 0,11 & 0,07 & 0,14 & & 0,03 \\
\hline & & Mínimo:- & 54,7 & 62,2 & 47,2 & 47,2 & 0,08 & -20 & 26,4 & 42,6 & 0,04 & -61 & 22,7 & 19,0 & 0,0 & 0,0 & 0,0 & 0,0 & 0,42 & 0,57 & 0,48 & & 0,84 \\
\hline & & Máximo: & 74,6 & 74,6 & 63,4 & 55,9 & 0,11 & 12 & 51,0 & 46,9 & 0,08 & 8 & 35,8 & 32,0 & 0,0 & 0,0 & 0,0 & 0,0 & 0,68 & 0,71 & 0,80 & & 0,91 \\
\hline & & $\mathrm{N}^{\circ}$ de Amostras: & 4 & 4 & 4 & 4 & 4 & 4 & 4 & 4 & 4 & 4 & 4 & 4 & 4 & 4 & 4 & 4 & 4 & 4 & 4 & & 4 \\
\hline & $29 / 10 / 08$ & 191 & 58,4 & 73,3 & 52,2 & 52,2 & 0,07 & -26 & 38,9 & 51,3 & 0,05 & -32 & 19,5 & 22,0 & 0,0 & 0,0 & 0,0 & 0,0 & 0,67 & 0,70 & 0,75 & & 0,98 \\
\hline & $05 / 11 / 08$ & 198 & 42,3 & 47,2 & 52,2 & 38,5 & 0,05 & -12 & 38,9 & 29,2 & 0,05 & 25 & 3,4 & 18,0 & 0,0 & 4,1 & 0,0 & 2,0 & 0,92 & 0,62 & 0,75 & & 0,76 \\
\hline & 11/11/08 & 204 & 64,6 & 63,4 & 48,5 & 39,8 & 0,08 & 2 & 41,3 & 31,7 & 0,05 & 23 & 23,3 & 31,7 & 0,0 & 0,0 & 0,0 & 0,0 & 0,64 & 0,50 & 0,85 & & 0,80 \\
\hline 4 & $18 / 11 / 08$ & 211 & 69,6 & 68,4 & 53,5 & 48,5 & 0,08 & 2 & 40,1 & 39,5 & 0,05 & 1 & 29,5 & 28,9 & 0,0 & 0,1 & 0,0 & 0,1 & 0,58 & 0,58 & 0,75 & & 0,81 \\
\hline & $25 / 11 / 08$ & 218 & 65,9 & 57,2 & 48,5 & 39,8 & 0,08 & 13 & 39,8 & 35,4 & 0,05 & 11 & 26,1 & 21,8 & 0,0 & 0,0 & 0,0 & 0,0 & 0,60 & 0,62 & 0,82 & & 0,89 \\
\hline & $02 / 12 / 08$ & 225 & 56,3 & 55,1 & 41,3 & 45,9 & 0,07 & 2 & 38,5 & 37,0 & 0,05 & 4 & 17,8 & 18,1 & 0,0 & 0,2 & 0,0 & 0,0 & 0,68 & 0,67 & 0,93 & & 0,81 \\
\hline & $09 / 12 / 08$ & 232 & 54,0 & 54,0 & 48,2 & 42,5 & 0,07 & 0 & 37,0 & 35,9 & 0,04 & 3 & 17,0 & 18,1 & 0,0 & 0,0 & 0,0 & 0,0 & 0,69 & 0,66 & 0,77 & & 0,84 \\
\hline & & Média: & 58,7 & 59,8 & 49,2 & 43,9 & 0,07 & -3 & 39,2 & 37,1 & 0,05 & 5 & 19,5 & 22,7 & 0,0 & 0,6 & 0,0 & 0,3 & 0,68 & 0,62 & 0,80 & & 0,84 \\
\hline & & Desvio padrão: & 9,2 & 9,0 & 4,1 & 5,1 & 0,01 & 12 & $\frac{1,4}{1,4}$ & 7,1 & 0,00 & 19 & 8,4 & 5,6 & 0,0 & 1,5 & 0,0 & 0,8 & 0,11 & 0,07 & 0,07 & & 0,07 \\
\hline & & Mínimo: & 42,3 & 47,2 & 41,3 & 38,5 & 0,05 & -26 & 37,0 & 29,2 & 0,04 & -32 & 3,4 & 18,0 & 0,0 & 0,0 & 0,0 & 0,0 & 0,58 & 0,50 & 0,75 & & 0,76 \\
\hline & & Máximo: & 69,6 & 73,3 & 53,5 & 52,2 & 0,08 & 13 & 41,3 & 51,3 & 0,05 & 25 & 29,5 & 31,7 & 0,0 & 4,1 & 0,0 & 2,0 & 0,92 & 0,70 & 0,93 & & 0,98 \\
\hline & & $\mathrm{N}^{\circ}$ de Amostras: & 7 & 7 & 7 & 7 & 7 & 7 & 7 & 7 & 7 & 7 & 7 & 7 & 7 & 7 & 7 & 7 & 7 & 7 & 7 & & 7 \\
\hline
\end{tabular}


Tabela C9 Valores e eficiências de fósforo $(P)$ e cargas de fósforo volumétrica (CNP) do afluente e do efluente do reator de leito expandido na Etapa II

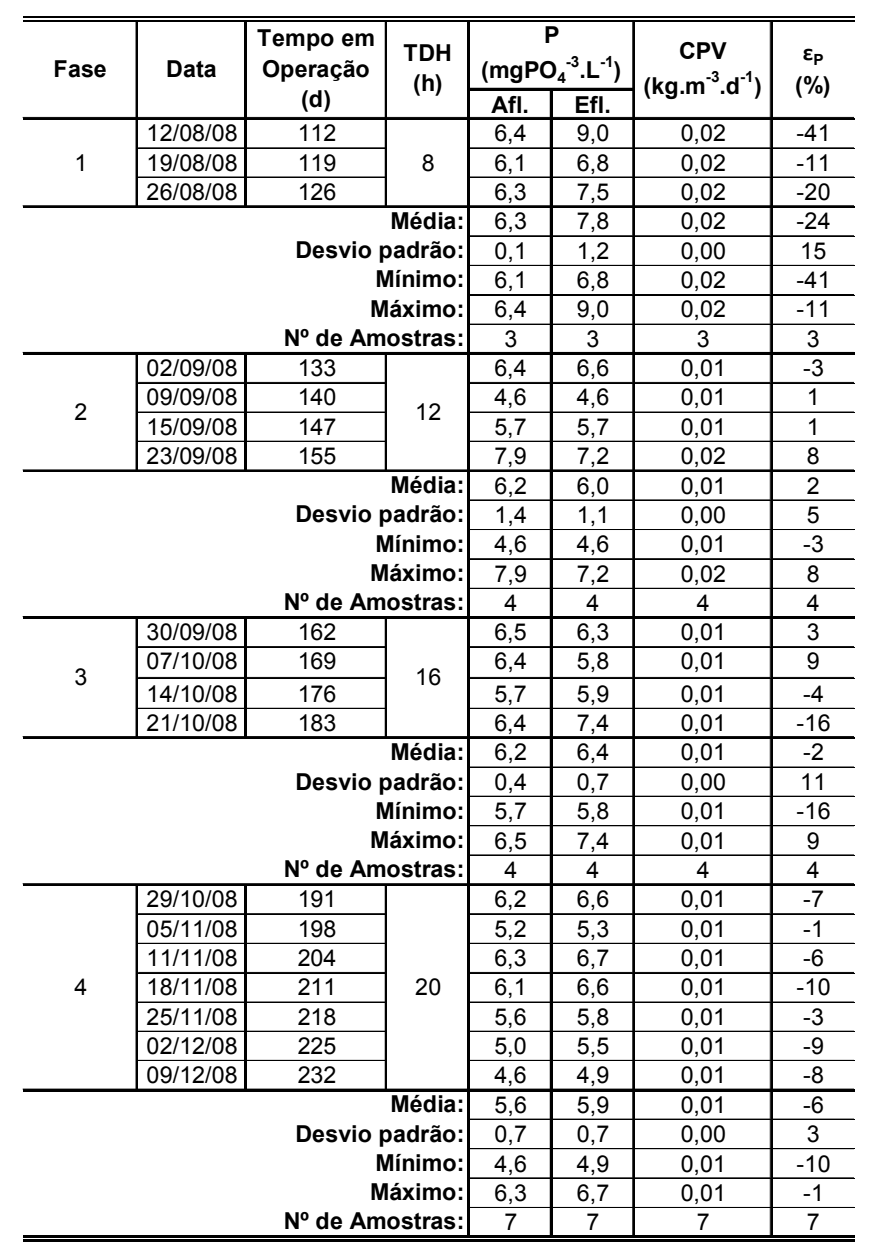


ANEXO D - RESULTADOS DE ANÁLISES E DETERMINAÇÕES:

PERFIS 1, 2 E 3 
Tabela D1 Valores de temperatura, potencial de oxi-redução (POR), condutividade e oxigênio dissolvido (OD) dos perfis $1 ; 2$ e 3 realizados ao longo da altura do reator de leito expandido

\begin{tabular}{|c|c|c|c|c|c|c|c|}
\hline Data & Etapa & Fase & $\begin{array}{c}\text { Ponto de } \\
\text { coleta }\end{array}$ & $\begin{array}{c}\text { Temp. } \\
\left({ }^{0} \mathrm{C}\right)\end{array}$ & $\begin{array}{l}\text { POR } \\
(\mathrm{mV})\end{array}$ & $\begin{array}{c}\text { Cond. } \\
\left(\mathrm{mS}^{\left.-\mathrm{cm}^{-1}\right)}\right.\end{array}$ & $\begin{array}{c}\text { OD } \\
\left(\mathrm{mg}^{-1} \mathrm{~L}^{-1}\right)\end{array}$ \\
\hline \multirow{5}{*}{$17 / 06 / 08$} & \multirow{5}{*}{ I } & \multirow{5}{*}{1} & afluente & 22,4 & -341 & 0,447 & 0,09 \\
\hline & & & 3 & 21,3 & -321 & 0,154 & 0,03 \\
\hline & & & 5 & 21,9 & -312 & 0,513 & 0,25 \\
\hline & & & 7 & 22,0 & -334 & 0,496 & 0,07 \\
\hline & & & efluente & 22,1 & -143 & 0,847 & 0,00 \\
\hline \multirow{5}{*}{$21 / 10 / 08$} & \multirow{5}{*}{ II } & \multirow{5}{*}{3} & afluente & 24,7 & -173 & 1,220 & 0,00 \\
\hline & & & 3 & 24,8 & -244 & 0,894 & 0,34 \\
\hline & & & 5 & 24,6 & 35 & 0,785 & 1,50 \\
\hline & & & 7 & 24,6 & 80 & 0,985 & 1,83 \\
\hline & & & efluente & 25,7 & 57 & 1,349 & 2,90 \\
\hline \multirow{5}{*}{$02 / 12 / 08$} & \multirow{5}{*}{ II } & \multirow{5}{*}{4} & afluente & 25,5 & -403 & 0,563 & 0,50 \\
\hline & & & 3 & 24,2 & -268 & 0,399 & 0,35 \\
\hline & & & 5 & 26,2 & 139 & 0,458 & 2,15 \\
\hline & & & 7 & 25,2 & 134 & 0,437 & 2,10 \\
\hline & & & efluente & 26,5 & 89 & 0,604 & 4,70 \\
\hline
\end{tabular}


Tabela D2 Valores de pH, alcalinidade parcial (AP), intermediária (Al) e total (AT) e ácidos voláteis (AGV) dos perfis 1; 2 e 3 realizados ao longo da altura do reator de leito expandido

\begin{tabular}{|c|c|c|c|c|c|c|c|c|}
\hline Data & Etapa & Fase & $\begin{array}{l}\text { Ponto de } \\
\text { coleta }\end{array}$ & $\mathrm{pH}$ & $\begin{array}{c}\mathrm{AP} \\
\left(\mathrm{mgCaCO}_{3} \cdot \mathrm{L}^{-1}\right)\end{array}$ & $\begin{array}{c}\mathrm{Al} \\
\left(\mathrm{mgCaCO}_{3} \cdot \mathrm{L}^{-1}\right)\end{array}$ & $\begin{array}{c}\mathrm{AT} \\
\left(\mathrm{mgCaCO}_{3} \cdot \mathrm{L}^{-1}\right)\end{array}$ & 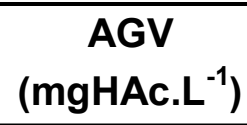 \\
\hline \multirow{5}{*}{$17 / 06 / 08$} & \multirow{5}{*}{ I } & \multirow{5}{*}{1} & afluente & 7,0 & 121 & 85 & 206 & 73 \\
\hline & & & 3 & 6,8 & 175 & 80 & 250 & 60 \\
\hline & & & 5 & 6,6 & 183 & 83 & 266 & 55 \\
\hline & & & 7 & 6,8 & 199 & 80 & 282 & 30 \\
\hline & & & efluente & 7,2 & 206 & 82 & 308 & 27 \\
\hline \multirow{5}{*}{ 21/10/08 } & \multirow{5}{*}{ II } & \multirow{5}{*}{3} & afluente & 5,9 & 16 & 81 & 97 & 122 \\
\hline & & & 3 & 6,1 & 32 & 101 & 133 & 130 \\
\hline & & & 5 & 6,2 & 57 & 128 & 185 & 114 \\
\hline & & & 7 & 6,3 & 45 & 103 & 147 & 117 \\
\hline & & & efluente & 6,9 & 104 & 49 & 153 & 32 \\
\hline \multirow{5}{*}{ 02/12/08 } & \multirow{5}{*}{ II } & \multirow{5}{*}{4} & afluente & 6,3 & 89 & 77 & 166 & 33 \\
\hline & & & 3 & 6,4 & 120 & 118 & 237 & 163 \\
\hline & & & 5 & 6,6 & 160 & 137 & 297 & 207 \\
\hline & & & 7 & 6,9 & 130 & 130 & 260 & 167 \\
\hline & & & efluente & 7,2 & 136 & 49 & 185 & 8 \\
\hline
\end{tabular}


Tabela D3 Valores de demanda química de oxigênio (DQO), demanda bioquímica de oxigênio (DBO), nitrogênio Kjeldhal total (NKT), amoniacal ( $\mathrm{N}$-amon) e orgânico ( $\mathrm{N}$-org) e fósforo $(\mathrm{P})$ dos perfis $1 ; 2$ e 3 realizados ao longo da altura do reator de leito expandido

\begin{tabular}{|c|c|c|c|c|c|c|c|c|c|}
\hline Data & Etapa & Fase & $\begin{array}{c}\text { Ponto de } \\
\text { coleta }\end{array}$ & $\begin{array}{c}\text { DQO }_{\text {filt }} \\
\left(\mathrm{mg} \cdot \mathrm{L}^{-1}\right)\end{array}$ & $\begin{array}{c}\text { DBO }_{\text {filt }} \\
\left(\mathrm{mg} \cdot \mathrm{L}^{-1}\right)\end{array}$ & $\begin{array}{c}\text { NKT } \\
\left(\mathrm{mg} \cdot \mathrm{L}^{-1}\right)\end{array}$ & $\begin{array}{l}\text { N-amon } \\
\left(\mathrm{mg}^{-1} \mathrm{~L}^{-1}\right)\end{array}$ & $\begin{array}{c}\text { N-org } \\
\left(\mathrm{mg} . \mathrm{L}^{-1}\right)\end{array}$ & $\begin{array}{c}P \\
\left(m g \cdot L^{-1}\right)\end{array}$ \\
\hline \multirow{5}{*}{$17 / 06 / 08$} & \multirow{5}{*}{ I } & \multirow{5}{*}{1} & afluente & 233 & 146 & 49,6 & 38,1 & 11,5 & 5,5 \\
\hline & & & 3 & 171 & 107 & 71,1 & 45,9 & 25,2 & 5,7 \\
\hline & & & 5 & 200 & 83 & 66,3 & 47,5 & 18,8 & 5,8 \\
\hline & & & 7 & 156 & 73 & 63,7 & 51,2 & 12,5 & 6,0 \\
\hline & & & efluente & 72 & 18 & 68,5 & 59,1 & 9,4 & 6,1 \\
\hline \multirow{5}{*}{$21 / 10 / 08$} & \multirow{5}{*}{ II } & \multirow{5}{*}{3} & afluente & 326 & 226 & 62,2 & 26,4 & 35,8 & 6,4 \\
\hline & & & 3 & 289 & 162 & 56,9 & 23,6 & 33,3 & 6,3 \\
\hline & & & 5 & 274 & 145 & 63,3 & 26,2 & 37,1 & 6,9 \\
\hline & & & 7 & 189 & 93 & 65,4 & 26,8 & 38,6 & 6,5 \\
\hline & & & efluente & 88 & 17 & 74,6 & 42,6 & 32 & 7,4 \\
\hline \multirow{5}{*}{$02 / 12 / 08$} & \multirow{5}{*}{ II } & \multirow{5}{*}{4} & afluente & 246 & 161 & 56,3 & 38,5 & 17,8 & 5,0 \\
\hline & & & 3 & 390 & 197 & 32,2 & 13,3 & 18,9 & 6,8 \\
\hline & & & 5 & 433 & 195 & 36,4 & 16,7 & 19,7 & 7,1 \\
\hline & & & 7 & 324 & 169 & 38,1 & 21,4 & 16,7 & 6,6 \\
\hline & & & efluente & 47 & 6 & 55,1 & 37,0 & 18,1 & 5,5 \\
\hline
\end{tabular}


ANEXO E - RESULTADOS DE ANÁLISES E DETERMINAÇÕES:

ENSAIO DE FLOTAÇÃO 
Tabela E1 Valores de sólidos em suspensão totais (SST), fixos (SSF) e voláteis (SSV), demanda química de oxigênio (DQO), cor, turbidez e fósforo (P) da amostra bruta e das amostras flotadas, em função das massas de ar aplicadas e velocidades ascensionais, durante o ensaio de flotação

\begin{tabular}{|c|c|c|c|c|c|c|c|c|c|}
\hline \multirow{2}{*}{$\begin{array}{c}\text { Fração de } \\
\text { Recirculação (\%) }\end{array}$} & \multirow{2}{*}{$\begin{array}{c}\text { Massa de ar aplicada } \\
\left(\mathrm{mg}_{\mathrm{ar}} \cdot \mathrm{L}_{\mathrm{am}}{ }^{-1}\right)\end{array}$} & Parâmetros & SST (mg. $\left.\mathrm{L}^{-1}\right)$ & SSF (mg. $\left.\mathrm{L}^{-1}\right)$ & SSV (mg. $\left.\mathrm{L}^{-1}\right)$ & DQO (mg. L $\left.^{-1}\right)$ & Cor (uC) & Turbidez (uT) & $\mathrm{P}\left(\mathrm{mgPO}_{4}^{-3} \cdot \mathrm{L}^{-1}\right)$ \\
\hline & & Amostra bruta & 174 & 18 & 156 & 331 & 912 & 109 & 5,4 \\
\hline 12 & 13,1 & \multirow{4}{*}{$\mathrm{v}=10 \mathrm{~cm} \cdot \mathrm{min}^{-1}$} & 85 & 9 & 76 & 162 & 509 & 40 & 4,1 \\
\hline 14 & 15,3 & & 68 & 7 & 61 & 144 & 437 & 35 & 4,2 \\
\hline 16 & 17,5 & & 63 & 3 & 59 & 127 & 431 & 29 & 4,1 \\
\hline 18 & 19,6 & & 64 & 5 & 59 & 134 & 445 & 27 & 4,2 \\
\hline 12 & 13,1 & \multirow{4}{*}{$\mathrm{v}=14 \mathrm{~cm} \cdot \mathrm{min}^{-1}$} & 94 & 11 & 83 & 169 & 546 & 49 & 4,3 \\
\hline 14 & 15,3 & & 78 & 8 & 70 & 157 & 498 & 39 & 4,2 \\
\hline 16 & 17,5 & & 75 & 7 & 69 & 164 & 489 & 39 & 4,3 \\
\hline 18 & 19,6 & & 73 & 8 & 66 & 142 & 479 & 33 & 4,2 \\
\hline 12 & 13,1 & \multirow{4}{*}{$\mathrm{v}=18 \mathrm{~cm} \cdot \mathrm{min}^{-1}$} & 104 & 12 & 92 & 188 & 601 & 56 & 4,5 \\
\hline 14 & 15,3 & & 95 & 10 & 86 & 172 & 546 & 50 & 4,5 \\
\hline 16 & 17,5 & & 85 & 8 & 77 & 187 & 536 & 42 & 4,4 \\
\hline 18 & 19,6 & & 79 & 8 & 71 & 173 & 507 & 43 & 4,4 \\
\hline
\end{tabular}

